\title{
WestVirginiaUniversity
}

THE RESEARCH REPOSITORY @ WVU

Graduate Theses, Dissertations, and Problem Reports

2006

\section{Benefits to signal timing optimization and ITS to corridor operations}

Darian Glitz

West Virginia University

Follow this and additional works at: https://researchrepository.wvu.edu/etd

\section{Recommended Citation}

Glitz, Darian, "Benefits to signal timing optimization and ITS to corridor operations" (2006). Graduate Theses, Dissertations, and Problem Reports. 1702.

https://researchrepository.wvu.edu/etd/1702

This Thesis is protected by copyright and/or related rights. It has been brought to you by the The Research Repository @ WVU with permission from the rights-holder(s). You are free to use this Thesis in any way that is permitted by the copyright and related rights legislation that applies to your use. For other uses you must obtain permission from the rights-holder(s) directly, unless additional rights are indicated by a Creative Commons license in the record and/ or on the work itself. This Thesis has been accepted for inclusion in WVU Graduate Theses, Dissertations, and Problem Reports collection by an authorized administrator of The Research Repository @ WVU. For more information, please contact researchrepository@mail.wvu.edu. 
Benefits to Signal Timing Optimization and ITS To Corridor Operations

\author{
Darian Glitz, P.E.
}

\author{
Thesis submitted to the \\ College of Engineering and Mineral Resources \\ at West Virginia University \\ in partial fulfillment of the requirements \\ for the degree of
}

Master of Science
in
Civil Engineering

David R. Martinelli, Ph.D., P.E., Chair

L. James French, Ph.D., P.E.

Michael H. Dufalla, Ph.D., P.E.

Department of Civil Engineering

\author{
Morgantown, West Virginia \\ 2006
}

Keywords: Traffic Congestion, Optimization Models, Signals 


\title{
ABSTRACT \\ Benefits to Signal Timing Optimization and ITS To Corridor Operations
}

\author{
Darian Glitz, P.E.
}

Traffic signals are one of the primary constraints on corridor capacity in the highway/ arterial network. The amount traffic is impeded is heavily dependent on the quality of the signal timings.

The purpose of this research was to conduct a case study of a congested corridor to demonstrate the benefits of traffic signal retiming/ optimization on corridor operations.

Tactically, this research involved development and application of a methodology to develop and assess signal timing plan alternatives. The research demonstrated the benefits in terms of delay, travel time, emissions, and fuel consumption. Strategically, this project can be used to provide a concrete example of the benefits of traffic signal timing improvement.

Four alternatives were developed. The fourth, a phasing change with coordination garnered the best results. The phasing change alone was found to be beneficial; however, implementing coordination in the corridor in conjunction with the phasing change yielded even greater benefits. 


\section{ACKNOWLEDGEMENTS}

The author would like to thank the people who helped in the completion of this thesis. Foremost, appreciation is expressed to Dr. David R. Martinelli, graduate advisor and committee chairperson, for assistance and unending patience over the course of my entire college career. The author would like to thank Dr. L. James French for lending his expertise in the field and for his assistance and guidance in formulating the research plan and the preparation of this thesis. Finally, the author wishes to express gratitude to Dr. Michael H. Dufalla for his participation on the Examination Committee, for his advocacy of higher education, and for his support throughout the entire project. 


\section{TABLE OF CONTENTS}

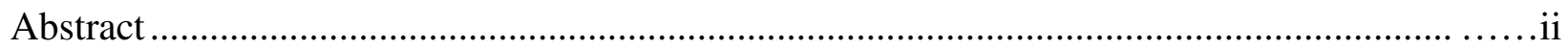

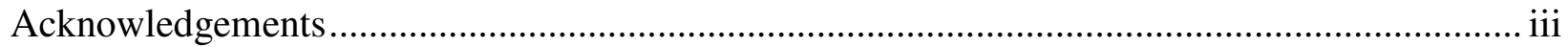

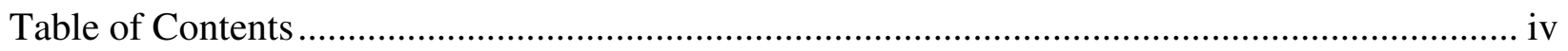

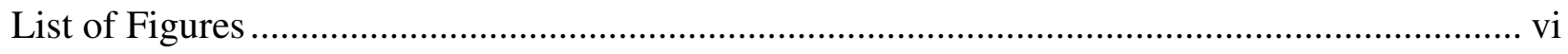

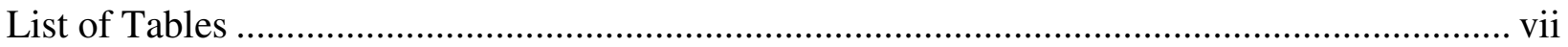

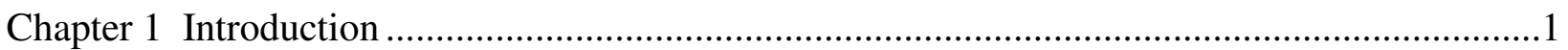

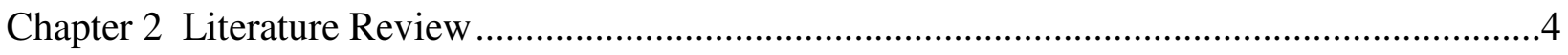

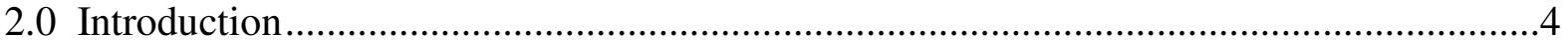

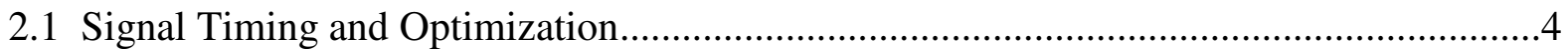

2.1.1 Typical Traffic Signal Controller Algorithms and Timings .....................................4

2.1.2 Bandwidth Maximization and Delay Minimization

Signal Timing Concepts..................................................................................

2.1.3 Arterial Signal Timing and Optimization ............................................................11

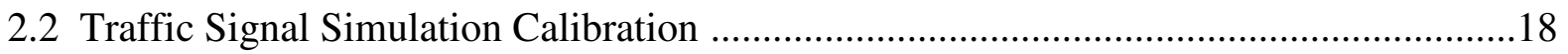

2.2.1 SimTraffic Calibration Variables ...................................................................19

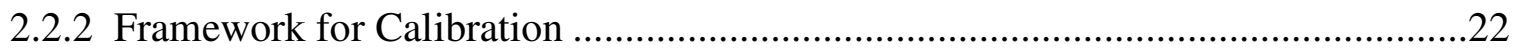

2.3 Benefits of Signal Timing Improvements..............................................................24

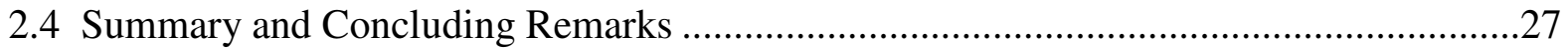

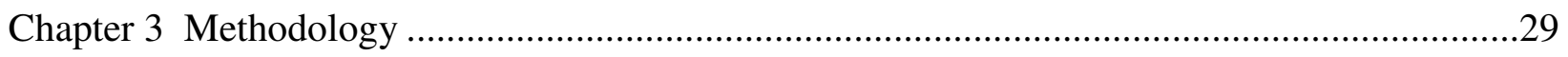

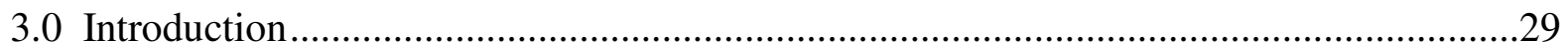

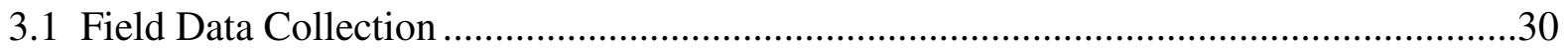

3.1.1 Turning Movement Counts ...............................................................................30

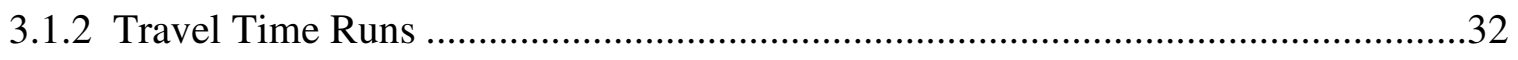

3.1.3 Queue Discharge Headways ................................................................................35

3.1.4 Cycle Lengths and Splits ...................................................................................36

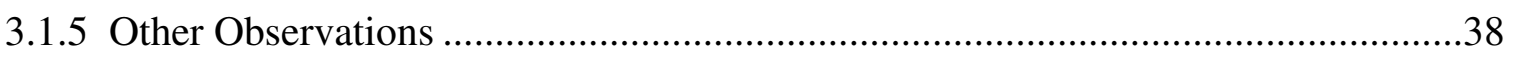

3.2 Synchro Model Coding ………..................................................................................

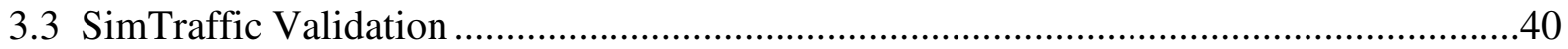


3.3.1 Queue Discharge Headways ................................................................................40

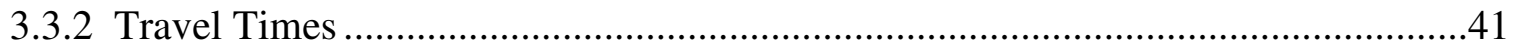

3.3.3 Queuing and Cycle Failure Observations …………..............................................42

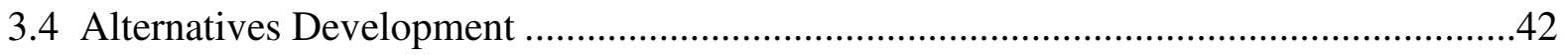

3.4.1 Phasing Change at Matthew Drive and

Cherry Tree Lane - Fully Actuated ......................................................................42

3.4.2 Synchro Optimized Coordinated Timing Plan..........................................................45

3.4.3 Custom Coordinated Timing Plan .........................................................................49

3.4.4 Phasing Change at Matthew Drive and

Cherry Tree Lane - Coordinated ......................................................................49

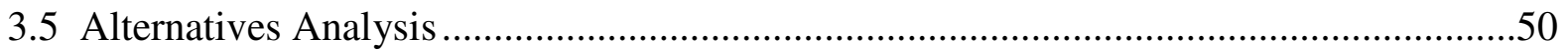

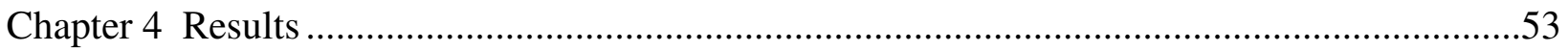

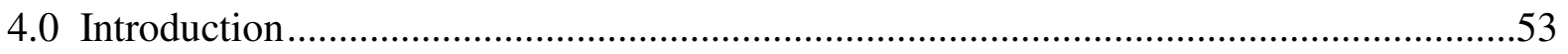

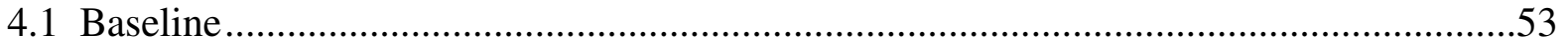

4.2 Phasing Change at Matthew Drive and Cherry Tree Lane - Fully Actuated ......................55

4.3 Synchro Optimized Coordinated Timing Plan................................................................57

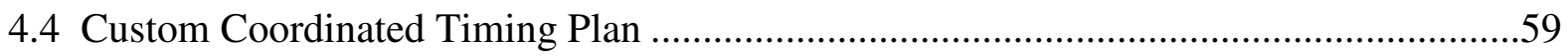

4.5 Phasing Change at Matthew Drive and Cherry Tree Lane - Coordinated .........................61

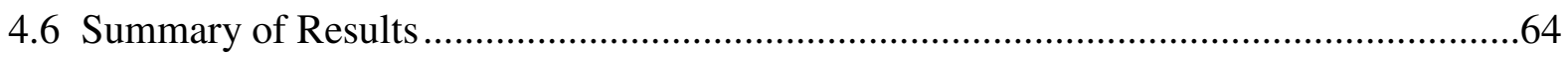

4.6.1 Findings Relative to Signal Timing Improvements for the Corridor.......................64

4.6.2 Methodological Findings ………………………...............................................69

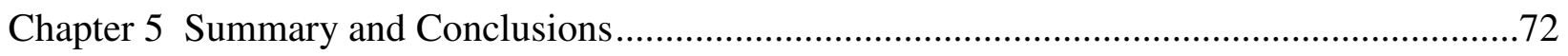

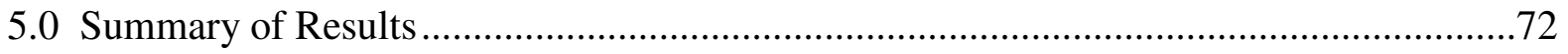

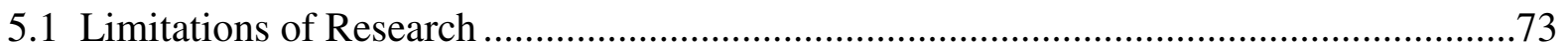

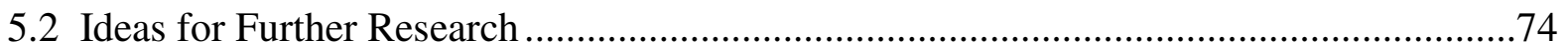

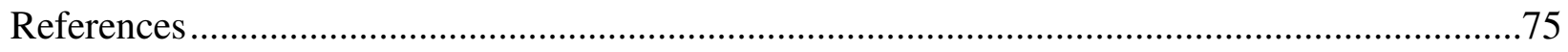

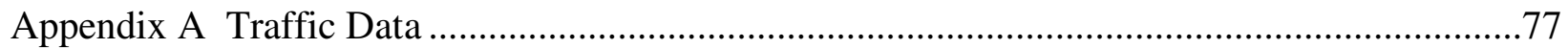

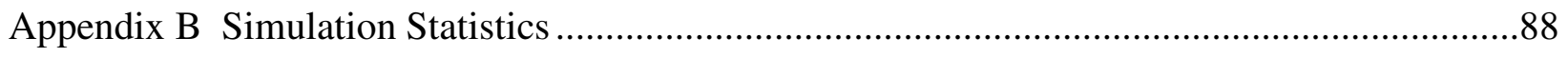

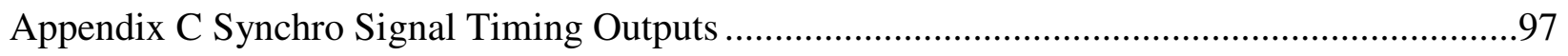

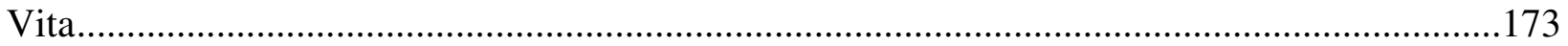




\section{LIST OF FIGURES}

Figure 3-1 Existing Lane Configurations ......................................................................29

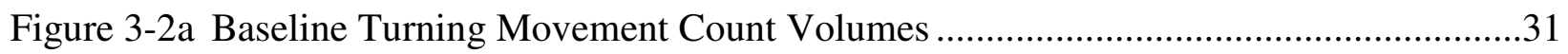

Figure 3-2b Baseline Turning Movement Count Volumes......................................................31

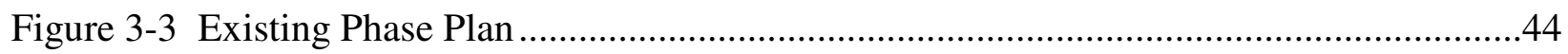

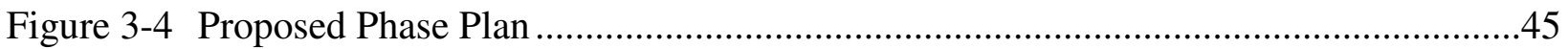




\section{LIST OF TABLES}

Table 2-1 Proposed Signal Control at Specific Intersections Along Arterials ........................12

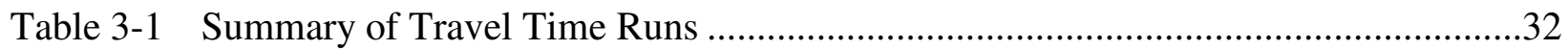

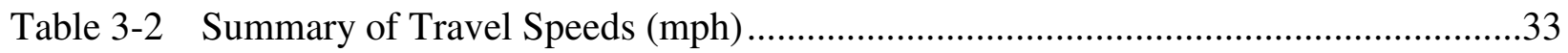

Table 3-3 Comparison of Delay at Matthew Drive and Cherry Tree Lane to Overall

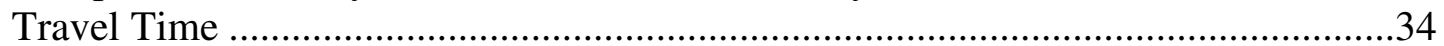

Table 3-4 Number of Times Stopped at the Work Parkway / Gabriel Plaza Drive intersection (of ten runs in each direction during each time period) .........................35

Table 3-5 Summary of Queue Discharge Headways at Matthew Drive / Cherry Tree

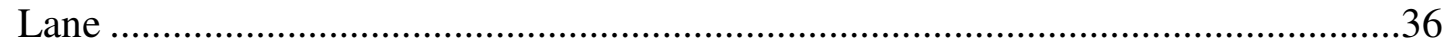

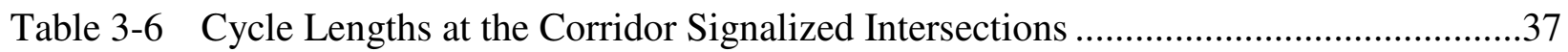

Table 3-7 Cycle Lengths and Splits at Matthew Drive / Cherry Tree Lane ............................37

Table 3-8 Comparison of Field Measured and Simulated Queue Discharge Headways ............40

Table 3-9 Comparison of Field-Measured and Simulated Travel Times...............................41

Table 3-10 Comparison of Through and Right-Turning Volumes on Eastbound S.R. 0021

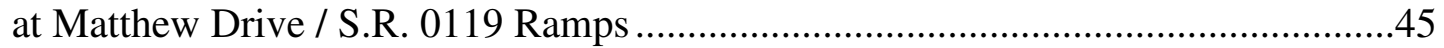

Table 3-11 Optimum Cycle Lengths According to Different Optimization Variables................47

Table 3-12 Comparison of the Various System Cycle Lengths with Engineering

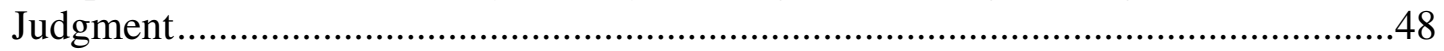

Table 4-1 Baseline Simulated Performance Measures.......................................................53

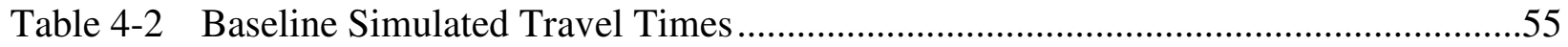

Table 4-3 Simulated Performance Measures - Phasing Change Alternative ..........................56

Table 4-4 Percentage Changes in Performance Measures as Compared to the Baseline Scenario - Phasing Change Alternative ..........................................................56

Table 4-5 Simulated Travel Times - Phasing Change Alternative.......................................57

Table 4-6 Simulated Performance Measures - Synchro Optimized Coordinated Timing

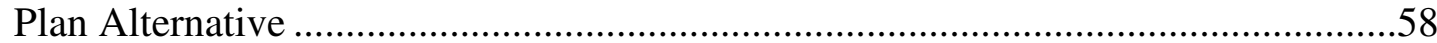

Table 4-7 Percentage Changes in Performance Measures as Compared to the Baseline Scenario - Synchro Optimized Coordinated Timing Plan Alternative

Table 4-8 Simulated Travel Times - Synchro Optimized Coordinated Timing Plan Alternative

Table 4-9 Simulated Performance Measures - Custom Coordinated Timing Plan Alternative 
Table 4-10 Percentage Changes in Performance Measures as Compared to the Baseline Scenario - Custom Coordinated Timing Plan Alternative ……………………........61

Table 4-11 Simulated Travel Times - Custom Coordinated Timing Plan Alternative ...............61

Table 4-12 Simulated Performance Measures - Phasing Change with Coordination..................62

Table 4-13 Percentage Changes in Performance Measures as Compared to the Baseline Scenario - Phasing Change with Coordination .......................................................63

Table 4-14 Percentage Changes in Performance Measures as Compared to the Fully Actuated Alternative .63

Table 4-15 Simulated Travel Times - Phasing Change with Coordination .................................64

Table 4-16 Summary of Delay per Vehicle Statistics from the 10 Simulation Runs ...................71 


\section{CHAPTER 1 - INTRODUCTION}

Traffic signals are one of the primary constraints on corridor capacity in the highway / arterial network. Since their function is to provide gaps in the main stream traffic when demand from minor streams exceeds available gaps, by their very nature, they are an impedance to through traffic. The extent to which through traffic is impeded is heavily dependent on the quality of the signal timings. Poor signal timings can result in significant congestion that could otherwise be avoided, or at the very least minimized. The results of congestion typically include driver delay and frustration, increased air pollution, wasted fuel, and lost productivity.

Concurrently, the demand for people's time has never been greater, and unnecessary delays are perceived as burdensome on the part of motorists. In addition, society is increasingly sensitive to the cost of energy, both in terms of rising fuel prices and the pollutants emitted into the air. As such, congestion is one element of our daily routine that truly degrades our quality of life.

The concept of traffic signal optimization is one that has received significant attention from the research community. It is recognized that timing traffic signals in corridors is a multiobjective problem, in which optimizing the solution to one variable can often work to the detriment of another. For example, optimizing the timings relative to the arterial greenband can cause excessive delay on the side streets. Conversely, optimizing solely on the basis of network delay does not ensure an adequate greenband on the arterial. Furthermore, some objectives, such as safety, are difficult to tie to a tangible variable, however, are still of great importance. As such, for any given problem, there are numerous alternatives which can be generated for consideration. To that end, improved algorithms and optimization procedures are constantly being developed, each aimed at providing analytical tools or field equipment that if implemented, will improve travel conditions on the major corridors without serious detriment to 
the minor traffic flows.

However, in spite of all of the research conducted in the area of optimization, it is widely recognized that the field operations of traffic signals in congested corridors are far from optimal. Indeed, the state-of-the-art in traffic signal optimization is far beyond the state-of-the-practice. Even basic traffic signal systems, such as the coordinated semi-actuated system that is common in PENNDOT District 12-0, seldom operate at their fullest potential.

There are many issues that contribute to this problem, including ownership and financial issues. However, it is hypothesized that one of the primary factors contributing to poor traffic signal operations is the lack of knowledge in the area of traffic signal optimization on the part of the owners and operators of the systems, which in Pennsylvania are the local municipalities. Additional background in the area is needed, including highly visible proven examples, so that congestion problems that might be alleviated through easily implemented timing changes at the traffic signals can be recognized and fixed.

The purpose of this research is to conduct a case study of a congested corridor in PENNDOT District 12-0 to demonstrate the benefits of traffic signal retiming / optimization on corridor operations. At a tactical level, this research will involve the development and application of a methodology to develop and assess traffic signal timing plan alternatives. The report generated will demonstrate the benefits of such a project in terms of delay, travel time, emissions, and fuel consumption. At a more strategic level, this project can be used to provide a concrete example of the benefits of traffic signal timing improvement. Therefore, it may encourage other localities in the area to undertake similar projects, particularly in District 12-0. In this way, the project has great potential to improve travel conditions not only in the corridor(s) selected for study, but all over District 12-0 and Pennsylvania as well.

In pursuit of this goal, the following research objectives are proposed: 
- To conduct a literature search that identifies similar studies in which the benefits of signal timing strategies were assessed

- To work with the Department to identify a congested corridor(s) for study

- To assemble the data required to model the traffic operations in the corridor(s), including geometric, traffic, and signal timing data

- To develop SimTraffic models of the corridor(s), and to use these models in an evaluation of the effects of signal timing changes

- To perform signal timing optimization on the corridor(s) and determine the anticipated benefits through testing that uses the SimTraffic model

- To document the findings of the study in a technical report and present the results to the Department

This report is organized in the following manner. Chapter 1 has provided an overview of the proposed research. Chapter 2 contains important background material and documented research as discovered through a literature review. Chapter 3 documents the methodology used in the research and Chapter 4 contains the results of the application of this methodology to a congested corridor in District 12-0. The conclusions and recommendations are contained in Chapter 5. 


\section{CHAPTER 2 - LITERATURE REVIEW}

\subsection{Introduction}

This chapter presents a review of the literature that was conducted on three categories important to the overall research topic:

- Signal Timing and Optimization

- Traffic Signal Simulation Calibration

- Benefits of Signal Timing Improvements

Each of these topics is provided in a separate section.

\subsection{Signal Timing and Optimization}

In this section, a sampling of the vast body of literature devoted to the topic of traffic signal timing and optimization is provided. It is the intent of this section to first provide the basics of arterial signal system timing and illustrate some of the various approaches to signal system timing. Some proposed optimization algorithms are provided, with a focus on the application of artificial intelligence in the form of genetic algorithms since this is an area of great interest in signal optimization in recent years. The signal optimization capabilities contained in the Synchro software program, which will be used to perform the signal optimization for this project, are then presented.

\subsubsection{Typical Traffic Signal Controller Algorithms and Timings}

This section will begin with a discussion of the typical algorithms contained in the controllers of signalized intersections. First, the operation of a basic actuated controller is described. This is followed by a detailed explanation of the signal timing parameters involved with semi-actuated coordinated control. This section is concluded with a brief introduction of traffic adaptive signal control. 


\section{Basic Actuated Control}

The following is a description of the algorithm operation for one phase of a typical basic actuated traffic signal controller, which is the type of controller used in the S.R. 0021 corridor (McShane and Roess, 1990).

"Prior to the beginning of the phase, a 'call' for green must be put in by the arrival of a vehicle. Once the previous phase yellow and red clearance interval times out, the phase is given the initial interval plus one unit extension for the arrival. If an additional arrival occurs, then a new unit extension is begun from the time of vehicle arrival (not simply added to the planned time)...If the maximum green is reached, then the last call is carried over and the process is begun again after the phase is revisited."

As can be seen, there are three key signal timings required by the algorithm to arrive at the green time for a given phase: initial interval, unit extension, and maximum green.

The initial interval and unit extension are set based on the detector layout on the approach served by the given phase. The maximum green can be based on a number of philosophies depending on the desired operation at the signalized intersection. Each of these parameters is discussed below.

The initial interval plus the unit extension is the minimum green that an approach will receive if no additional detections are present once the phase is given the green. Because the unit extension can be short, the majority of time in this minimum green is the initial interval. It should be designed to allow the space between the detector and the stop line to clear of vehicles (McShane and Roess, 1990). Because there are different types of detection at different sizes and distances from the stop bar, the initial interval can range from zero seconds to as much as 20 to 30 seconds. Based on experience, PENNDOT typically sets the initial interval to six seconds for 
a minor phase and 12 seconds for the main street through phase. These intervals are set so that the resulting minimum greens do not violate driver expectancy and are not so short as to give the appearance of equipment malfunction to the driver.

The unit extension time is the time the green is extended for each arrival at the detector, from the instant of arrival at the detector (McShane and Roess, 1990). To avoid vehicles being trapped between the detector and the stop line, it is necessary that the vehicle interval be at least the "passage time" of a vehicle from the detector to the stop line (McShane and Roess, 1990).

The maximum green is simply the total time to be allowed to the phase (McShane and Roess, 1990). If it is anticipated that each phase at an intersection will be called and consistently extended to the maximum green, then the actuated controller will replicate fixed-time operation, in which case the maximum green can be set to the optimized green time for fixed-time operation. If demand at the intersection is less, and it is desired to serve vehicles in a manner that takes full advantage of the detection and actuated operation, the maximum green time can be set high enough so that the phase ends because the unit extension time expires without another detection being sent to the controller, instead of the phase ending because the maximum green has been reached.

Other signal timings that are included in actuated controllers and in fact all controllers are clearance intervals. Each phase ends at a minimum with an amber interval that allows vehicles time to either travel through the intersection or stop depending on their distance to the intersection when the green interval ends (McShane and Roess, 1990). This amber interval can be followed by an all red clearance interval, in which additional time is provided to clear the intersection. These intervals are set based on intersection geometry and are not set based on traffic demand. They do not change from phase-to-phase like a green time might, and do not 
explicitly factor into the duration of green provided for each phase.

\section{Semi-Actuated Coordinated Control}

As can be seen, there are three primary signal timings for each phase that might be optimized in achieving optimum green for a basic actuated phase. However, in coordinated environments, only minor non-coordinated movements are actuated since actuating the movements to be coordinated would result in operations at each individual intersection being so unpredictable that no coordination could be achieved. The typical signal controller operation in a coordinated environment in Pennsylvania is semi-actuated operation.

In semi-actuated operation, the actuated features are turned off for the main street through phase since it serves the traffic movement to be coordinated. In this operation, the main street through phase receives a minimum green interval that is typically set to be high enough that if it receives no other green time, it will still be of sufficient duration to serve demand or achieve other specified objectives. The main street through phase also receives any time not used by the minor uncoordinated phases through their actuated operation.

Providing coordination requires the introduction of three additional signal timings: cycle length, split, and offset (McShane and Roess, 1990). The semi-actuated operation requires the introduction of three more signal timing parameters: yield point, force off, and permissive period. Each of these is discussed below.

A cycle length is one complete sequence of signal indications (McShane and Roess, 1990). In a coordinated system, each intersection should have the same cycle length, which is called the system cycle length. In intersections with significantly less demand for the minor movements, a cycle length that is half the system cycle length can also be used. Using a duration that is half the system cycle length keeps the intersection coordinated with the system while 
reducing the wait time for motorists on minor movements.

The split for a given phase is the percentage of the cycle length devoted to the given phase. The split includes the green time and clearance interval(s). Splits are typically provided in percentage form, in which case the sum of all the splits at an intersection must equal $100 \%$.

The offset is defined as the difference between some reference point in the system cycle length time and the beginning or ending of green at a given signalized intersection in the system (McShane and Roess, 1990). The point in time to which offsets are generally referenced is the beginning or ending of green at the master controller (McShane and Roess, 1990). Each intersection in the system will have an offset. The offsets need not be the same from intersection-to-intersection; however, they need not necessarily be different.

The yield point is the time in the cycle when the coordinated phase will end and yield to the non-coordinated actuated phases if the appropriate call has been placed (Khatab and Fin, 2000).

Each non-coordinated phase has an associated force-off point, which is assigned to each actuated phase so the phase being served can terminate to service another actuated phase (Khatab and Fin, 2000).

The beginning of each permissive period is usually the force-off point of the proceeding phase. The end permissive period is the time when there is still sufficient time remaining to service the minimum green or pedestrian crossing time (the greater of the two values) and all vehicle clearances (Khatab and Fin, 2000).

As can be seen, there are a variety of signal timing parameters that are subject to optimization in a corridor signal timing improvement project. They are as follows: System Parameter: 


\section{Cycle Length}

Coordinated Non-Actuated Phase at Each Intersection:

Split

Yield Point

Offset

Each Non-Coordinated Fully-Actuated Phase at Each Intersection:

Split

Initial Interval

Unit Extension

Force Off

Permissive Period

A number of strategies exist for optimizing some of these parameters. Cycle length, splits, and offsets are examples of parameters which are frequently the target of optimization schemes. For others, there has been very little effort devoted to optimization schemes. These include the actuated signal timing parameters of initial interval and unit extension, as well as the semi-actuated coordinated system parameters of yield point, force-off points, and permissive periods. Ironically, while most software packages produce optimal cycle length and split timings, the controller unit requires yield point, force-off points, and permissive periods ((Khatab and Fin, 2000). Very little guidance has traditionally been provided for optimizing this set of parameters or translating between what is provided by the software packages and what is needed by the controllers (Khatab and Fin, 2000). However, that issue is beyond the scope of this research. 


\section{$\underline{\text { Traffic Adaptive Signal Control Systems }}$}

SCOOT (Split Cycle Offset Optimization Technique) and SCATS (Sydney Coordinated Adaptive Traffic System) are traffic adaptive signal control systems that utilize entirely different control algorithms and detection schemes than the controllers described above. In short, the SCOOT minimizes a performance index which is a function of average queue lengths and number of stops at all approaches in the network (Hansen, Martin, and Perrin, 2000). The SCOOT system relies heavily on extensive detectorization of the network streets. The SCOOT system is used in Dublin, Toronto, San Diego, Anaheim, London, and Bangkok.

SCATS provides dynamic control by closely monitoring traffic flows and headways at the stop bars. Based on the volumes and headways gathered on one minute intervals, green times (splits) are reallocated to the phases of greatest need. The SCATS system is used in Dun Laoghaire / Rathdown (Ireland), Hong Kong, Sydney, Melbourne, and Oakland County (MI).

These systems have had very minor implementation in the United States, and no such installations are known in Pennsylvania. They have been introduced in this literature review to aid in keeping the research in context; however, providing details related to their operation is beyond the scope of the research.

\subsubsection{Bandwidth Maximization and Delay Minimization Signal System Timing Concepts}

The parameters discussed in Section 2.1.1 can be used to achieve a variety of traffic operations in a corridor. Before discussing the various signal timing strategies and optimization algorithms, it is appropriate to discuss two concepts or philosophies that can be applied to guide signal timing in a corridor. These concepts are bandwidth maximization and delay minimization. Each is discussed below.

A green band is a "window" of green time through the arterial signal system through 
which a platoon of vehicles can travel without stopping (McShane and Roess, 1990). The duration of this window is the bandwidth. One concept in setting cycle length, splits, and offsets is to maximize the green band to move the anticipated platoons on the main street. A typical software package that performs this type of signal timing is the PASSER program.

A second concept in the setting of cycle length, splits, and offsets is to minimize delay in the system (McShane and Roess, 1990). In this approach, relationships that define system delay as a function of cycle length, offsets, and splits are used to find combinations that result in overall minimum of delay. A typical software package that performs this type of signal system timing is TRANSYT-7F.

Note that these two concepts generally result in different timing schemes, as minimizing delay does not necessarily provide any green band on the main street. Similarly, providing the green band on the main street may cause excessive delay to the side streets and other minor movements.

\subsubsection{Arterial Signal Timing and Optimization}

With a basic understanding of the signal system timing concepts and parameters subject to optimization in place, it is now appropriate to examine a sampling of literature devoted to the issues related to arterial signal system timing and optimization.

\section{Signal System Type}

In the area of signal system type, Skabardonis, Bertini, and Gallagher (1999) performed research in the selection between pretimed, semi-actuated, and fully actuated control on arterials and grid networks based on cross street traffic and turning movements. While they did not propose any specific signal optimization algorithms, their findings include two interesting observations that come to bear on the research at hand. First, their key finding for arterials is 
shown in Table 2-1.

Table 2-1 Proposed Signal Control at Specific Intersections Along Arterials

\begin{tabular}{|c|c|c|c|}
\hline Cross Street Traffic & Turning Movements* & \multicolumn{2}{|c|}{ Arterial Volume / Cross Street Volume } \\
\cline { 3 - 4 } v/c & & $\leq 1.3$ & $>1.3$ \\
\hline \hline Low-Moderate & $\leq 20 \%$ & Actuated (1) & Actuated (2) \\
v/c $\leq 0.8$ & $>20 \%$ & Actuated (2) & Actuated \\
\hline High & $\leq 20 \%$ & Pretimed & Pretimed \\
\cline { 2 - 4 } v/c $>0.8$ & $>20 \%$ & Pretimed & Pretimed \\
\hline
\end{tabular}

*Percent of Arterial Through Traffic

(1) Pretimed control at intersections with balanced volumes and high turning traffic from the cross street without exclusive lanes.

(2) Pretimed operation if the early start of the green leads to additional stops and delay at the downstream signal. Also, boundary intersections may operate as pretimed if they are critical to the arterial's time-space diagram and define the leading edge of the green bandwidth.

Source: Skabardonis, A., Bertini, R., Gallagher, B. "Development and Application of Control Strategies for Signalized Intersections in Coordinated Systems.”

As can be seen, there were no instances where fully actuated control was recommended for arterials. Incidentally, fully-actuated control is the type of control used at each intersection in the S.R. 0021 corridor. In general, the semi-actuated scheme is recommended unless the cross street operates at a high v/c ratio. It is anticipated that if the side street is near saturation, then the system would operate like a fixed time signal with the side street phasing terminating with a "max out" in most instances even if it were semi-actuated.

Second, it was noted that one finding of their field implementation was that the effectiveness of coordinated actuated (semi-actuated) signal control depends significantly on the selection of yield points, force-offs, and maximum green times. As noted earlier, signal optimization programs and algorithms rarely deal with yield points and force-offs.

\section{Arterial Signal Cycle Length}

Turning attention to signal timing, the first article to be examined is contained in the 
McShane and Roess textbook Traffic Engineering (1990). This text provides significant guidance on the determination of cycle length and offsets as function of signal spacing and arterial speed. Several examples are provided for one way streets, two-way streets, and grids. However, the most interesting observations were made relative to their critique of signal system timing based on building up from the intersection level. Their main assertion was that the system cycle length, which is a crucial parameter, should be specified primarily on the geometry and platoon speed to enhance progression. They went so far as to provide the following example:

"If the system considerations dictate a cycle length of 70 seconds, and one of the intersections requires a cycle length of 80 seconds to achieve its target $\mathrm{v} / \mathrm{c}$ ratio, some would say 'Oh, set the system at 80 seconds.' Rather, it is much more appropriate to work very hard to improve that one intersection, for the value of an effective system cycle length can far exceed the trouble of such improvements."

They went on to note that the historical approach of setting the cycle length based on intersection-based concerns is faulty because intersection performance and capacity are both relatively insensitive to cycle length over a significant range. As will be seen, this approach is in stark contrast to most signal timing strategies and optimization algorithms.

\section{Signal Optimization Algorithms}

In this subsection, a variety of signal optimization algorithms are presented, beginning with some of those contained in the popular signal timing software programs such as TRANSYT-7F, PASSER, and Synchro, and progressing to more advanced algorithms, including those utilizing artificial intelligence.

Two signal optimization algorithms are contained in TRANSYT-7F. Both are aimed at 
minimizing a disutility index, which is based on delay, stops, and queue lengths. One utilizes a hill-climbing technique to minimize the disutility index, which is an iterative process in searching for the optimum signal timing plan (Yang, 2001). The second algorithm uses a genetic algorithm approach to optimization, which is a search algorithm based on the mechanics of natural selection and evolution, and which allows the program to avoid being trapped in local optimums (Park and Schneeberger, 2003). The variables required to compute the disutility index are provided by a macrosimulation model running within the program. The signal timing parameters are varied and simulated while the appropriate statistics are collected (Park and Schneeberger, 2003).

Once the signal system length has been determined, TRANSYT-7F then optimizes splits and offsets based on minimizing delay, stops, and queue lengths. This approach has been found to only be appropriate for undersaturated conditions (Yang, 2001).

In contrast to the TRANSYT-7F program, which focuses on minimizing a delay-based performance index, PASSER is a software package that works within a given cycle length and splits to find offsets that maximize arterial green band. The cycle length and splits are computed with the PASSER package, but are based on Webster's Method (Yang, 2001). The PASSER program then uses time-space relationships to examine phase sequences and offsets to find the combination yielding the largest green bands (Yang, 2001). Again, this is clearly an intersectionbased analysis of the type rejected by the McShane and Roess proposed theory.

Synchro uses a performance index (PI) in the optimization of cycle length (Trafficware, 2001). It is calculated from the Percentile Signal Delay (D), a Queue Penalty (QP), and Vehicle Stops (St), as follows:

$$
\mathrm{PI}=\left(\mathrm{D} * 1+\mathrm{St}^{*} 10+\mathrm{QP} * 100\right) / 3600
$$


The queue penalty is a quantification of the affects of queuing. It is calculated by multiplying the volume affected by blocking by the percent of time blocked.

Splits at each intersection are then optimized based on each lane group's $90^{\text {th }}$ percentile traffic flow divided by its adjusted saturation flow rate (Trafficware, 2001). This appears to be a variation of Webster's Method.

In optimizing offsets, Synchro evaluates the delays associated with varying offsets. First, the optimizer evaluates every eighth second around the cycle. The optimizer then varies the offset by four seconds, then one second, around those offsets with the least delay in each step (Trafficware, 2001).

The Synchro program provides cycle length, splits, and offsets, which can be implemented in typical hardware available to PENNDOT. Additionally, it deals with the issue of semi-actuated control, which is unlike some competing programs, including TRANSYT-7F, which only deals with pretimed systems.

A similar but more recent and sophisticated optimization algorithm proposed by Chang and Guey-Yin (2004) was a dynamic control method, which is one that can be changed with changing traffic conditions. This algorithm optimized cycle, splits, and offsets to minimize stops and total delay on a network. In the network, the algorithm identified a pivot control intersection (most congested) and progression routes to maximize flow to the pivot control intersection on a cycle-by-cycle basis. In practice, the pivot control intersection would dictate the cycle length, splits, and offsets at each intersection in the network for one cycle. The pivot control intersection would then change from cycle-to-cycle depending on the congestion in the network. Field implementation would require specialized software in signal hardware to run this algorithm since it is dynamic and thus needs to operate in real-time. In addition, this approach is 
in conflict with the proposed theories regarding cycle length selection by McShane and Roess (1990).

The review of the recent signal optimization literature revealed a number of genetic algorithms, including one contained in the popular TRANSYT-7F program. A few of these are reviewed below, followed by a comparison of the results of a genetic algorithm compared to some of the traditionally-used signal optimization software packages.

Before discussing the various signal timing applications of genetic algorithms, it is appropriate to define genetic algorithms in general terms. Genetic algorithms are mathematical optimization procedures used to find minimum or maximum values for variables that are a function of many variables with complex relationships. It is considered a form of artificial intelligence, and was summarized by Luger (2002) as follows:

"Genetic algorithms are based on a biological metaphor: They view learning as a competition among a population of evolving candidate problem solutions. A 'fitness' function evaluates each solution to decide whether it will contribute to the next generation of solutions. Then, through operations analogous to gene transfer in sexual reproduction, the algorithm creates a new population of candidate solutions."

It is beyond the scope of this research to probe into the area of genetic algorithms and artificial intelligence applications in signal timing optimization, however, since it is an area of focus in the evolving state-of-the-art of signal timing optimization, a cursory review will be provided.

Abu-Lebdeh and Benekohal (2004) presented a procedure for signal control to manage queues on oversaturated two-way arterials such that queues are always contained within 
respective links and spillbacks are prevented. The procedure focused on determining the offset for each intersection on a dynamic basis. This work built on other research that proposed signal timing procedures based on queue management in under-capacity conditions, and those that were static in nature. The proposed algorithm was found to be effective at minimizing queue spillback in simulations. Progression was also provided in the primary direction. In order for such a dynamic algorithm to be implemented, the algorithm would have to be programmed into the master controller or computer algorithm controlling offsets for a signal system.

Ceylan and Bell (2004) proposed an optimization algorithm that included the linking of a model predicting total and stops with a traffic assignment model. As such, this complex optimization algorithm accounted for the changes in drivers' route selection based on the traffic signal timings.

Park, B., Messer, C.J., and Urbanik, T. (2000) applied genetic algorithms to the problem of over-saturated signalized intersections in signal systems. Three different optimization strategies were tested under oversaturated conditions: throughput maximization, delay minimization, and modified delay minimization with a penalty function. The parameters optimized included cycle length, offset, and green splits. It was recommended that the delay minimization optimization be used since it generated the least queue times in the system. It should be noted however, that minimum queue time did not correspond to maximum throughput. This algorithm could be used to develop signal timing parameters for implementation in a broad range of existing traffic signal controllers since the analysis is performed off-line and programmed into the signal hardware.

\section{Research Comparing Commercially Available Software Packages}

Having outlined a variety of approaches to the signal optimization problem, two 
interesting research projects were discovered during the literature search that compared some of the aforementioned optimization packages.

Park and Schneeberger (2003) prepared signal timing plans for the Lee-Jackson Memorial Highway Network in Virginia using three different optimization algorithms: Synchro, TRANSYT-7F, and a genetic algorithm. They were evaluated using a VISSIM simulation model against (1) one another, (2) the current plan that was developed by the Virginia DOT through the field adjustment of a previous plan, and (3) this previously implemented timing plan. The results indicated that the current plan was a significant improvement (17.1\% reduction in travel time and a $36.6 \%$ reduction in delay) over the previous plan, but that the three optimized timings plans did not provide any significant improvements over the existing plan. Consequently, the research recommended that Virginia DOT continue to time traffic signals as they have in the past, and to evaluate the timing plans regularly so that the plan can be kept up-to-date.

Yang (2001) developed timing plans for an arterial in Kansas (Iowa Street) from three signal timing optimization programs, which were then compared using NETSIM. The signal timing optimization programs tested included Synchro, TRANSYT-7F, and PASSER. It was found that PASSER yielded the best plan based on an evaluation of delay, stops, speed, fuel consumption, and emissions. It was found that Synchro was good at entering and transferring data, and TRANSYT-7F always gave longer cycle lengths, which resulted in higher delay and fuel consumption. A framework for developing timing plans using all three was also provided. In short, it was recommended that Synchro be used for all data entry, that all three optimization programs be used, and that a single plan be selected and input to Synchro for fine-tuning.

\subsection{Traffic Signal Simulation Calibration}

In this section, select articles related to traffic simulation calibration, with a focus on 
traffic signals, is provided. The intent of this section is to illustrate the importance of model calibration, and to identify which parameters play the most crucial role in calibration, particularly in SimTraffic, which will be used in this research. It is also to present an overall framework for the calibration of a traffic microsimulation model.

\subsubsection{SimTraffic Calibration Variables}

Calibration is defined as the adjustment of model parameters to improve the model's ability to reproduce local driver behavior and traffic performance characteristics (Dowling, Skabardonis, Halkias, McHale and Zammit, 2004). Following the users' manuals for most simulation models will provide the user with a functioning model of the traffic network in question. However, in most instances, unless great care is taken in the calibration of the simulation model, results can be in error by as much as 70\% (Dowling, et al, 2004), which would minimize the usefulness of the model and its results.

The SimTraffic microsimulation model (Trafficware, 2001) is packaged with the Synchro signal optimization model. The transfer of data between the Synchro model and the SimTraffic model is so seamless that no additional data entry beyond what is provided in Synchro is typically required to have an operating SimTraffic model. However, there are many parameters in SimTraffic that can be used to calibrate the model to prevailing conditions. The signal timing information and roadway geometrics are input into the SimTraffic model from Synchro. This includes all of the information needed to emulate the controller and roadway environment. The parameters in SimTraffic that might be used to aid in the calibration of the model fall under two categories: Driver Parameters and Vehicle Parameters. Both of these are discussed below (Trafficware, 2001): 


\section{Vehicle Parameters}

Vehicle Occurrence changes the proportion of cars and car pools with the non-heavy fleet and the proportion of trucks and buses within the heavy fleet. The percentage of non-heavy / heavy is taken from the input in Synchro.

Maximum Speed and Maximum Acceleration are used together to determine the acceleration available at a given speed. The acceleration available declines linearly with increasing speed. The maximum speed is $110 \mathrm{ft} / \mathrm{s}$ while the maximum acceleration is 10 $\mathrm{ft} / \mathrm{sec} / \mathrm{sec}$.

Vehicle Length is used to determine the length of each vehicle type. It is the bumper-tobumper length. A distance of five feet is assumed between stopped vehicles.

\section{Driver Parameters}

Each driver in the model is randomly assigned a number between 1 and 10 for the basis of defining their characteristics. Drivers assigned a low number are less aggressive than the drivers assigned high numbers. The number is used as a basis for the selection of a value for the following parameters:

Yellow Decel is the maximum deceleration rate a driver is willing to use when faced with a yellow indication. The default values range from $12 \mathrm{ft} / \mathrm{sec} / \mathrm{sec}$ to $7 \mathrm{ft} / \mathrm{sec} / \mathrm{sec}$. Increasing the yellow deceleration rate will make the simulated drivers less likely to run red lights.

Speed Factor is a multiplier that is applied to the link speed to determine the maximum speed for the simulated driver. The default speed factors range from 0.75 to 1.27 .

Courtesy Decel Rate is the maximum deceleration rate a vehicle will accept to allow an ahead vehicle in an adjacent lane to make a mandatory lane change. The higher numbers are associated with more courteous drivers. Default values were not indicated in the user's manual. 
Example values of $11 \mathrm{ft} / \mathrm{sec} / \mathrm{sec}$ were provided for the courteous driver, and $4 \mathrm{ft} / \mathrm{sec} / \mathrm{sec}$ for the non-courteous driver.

Yellow React is the amount of time it takes the driver to react to a yellow indication. It ranges from 0.7 seconds to 1.7 seconds. More aggressive drivers will have a longer reaction time.

Green React is the amount of time it takes the driver to respond to a green indication. It ranges from 0.2 to 0.8 seconds, with the shorter values corresponding to the aggressive drivers.

Headways are the amount of time between vehicles that the drivers try to maintain. SimTraffic has different headways for $0 \mathrm{mph}, 30 \mathrm{mph}$, and $50 \mathrm{mph}$.

Gap Acceptance Factor is an adjustment to approach gap times for minor movements that must yield to major movements. The default values are 1.15 to 0.85 , with the lower values corresponding to aggressive drivers.

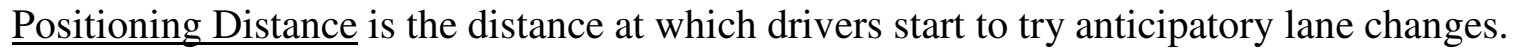
It ranges from $100 \mathrm{ft}$ to $1,500 \mathrm{ft}$. Using lower values will cause balanced lane use upstream of a heavy movement, using higher values reduces last minute lane changes.

Mandatory Lane Change Start Factor determines where in the link changes must start. The lower the value, the further upstream the change starts, which is indicative of conservative drivers.

Note that SimTraffic User's Manual (Trafficware, 2001) provides guidance for the calibration of speeds and headways, and yellow deceleration rates. They also note that to calibrate the model to local conditions, field studies should include the collection of the following data:

- Speeds within intersections 
- Headways between intersections

- Reaction time to green light

Details will not be reiterated here, as the reader is referred to the User's Manual for more details (Trafficware, 2001).

\subsubsection{Framework for Calibration}

Dowling, et al (2004) provided guidance on microsimulation model calibration as part of an FHWA-sponsored project undertaken in response to the recent trend towards the increased usage of microsimulation models in practice. They proposed a top-down three-step approach, which is described later in this section.

They first noted that the fundamental assumption in calibration is that the travel behavior models in the simulation model are essentially sound and that only adjustment of the models to local traffic conditions is needed (Dowling et al, 2004). This is a significant but necessary assumption, as in most cases, there may be alternative travel behavior models available, however, swapping one for another is usually beyond the capabilities provided to users.

They next provided guidance for the categorization of the parameters that can be adjusted during the calibration. This guidance is as follows (Dowling et al, 1004):

1. Separate out those parameters which the analyst is reasonable sure are correct and those that the analyst will have no basis for changing due to the lack of data.

2. Divide the remaining parameters into those that effect capacity, and those that effect route choice. (Note that in this application of the SimTraffic model, route choice will not be an issue.) 
3. Separate each of these groups into those that affect the simulation on a global basis and those that are more localized. The global parameters are adjusted first, followed by finetuning with the more localized parameters.

They next provided a list of data that can be field-collected that is most useful in the calibration of models. For arterials of the type to be modeled in this research, they identified capacity (saturation flow rate), travel time, queue length and delay as the most useful fieldmeasured parameters (Dowling et al, 2004). They further indicated that traffic volumes and travel times should be calibrated to within $85 \%$ of the field-measured values, whereas items such as queuing should be calibrated visually to the analyst's satisfaction. Delay and queue length are also predicted by the Highway Capacity Manual, which can be used as a source for calibration.

Finally, they provided the following three-step approach to calibration.

\section{Step 1: Capacity Calibration}

In this step, parameters are adjusted to best replicate local field measurements of capacity at bottlenecks (Dowling et al, 2004). With the emphasis on traffic signal simulation in this research, this step is considered crucial. It was noted that for signalized intersections, this entails matching the saturation flow rate (or queue discharge headway) between the model and field. Traffic volumes on each approach can be increased in the model for the purpose of building queues to enable the measurement.

According to the Highway Capacity Manual (TRB, 2003), capacity at signalized intersections is generally a function of the percentage of effective green time and the saturation flow rate. If the saturation flow rate can be properly estimated, it then becomes a matter of whether the controller is emulated properly, and whether the lost time at the beginning and end of each phase is properly calibrated. Too much capacity with a properly adjusted saturation flow 
rate might indicate too little start-up time or too much yellow and red light running.

\section{Step 2: Route Choice Calibration}

It was indicated in the description of this step that if the model network consists of only a single facility, then no route choice calibration is possible or needed. Since that is the case, there will be no route choice calibration in this research.

\section{Step 3: System Performance Calibration}

It was indicated that in this step, overall traffic performance parameters such as travel time and queue lengths should be compared to the respective field-measured values (Dowling et al, 2004). Changes can be made to parameters such as free-flow speeds and link capacities. It was noted that since changes at this step can compromise calibration efforts made during previous steps, these changes should be made sparingly.

In SimTraffic, key calibration parameters that might be used during the capacity calibration are: Headways, Green React, Yellow React, and Yellow Decel. The Gap Acceptance Factor might also be important for the capacity of permitted left-turns and right-turns on red. Note that all of these parameters were driver-based. Key calibration parameters for travel time might be the vehicle-based maximum speed and maximum acceleration and the drive-based speed factor. However, the researcher may not have the data available to support changes in these values in all instances.

\subsection{Benefits of Signal Timing Improvements}

In this section, literature related to the benefits of retiming traffic signals is briefly reviewed. Literature providing general insights into the types of benefits that occur were reviewed, as well as literature documenting case studies which estimated the benefits of the signal timing upgrades. 
McShane and Roess (1990) provided a list of the anticipated benefits of traffic signal coordination. These included:

- Reduction in user costs resulting from fewer stops and delay.

- Queue length reduction, which reduces queue spillback between intersections, and generally causes congestion in an area to worsen.

- Conservation of energy and the preservation of the environment. Typical signal retiming projects can result in fuel consumption savings of 6 to $12 \%$, carbon monoxide reductions of $13 \%$, and hydrocarbon particle reductions of $10 \%$ according to estimates by the Pittsburgh Area Metropolitan Planning Organization (MPO) (1996).

- Maintenance of a preferred speed on the arterial, which can be used as a form of speed control.

- Platooning of traffic, which tends to smooth traffic flow, reduce speed differentials, and shorten queues.

User costs are discussed in greater detail below since they are such a significant element of the benefits of signal timing.

When traffic is progressed through a system of signals without stopping, clearly the cost of this travel borne by users should be less. AASHTO (2003) indicated that the three savings in user costs resulting from traffic signal timing improvements are:

- Travel time improvements resulting from less delay experienced by vehicle users.

- Lower operating costs resulting from a reduction in the time spent idling or traveling very slowly while queued.

- Lower accident costs, if applicable.

Numerous studies have cited instances of less delay and operating costs resulting from 
signal timing improvements. Maccubbin, Staples, and Mercer (2003) indicated that implementation of signal coordination along 76 corridors at California cities reduced vehicle delay when traveling the corridors by $25 \%$. Assigning a monetary value to reductions in delay, fuel use, and emissions achieved during a \$4.7 million dollar upgrade of the Richmond, Virginia, signal system yielded benefits of $\$ 4.2$ million annually with a $12 \%$ decline in fuel consumption.

Huffline and Adams (1995) examined the crash patterns on 16 corridors both before and after signal timing projects to improve signal coordination. Although signal coordination is commonly believed to improve safety on congested arterials, the patterns observed were mixed, increasing in some corridors and decreasing in others. On congested, low speed, high access arterials, coordination improvements typically yielded a decrease in rear-end crashes and an increase in turning crashes. Open, high speed, low access arterials experienced a reduction in rear-end crashes and an increase in fixed object crashes. One criticism of the study is that only one year of "before" and one year of "after" data was used in the study.

In contrast, Maccubbin, Staples, and Mercer (2003) indicated that signal coordination along a Phoenix, Arizona, corridor resulted in a $6.7 \%$ reduction in crash risk, calculated based on improved travel speeds and a reduction in the average number of stops.

In a study entitled Traffic Signal Opportunities for Southwestern Pennsylvania (1996), the MPO for the Pittsburgh region quantified the following user cost savings:

- Travel time reductions of $8 \%$ to $15 \%$ per trip

- Travel speed increases of $14 \%$ to $22 \%$

- Vehicular stops reductions of $0 \%$ to $35 \%$

- Travel delay reductions of $13 \%$ to $37 \%$

This study also indicated that of the 2,000 signalized intersections in the six-county 
Pittsburgh metropolitan region, that $37 \%$ would benefit from retiming, $13 \%$ needed minor equipment improvements, and $13 \%$ required major equipment improvements.

Other areas where costs are reduced due to signal timing improvements are as follows (Weisbrod, Vary, and Treyz, 2001):

- The value of freight travel time

- Peak spreading and the value of departure time choice

- Business production / delivery costs

- Logistic costs (including the impacts on Just-In-Time inventory)

- Business cost of worker commuting

- Accessibility and business location

- Overall business productivity

\subsection{Summary and Concluding Remarks}

The literature search focused on three areas of importance to the proposed research.

First, an overview of signal timing and optimization was provided. Several concepts for arterial signal timing and optimization were proposed. Of great interest was the contrast of the McShane and Roess (1990) concept for establishing signal system cycle length with the most popular optimization models. McShane and Roess (1990) recommend that the cycle length should be based on arterial geometry and platoon speed, whereas most of the popular optimization models adopt an intersection-based approach in which the system cycle length is equal to the longest cycle required by any individual intersection. McShane and Roess (1990) expressly disregarded this approach as inappropriate.

Another interesting item was the inability of advanced signal optimization algorithms, including those utilizing artificial intelligence, to develop a better signal timing plan than that 
developed by the Virginia DOT based on field adjustment of an existing plan (Park and Schneeberger, 2003).

Second, an overview of the calibration of SimTraffic microsimulation model was provided, along with a framework for microsimulation calibration (Dowling et al, 2004). It was noted that saturation flow rate (queue discharge headway) would be a key parameter in the calibration. Travel times and queue lengths will also be important.

Finally, some of the benefits of traffic signal retiming were identified, with a focus on economic benefits and environmental benefits. A study performed in the Pittsburgh area (SPRPC, 1996) illustrated the need for signal optimization projects such as that which is the subject of this research. 


\section{CHAPTER 3 - METHODOLOGY}

\subsection{Introduction}

In this chapter, the research methodology is described in detail. From a tactical perspective, the primary goal was to develop a Synchro / SimTraffic model of the S.R. 0021 corridor in South Union Township, Fayette County, Pennsylvania, from Daniel Drive to Santa Maria Drive. A schematic of the study area, which includes lane configurations at each of the signalized intersections, is shown in Figure 3-1.

The major tasks involved in the research were field data collection, Synchro model coding, SimTraffic model validation, the development of alternatives, and the analysis of alternatives. Each is described in a separate section below.

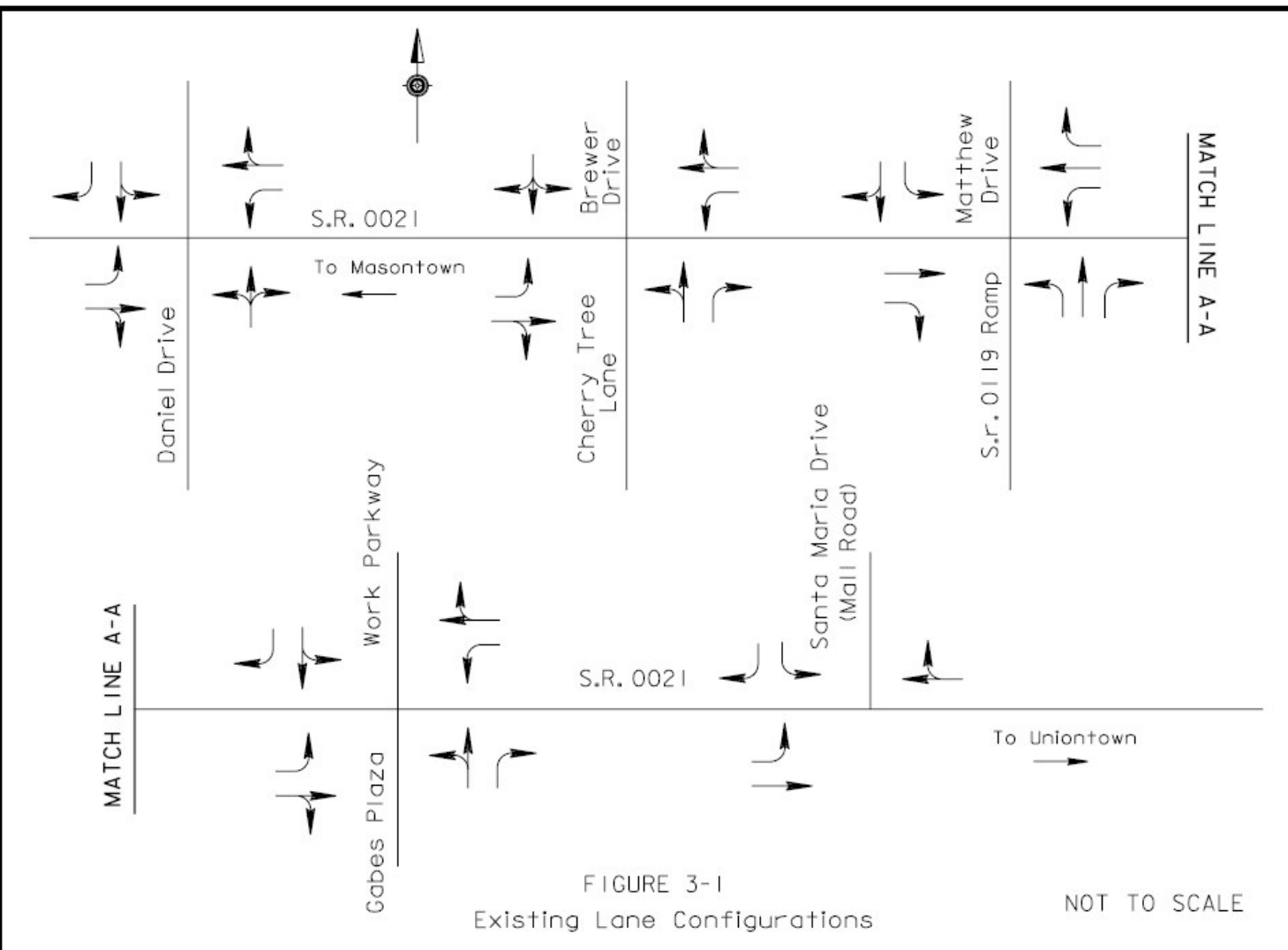




\subsection{Field Data Collection}

Several types of field data were collected in support of this analysis. The full set of collected traffic data is contained in Appendix A. Each of the data collection efforts is described below. All field data collection was performed in the month of October, 2005. There were no special events, crashes, or precipitation at any of the times of data collection. With the Uniontown Hospital located just east of the corridor on S.R. 0021, some emergency vehicle traffic was expected, however, emergency vehicle traffic was rare, and was much less than expected.

\subsubsection{Turning Movement Counts}

Turning movement counts were collected on Wednesday, October 12, 2005 between the hours of 7 am and $9 \mathrm{am}, 11 \mathrm{am}$ and $1 \mathrm{pm}$, and $3 \mathrm{pm}$ and $6 \mathrm{pm}$ at the following intersections on S.R. 0021 in South Union Township, Fayette County, Pennsylvania:

- Daniel Drive

- Cherry Tree Lane / Brewer Drive

- Matthew Drive / S.R. 0119 Ramps

- Work Parkway / Gabriel's Plaza drive

- Santa Maria Drive / Uniontown Mall drive

Data were collected in 15-minute intervals. Any vehicle with more than four tires in contact with the pavement was classified as a truck. The total traffic volume entering the corridor was summed for each 15-minute interval. In each peak period, the four consecutive intervals with the highest total entering traffic were identified as the peak hours. The am, midday, and pm peak hours were identified as 8:00 am to 9:00 am, 11:45 am to 12:45 pm, and 3:45 to 4:45 pm respectively. The turning movement count data are summarized in Figure 3-2. 

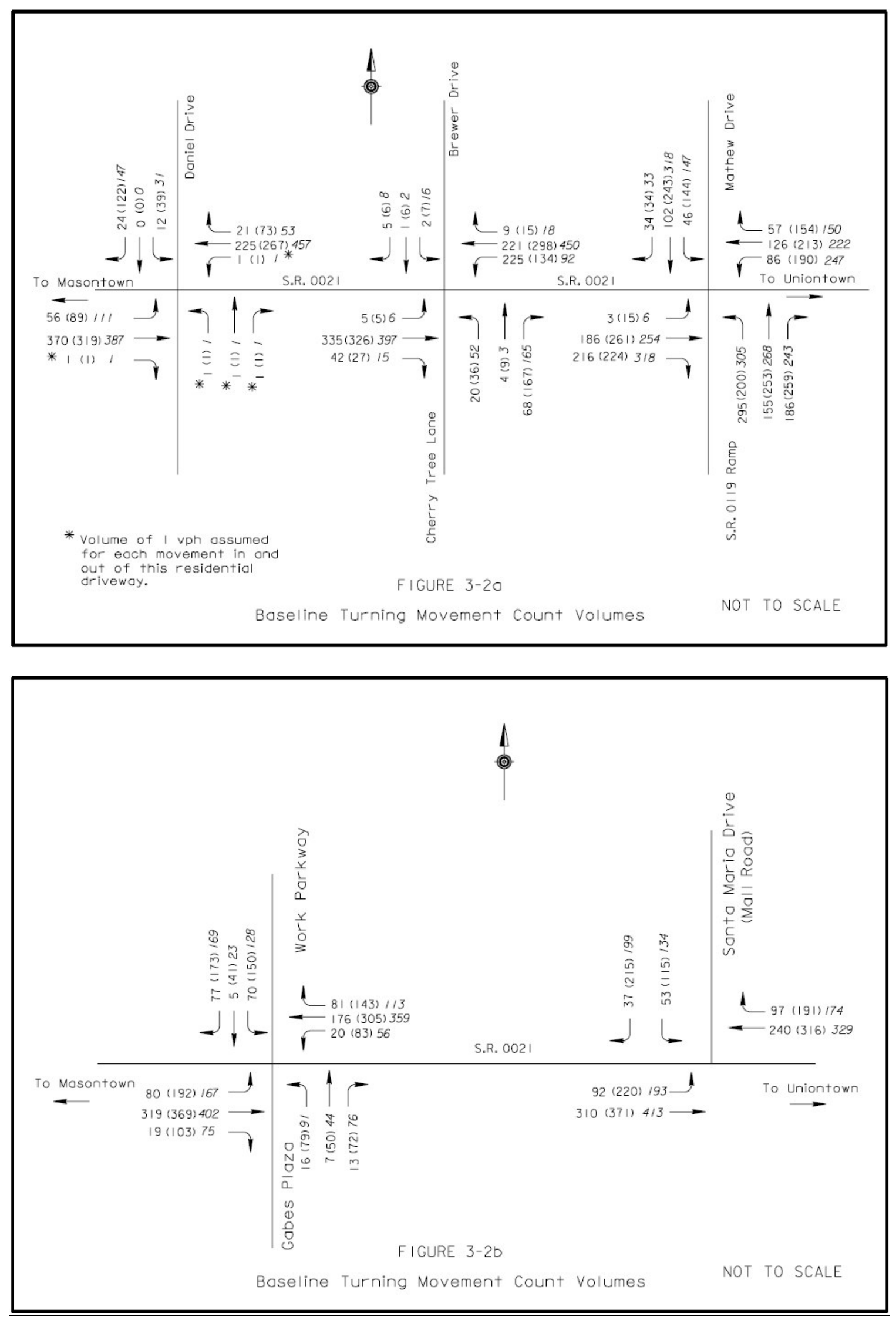
The full set of data is provided in Appendix A.

\subsubsection{Travel Time Runs}

Midday and PM Peak travel time runs were conducted on Monday, October 17, 2005 and AM Peak travel time runs were conducted on Tuesday, October 18, 2005. Ten runs were made in each direction during each peak period, with an emphasis on conducting the runs during the peak hours identified from the turning movement counts. The travel time runs were conducted to measure the travel time between the Daniel Drive intersection in the west and the Santa Maria Drive / Uniontown Mall Drive in the east. In addition to noting the total travel time between these intersections, any durations of stopped delay were noted. The details of the travel time runs are contained in Appendix A. Table 3-1 provides a summary of the travel time data. The travel time runs were conducted using the probe vehicle technique, which was quite simple considering S.R. 0021 was only a single lane in each direction (i.e., there were no opportunities for passing).

Table 3-1 Summary of Travel Time Runs

\begin{tabular}{|c|c|c|c|c|c|c|c|c|}
\hline & \multicolumn{4}{|c|}{ Eastbound S.R. 0021} & \multicolumn{4}{|c|}{ Westbound S.R. 0021} \\
\hline & Ave. & $\begin{array}{c}\text { St. } \\
\text { Dev. }\end{array}$ & Max. & $\begin{array}{l}\text { Margin } \\
\text { of Err. }\end{array}$ & Ave. & $\begin{array}{c}\text { St. } \\
\text { Dev. }\end{array}$ & Max. & $\begin{array}{c}\text { Margin of } \\
\text { Err. }\end{array}$ \\
\hline $\begin{array}{l}\text { AM } \\
\text { Peak }\end{array}$ & $1: 58$ & $0: 25$ & $2: 33$ & $+/-0: 15$ & $1: 41$ & $0: 37$ & $2: 38$ & $+/-0: 23$ \\
\hline $\begin{array}{l}\text { Midday } \\
\text { Peak }\end{array}$ & $3: 08$ & $0: 46$ & $4: 21$ & $+/-0: 29$ & $2: 23$ & $0: 48$ & $3: 33$ & $+/-0: 30$ \\
\hline $\begin{array}{l}\text { PM } \\
\text { Peak }\end{array}$ & $3: 29$ & $1: 10$ & $5: 14$ & $+/-0: 43$ & $2: 12$ & 1:09 & $4: 28$ & $+/-0: 43$ \\
\hline
\end{tabular}

The margin of error in average travel time at the $95^{\text {th }}$ confidence level interval was computed by taking 1.96 (Z-value for $95 \%$ confidence) times the standard error of the mean. This is shown in equation form below: 
Margin of Error $=1.96 \times\left[\mathrm{s} /\left(\mathrm{n}^{1 / 2}\right)\right]$

where:

$\mathrm{s}=$ standard deviation

$\mathrm{n}=$ sample size $(10$ in this case $)$

It is approximately 3,000 feet from Daniel Drive to Santa Maria Drive / Uniontown Mall drive along S.R. 0021. Therefore, the average speeds ranged from $23 \mathrm{mph}$ to $12 \mathrm{mph}$. Table 3-2 provides a summary of the travel time data in terms of travel speed.

Table 3-2 Summary of Travel Speeds (mph)

\begin{tabular}{||l||c|c|c||c|c|c||}
\hline \multicolumn{1}{|c||}{} & \multicolumn{3}{c||}{ Eastbound S.R. 0021 } & \multicolumn{3}{c||}{ Westbound S.R. 0021 } \\
\cline { 2 - 7 } & Average & $\begin{array}{c}\text { Standard } \\
\text { Deviation }\end{array}$ & $\begin{array}{c}\text { Margin of } \\
\text { Error }\end{array}$ & Average & $\begin{array}{c}\text { Standard } \\
\text { Deviation }\end{array}$ & $\begin{array}{c}\text { Margin of } \\
\text { Error }\end{array}$ \\
\hline \hline AM Peak & 18.1 & 4.0 & $+/-2.5$ & 23.1 & 9.3 & $+/-5.8$ \\
\hline $\begin{array}{l}\text { Midday } \\
\text { Peak }\end{array}$ & 11.5 & 3.1 & $+/-1.9$ & 16.3 & 7.0 & $+/-4.3$ \\
\hline PM Peak & 11.7 & 7.2 & $+/-4.5$ & 19.4 & 9.3 & $+/-5.8$ \\
\hline
\end{tabular}

Travel times were much higher in the westbound direction than in the eastbound direction during all periods of the day. As will be illustrated later in the report, this was due to the phasing at the Matthew Drive and Cherry Tree Lane intersections. Note that in the field, the signalization at the intersections of Matthew Drive / S.R. 0119 Ramps and Cherry Tree Lane / Brewer Drive was under the control of a single controller. A primary objective of the phasing employed at these two intersections was to prevent queues on westbound S.R. 0021 at Cherry Tree Lane / Brewer Drive from spilling back into the Matthew Drive / S.R. 0119 ramps intersection. Because of this, eastbound S.R. 0021 was held back at the Cherry Tree Lane / Brewer Drive intersection during a phase where they could be permitted to flow. This caused a great restriction on capacity in the eastbound direction of S.R. 0021. 
Table 3-3 provides an additional summary of data from the travel time runs. In this table, a comparison of the delay at the two-intersection system at Matthew Drive and Cherry Tree Lane to the overall travel time is provided. It was noted in the travel time runs that a substantial amount of the overall delay occurred at these intersections. Since these intersections were operated by a single controller, their operation is similar to that of a single intersection.

Operations at each intersection were so closely coordinated; vehicles were rarely stopped at both intersections.

Table 3-3 Comparison of Delay at Matthew Drive and Cherry Tree Lane to Overall Travel Time

\begin{tabular}{|c|c|c|c|c|c|c|}
\hline & \multicolumn{3}{|c|}{ Eastbound S.R. 0021} & \multicolumn{3}{|c|}{ Westbound S.R. 0021} \\
\hline & $\begin{array}{c}\text { Average } \\
\text { Delay }\end{array}$ & $\begin{array}{c}\text { Travel } \\
\text { Time }\end{array}$ & $\begin{array}{l}\% \text { of } \\
\text { Time }\end{array}$ & $\begin{array}{c}\text { Average } \\
\text { Delay }\end{array}$ & $\begin{array}{l}\text { Travel } \\
\text { Time }\end{array}$ & $\begin{array}{l}\% \text { of } \\
\text { Time }\end{array}$ \\
\hline AM Peak & $0: 58$ & $1: 58$ & $49 \%$ & $0: 43$ & $1: 41$ & $42 \%$ \\
\hline $\begin{array}{l}\text { Midday } \\
\text { Peak }\end{array}$ & $1: 27$ & $3: 08$ & $47 \%$ & $0: 59$ & $2: 23$ & $41 \%$ \\
\hline PM Peak & $1: 48$ & $3: 29$ & $52 \%$ & $1: 13$ & $2: 12$ & $56 \%$ \\
\hline
\end{tabular}

As can be seen, nearly half of the time spent traveling in the corridor was spent waiting at the two-intersection system at Matthew Drive and Cherry Tree Lane. This suggests that signal timing alternatives to improve travel time in the corridor should provide some focus on this twointersection system.

In contrast, Table 3-4 provides a summary of the number of times the probe vehicle was stopped at the Work Parkway / Gabriel Plaza drive intersection. This was the intersection which stopped the probe vehicle the most often, other than the two-intersection system at Matthew Drive and Cherry Tree Lane. The probe vehicle stopped so infrequently at the Santa Maria Drive / Uniontown Mall drive and Daniel Drive that in general, the clock for the travel time runs was started when the probe vehicle entered these intersections instead of when the probe vehicle 
entered the queue. The exception to this occurred when the queue on eastbound S.R. 0021 at the two-signal system at Matthew Drive / Cherry Tree Lane extended through the Daniel Drive intersection.

Table 3-4 Number of Times Stopped at the Work Parkway / Gabriel Plaza Drive intersection (of ten runs in each direction during each time period)

\begin{tabular}{|l||c|c|}
\hline & Eastbound & Westbound \\
\hline AM Peak & 2 & 2 \\
\hline Midday Peak & 3 & 6 \\
\hline PM Peak & 2 & 5 \\
\hline
\end{tabular}

The probe vehicle was rarely stopped at the Work Parkway / Gabriel's Plaza intersection in the eastbound direction. In the westbound direction, it was stopped during approximately half the runs in the midday and pm peaks.

\subsubsection{Queue Discharge Headways}

Understanding the importance of having an accurate estimation of capacity at bottlenecks for use in the SimTraffic simulation model, queue discharge headways were measured at the two-intersection system at Cherry Tree Lane and Matthew Drive. Queue discharge headway is the inverse of saturation flow rate and was field-measured using the procedure in the Highway Capacity Manual (HCM). This involved measuring the total time for a standing queue to dissipate and dividing it by the number of vehicles in the queue, omitting the first four vehicles. Queue Discharge Headway is shown in equation form below:

Queue Discharge Headway = Time to Discharge Queue / Number of Vehicles in Queue The details of the collected queue discharge headway data are contained in Appendix A. Table 3-5 shows the average queue discharge headways for the critical lanes in the Matthew Drive / Cherry Tree Lane two-intersection system, along with the number of cycles observed, 
and the corresponding saturation flow rate. Note that the sample size was limited by the availability of queues and the time available in the pm peak, as all were measured during the pm peak on Monday, October 17, 2005.

Table 3-5 Summary of Queue Discharge Headways at Matthew Drive / Cherry Tree Lane

\begin{tabular}{|l||c|c|c||}
\hline \hline Movement & $\begin{array}{c}\text { Cycles } \\
\text { Observed }\end{array}$ & $\begin{array}{c}\text { Queue Discharge } \\
\text { Headway }\end{array}$ & $\begin{array}{c}\text { Saturation } \\
\text { Flow Rate }\end{array}$ \\
\hline \hline EB S..R. 0021 TH/RT & 3 & 2.1 & 1,750 \\
\hline WB S.R. 0021 LT & 4 & 2.2 & 1,640 \\
\hline NB S.R. 0119 Ramps LT & 6 & 2.3 & 1,560 \\
\hline SB Matthew Drive TH/RT & 2 & 2.2 & 1,640 \\
\hline
\end{tabular}

\section{$\underline{3.1 .4 \text { Cycle Lengths and Splits }}$}

Cycle lengths and splits at all of the intersections were measured twice during each peak period on Monday, October 17 and Tuesday, October 18, 2005. In addition, the cycle length and splits at the two-intersection system at Cherry Tree Lane and Matthew Drive were observed continuously from 3:04 pm to 4:50 pm on Wednesday, October 26, 2005 in response to a specific need. A total of 36 cycles were observed. All of the cycle length data are contained in Appendix A. The cycle lengths from the initial effort are presented in Table 3-6. The cycle lengths and splits from the follow-up effort at Cherry Tree Lane and Matthew Drive are presented in Table 37. In Table 3-7, only the critical phases were measured and presented. The critical phases in this system were the westbound left-turns and eastbound through/right lane on S.R. 0021 and the northbound left-turn and southbound through/right lane on Matthew Drive / S.R. 0119 Ramps. Other movements and phases in the intersections are of lower volume and do not dictate cycle length or capacity. 
Table 3-6 Cycle Lengths at the Corridor Signalized Intersections

\begin{tabular}{|l|c|c|c|c|c|c|}
\hline & AM 1 & AM 2 & MD 1 & MD 2 & PM 1 & PM 2 \\
\hline \hline Uniontown Mall & $01: 00$ & $01: 45$ & $01: 06$ & $00: 47$ & $02: 05$ & $01: 55$ \\
\hline Work Parkway & $02: 35$ & --- & $02: 05$ & $01: 45$ & $00: 47$ & $01: 20$ \\
\hline Matthew / Cherry Tree & $02: 00$ & $01: 52$ & $03: 15$ & $03: 30$ & $03: 00$ & $02: 45$ \\
\hline Daniel Drive & $05: 18$ & --- & $01: 10$ & $02: 41$ & $01: 45$ & --- \\
\hline
\end{tabular}

--- insufficient demand for the minor phases to cause the controller to cycle

All of the intersections are fully-actuated, having cycle lengths that vary from cycle-to-

cycle and from one another. Clearly, the longest cycle lengths were found at the two-intersection system at Matthew Drive and Cherry Tree Lane, which was the bottleneck in the corridor. The longer cycle lengths at Daniel Drive and Work Parkway were a function of the lack of side road demand more than heavy traffic.

Table 3-7 Cycle Lengths and Splits at Matthew Drive / Cherry Tree Lane

\begin{tabular}{|l|c|c|c|c|c|}
\hline & WB LT & EB TH/RT & NB LT & SB TH/RT & Cycle Length \\
\hline $\begin{array}{l}\text { Average } \\
\text { Duration }\end{array}$ & $00: 37$ & $00: 53$ & $00: 42$ & $00: 45$ & $02: 57$ \\
\hline Standard Dev & $00: 09$ & $00: 14$ & $00: 14$ & $00: 07$ & $00: 29$ \\
\hline $\begin{array}{l}\text { Maximum } \\
\text { Duration }\end{array}$ & $00: 52$ & $01: 39$ & $01: 21$ & $00: 52$ & $04: 18$ \\
\hline $\begin{array}{l}\text { Minimum } \\
\text { Duration }\end{array}$ & $00: 19$ & $00: 33$ & $00: 23$ & $00: 30$ & $02: 03$ \\
\hline Splits (\%) & $21 \%$ & $30 \%$ & $24 \%$ & $25 \%$ & $100 \%$ \\
\hline
\end{tabular}

Table 3-7 illustrates that there was significant variation in the timings from cycle-to-cycle at this crucial intersection. With cycle lengths that ranged from two minutes to over four, demand and signal operations were anything but steady or constant during the peak time. This was also seen as a sign that signal coordination may not be successful in this corridor unless the 
capacity problems at this two-intersection system could be alleviated since installing

coordination would take much of this flexibility away. At a signalized bottleneck intersection, making the most efficient use of the available time is crucial.

\subsubsection{Other Observations}

Other observations were made in the field during the various data collection efforts. These were to be used in a qualitative way in the validation of the model. Phenomenon that occurred in the simulation model but not in the field, or vice versa, would indicate a problem with the model.

- During the am peak, there were no long queues, cycle failures, or over-capacity conditions observed.

- During the midday peak, long queues were observed on S.R. 0021 eastbound at the Cherry Tree Lane / Brewer Drive intersection for less than five cycles. These queues spilled back into the Daniel Drive intersection. No other problems were observed.

- In most cases in the pm peak, there were no cycle failures at the two-signal system at Cherry Tree Lane and Matthew Drive. However, there were a few instances where eastbound S.R. 0021 traffic at Cherry Tree Lane and southbound Matthew Drive traffic were not able to clear. At its maximum, queues on eastbound S.R. 0021 reached approximately 60 vehicles, and extended through the Daniel Drive intersection, around a horizontal curve, and into the middle of a vertical curve to the west of Daniel Drive. It was suspected that the likelihood of rear-end crashes was increased when queues were present in these curves due to sight distance concerns and grades. The queues on eastbound S.R. 0021 lasted several cycles over a 30 to 45 minute period.

- The westbound S.R. 0021 traffic at the Work Parkway intersection queued back into the Santa Maria Drive / Uniontown Mall intersection for less than five cycles during the pm 
peak. It was suspected that this was attributable to queuing problems at the Matthew Drive intersection. This problem was only a few minutes in duration.

- A clearance phase installed at the Cherry Tree Lane and Matthew Drive two-signal system caused left-turn traps for the left-turning vehicles from eastbound S.R. 0021 into Brewer Drive (opposite of Cherry Tree Lane) and from westbound S.R. 0021 into the S.R. 0119 ramps. This was observed during the pm peak and found not to be an issue in most cases at Brewer Drive because of the rarity of left-turning vehicles. However, it was an issue for the westbound left-turns into the S.R. 0119 ramps on almost every cycle in the pm peak. Many times, the only thing that prevented a crash was eastbound S.R. 0021 through traffic stopping even though they had a green indication.

\subsection{Synchro Model Coding}

A Synchro model was coded for each peak period in accordance with the user's manual. The following data were used in the model:

- Turning movement counts from the field data collection, including peak hour factors and percentages of trucks.

- Phasing plans and signal timings from the field observations, including yellow and all red clearance intervals and actuated signal timings from intersection drawings supplied by PENNDOT.

- Intersection geometry, including lane configurations, grades, lane lengths, intersection spacings, lane widths, and detector layout from the intersection drawings supplied by PENNDOT.

- Free-flow speeds for the links as estimated from the travel time runs.

- Assumed value of $1600 \mathrm{pcphgpl}$ for ideal saturation flow rate 
The most attention was devoted to the two-intersection system at Matthew Drive and Cherry Tree Lane. From the field data, it was clear that this intersection was the key bottleneck in the corridor, and that it needed to be represented accurately in the SimTraffic model to provide meaningful results. The model was simulated in SimTraffic several times in an iterative fashion until the model provided reasonable results. Most adjustments were made to the signal timings, which was expected considering their highly variable nature in the field. The Synchro models for each peak period are contained on the accompanying CD-ROM. The traffic signal timings and traffic volumes for each alternative are provided in Appendix C.

\subsection{SimTraffic Validation}

Three items were used to validate the SimTraffic model: queue discharge headways, travel time, and a match of queuing and cycle failure to the satisfaction of the modeler. Each is described below:

\subsubsection{Queue Discharge Headways}

Queue discharge headways were not a model output, therefore, they were manually measured by repeating the same method (HCM) used in the field. Three instances of each of the same critical movements measured in the field were recorded for comparison to the field data. The comparison is provided in Table 3-8.

Table 3-8 Comparison of Field Measured and Simulated Queue Discharge Headways

\begin{tabular}{|l|c|c|c|}
\hline \hline Movement & Field & Simulation & $\%$ Difference \\
\hline \hline EB S.R. 0021 TH/RT & 2.1 & 2.2 & $-6 \%$ \\
\hline WB S.R. 0021 LT & 2.2 & 2.3 & $-6 \%$ \\
\hline NB S.R. 0119 Ramps LT & 2.3 & 2.4 & $-4 \%$ \\
\hline SB Matthew Drive TH/RT & 2.2 & 2.2 & $0 \%$ \\
\hline
\end{tabular}


As can be seen, the field-measured and simulated values for queue discharge headway matched very closely on these four critical movements. With the simulated headways being slightly larger than the field-measured counterparts, if anything, the model will underestimate capacity at this bottleneck, which makes the model more conservative. However, the objective was to match the parameters within $15 \%$, which was achieved.

\subsubsection{Travel Times}

In the SimTraffic model, travel time information was output as an aggregation of all vehicles traveling on a link, including those that turned in from side roads and turned off to side roads. The travel time measured in the field was by a probe vehicle traveling the length of the corridor without any turns. Since SimTraffic does not output this measure, it was manually measured in the simulation using vehicles that traveled the length of the corridor. Ten travel time runs were conducted in each direction during each peak period. The objective was to match the average travel times from the model to the field collected travel times within $15 \%$, which was met in all instances. All of the average model travel times are within the $95 \%$ margin of error in the average field-measured travel times shown in Table 3-1. A comparison between the fieldmeasured and simulated travel times are provided in Table 3-9.

Table 3-9 Comparison of Field-Measured and Simulated Travel Times

\begin{tabular}{||c||c|c|c||c|c|c||}
\hline \multicolumn{1}{||}{} & \multicolumn{3}{c||}{ Eastbound } & \multicolumn{3}{c||}{ Westbound } \\
\cline { 2 - 7 } & Field & Model & \% Diff & Field & Model & \% Diff \\
\hline \hline AM Peak & $01: 58$ & $01: 44$ & $-11 \%$ & $01: 41$ & $01: 37$ & $-4 \%$ \\
\hline Midday Peak & $03: 08$ & $03: 20$ & $7 \%$ & $02: 23$ & $02: 22$ & $0 \%$ \\
\hline PM Peak & $03: 29$ & $03: 42$ & $7 \%$ & $02: 12$ & $02: 17$ & $4 \%$ \\
\hline
\end{tabular}




\subsubsection{Queuing and Cycle Failure Observations}

Signal timings were modified until the SimTraffic simulation provided an accurate representation of the problems that were observed in the field. Three main items were of importance: queuing and cycle failure on eastbound S.R. 0021 at Cherry Tree Lane, queuing and cycle failure on southbound Matthew Drive, and queue overflow in the westbound S.R. 0021 left-turn lane into the S.R. 0119 ramps. The former two were problems observed in the field, but only for some of the cycles in the midday and pm peaks. The latter was not observed in the field but was observed in some of the early runs of the model. The model timings were modified by a few seconds to the satisfaction of the modeler. When these models were finalized, they were identified as the "Baseline" models.

\subsection{Alternatives Development}

Four alternatives were developed for assessment in SimTraffic.

- Phasing Change at Matthew Drive and Cherry Tree Lane - Fully Actuated

- Synchro Optimized Coordinated Timing Plan

- Custom Coordinated Timing Plan

- Phasing Change at Matthew Drive and Cherry Tree Lane - Coordinated

Each is described below:

\subsubsection{Phasing Change at Matthew Drive and Cherry Tree Lane - Fully Actuated}

Since the two-signal system at Matthew Drive and Cherry Tree Lane is a bottleneck, a fully actuated setting might operate best. The system was examined in the field to determine how operations can be improved without employing coordination in the corridor. Field examination revealed that the actuation worked as expected, indicating that hardware malfunctions were not an issue. Similarly, field observation demonstrated that the distribution of 
green time provided opportunities for traffic to clear during most cycles. Cycle failures occurred during times of excessively high volumes which pushed the intersection over-capacity. However, with cycle lengths that varied from two minutes to over four minutes, the signal appeared to be fairly responsive to traffic demands within the bounds of reasonableness. The conclusion of the field-examination was that it was not expected that additional capacity could be gleaned from the two-intersection system by simply retiming the existing phase plan or fixing the hardware.

The phase plan at the intersection was examined to determine if additional capacity might be gleaned from its reconfiguration. The existing phase plan is shown in Figure 3-3. One phase was identified as having the potential to increase the capacity if changed. During the phase in which the northbound left-turns from the S.R. 0119 ramps were protected at the Matthew Drive intersection, the Cherry Tree Lane intersection provided a green indication for westbound S.R. 0021 with protected left-turning. Consequently, eastbound S.R. 0021 was provided with a red indication. This provided the traffic turning left from the ramps with a green indication at the Cherry Tree Lane intersection regardless of whether they desire to travel straight or turn left into Cherry Tree Lane. However, it kept all traffic on S.R. 0021 eastbound from reaching the Matthew Drive intersection, where approximately half of them would have turned right into the ramps. See Table 3-10 for a summary of the peak hour turning movements on the eastbound S.R. 0021 approach to Matthew Drive / S.R. 0119 Ramps. These right-turns would have been protected during this phase since it is the left-turns from the ramp that are moving in a protected phase. Holding this traffic back at Cherry Tree Lane so that they cannot reach the S.R. 0119 ramps was a significant loss of capacity. In addition, with all eastbound traffic stored upstream of the Cherry Tree Lane intersection, including right-turning vehicles, the right-turn vehicles and 
straight-through vehicles were not given the opportunity to fill in the right-turn and through lanes in a stopped condition. Because they were flowing as they entered these lanes, the capacity for this direction was dictated by the saturation flow rate across the stop bar at Cherry Tree Lane, and the capacity of the right-turn lane at Matthew Drive was not realized.

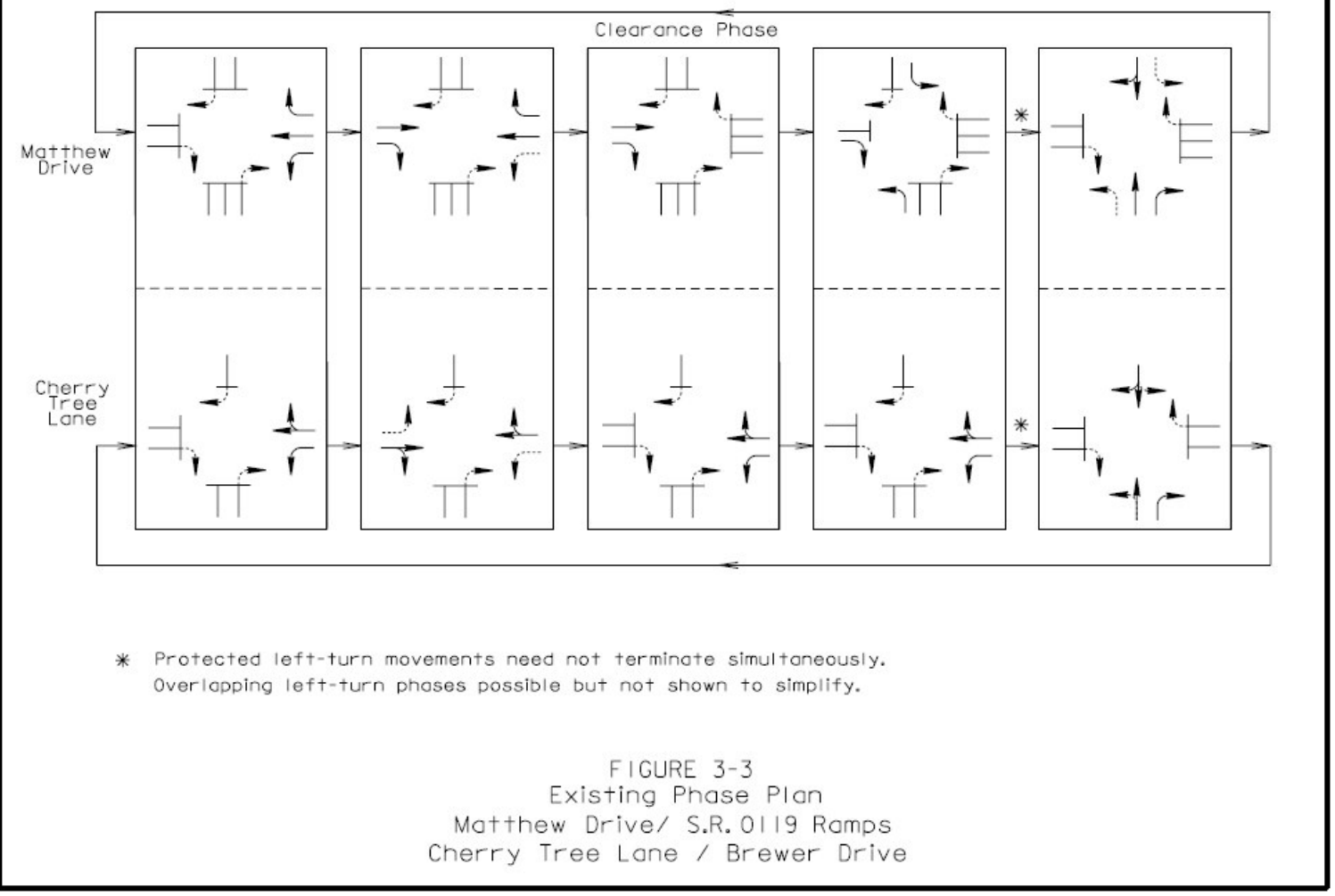

For these reasons, eastbound S.R. 0021 at Cherry Tree Lane was provided with a green indication in lieu of the protected left-turn from westbound S.R. 0021 during the protected northbound left-turn phase from the S.R.0119 ramps. In addition, because of the left-turn trap problem discussed in Section 3.1, the clearance phase causing the left-turn traps was eliminated. Finally, because it was noted that eastbound S.R. 0021 at Matthew Drive sometimes backed up to Cherry Tree Lane due to right-turns on red out of Cherry Tree Lane, a restriction on rightturns on red from Cherry Tree Lane was proposed to the Department. It was believed that this would reserve storage space for through traffic on S.R. 0021 in this short area. However, in 
discussions with the Department, it was decided that this restriction would be unacceptable to the business community in the Cherry Tree Lane area, so it was not imposed. No other changes in the corridor were made. The proposed phase plan is shown in Figure 3-4.

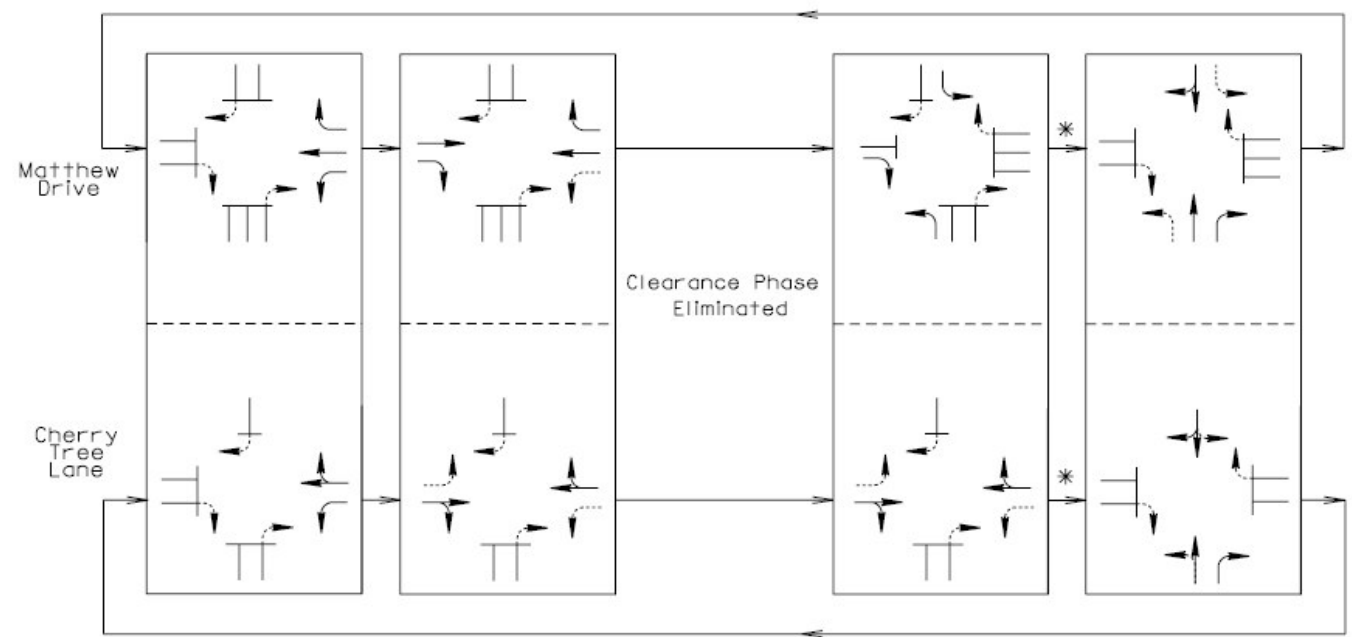

* Protected left-turn movements need not terminate simultaneously. Overlopping left-turn phoses possible but not shown to simplify.

FIGURE 3-4

Proposed Phase PIan

Matthew Drive/ S.R. 0119 Ramps

Cherry Tree Lone / Brewer Drive

Table 3-10 Comparison of Through and Right-Turning Volumes on Eastbound S.R. 0021 at Matthew Drive / S.R. 0119 Ramps

\begin{tabular}{|l||c|c|}
\hline \hline Period & EB Through & EB Right-Turn \\
\hline \hline AM Peak & 186 & 216 \\
\hline Midday Peak & 261 & 224 \\
\hline PM Peak & 254 & 318 \\
\hline
\end{tabular}

\subsubsection{Synchro Optimized Coordinated Timing Plan}

In this alternative, the Synchro optimization algorithm was used to select the cycle length, splits, and offsets within certain constraints set by the user. The range of cycle lengths was restricted to be between 180 and 210 seconds during the midday and pm peaks, and 100 to 
150 seconds during the am peak. The minimum green times were set to 6 seconds for minor phases and 12 seconds for S.R. 0021 mainline phases. Half cycles were permitted. No restrictions were placed on offsets. No changes were made to existing phase plans. The twosignal system at Matthew Drive and Cherry Tree Lane was selected as the master intersection location.

As noted in Chapter 2, the Synchro optimization algorithm selects the system cycle length that minimizes a variable that is a composite of several factors including delays and queuing. Synchro also allows other variables to be used in the optimization, however, the user must select the "manual" optimization option and review the various performance measures for each cycle length. The other variables reported by Synchro that could be used in the selection of system cycle length are as follows:

- Queue Delay, which is a measure of the affect of queues and queue blocking on short links and short turn lanes.

- Total Delay

- Delay per Vehicle

- Total Stops

- Stops per Vehicle

- Fuel Consumption

- Unserved Vehicles, which is simply the volume minus the capacity

- Dilemma Vehicles, which is the number of vehicles arriving while the signal is turning yellow

- Percent Dilemma Vehicles

- Average Speed 
As a comparison of impact of using a different optimization variable, the cycle length yielding the maximum or minimum value as appropriate for each variable is provided in Table 311. In cases of ties, the lowest cycle length was selected. In the am peak, the range of cycle lengths tested was from 50 seconds to 150 seconds in 10 second increments. In the midday and pm peaks, the cycle lengths ranged from 50 seconds to 250 seconds in 10 second increments. The first column, entitled "Perf Index" is the performance index Synchro uses to optimize cycle length when the "automatic" option is selected.

Table 3-11 Optimum Cycle Lengths According to Different Optimization Variables

\begin{tabular}{|c|c|c|c|c|c|c|c|c|c|c|c|}
\hline & $\begin{array}{c}\text { Perf } \\
\text { Index }\end{array}$ & $\begin{array}{l}\text { Queue } \\
\text { Delay }\end{array}$ & $\begin{array}{l}\text { Total } \\
\text { Delay }\end{array}$ & Delay/Veh & $\begin{array}{l}\text { Total } \\
\text { Stops }\end{array}$ & Stops/Veh & Fuel & $\begin{array}{c}\text { Unsrv } \\
\text { Veh }\end{array}$ & $\begin{array}{l}\text { Dil } \\
\text { Veh }\end{array}$ & $\begin{array}{c}\% \\
\text { Dil } \\
\text { Veh }\end{array}$ & $\begin{array}{l}\text { Ave } \\
\text { Spd }\end{array}$ \\
\hline AM & 120 & 50 & 120 & 120 & 100 & 100 & 100 & 110 & 150 & 150 & 50 \\
\hline MD & 100 & 80 & 100 & 100 & 220 & 200 & 100 & 180 & 240 & 200 & 50 \\
\hline PM & 150 & 80 & 150 & 150 & 240 & 230 & 140 & 250 & 250 & 200 & 50 \\
\hline
\end{tabular}

As a comparison, in the alternative entitled "Custom Coordinated," the engineer used their best judgment to determine a traffic signal plan for the corridor. The system cycle lengths used were 120 seconds in the am peak and 210 seconds in the midday and pm peaks. These cycle lengths were compared to those predicted by the various optimization variables to determine which variables matched those from engineering judgment in this case. The results are shown in Table 3-12. The "average difference" was calculated by determining the difference between the cycle length from engineering judgment and that from the optimization for the am, midday, and pm peak. Each of these differences were squared to remove the sign and summed. The square root of the sum was taken and the resultant was divided by three since it was to represent the average difference over the three periods. The column "High or Low" is indicates whether the performance measure yielded a cycle length which was higher or lower than the cycle length from engineering judgment. As can be seen, "Stops per Vehicle", "Percent 
Dilemma Vehicles", "Total Stops", "Unserved Vehicles", and "Dilemma Vehicles" yielded cycle lengths that were most similar to engineering judgment. "Total Delay", "Delay per Vehicle", and "Fuel Consumption" yielded cycle lengths that were very similar to the performance index used by Synchro in the automatic optimization mode. "Queue Delay" and "Average Speed" were not in agreement with either the performance index or engineering judgment, mainly because they were largely insensitive to cycle length, and the shortest cycle length yielding the optimum value was the lowest cycle length tested, which was 50 seconds.

Table 3-12 Comparison of the Various System Cycle Lengths with Engineering Judgment

\begin{tabular}{|l|c|c|}
\hline Performance Measure & $\begin{array}{c}\text { Average } \\
\text { Difference }\end{array}$ & High or Low \\
\hline Stops / Vehicle & 10 & Low \\
\hline \% Dilemma Vehicles & 11 & High \\
\hline Total Stops & 12 & High \\
\hline Unserved Vehicles & 17 & High \\
\hline Dilemma Vehicles & 19 & High \\
\hline Performance Index & 42 & Low \\
\hline Total Delay & 42 & Low \\
\hline Delay / Vehicle & 42 & Low \\
\hline Fuel Consumed & 44 & Low \\
\hline Queue Delay & 66 & Low \\
\hline Average Speed & 79 & Low \\
\hline
\end{tabular}

For the purposes of this alternative, the Synchro performance index (i.e., automatic option) will be used for the selection of system cycle length. The cycle lengths that correspond with the "engineering judgment" and hence some of the other performance measures are being tested as part of the alternative discussed next in Section 3.4.3. However, this analysis was shown because it is interesting to note that Synchro's performance index is not necessarily in agreement with engineering judgment. 


\subsubsection{Custom Coordinated Timing Plan}

Based on field observations and the simulated analysis of the Synchro Optimized

Coordinated Timing Plan, it was apparent that the timings at the two-signal system at Matthew Drive and Cherry Tree Lane could not be changed much without creating problems. Therefore, a coordinated timing plan was created in which the exact timings from the baseline simulation run were used at the two-signal system. This was a 210 -second cycle length in the midday and pm peaks and a 120-second cycle length in the am peak. A full cycle length was employed at Daniel Drive since demand was typically low and queuing on this side road approach did not figure to be a problem. Half-cycles were employed at Work Parkway and Santa Maria Drive / Uniontown Mall due to concerns related to queuing on these approaches. The splits were kept approximately the same or kept in proportion to those used in the baseline model. The Synchro optimization algorithm was used to develop offsets for each intersection assuming the twointersection system was the location of the master.

\subsubsection{Phasing Change at Matthew Drive and Cherry Tree Lane - Coordinated}

Based on discussions with the Pennsylvania Department of Transportation, in which they indicated both a desire for coordination on S.R. 0021 and a willingness to consider the phasing changes described in Section 3.4.1, this fourth alternative was evaluated. It includes coordination in the corridor and the phasing changes listed below and described in Section 3.4.1.

- Eastbound S.R. 0021 at Cherry Tree Lane was provided with a green indication in lieu of the protected left-turn from westbound S.R. 0021 during the protected northbound leftturn phase from the S.R.0119 ramps.

- The clearance phase causing the left-turn traps was eliminated.

- Right-turns on red from Cherry Tree Lane were restricted. 
The coordination parameters of cycle length, splits, and offsets were developed using Synchro and adjusted manually. The system cycle lengths used were 100 seconds, 110 seconds, and 140 seconds in the am, midday, and pm peaks respectively. In the pm peak, the 140 -second cycle length was used at Daniel Drive and the two-signal system at Cherry Tree Lane and Matthew Drive, while half-cycles (70 seconds) were used at Work Parkway and Santa Maria Drive / Uniontown Mall.

\subsection{Alternatives Analysis}

The baseline and alternatives models were analyzed by running each simulation ten times using different seed numbers and averaging the resultant performance measures. The network was simulated for one hour. The first 15-minutes were used as seed time and statistics were not queried. Statistics were then collected during the final 45-minutes. In this way, the peak hour volumes were not simulated for more than one hour, which was representative of field conditions and important since over-capacity conditions exist.

The seed numbers were selected randomly using the RAND function in Excel. A seed number of 1 was used since it is the program default and was the seed number used in model validation. The other nine seed numbers were between one and one million and were as follows: 196707, 245122, 437068, 518658, 556682, 689432, 759075, 862089, and 950495.

The following measures of effectiveness were queried for each run and averaged. Each performance measure was queried specifically for the links comprising S.R. 0021, and for the network as a whole. In this way, it could be determined if the alternatives provided benefits for S.R. 0021 at the expense of the side roads.

- Delay / Vehicle (seconds) - The Highway Capacity Manual performance measure for signalized intersection level of service. It is based on the free flow travel time through 
the corridor compared to the delay caused by the traffic control devices and interference from other drivers.

- Travel Time (hr) - The total time spent traveling in the system, including delay and free flow travel times.

- Average Speed (mph) - The total vehicle miles traveled divided by the total time spent traveling.

- Fuel Used (gal) - The total fuel consumed during the simulated time period.

- Fuel Efficiency (mpg) - The total fuel consumed divided by the total vehicle miles traveled.

- $\mathrm{HC}(\mathrm{g})$ - The quantity of hydrocarbon pollutants emitted during the simulation period.

- $\mathrm{CO}(\mathrm{g})$ - The quantity of carbon monoxide emitted during the simulation period.

- NOx (g) - The quantity of nitrous oxide pollutants emitted during the simulation period.

These performance measures were selected because they provided indications of transportation efficiency, fuel efficiency, and pollution, which quantified the main anticipated benefits of signal retiming projects. They also captured two of the three components of user cost, those being delay and operating costs.

In addition, because travel time was a crucial performance measure to the Department, and was used in model validation, 10 travel time runs on S.R. 0021 were averaged from each direction of each model (seed $=1$ only) for each alternative. Note that because they were performed manually, they were extremely time-intensive, and it was not feasible to perform them for all ten runs of each model in which the seed number was varied. Gathering 10 travel time runs in each direction for each time period and each alternative involved 240 total travel time runs. Gathering them for each of the 10 runs with different seeds would have increased the 
number of runs to 2400 , which was considered unreasonable and not something that would be done in practice. 


\section{CHAPTER 4 - RESULTS}

\subsection{Introduction}

This chapter presents the findings of the alternatives analysis of the four signal timing strategies identified in Section 3.4. Each of the alternatives was compared to the baseline condition using the validated SimTraffic model described in Chapter 3. Appendix B contains the statistics from the SimTraffic model runs. Appendix C contains the Synchro printouts of the traffic volumes and traffic signal timings used in each alternative. Each section below provides the key performance measures relating to each of the alternatives, beginning with the baseline scenario. Section 4.6 then provides a summary of the engineering analysis and important lessons learned relative to the methodology used to assess the alternatives.

\subsection{Baseline}

The key statistics from the baseline condition are provided in Tables 4-1 and 4-2.

Looking at the delay per vehicle statistic in the baseline model, the LOS for the total network was worse than that experienced on S.R. 0021 in all time periods. Both the network and S.R. 0021 operate at LOS F in the pm peak period, as both have delays per vehicle in excess of 80 seconds, which is the threshold for LOS F specified by the Highway Capacity Manual. Table 4-1 Baseline Simulated Performance Measures

\begin{tabular}{|c|c|c|c|c|c|c|}
\hline & \multicolumn{3}{|c|}{ S.R. 0021} & \multicolumn{3}{|c|}{ Total Network } \\
\hline & AM Peak & $\begin{array}{c}\text { Midday } \\
\text { Peak }\end{array}$ & PM Peak & AM Peak & $\begin{array}{c}\text { Midday } \\
\text { Peak }\end{array}$ & PM Peak \\
\hline Delay/Veh (s) & 27.9 & 46.7 & 84.7 & 43.7 & 69.6 & 113.0 \\
\hline Travel Time (hr) & 22.6 & 44.9 & 71.2 & 41.4 & 84.7 & 123.4 \\
\hline Ave Speed (mph) & 19 & 13 & 10 & 16 & 12 & 10 \\
\hline Fuel Used (gal) & 63.7 & 89.3 & 94.5 & 100.3 & 151.3 & 154.5 \\
\hline Fuel Eff (mpg) & 6.5 & 6.6 & 6.9 & 6.8 & 6.9 & 7.3 \\
\hline
\end{tabular}




\begin{tabular}{|l||c|c|c||c|c|c||}
\hline \hline $\mathrm{HC}(\mathrm{g})$ & 138 & 225 & 263 & 223 & 380 & 429 \\
\hline $\mathrm{CO}(\mathrm{g})$ & 6177 & 10236 & 10797 & 10166 & 16136 & 16672 \\
\hline NOx $(\mathrm{g})$ & 477 & 760 & 823 & 749 & 1254 & 1318 \\
\hline
\end{tabular}

The average travel time computed from 10 probe vehicles in a single simulation run ( direct output of the SimTraffic model and averaged over 10 simulation runs. This is shown in Table 4-2. As an example, during the am peak, the 10 probe vehicle runs in the eastbound and westbound direction yielded average travel times of 1:44 and 1:37 respectively, thus the average of these two travel times was 1:41. Furthermore, an average speed of $19 \mathrm{mph}$ was 28 feet per second (ft/s). Since the corridor is 3,000 feet in length, the average travel time at $28 \mathrm{ft} / \mathrm{s}$ was 107 seconds or 1:47. The ten probe vehicle runs corresponded well with the average speed from SimTraffic, generally tracking the increases and decreases in concert with one another. However, in absolute terms, they differed by over $10 \%$ in the pm peak, demonstrating that there was merit in examining both.

Another comparison was made between the 10 probe vehicle runs and the average speeds on S.R. 0021 from the simulation run $(\mathrm{seed}=1)$ from which the 10 probe vehicles were selected. These average speeds were $19 \mathrm{mph}, 13 \mathrm{mph}$, and $11 \mathrm{mph}$ in the am, midday, and pm peaks respectively. The travel time which corresponded to a speed of $11 \mathrm{mph}$ was 3:05. As can be seen, the 10 probe vehicle runs corresponded well with the SimTraffic queried average speed statistic. One concern was that the SimTraffic average speed statistic was rounded to the nearest $1 \mathrm{mph}$. In the case of the pm peak travel time, this was a difference of almost 20 seconds, or $10 \%$, which was considered significant. In addition, the SimTraffic output did not provide the average speed by direction, which in this case was crucial considering the disparity in travel 
times in each direction. It may have been possible to get directional data by coding the network differently, or by manually aggregating data from a more detailed level, however, it was not an option that could be selected directly.

Table 4-2 Baseline Simulated Travel Times

\begin{tabular}{|l||c|c|c|c|c|}
\hline \multirow{2}{*}{} & \multicolumn{3}{|c|}{10 Probe Vehicles } & \multicolumn{2}{c|}{ SimTraffic Average Speed } \\
\cline { 2 - 6 } & EB & WB & Average & Speed (mph) & Travel Time \\
\hline \hline AM Peak & $01: 44$ & $01: 37$ & $01: 41$ & 19 & $01: 47$ \\
\hline Midday Peak & $03: 20$ & $02: 22$ & $02: 51$ & 13 & $02: 37$ \\
\hline PM Peak & $03: 42$ & $02: 17$ & $03: 00$ & 10 & $03: 24$ \\
\hline
\end{tabular}

\subsection{Phasing Change at Matthew Drive and Cherry Tree Lane - Fully Actuated}

The statistics from the model modified to reflect the phasing change at the Matthew Drive / S.R. 0119 intersection, described in Section 3.4.1, can be found in Tables 4-3, 4-4, and 45. As can be seen, the simulation predicted that this alternative has the potential to make a significant reduction in the congestion in the area, both on S.R. 0021 and the side roads as well. LOS F conditions were projected to be alleviated, and delay was projected to be cut by 15 to $50 \%$. Fuel efficiency and pollution emissions appeared to be less sensitive than the delay and travel time measures, as changes in these variables were more on the order of $10 \%$, with carbon monoxide emissions actually rising, likely due to the increase in speeds.

Table 4-5 shows travel time reductions of 20 to $30 \%$ in the midday and pm peaks, with a slight increase in the am peak. This increase was not projected by the average speed statistic from SimTraffic, which was $19 \mathrm{mph}$ in the baseline scenario and $21 \mathrm{mph}$ for this alternative. The increase projected by the 10 probe vehicle technique was considered to have merit because during the am field travel time runs, little congestion occurred, and travel time was largely dictated by the probability of arriving on green at each intersection. Because the cycle length 
and amount of green time provided to S.R. 0021 at the Matthew Drive / S.R. 0119 intersection was reduced, the likelihood of the through-traveling probe vehicle arriving on green was reduced. This may not have been captured with the SimTraffic method of averaging all vehicles on S.R. 0021 together for average speed.

Table 4-3 Simulated Performance Measures - Phasing Change Alternative

\begin{tabular}{|c|c|c|c|c|c|c|}
\hline & \multicolumn{3}{|c|}{ S.R. 0021} & \multicolumn{3}{|c|}{ Total Network } \\
\hline & AM Peak & $\begin{array}{c}\text { Midday } \\
\text { Peak }\end{array}$ & PM Peak & AM Peak & $\begin{array}{c}\text { Midday } \\
\text { Peak }\end{array}$ & PM Peak \\
\hline Delay/Veh (s) & 20.9 & 35.6 & 44.6 & 33.6 & 59.4 & 71.3 \\
\hline Travel Time (hr) & 20.0 & 38.5 & 47.6 & 37.1 & 77.6 & 93.5 \\
\hline Ave Speed (mph) & 21 & 15 & 14 & 19 & 13 & 12 \\
\hline Fuel Used (gal) & 63.8 & 88.2 & 85.4 & 99.1 & 150.0 & 142.6 \\
\hline Fuel Eff (mpg) & 6.5 & 6.7 & 7.8 & 6.9 & 6.9 & 8.2 \\
\hline $\mathrm{HC}(\mathrm{g})$ & 135 & 218 & 240 & 216 & 372 & 398 \\
\hline $\mathrm{CO}(\mathrm{g})$ & 6743 & 10406 & 11190 & 10109 & 16272 & 17013 \\
\hline NOx $(g)$ & 475 & 756 & 805 & 742 & 1248 & 1288 \\
\hline
\end{tabular}

Table 4-4 Percentage Changes in Performance Measures as Compared to the Baseline Scenario - Phasing Change Alternative

\begin{tabular}{|l||c|c|c||c|c|c||}
\hline \multicolumn{1}{|c||}{} & \multicolumn{3}{c||}{ S.R. 0021 } & \multicolumn{3}{c||}{ Total Network } \\
\cline { 2 - 7 } & AM Peak & $\begin{array}{c}\text { Midday } \\
\text { Peak }\end{array}$ & PM Peak & AM Peak & $\begin{array}{c}\text { Midday } \\
\text { Peak }\end{array}$ & PM Peak \\
\hline \hline Delay/Veh (s) & $-24.9 \%$ & $-23.8 \%$ & $-47.3 \%$ & $-23.1 \%$ & $-14.6 \%$ & $-36.9 \%$ \\
\hline Travel Time (hr) & $-11.3 \%$ & $-14.2 \%$ & $-33.2 \%$ & $-10.4 \%$ & $-8.3 \%$ & $-24.3 \%$ \\
\hline Ave Speed (mph) & $12.4 \%$ & $15.2 \%$ & $44.9 \%$ & $13.4 \%$ & $8.9 \%$ & $28.1 \%$ \\
\hline Fuel Used (gal) & $0.2 \%$ & $-1.3 \%$ & $-9.6 \%$ & $-1.2 \%$ & $-0.8 \%$ & $-7.7 \%$ \\
\hline Fuel Eff (mpg) & $0.0 \%$ & $1.4 \%$ & $12.8 \%$ & $1.3 \%$ & $0.9 \%$ & $11.4 \%$ \\
\hline HC (g) & $-2.4 \%$ & $-3.1 \%$ & $-9.0 \%$ & $-2.9 \%$ & $-2.1 \%$ & $-7.3 \%$ \\
\hline CO (g) & $9.2 \%$ & $1.7 \%$ & $3.6 \%$ & $-0.6 \%$ & $0.8 \%$ & $2.0 \%$ \\
\hline \hline
\end{tabular}




\begin{tabular}{|l||l|l|l|l|l|l|}
\hline NOx $(\mathrm{g})$ & $-0.3 \%$ & $-0.6 \%$ & $-2.2 \%$ & $-1.0 \%$ & $-0.5 \%$ & $-2.3 \%$ \\
\hline
\end{tabular}

Table 4-5 Simulated Travel Times - Phasing Change Alternative

\begin{tabular}{||c|c|c|c|c|c|c||}
\hline \hline & \multicolumn{3}{c|}{ Eastbound } & \multicolumn{3}{c||}{ Westbound } \\
\cline { 2 - 7 } & Alternative & Baseline & $\%$ Diff & Alternative & Baseline & $\%$ Diff \\
\hline \hline AM Peak & $1: 46$ & $01: 44$ & $+1 \%$ & $1: 46$ & $01: 37$ & $+10 \%$ \\
\hline Midday Peak & $2: 32$ & $03: 20$ & $-24 \%$ & $1: 53$ & $02: 22$ & $-21 \%$ \\
\hline PM Peak & $2: 31$ & $03: 42$ & $-32 \%$ & $1: 45$ & $02: 17$ & $-24 \%$ \\
\hline \hline
\end{tabular}

\subsection{Synchro Optimized Coordinated Timing Plan}

The statistics, from the model modified to implement the Synchro Optimized

Coordination Plan, described in Section 3.4.2, can be found in Tables 4-6, 4-7, and 4-8. As can be seen, this alternative demonstrated the potential to improve conditions on S.R. 0021 in the midday and pm peaks in the simulations. However, conditions on the overall network were projected to worsen. The most dramatic illustration of this was found with the delay per vehicle statistic in the pm peak. Delay was projected to be cut by over $30 \%$ on S.R. 0021, alleviating LOS F conditions and nearly achieving LOS D. However, total network delay increased from 113 seconds per vehicle to over 130 seconds per vehicle, which was an increase of over $15 \%$, and the highest of any of the scenarios tested. Since conditions on S.R. 0021 actually improved in the simulation, the overall increase in traffic congestion was an indicator that the increase in congestion on the side roads was even more dramatic. These findings suggest that the benefits of the progression provided on S.R. 0021 by coordination were outweighed by the costs of the loss of flexibility in serving side road demand, particularly at the critical two-intersection system at Matthew Drive and Cherry Tree Lane. This was hypothesized after review of the field-measured travel time data when it was found that half of the travel time in the corridor was spent waiting at this two-intersection system, and that drivers were not frequently stopped at the other 
intersections in the corridor. The high variability in cycle length and splits observed in the field at this intersection during the pm peak also reinforced this hypothesis.

Another interesting finding was that the coordination actually increased travel times in the simulation during the lightly-traveled am peak. This was reflected in both the probe vehicle runs and the average travel speed statistic output by SimTraffic.

Table 4-6 Simulated Performance Measures - Synchro Optimized Coordinated Timing Plan Alternative

\begin{tabular}{|l||c|c|c|c|c|c|}
\hline \multirow{2}{*}{} & \multicolumn{3}{c|}{ S.R. 0021 } & \multicolumn{3}{c|}{ Total Network } \\
\cline { 2 - 7 } & AM Peak & $\begin{array}{c}\text { Midday } \\
\text { Peak }\end{array}$ & PM Peak & AM Peak & $\begin{array}{c}\text { Midday } \\
\text { Peak }\end{array}$ & PM Peak \\
\hline Delay/Veh (s) & 34.3 & 39.4 & 57.6 & 50.9 & 76.0 & 130.6 \\
\hline Travel Time (hr) & 24.9 & 40.6 & 55.0 & 45.5 & 89.1 & 136.1 \\
\hline Ave Speed (mph) & 17 & 15 & 12 & 15 & 12 & 10 \\
\hline Fuel Used (gal) & 64.8 & 85.2 & 84.8 & 101.8 & 151.9 & 158.3 \\
\hline Fuel Eff (mpg) & 6.4 & 6.9 & 7.7 & 6.7 & 6.8 & 7.2 \\
\hline HC (g) & 139 & 215 & 241 & 224 & 382 & 443 \\
\hline CO (g) & 6521 & 9943 & 10748 & 9974 & 15983 & 16947 \\
\hline NOx (g) & 470 & 734 & 779 & 748 & 1248 & 1314 \\
\hline
\end{tabular}


Table 4-7 Percentage Changes in Performance Measures as Compared to the Baseline Scenario - Synchro Optimized Coordinated Timing Plan Alternative

\begin{tabular}{|l||c|c|c||c|c|c||}
\hline \multirow{2}{*}{} & \multicolumn{3}{|c|}{ S.R. 0021 } & \multicolumn{3}{c||}{ Total Network } \\
\cline { 2 - 7 } & AM Peak & $\begin{array}{c}\text { Midday } \\
\text { Peak }\end{array}$ & PM Peak & AM Peak & $\begin{array}{c}\text { Midday } \\
\text { Peak }\end{array}$ & PM Peak \\
\hline \hline Delay/Veh (s) & $22.9 \%$ & $-15.6 \%$ & $-32.0 \%$ & $16.6 \%$ & $9.3 \%$ & $15.5 \%$ \\
\hline Travel Time (hr) & $10.2 \%$ & $-9.5 \%$ & $-22.8 \%$ & $9.7 \%$ & $5.3 \%$ & $10.3 \%$ \\
\hline Ave Speed (mph) & $-9.2 \%$ & $9.8 \%$ & $26.5 \%$ & $-6.1 \%$ & $-3.3 \%$ & $5.2 \%$ \\
\hline Fuel Used (gal) & $1.8 \%$ & $-4.6 \%$ & $-10.3 \%$ & $1.5 \%$ & $0.4 \%$ & $2.5 \%$ \\
\hline Fuel Eff (mpg) & $-1.7 \%$ & $4.9 \%$ & $12.2 \%$ & $-1.5 \%$ & $-0.6 \%$ & $-2.6 \%$ \\
\hline HC (g) & $0.2 \%$ & $-4.4 \%$ & $-8.3 \%$ & $0.7 \%$ & $0.6 \%$ & $3.2 \%$ \\
\hline CO (g) & $5.6 \%$ & $-2.9 \%$ & $-0.4 \%$ & $-1.9 \%$ & $-0.9 \%$ & $1.6 \%$ \\
\hline NOx (g) & $-1.4 \%$ & $-3.4 \%$ & $-5.3 \%$ & $-0.2 \%$ & $-0.4 \%$ & $-0.3 \%$ \\
\hline
\end{tabular}

Table 4-8 Simulated Travel Times - Synchro Optimized Coordinated Timing Plan Alternative

\begin{tabular}{|l|c|c|c|c|c|c||}
\hline \hline & \multicolumn{3}{|c|}{ Eastbound } & \multicolumn{3}{c||}{ Westbound } \\
\cline { 2 - 7 } & Alternative & Baseline & $\%$ Diff & Alternative & Baseline & \% Diff \\
\hline \hline AM Peak & $2: 21$ & $01: 44$ & $+35 \%$ & $1: 45$ & $01: 37$ & $+8 \%$ \\
\hline Midday Peak & $2: 32$ & $03: 20$ & $-24 \%$ & $2: 02$ & $02: 22$ & $-14 \%$ \\
\hline PM Peak & $3: 13$ & $03: 42$ & $-13 \%$ & $1: 48$ & $02: 17$ & $-21 \%$ \\
\hline \hline
\end{tabular}

\subsection{Custom Coordinated Timing Plan}

The statistics, from the model modified to implement the Custom Coordinated Plan described in Section 3.4.3, can be found in Tables 4-9, 4-10, and 4-11. As noted in Section 3.4.3, this alternative was developed to maintain the existing signal operations at the critical twointersection system at Matthew Drive and Cherry Tree Lane to the extent possible. It was hypothesized that the conditions would not be degraded at this critical two-intersection system, and that whatever progression could be gleaned from the coordination worked in around this critical area would provide at least a modest benefit. Again, the implementation of coordination 
in this corridor decreased the level of operations on the overall network, even though operations on S.R. 0021 were benefited. It was originally hypothesized that this was due to additional delay on the non-saturated side road approaches at other intersections, however, cycle failure and long queuing on southbound Matthew Drive, which were problems in baseline runs when the intersection was fully-actuated, were observed in the simulations of this alternative. The loss of flexibility to alter the cycle length and splits at the critical two-intersection system caused significant problems even though the same maximum green timings were used. To a certain extent, this even negated the anticipated benefits on S.R. 0021, as travel times in the eastbound direction increased in all three time periods, as shown in Table 4-11.

Table 4-9 Simulated Performance Measures - Custom Coordinated Timing Plan Alternative

\begin{tabular}{|l|c|c|c|c|c|c|}
\hline \multirow{2}{*}{} & \multicolumn{3}{|c||}{ S.R. 0021 } & \multicolumn{3}{c|}{ Total Network } \\
\cline { 2 - 7 } & AM Peak & $\begin{array}{c}\text { Midday } \\
\text { Peak }\end{array}$ & PM Peak & AM Peak & $\begin{array}{c}\text { Midday } \\
\text { Peak }\end{array}$ & PM Peak \\
\hline Delay/Veh (s) & 26.4 & 46.2 & 73.6 & 46.5 & 78.0 & 121.8 \\
\hline Travel Time (hr) & 22.0 & 44.7 & 64.6 & 42.7 & 90.7 & 130.5 \\
\hline Ave Speed (mph) & 19 & 13 & 10 & 16 & 12 & 9 \\
\hline Fuel Used (gal) & 58.8 & 87.2 & 88.6 & 96.6 & 152.4 & 155.6 \\
\hline Fuel Eff (mpg) & 7.1 & 6.8 & 7.4 & 7.1 & 6.8 & 7.3 \\
\hline HC (g) & 116 & 218 & 252 & 216 & 383 & 436 \\
\hline CO (g) & 6123 & 9829 & 10623 & 9625 & 15865 & 16716 \\
\hline NOx (g) & 433 & 731 & 793 & 718 & 1247 & 1314 \\
\hline
\end{tabular}


Table 4-10 Percentage Changes in Performance Measures as Compared to the Baseline Scenario - Custom Coordinated Timing Plan Alternative

\begin{tabular}{|l||c|c|c||c|c|c||}
\hline \multirow{2}{*}{} & \multicolumn{3}{|c|}{ S.R. 0021 } & \multicolumn{3}{c||}{ Total Network } \\
\cline { 2 - 7 } & AM Peak & $\begin{array}{c}\text { Midday } \\
\text { Peak }\end{array}$ & PM Peak & AM Peak & $\begin{array}{c}\text { Midday } \\
\text { Peak }\end{array}$ & PM Peak \\
\hline \hline Delay/Veh (s) & $-5.5 \%$ & $-1.2 \%$ & $-13.1 \%$ & $6.5 \%$ & $12.1 \%$ & $7.8 \%$ \\
\hline Travel Time (hr) & $-2.7 \%$ & $-0.4 \%$ & $-9.4 \%$ & $2.9 \%$ & $7.1 \%$ & $5.8 \%$ \\
\hline Ave Speed (mph) & $1.6 \%$ & $0.8 \%$ & $6.1 \%$ & $-1.8 \%$ & $-4.9 \%$ & $-2.1 \%$ \\
\hline Fuel Used (gal) & $-7.7 \%$ & $-2.4 \%$ & $-6.3 \%$ & $-3.6 \%$ & $0.8 \%$ & $0.7 \%$ \\
\hline Fuel Eff (mpg) & $8.3 \%$ & $3.0 \%$ & $7.0 \%$ & $4.0 \%$ & $-0.7 \%$ & $-0.5 \%$ \\
\hline HC (g) & $-16.4 \%$ & $-3.0 \%$ & $-4.4 \%$ & $-3.1 \%$ & $0.8 \%$ & $1.6 \%$ \\
\hline CO (g) & $-0.9 \%$ & $-4.0 \%$ & $-1.6 \%$ & $-5.3 \%$ & $-1.7 \%$ & $0.3 \%$ \\
\hline NOx (g) & $-9.1 \%$ & $-3.8 \%$ & $-3.6 \%$ & $-4.2 \%$ & $-0.5 \%$ & $-0.3 \%$ \\
\hline
\end{tabular}

Table 4-11 Simulated Travel Times - Custom Coordinated Timing Plan Alternative

\begin{tabular}{||c|c|c|c|c|c|c||}
\hline \hline & \multicolumn{3}{c|}{ Eastbound } & \multicolumn{3}{c||}{ Westbound } \\
\cline { 2 - 7 } & Alternative & Baseline & $\%$ Diff & Alternative & Baseline & $\%$ Diff \\
\hline \hline AM Peak & $1: 59$ & $01: 44$ & $+14 \%$ & $1: 24$ & $01: 37$ & $-13 \%$ \\
\hline Midday Peak & $4: 00$ & $03: 20$ & $+20 \%$ & $1: 57$ & $02: 22$ & $-18 \%$ \\
\hline PM Peak & $4: 19$ & $03: 42$ & $+17 \%$ & $1: 57$ & $02: 17$ & $-15 \%$ \\
\hline \hline
\end{tabular}

\subsection{Phasing Change at Matthew Drive and Cherry Tree Lane - Coordinated}

The statistics, from the model modified to implement the coordinated plan described in

Section 3.4.4, can be found in Tables 4-12, 4-13, 4-14, and 4-15. As noted in Section 3.4.4, this alternative was developed to implement both coordination in the corridor and the proposed phasing changes at the two-intersection system at Matthew Drive and Cherry Tree Lane. An additional table (Table 4-14) is provided that compares this alternative to fully actuated alternative, so that the benefits of implementing coordination could be determined. In Table 415, which provides the results from the 10 travel time runs, the travel times are not compared to 
the baseline runs, but are instead compared to the fully actuated alternative.

As can be seen, this alternative is the most beneficial of all those considered, and unlike the other coordinated alternatives considered, the benefits of coordination outweigh the costs. This is illustrated by the reduction in delay on both S.R. 0021 and the overall network relative to the fully actuated alternative. This was the case in all instances except during in the am peak. It is hypothesized that the reason coordination was beneficial in this alternative, but not the other alternatives, was that this alternative has a shorter cycle length and under-capacity conditions at the critical two-intersection system at Matthew Drive and Cherry Tree Lane.

Table 4-12 Simulated Performance Measures - Phasing Change with Coordination

\begin{tabular}{|l||c|c|c||c|c|c||}
\hline \multicolumn{1}{|c||}{} & \multicolumn{3}{c||}{ S.R. 0021 } & \multicolumn{3}{c||}{ Total Network } \\
\cline { 2 - 7 } & AM Peak & $\begin{array}{c}\text { Midday } \\
\text { Peak }\end{array}$ & PM Peak & AM Peak & $\begin{array}{c}\text { Midday } \\
\text { Peak }\end{array}$ & PM Peak \\
\hline \hline Delay/Veh (s) & 18.9 & 28.5 & 34.5 & 34.4 & 47.8 & 57.0 \\
\hline Travel Time (hr) & 19.2 & 33.9 & 41.5 & 37.5 & 69.5 & 82.7 \\
\hline Ave Speed (mph) & 22 & 17 & 16 & 18 & 15 & 14 \\
\hline Fuel Used (gal) & 57.0 & 82.7 & 79.8 & 93.3 & 143.6 & 135.4 \\
\hline Fuel Eff (mpg) & 7.3 & 7.1 & 8.3 & 7.3 & 7.2 & 8.6 \\
\hline HC (g) & 124 & 207 & 230 & 207 & 357 & 384 \\
\hline CO (g) & 6114 & 9959 & 11032 & 9547 & 15869 & 16921 \\
\hline NOx (g) & 428 & 727 & 782 & 704 & 1221 & 1266 \\
\hline \hline
\end{tabular}


Table 4-13 Percentage Changes in Performance Measures as Compared to the Baseline Scenario - Phasing Change with Coordination

\begin{tabular}{|l||c|c|c||c|c|c||}
\hline \multirow{2}{*}{} & \multicolumn{3}{|c|}{ S.R. 0021 } & \multicolumn{3}{c||}{ Total Network } \\
\cline { 2 - 7 } & AM Peak & $\begin{array}{c}\text { Midday } \\
\text { Peak }\end{array}$ & PM Peak & AM Peak & $\begin{array}{c}\text { Midday } \\
\text { Peak }\end{array}$ & PM Peak \\
\hline \hline Delay/Veh (s) & $-32.1 \%$ & $-39.0 \%$ & $-59.3 \%$ & $-21.3 \%$ & $-31.3 \%$ & $-49.5 \%$ \\
\hline Travel Time (hr) & $-14.8 \%$ & $-24.4 \%$ & $-41.8 \%$ & $-9.6 \%$ & $-17.9 \%$ & $-33.0 \%$ \\
\hline Ave Speed (mph) & $16.8 \%$ & $31.1 \%$ & $64.3 \%$ & $10.4 \%$ & $22.0 \%$ & $45.8 \%$ \\
\hline Fuel Used (gal) & $-10.6 \%$ & $-7.4 \%$ & $-15.5 \%$ & $-7.0 \%$ & $-5.1 \%$ & $-12.4 \%$ \\
\hline Fuel Eff (mpg) & $12.0 \%$ & $8.2 \%$ & $20.8 \%$ & $7.3 \%$ & $5.5 \%$ & $16.6 \%$ \\
\hline HC (g) & $-10.5 \%$ & $-8.1 \%$ & $-12.8 \%$ & $-6.9 \%$ & $-6.0 \%$ & $-10.6 \%$ \\
\hline CO (g) & $-1.0 \%$ & $-2.7 \%$ & $2.2 \%$ & $-6.1 \%$ & $-1.7 \%$ & $1.5 \%$ \\
\hline NOx (g) & $-10.2 \%$ & $-4.3 \%$ & $-4.9 \%$ & $-6.1 \%$ & $-2.6 \%$ & $-3.9 \%$ \\
\hline
\end{tabular}

Table 4-14 Percentage Changes in Performance Measures as Compared to the Fully Actuated Alternative

\begin{tabular}{|l||c|c|c||c|c|c||}
\hline \multirow{2}{*}{} & \multicolumn{3}{||}{ S.R. 0021 } & \multicolumn{3}{c||}{ Total Network } \\
\cline { 2 - 7 } & AM Peak & $\begin{array}{c}\text { Midday } \\
\text { Peak }\end{array}$ & PM Peak & AM Peak & $\begin{array}{c}\text { Midday } \\
\text { Peak }\end{array}$ & PM Peak \\
\hline \hline Delay/Veh (s) & $-9.6 \%$ & $-20.0 \%$ & $-22.7 \%$ & $2.3 \%$ & $-19.5 \%$ & $-20.0 \%$ \\
\hline Travel Time (hr) & $-3.9 \%$ & $-11.9 \%$ & $-12.9 \%$ & $0.9 \%$ & $-10.5 \%$ & $-11.5 \%$ \\
\hline Ave Speed (mph) & $3.8 \%$ & $13.8 \%$ & $13.4 \%$ & $-2.7 \%$ & $11.9 \%$ & $13.8 \%$ \\
\hline Fuel Used (gal) & $-10.7 \%$ & $-6.2 \%$ & $-6.6 \%$ & $-5.9 \%$ & $-4.3 \%$ & $-5.1 \%$ \\
\hline Fuel Eff (mpg) & $12.0 \%$ & $6.7 \%$ & $7.1 \%$ & $5.9 \%$ & $4.6 \%$ & $4.6 \%$ \\
\hline HC (g) & $-8.4 \%$ & $-5.1 \%$ & $-4.1 \%$ & $-4.1 \%$ & $-4.0 \%$ & $-3.5 \%$ \\
\hline CO (g) & $-9.3 \%$ & $-4.3 \%$ & $-1.4 \%$ & $-5.6 \%$ & $-2.5 \%$ & $-0.5 \%$ \\
\hline NOx (g) & $-10.0 \%$ & $-3.8 \%$ & $-2.8 \%$ & $-5.2 \%$ & $-2.1 \%$ & $-1.7 \%$ \\
\hline \hline
\end{tabular}


Table 4-15 Simulated Travel Times - Phasing Change with Coordination

\begin{tabular}{|l|c|c|c||c|c|c|}
\hline \multirow{2}{*}{} & \multicolumn{3}{|c||}{ Eastbound } & \multicolumn{3}{c|}{ Westbound } \\
\cline { 2 - 7 } & Coordinated & Actuated & \% Diff & Coordinated & Actuated & \% Diff \\
\hline \hline AM Peak & $01: 36$ & $1: 46$ & $-8.7 \%$ & $01: 32$ & $1: 46$ & $-14.0 \%$ \\
\hline Midday Peak & $01: 58$ & $2: 32$ & $-22.6 \%$ & $01: 57$ & $1: 53$ & $4.2 \%$ \\
\hline PM Peak & $02: 33$ & $2: 31$ & $1.5 \%$ & $01: 40$ & $1: 45$ & $-5.0 \%$ \\
\hline
\end{tabular}

\subsection{Summary of Results}

\subsubsection{Findings Relative to Signal Timing Improvements for the Corridor}

Four alternatives for improving the signal operations in the S.R. 0021 corridor were investigated. The corridor made for an interesting case study because it contained five signalized intersections in a 3000-foot area, which was an average spacing of approximately 750 feet, which was much less than the half-mile threshold for coordinating signals commonly applied by engineers. However, it also contained a critical two-intersection system that experienced periods of over-capacity conditions and sometimes required cycle lengths on the order of $4 \mathrm{~min} 30 \mathrm{sec}$ in the field to serve the demand. The simulation model used to evaluate the one fully-actuated and three coordinated alternatives suggested that the benefits of progression provided by the coordinated alternatives were far outweighed by the costs of the loss of flexibility in serving demand at the critical two-intersection system unless the capacity-problems at the twointersection system were resolved. The alternative with the most attractive statistics from the simulation model was the one in which the phasing was changed at the two-intersection system at Matthew Drive and Cherry Tree Lane, and the corridor was coordinated. In summary, this alternative involved the following phasing changes: 
- At the Cherry Tree Lane intersection, the phasing was changed to allow eastbound S.R. 0021 through traffic to flow during the phase at the Matthew Drive intersection in which the left-turns from northbound S.R. 0119 were protected.

- The clearance phase causing the left-turn trap problem was eliminated.

Since the phase in which the change was proposed was field-measured to be an average of 42 seconds in the pm peak with a maximum of 81 seconds, and the majority of traffic from this approach then turned right onto the S.R. 0119 ramps, this phase change added significant capacity in the eastbound direction. Simulation indicated that LOS F conditions were projected to be alleviated, and delay was projected to be cut by 20 to $60 \%$. Travel time reductions of 20 to $30 \%$ in the midday and pm peaks were also found in the simulations.

The primary drawback of making this change is the risk of traffic backing up from the westbound left-turn movement into Cherry Tree Lane and spilling over into the Matthew Drive intersection. This could occur if motorists enter the Cherry Tree Lane intersection on eastbound S.R. 0021 when there is no storage space available between Matthew Drive and Cherry Tree Lane. The question of whether motorists are courteous enough not to block the intersection was not answered best with simulation. The simulation indicated that the eastbound queue from Matthew Drive will spill over through the Cherry Tree Lane intersection, but that was the extent of the usefulness of the model in this regard. In deciding whether to accept this risk, the Department should consider the following drawbacks of the current phasing:

- The current phasing was found to be the cause of the over-capacity conditions in the corridor.

- Two left-turn traps were observed in the current phasing, of which the one at the Matthew Drive intersection was an issue in almost every cycle in the pm peak. 
- The eastbound storage space between Matthew Drive and Cherry Tree Lane was observed in the field to be filled by right-turns-on-red out of Cherry Tree Lane. These were also observed to block the eastbound right-turn lane at Matthew Drive.

- The westbound storage space between Matthew Drive and Cherry Tree Lane was observed to be filled by right-turns out of Matthew Drive. These motorists were not observed to block the Matthew Drive intersection.

- The current phasing caused queue spillback in the eastbound direction through the Daniel Drive intersection, and the horizontal and vertical curves to the east, during the field view.

- The risk of the westbound left-turns at Cherry Tree Lane spilling back into the Matthew Drive intersection can be mitigated with a queue preemption system in the westbound left-turn lane at Cherry Tree Lane. However, note that the activation of the queue preemption phase will cause a left-turn trap for the eastbound left-turns at this intersection unless all left-turns at this intersection are provided with protected-only leftturning treatment, which is undesired for capacity purposes.

This alternative also included the following signal timing changes to implement coordination in the corridor (note that offsets are referenced to the end of green for S.R. 0021; phases numbers use NEMA system except for the two-signal system at Cherry Tree Lane / Matthew Drive, where they are numbered sequentially due to complex phasing):

\section{AM PEAK}

Cycle Length: 100 Seconds

Offsets: Daniel = $92 \mathrm{sec}$; Matthew Drive $/$ Cherry Tree Lane $=0$ sec; Work Parkway $=12$ sec; Uniontown Mall $=91 \mathrm{sec}$ 
Splits:

Daniel Drive:

Phase $2+5=22 \mathrm{sec}$; Phase $2+6=46 \mathrm{sec} ;$ Phase $4+8=32 \mathrm{sec}$

Cherry Tree Lane / Matthew Drive:

Phase 1 Protected westbound lefts at both intersections $=17 \mathrm{sec}$

Phase 2 Mainline green at both $=27 \mathrm{sec}$

Phase 3 Protected lefts from side roads at Matthew + mainline green at Cherry Tree $=14 \mathrm{sec}$

Phase 4 Protected NB lefts and through at Matthew + mainline green at Cherry Tree Lane "phase overlap" = $22 \mathrm{sec}$

Phase 5 Side road green at both $=20 \mathrm{sec}$

Work Parkway:

Phase $1=16 \mathrm{sec}$

Phase $2=56 \mathrm{sec}$

Phase $5=17 \mathrm{sec}$

Phase $6=55 \mathrm{sec}$

Phase $4+8=28 \mathrm{sec}$

Uniontown Mall:

Phase $2+5=21 \mathrm{sec}$

Phase $2+6=51 \mathrm{sec}$

Phase $4=28 \mathrm{sec}$

\section{MIDDAY PEAK}

Cycle Length: 110 Seconds

Offsets: Daniel $=48 \mathrm{sec} ;$ Matthew Drive $/$ Cherry Tree Lane $=0 \mathrm{sec} ;$ Work Parkway $=38 \mathrm{sec}$; Uniontown Mall $=90 \mathrm{sec}$

Splits:

Daniel Drive:

Phase $2+5=18 \mathrm{sec}$

Phase $2+6=54 \mathrm{sec}$

Phase $4+8=38 \mathrm{sec}$

Cherry Tree Lane / Matthew Drive:

Phase 1 Protected westbound lefts at both intersections $=22 \mathrm{sec}$

Phase 2 Mainline green at both $=34 \mathrm{sec}$

Phase 3 Protected lefts from side roads at Matthew + mainline green at Cherry Tree $=21 \mathrm{sec}$

Phase 4 Protected NB lefts and through at Matthew + mainline green at Cherry Tree Lane "phase overlap" $=3 \mathrm{sec}$

Phase 5 Side road green at both $=30 \mathrm{sec}$ 
Work Parkway:

Phase $1=12 \mathrm{sec}$

Phase $2=56 \mathrm{sec}$

Phase $5=18 \mathrm{sec}$

Phase $6=50 \mathrm{sec}$

Phase $4+8=42 \mathrm{sec}$

Uniontown Mall:

Phase $2+5=23 \mathrm{sec}$

Phase $2+6=60 \mathrm{sec}$

Phase $4=27 \mathrm{sec}$

\section{PM PEAK}

Cycle Length: 140 Seconds at Daniel Drive and Matthew Drive / Cherry Tree Lane, 70 seconds at Work Parkway and Uniontown Mall

Offsets: Daniel = $127 \mathrm{sec}$; Matthew Drive $/$ Cherry Tree Lane $=0$ sec; Work Parkway = 12 sec; Uniontown Mall $=27 \mathrm{sec}$

Splits:

Daniel Drive:

Phase $2+5=25 \mathrm{sec}$

Phase $2+6=85 \mathrm{sec}$

Phase $4+8=30 \mathrm{sec}$

Cherry Tree Lane / Matthew Drive:

Phase 1 Protected westbound lefts at both intersections $=32 \mathrm{sec}$

Phase 2 Mainline green at both $=31 \mathrm{sec}$

Phase 3 Protected lefts from side roads at Matthew + mainline green at Cherry Tree $=31 \mathrm{sec}$

Phase 4 Protected NB lefts and through at Matthew + mainline green at Cherry Tree Lane "phase overlap" = $5 \mathrm{sec}$

Phase 5 Side road green at both $=46 \mathrm{sec}$

Work Parkway:

Phase $1=12 \mathrm{sec}$

Phase $2=35 \mathrm{sec}$

Phase $5=12 \mathrm{sec}$

Phase $6=35 \mathrm{sec}$

Phase $4+8=23 \mathrm{sec}$

Uniontown Mall:

Phase $2+5=12 \mathrm{sec}$

Phase $2+6=37 \mathrm{sec}$ 
Phase $4=21 \mathrm{sec}$

These timings can be used as a starting point for the implementation of a coordinated timing plan. At a minimum, they should be field-adjusted once implemented.

\subsubsection{Methodological Findings}

Relative to the methodology, using the 10 probe vehicle travel time runs in conjunction with the average travel speed statistic output by SimTraffic provided a good indication of conditions on S.R. 0021. They were in relative agreement but did indicate different phenomenon on occasion. The advantage of the SimTraffic statistic was that it was directly output by the program, and as such was not labor-intensive and could be gathered for multiple runs of the simulation. The disadvantages were that it did not match the methodology used to gather travel time in the field, was not provided by direction, and was rounded to the nearest $1 \mathrm{mph}$, which could make a significant difference at the low speeds that are typical in congested corridors.

In addition, it was found that the transportation-related performance measures of delay and travel time were more sensitive to the alternatives than fuel consumption and pollution measures. The pollution measures in particular provided mixed results since increased speeds increase some pollutants. However, in general, the variables used provided enough information upon which to assess the alternatives. The fuel consumption measures provided an indication of operating costs, but if operating costs could have been directly output by the model, it is believed that it would have been more beneficial.

Finally, it was desired to assess the statistical benefits of running each simulation 10 times with 10 different seed numbers. Table 4-16 contains a summary of the average, standard deviation, and margin of error at $95 \%$ confidence for the delay per vehicle statistics for S.R. 0021 and the total network for each alternative. Delay per Vehicle was selected since it is a 
commonly used performance measure by transportation engineers and appears in the Highway Capacity Manual as the performance measure to assess signalized and unsignalized level of service.

As can be seen, delay per vehicle was more variable in the pm peak, which was a period of high congestion. In general, the margin of error would not have caused a different level of service to be predicted since the ranges are generally on the order of 15 to $25 \mathrm{sec} / \mathrm{veh}$ in width. The analysis may have resulted in a different LOS during some of the pm peak runs, but during these highly congested periods, the LOS F was typically projected, which has a wide range since it has no upper limit on delay. However, this analysis underscored the importance of repeating the simulation with different seed numbers when congestion and over-capacity conditions are an issue. Increasing the number of runs beyond 10 with congested networks would not be unwarranted. 
Table 4-16 Summary of Delay per Vehicle Statistics from the 10 Simulation Runs

\begin{tabular}{|c|c|c|c|c|c|}
\hline Alternative & $\begin{array}{l}\text { SR } 21 \text { or } \\
\text { Network }\end{array}$ & Time Period & Average & Standard Deviation & $\begin{array}{l}\text { Margin of } \\
\text { Error }\end{array}$ \\
\hline \multirow{6}{*}{ Baseline } & \multirow{3}{*}{ SR 21} & AM Peak & 27.9 & 2.2 & $+/-1.4$ \\
\hline & & Midday Peak & 46.7 & 4.9 & $+/-3.0$ \\
\hline & & PM Peak & 84.7 & 24.5 & $+/-15.2$ \\
\hline & \multirow{3}{*}{ Network } & AM Peak & 43.7 & 2.6 & $+/-1.6$ \\
\hline & & Midday Peak & 69.6 & 5.9 & $+/-3.7$ \\
\hline & & PM Peak & 113.0 & 24.9 & $+/-15.4$ \\
\hline \multirow{6}{*}{$\begin{array}{l}\text { Phasing Change } \\
\text { - Fully Actuated }\end{array}$} & \multirow{3}{*}{ SR 21} & AM Peak & 20.9 & 0.7 & $+/-0.4$ \\
\hline & & Midday Peak & 35.6 & 1.6 & $+/-1.0$ \\
\hline & & PM Peak & 44.6 & 4.9 & $+/-3.0$ \\
\hline & \multirow{3}{*}{ Network } & AM Peak & 33.6 & 1.2 & $+/-0.7$ \\
\hline & & Midday Peak & 59.4 & 1.8 & $+/-1.1$ \\
\hline & & PM Peak & 71.3 & 5.5 & $+/-3.4$ \\
\hline \multirow{6}{*}{$\begin{array}{l}\text { Synchro } \\
\text { Optimized Plan }\end{array}$} & \multirow{3}{*}{ SR 21} & AM Peak & 34.3 & 5.6 & $+/-3.5$ \\
\hline & & Midday Peak & 39.4 & 2.8 & $+/-1.7$ \\
\hline & & PM Peak & 57.6 & 16.1 & $+/-10.0$ \\
\hline & \multirow{3}{*}{ Network } & AM Peak & 50.9 & 4.8 & $+/-3.0$ \\
\hline & & Midday Peak & 76.0 & 11.6 & $+/-7.1$ \\
\hline & & PM Peak & 130.6 & 17.0 & $+/-10.5$ \\
\hline \multirow{6}{*}{$\begin{array}{l}\text { Custom } \\
\text { Coordinated } \\
\text { Plan }\end{array}$} & \multirow{3}{*}{ SR 21} & AM Peak & 26.4 & 2.0 & $+/-1.2$ \\
\hline & & Midday Peak & 46.2 & 3.6 & $+/-2.2$ \\
\hline & & PM Peak & 73.6 & 16.0 & $+/-9.9$ \\
\hline & \multirow{3}{*}{ Network } & AM Peak & 46.5 & 3.0 & $+/-1.9$ \\
\hline & & Midday Peak & 78.0 & 4.2 & $+/-2.6$ \\
\hline & & PM Peak & 121.8 & 22.5 & $+/-13.9$ \\
\hline \multirow{6}{*}{$\begin{array}{l}\text { Phasing Change } \\
\text { - Coordinated }\end{array}$} & \multirow{3}{*}{ SR 21} & AM Peak & 18.9 & 1.0 & $+/-0.6$ \\
\hline & & Midday Peak & 28.5 & 3.1 & $+/-1.9$ \\
\hline & & PM Peak & 34.5 & 3.3 & $+/-2.0$ \\
\hline & \multirow{3}{*}{ Network } & AM Peak & 34.4 & 1.1 & $+/-0.7$ \\
\hline & & Midday Peak & 47.8 & 1.2 & $+/-0.7$ \\
\hline & & PM Peak & 57.0 & 4.8 & $+/-3.0$ \\
\hline
\end{tabular}




\section{CHAPTER 5 - SUMMARY AND CONCLUSIONS}

\subsection{Summary of Results}

The purpose of this research was to develop and use the SimTraffic microsimulation model in the assessment of signal timing alternatives on a congested corridor. This research made contributions both in the development of a methodology to accomplish such a project, and in the actual engineering analysis of signal timing alternatives for the corridor. The key findings of each are discussed below.

First, this methodology relied heavily on field-collected data supplemented by engineering drawings supplied by PENNDOT. The field traffic data collection included turning movement counts, truck counts, probe vehicle travel time runs, queue discharge headways / saturation flow rates for critical movements, cycle lengths and splits for critical phases, and queue lengths / cycle failure observations during congested periods. A separate model was developed for each peak period, however, the main difference between the models were the traffic volumes_-including trucks—and the traffic signal timings. These data were meticulously entered into the model, and only slight modifications of the signal timings were required to replicate the operational problems and travel times observed in the field.

Additionally, the probe vehicle travel times measured from the simulation were found to be highly beneficial. However, they are labor intensive since they are not a direct output of simulation. As such, they were only compiled for one of the 10 runs of each model. However, they were compiled for the same run $($ seed=1) in all cases.

Furthermore, the 10 runs of the model are expected to be sufficient for networks with little to moderate congestion. However, for models with heavy congestion and over-capacity conditions, additional runs may prove to be beneficial. 
Finally, the simulation model was used to assess four signal timing alternatives to improve operations in the congested corridor of S.R. 0021 between Daniel Drive and Santa Maria Drive / Uniontown Mall drive in South Union Township, Pennsylvania. This corridor has five signalized intersections in a space of 3000 feet. In spite of the close spacing of the signals, the findings of the engineering analysis and simulation surprisingly indicated that the benefits of progression provided by coordination were far outweighed by the costs incurred through the reduction of flexibility at the critical two-intersection system at the Cherry Tree Lane and Matthew Drive intersections when semi-actuated control with a fixed cycle length was imposed, unless the capacity-problems at the two-intersection were resolved. These findings were reinforced by the field-collected travel time information, which demonstrated that half the travel time in the corridor was spent stopped at this two-intersection system, and that the likelihood at being stopped at another signalized intersection in the corridor was minimal. A phasing change that improved operations at the critical two-intersection system was proposed. This was found to be beneficial whether the corridor was coordinated or not, however, implementing coordination in the corridor in conjunction with the phasing change yielded even greater benefits.

\subsection{Limitations of Research}

One of the key limitations is that this methodology was only applied to one congested corridor. If additional corridors could be studied, areas to improve the methodology would most certainly be identified. Another limitation is that none of the alternative models could be validated since none of the alternatives were implemented in the field. Finally, if time-permitted, the 10 probe vehicle travel time runs could have been run for each of 10 simulation runs to determine their variability with varying seed numbers. 


\subsection{Ideas for Further Research}

Two ideas for follow-on research naturally flow from the work performed in this project. First, one of the alternative timing plans developed as part of this project can be implemented in the field and evaluated. The travel time runs could be performed after implementation and compared to those predicted by the simulation model. In addition, queuing and cycle failure could be observed and compared to that observed in the simulation model. The literature revealed few instances where field data from implemented signal retiming projects were used for comparison to the simulation model used to assess the alternatives.

A second idea for follow-on research involves the treatment of critical intersections in a corridor setting. In this case, the simulation suggests that the flexibility provided by fullyactuated control at the critical intersection outweighs the benefits of progression along the corridor unless congested conditions at the critical intersection can be resolved. Again, it might be interesting to implement a coordinated plan in the field without resolving the congestion problems at the critical two-intersection system to determine if traffic conditions do indeed worsen, thus validating the model findings. It would also be interesting to study similar corridors to determine if this can be generalized. 


\section{REFERENCES}

Abu-Lebdeh, G., and Benekohal, R., "Genetic Algorithms for Traffic Signal Control and Queue Management of Oversaturated Two-Way Arterials", Transportation Research Record 1727,

Transportation Research Board, National Research Council, Washington, D.C., 2000, pp 61-67.

American Association of State Highway and Transportation Officials, "User Benefit_Analysis for Highways”, Publ. No.:AE-UBA -2, Washington, D.C., August 2003, pp 3-26, pp 3-40.

Ceylan, H., and Bell, M., "Traffic Signal Timing Optimization Based on Genetic Algorithm Approach, Including Drivers' Routing", Transportation Research Part B: Methodology, vol. 38, 2004, pp 329-342.

Chang, T., and Guey-Yin, S., "Modeling and Optimization of an Oversaturated Signalized Network", Transportation Research Part B: Methodology, vol. 38, 2004, pp 687-707.

Dowling, R., Skabardonis, A., Halkias, J., McHale, G., and Zammit, G., "Guidelines for Calibration of Microsimulation Models: Framework and Applications", Transportation Research Record 1876, Transportation Research Board, National Research Council, Washington, D.C., 2004, pp 1-9.

Hansen, B., Martin, P., and Perrin, H., "SCOOT Real-Time Adaptive Control in a CORSIM Simulation Environment", Transportation Research Record 1727, Transportation Research Board, National Research Council, Washington, D.C., 2000, pp 27-31.

Huffline, C., and Adams, D., "Safety Benefits of Signal Coordination”, Institute of Transportation Engineers 1995 Compendium of Technical Papers, August 1995, pp 219-224.

Luger, G. F., Artificial Intelligence, Structures and Strategies for Complex Problem Solving, Fourth Edition, Harlow, England: Addison-Wesley, 2002, pp 471.

Maccubbin, R., Staples,B., and Mercer, M., "Intelligent Transportation Systems Benefits and Costs: 2003 Update”, FHWA-OP-03-075, Federal Highway Administration, Washington, D.C., 2003.

McShane, W., and Roess, R., Traffic Engineering, New Jersey, Prentice Hall, Inc, 1990, pp 509548.

Park, B., Messer, C.J., and Urbanik, T., "Enhanced Genetic Algorithm for Signal-Timing Optimization of Over Saturated Intersections", Transportation Research Record 1727, Transportation Research Board, National Research Council, Washington, D.C., 2000, pp 32-41.

Park, B., and Schneeberger, J., "Evaluation of Traffic Signal Optimization Methods Using a Stochastic and Microscopic Simulation Program." UVACTS-5-0-4, Center for Transportation Studies at the University of Virginia, Charlottesville, VA, 2003. 
Skabardonis, A., Bertini, R., Gallagher, B., "Development and Application of Control Strategies for Signalized Intersections in Coordinated Systems", Transportation Research Record 1634, 1999, pp 110-117.

SimTraffic 5.0 User Guide, Trafficware, Albany, CA., 2001.

Southwestern Pennsylvania Regional Planning Commission, "Traffic Signal Opportunities for Southwestern Pennsylvania”, June 1996.

Synchro 5.0 User Guide, Trafficware, Albany, CA., 2001.

Transportation Research Board National Research Council, Highway Capacity Manual 2000, Washington, D.C., TRB 2000, pp 6-14.

Weisbrod, G., Vary, D., and Treyz, G., "Economic Impacts of Congestion”, NCHRP Report 463, Transportation Research Board, Washington, D.C., 2001, pp 11-33.

Yang, X., "Comparison Among Computer Packages in Providing Timing Plans for Iowa Arterial in Lawrence, Kansas", Journal of Transportation Engineering, vol. 127, no. 4, 2001, pp 311-318. 
APPENDIX A - TRAFFIC DATA 


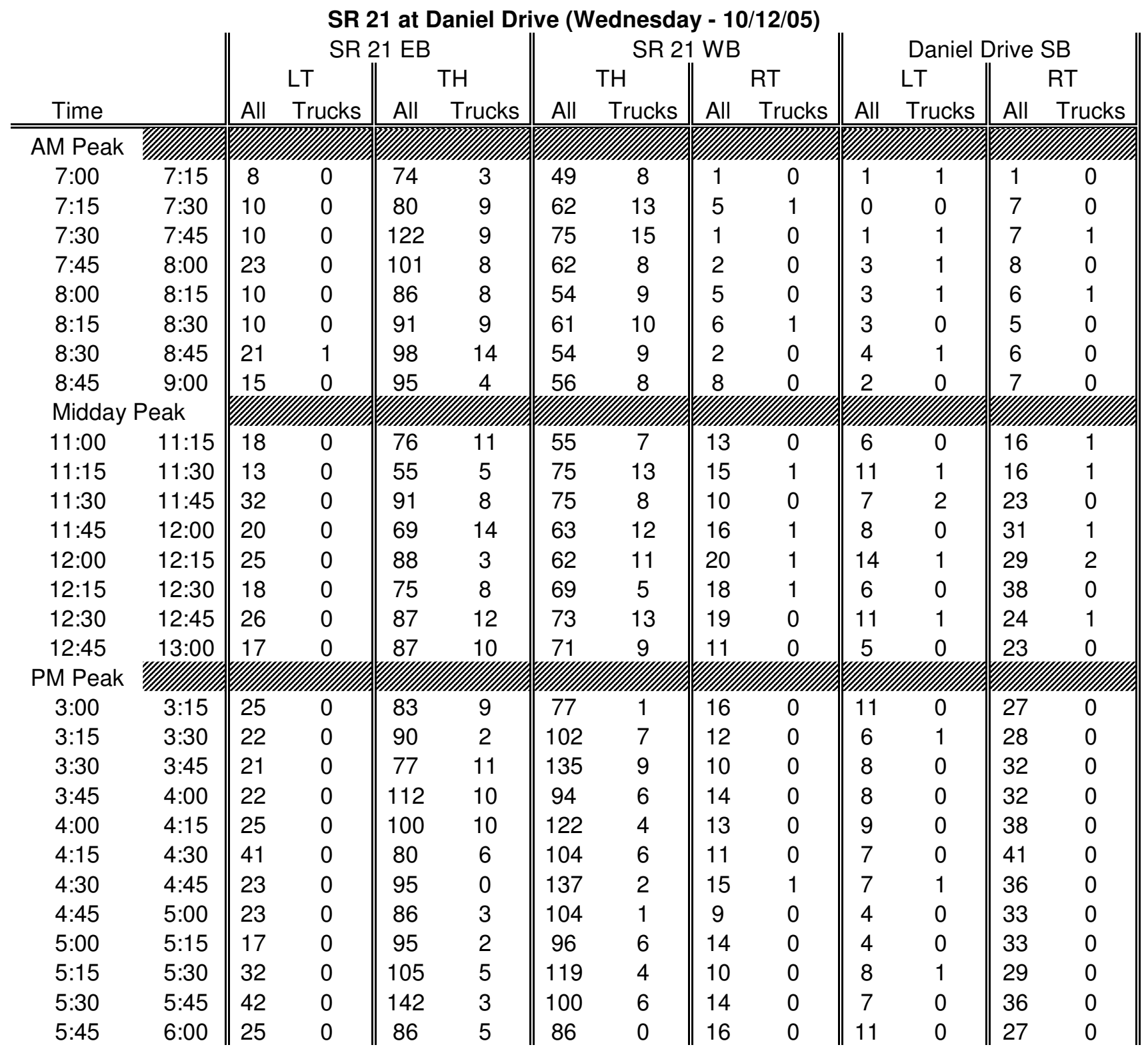




\begin{tabular}{|c|c|c|c|c|c|c|c|c|c|c|c|c|c|c|c|c|c|c|c|c|c|c|c|c|c|}
\hline \multicolumn{26}{|c|}{ SR 21 at Cherry Tree Lane / Brewer Drive (Wednesday - 10/12/05) } \\
\hline \multirow{3}{*}{\multicolumn{2}{|c|}{ Time }} & \multicolumn{6}{|c|}{$\mathrm{SR} 21 \mathrm{~EB}$} & \multicolumn{6}{|c|}{ SR 21 WB } & \multicolumn{6}{|c|}{ Cherry Tree Lane NB } & \multicolumn{6}{|c|}{ Brewer Drive SB } \\
\hline & & \multirow{2}{*}{$\begin{array}{l}\mathrm{LT} \\
\text { All }\end{array}$} & \multirow[b]{2}{*}{$\mathrm{T}$} & \multirow{2}{*}{$\begin{array}{l}\mathrm{TH} \\
\text { All }\end{array}$} & \multirow[b]{2}{*}{$\mathrm{T}$} & \multirow{2}{*}{$\begin{array}{l}\text { RT } \\
\text { All } \\
\end{array}$} & \multirow[b]{2}{*}{$\mathrm{T}$} & \multirow{2}{*}{$\begin{array}{l}\text { LT } \\
\text { All }\end{array}$} & \multirow[b]{2}{*}{$\mathrm{T}$} & \multirow{2}{*}{$\begin{array}{l}\text { TH } \\
\text { All } \\
\end{array}$} & \multirow[b]{2}{*}{$\mathrm{T}$} & \multirow{2}{*}{$\begin{array}{l}\text { RT } \\
\text { All }\end{array}$} & \multirow[b]{2}{*}{$\mathrm{T}$} & \multirow{2}{*}{$\begin{array}{l}\text { LT } \\
\text { All } \\
\end{array}$} & & $\mathrm{TH}$ & & RT & & LT & & $\mathrm{TH}$ & & RT & \\
\hline & & & & & & & & & & & & & & & $\mathrm{T}$ & All & $\mathrm{T}$ & All & $\mathrm{T}$ & All & $\mathrm{T}$ & All & $\mathrm{T}$ & All & $\mathrm{T}$ \\
\hline AM & eak & & & & & & & & & & & & & & & & & & & & & & & & \\
\hline $7: 00$ & $7: 15$ & 1 & 0 & 68 & 4 & 6 & 0 & 21 & 0 & 50 & 8 & 0 & 0 & 0 & 0 & 1 & 0 & 6 & 0 & 0 & 0 & 0 & 0 & 0 & 0 \\
\hline $7: 15$ & $7: 30$ & 0 & 0 & 77 & 9 & 3 & 0 & 29 & 0 & 66 & 14 & 3 & 0 & 1 & 0 & 0 & 0 & 4 & 0 & 0 & 0 & 0 & 0 & 1 & 0 \\
\hline $7: 30$ & $7: 45$ & 0 & 0 & 113 & 10 & 10 & 0 & 31 & 0 & 73 & 15 & 2 & 0 & 2 & 0 & 1 & 0 & 11 & 0 & 0 & 0 & 0 & 0 & 1 & 0 \\
\hline $7: 45$ & $8: 00$ & 0 & 0 & 100 & 9 & 4 & 0 & 46 & 0 & 62 & 8 & 3 & 0 & 2 & 0 & 0 & 0 & 13 & 0 & 0 & 0 & 1 & 0 & 0 & 0 \\
\hline $8: 00$ & $8: 15$ & 1 & 0 & 80 & 9 & 8 & 0 & 58 & 1 & 57 & 9 & 1 & 0 & 2 & 0 & 0 & 0 & 4 & 0 & 0 & 0 & 1 & 0 & 0 & 0 \\
\hline $8: 15$ & $8: 30$ & 1 & 0 & 83 & 9 & 10 & 0 & 56 & 0 & 62 & 11 & 2 & 0 & 3 & 0 & 1 & 0 & 19 & 0 & 0 & 0 & 0 & 0 & 2 & 0 \\
\hline $8: 30$ & $8: 45$ & 2 & 0 & 93 & 15 & 7 & 0 & 49 & 0 & 49 & 9 & 3 & 0 & 5 & 0 & 1 & 0 & 28 & 0 & 2 & 0 & 0 & 0 & 2 & 0 \\
\hline $8: 45$ & 9:00 & 1 & 0 & 79 & 4 & 17 & 0 & 62 & 0 & 53 & 8 & 3 & 0 & 10 & 0 & 2 & 0 & 17 & 0 & 0 & 0 & 0 & 0 & 1 & 0 \\
\hline Midda & Peak & & ש & & & & & & & & & & & & & & & & & & & & & & \\
\hline $11: 00$ & $11: 15$ & 1 & 0 & 73 & 11 & 8 & 0 & 37 & 0 & 61 & 7 & 5 & 0 & 6 & 0 & 1 & 0 & 42 & 1 & 2 & 0 & 1 & 0 & 1 & 0 \\
\hline $11: 15$ & $11: 30$ & 1 & 0 & 54 & 6 & 11 & 0 & 41 & 0 & 77 & 14 & 2 & 0 & 12 & 0 & 1 & 0 & 47 & 0 & 3 & 0 & 0 & 0 & 1 & 0 \\
\hline $11: 30$ & $11: 45$ & 0 & 0 & 92 & 10 & 6 & 0 & 50 & 2 & 79 & 8 & 3 & 0 & 5 & 0 & 1 & 0 & 46 & 0 & 0 & 0 & 2 & 0 & 1 & 0 \\
\hline $11: 45$ & $12: 00$ & 0 & 0 & 73 & 14 & 4 & 0 & 33 & 0 & 70 & 13 & 3 & 0 & 8 & 0 & 1 & 0 & 53 & 0 & 1 & 0 & 1 & 0 & 1 & 0 \\
\hline $12: 00$ & $12: 15$ & 0 & 0 & 96 & 4 & 6 & 0 & 34 & 0 & 72 & 11 & 2 & 0 & 8 & 1 & 4 & 0 & 51 & 0 & 0 & 0 & 3 & 0 & 2 & 0 \\
\hline $12: 15$ & $12: 30$ & 4 & 0 & 70 & 8 & 7 & 0 & 28 & 3 & 77 & 6 & 1 & 0 & 9 & 0 & 4 & 0 & 30 & 2 & 3 & 0 & 1 & 0 & 1 & 0 \\
\hline $12: 30$ & $12: 45$ & 1 & 0 & 87 & 13 & 10 & 0 & 39 & 0 & 79 & 12 & 9 & 0 & 11 & 1 & 0 & 0 & 33 & 1 & 3 & 0 & 1 & 1 & 2 & 0 \\
\hline $12: 45$ & $13: 00$ & 0 & 0 & 84 & 10 & 8 & 0 & 28 & 0 & 75 & 9 & 2 & 0 & 7 & 0 & 0 & 0 & 34 & 0 & 2 & 0 & 3 & 0 & 0 & 0 \\
\hline PM & eak & & & & & & & & & & & & & & & & & & & & & & & & \\
\hline 3:00 & $3: 15$ & 1 & 0 & 85 & 9 & 8 & 0 & 29 & 0 & 80 & 1 & 1 & 0 & 10 & 0 & 3 & 0 & 42 & 2 & 1 & 0 & 0 & 0 & 3 & 0 \\
\hline 3:15 & $3: 30$ & 2 & 0 & 94 & 3 & 0 & 0 & 31 & 0 & 102 & 7 & 2 & 0 & 11 & 0 & 5 & 0 & 34 & 0 & 3 & 0 & 0 & 0 & 1 & 0 \\
\hline $3: 30$ & $3: 45$ & 0 & 0 & 74 & 11 & 11 & 0 & 30 & 1 & 139 & 9 & 2 & 0 & 6 & 0 & 1 & 0 & 41 & 1 & 0 & 0 & 1 & 0 & 0 & 0 \\
\hline $3: 45$ & $4: 00$ & 3 & 0 & 111 & 10 & 6 & 0 & 27 & 1 & 96 & 6 & 2 & 0 & 10 & 0 & 0 & 0 & 40 & 1 & 4 & 0 & 0 & 0 & 2 & 0 \\
\hline 4:00 & $4: 15$ & 1 & 0 & 104 & 10 & 4 & 0 & 29 & 0 & 120 & 4 & 4 & 0 & 14 & 0 & 1 & 0 & 49 & 0 & 3 & 0 & 1 & 0 & 1 & 0 \\
\hline $4: 15$ & $4: 30$ & 0 & 0 & 85 & 6 & 2 & 0 & 16 & 0 & 99 & 6 & 7 & 0 & 14 & 0 & 0 & 0 & 34 & 0 & 1 & 0 & 0 & 0 & 2 & 0 \\
\hline $4: 30$ & $4: 45$ & 2 & 0 & 97 & 1 & 3 & 0 & 20 & 0 & 135 & 3 & 5 & 0 & 14 & 0 & 2 & 0 & 42 & 0 & 8 & 0 & 1 & 0 & 3 & 0 \\
\hline $4: 45$ & $5: 00$ & 2 & 0 & 86 & 3 & 2 & 0 & 3 & 0 & 106 & 1 & 5 & 0 & 4 & 0 & 2 & 0 & 37 & 0 & 3 & 0 & 0 & 0 & 3 & 0 \\
\hline 5:00 & $5: 15$ & 1 & 0 & 94 & 2 & 4 & 0 & 10 & 1 & 98 & 5 & 2 & 0 & 9 & 1 & 3 & 0 & 39 & 0 & 5 & 0 & 0 & 0 & 3 & 0 \\
\hline $5: 15$ & $5: 30$ & 3 & 0 & 107 & 6 & 3 & 0 & 7 & 0 & 123 & 4 & 2 & 0 & 6 & 0 & 0 & 0 & 28 & 0 & 3 & 0 & 0 & 0 & 0 & 0 \\
\hline $5: 30$ & $5: 45$ & 2 & 0 & 146 & 3 & 1 & 0 & 5 & 0 & 99 & 6 & 1 & 0 & 11 & 0 & 0 & 0 & 28 & 0 & 5 & 0 & 0 & 0 & 4 & 0 \\
\hline $5: 45$ & $6: 00$ & 1 & 0 & 95 & 5 & 1 & 0 & 10 & 0 & 97 & 0 & 4 & 0 & 4 & 0 & 0 & 0 & 19 & 0 & 5 & 0 & 0 & 0 & 1 & 0 \\
\hline
\end{tabular}


SR 21 at Matthew Drive / US 119 Ramps (Wednesday - 10/12/05)

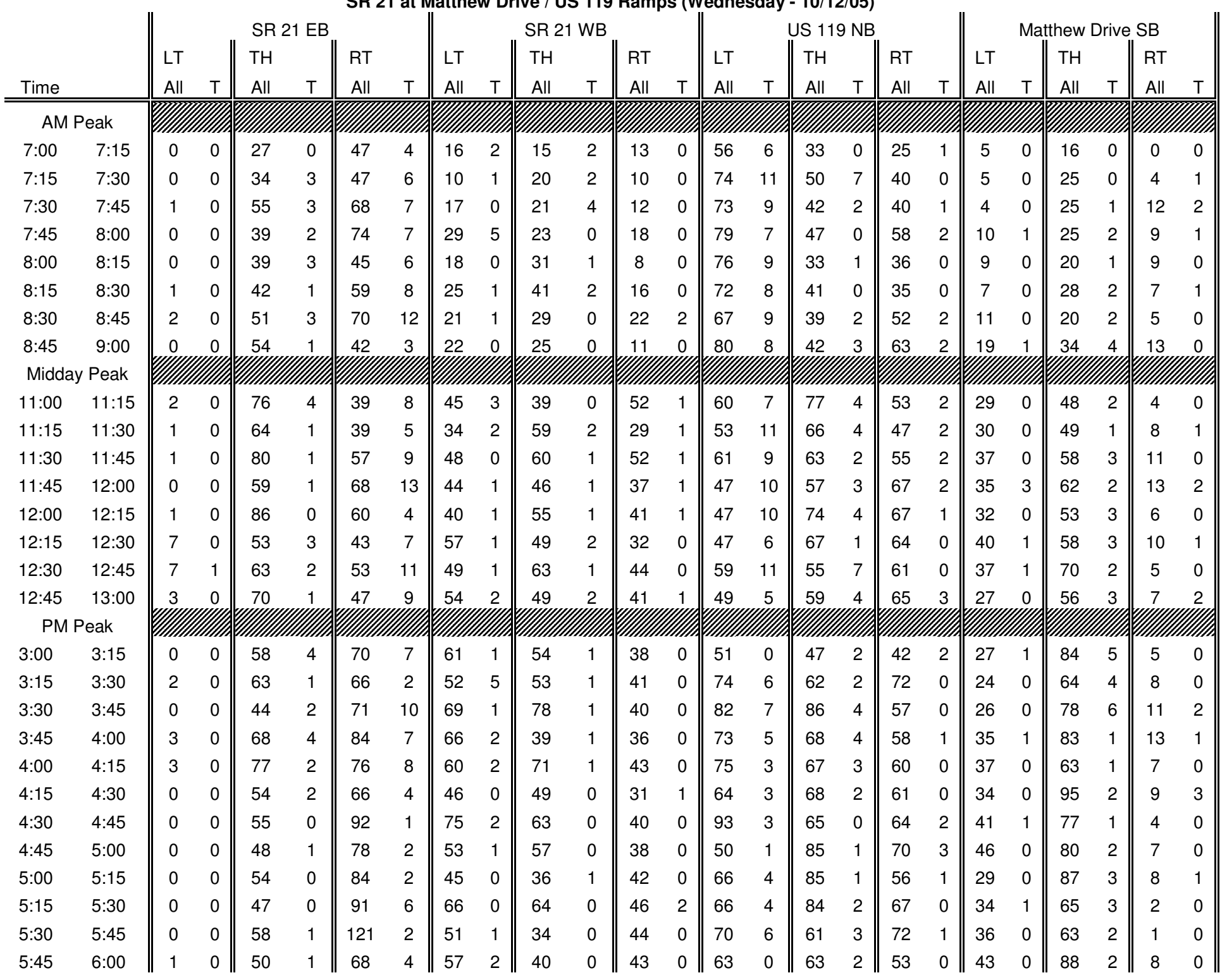




\begin{tabular}{|c|c|c|c|c|c|c|c|c|c|c|c|c|c|c|c|c|c|c|c|c|c|c|c|c|c|}
\hline \multicolumn{26}{|c|}{ SR 21 at Gabe's Plaza / Work Parkway (Wednesday - 10/12/05) } \\
\hline \multirow{3}{*}{\multicolumn{2}{|c|}{ Time }} & \multicolumn{6}{|c|}{ SR $21 \mathrm{~EB}$} & \multicolumn{6}{|c|}{ SR 21 WB } & \multicolumn{6}{|c|}{ Gabe's Plaza NB } & \multicolumn{6}{|c|}{ Work Parkway SB } \\
\hline & & \multirow{2}{*}{$\begin{array}{l}\mathrm{LT} \\
\text { All }\end{array}$} & \multirow[b]{2}{*}{$\mathrm{T}$} & \multicolumn{2}{|l|}{$\mathrm{TH}$} & \multicolumn{2}{|l|}{ RT } & \multicolumn{2}{|l|}{ LT } & \multicolumn{2}{|l|}{$\mathrm{TH}$} & \multicolumn{2}{|l|}{ RT } & \multicolumn{2}{|l|}{ LT } & \multicolumn{2}{|l|}{$\mathrm{TH}$} & \multicolumn{2}{|l|}{ RT } & \multicolumn{2}{|l|}{ LT } & \multicolumn{2}{|l|}{$\mathrm{TH}$} & \multicolumn{2}{|l|}{ RT } \\
\hline & & & & All & $\mathrm{T}$ & All & $\mathrm{T}$ & All & $\mathrm{T}$ & All & $\mathrm{T}$ & All & $\mathrm{T}$ & All & $\mathrm{T}$ & All & $\mathrm{T}$ & All & $\mathrm{T}$ & All & $\mathrm{T}$ & All & $\mathrm{T}$ & All & $\mathrm{T}$ \\
\hline $\mathrm{AM}$ & eak & & & & & & & & & & & & & & & & & & & & & & & & \\
\hline 7:00 & $7: 15$ & 9 & 1 & 46 & 0 & 2 & 0 & 0 & 0 & 36 & 5 & 12 & 2 & 2 & 1 & 0 & 0 & 1 & 0 & 12 & 1 & 0 & 0 & 10 & 0 \\
\hline $7: 15$ & 7:30 & 13 & 1 & 65 & 2 & 1 & 0 & 1 & 0 & 28 & 3 & 24 & 1 & 0 & 0 & 2 & 1 & 1 & 0 & 10 & 1 & 1 & 0 & 12 & 0 \\
\hline $7: 30$ & $7: 45$ & 10 & 0 & 86 & 3 & 3 & 1 & 0 & 0 & 33 & 3 & 14 & 0 & 2 & 1 & 1 & 0 & 2 & 0 & 13 & 1 & 0 & 0 & 15 & 0 \\
\hline $7: 45$ & 8:00 & 20 & 0 & 83 & 5 & 4 & 0 & 1 & 0 & 36 & 1 & 11 & 1 & 12 & 4 & 2 & 0 & 1 & 0 & 12 & 0 & 1 & 0 & 22 & 0 \\
\hline 8:00 & $8: 15$ & 19 & 0 & 59 & 3 & 6 & 0 & 2 & 0 & 38 & 0 & 15 & 1 & 6 & 2 & 2 & 0 & 2 & 0 & 17 & 0 & 1 & 0 & 13 & 0 \\
\hline $8: 15$ & $8: 30$ & 16 & 0 & 67 & 1 & 1 & 0 & 3 & 0 & 57 & 3 & 17 & 0 & 2 & 0 & 0 & 0 & 1 & 0 & 16 & 1 & 0 & 0 & 23 & 0 \\
\hline 8:30 & $8: 45$ & 22 & 1 & 88 & 4 & 4 & 0 & 9 & 0 & 54 & 3 & 22 & 2 & 4 & 0 & 0 & 0 & 2 & 0 & 15 & 1 & 0 & 0 & 14 & 0 \\
\hline $8: 45$ & 9:00 & 23 & 0 & 105 & 3 & 8 & 1 & 6 & 0 & 27 & 0 & 27 & 3 & 4 & 0 & 5 & 0 & 8 & 1 & 22 & 0 & 4 & 0 & 27 & 0 \\
\hline Midd & Peak & & & & & & & & & & & & & & & & & & & & & & & & \\
\hline $11: 00$ & $11: 15$ & 31 & 0 & 102 & 4 & 25 & 2 & 19 & 0 & 78 & 4 & 22 & 0 & 19 & 0 & 12 & 1 & 8 & 0 & 29 & 1 & 6 & 0 & 39 & 0 \\
\hline $11: 15$ & $11: 30$ & 61 & 2 & 52 & 0 & 28 & 2 & 15 & 3 & 56 & 2 & 31 & 1 & 30 & 2 & 12 & 0 & 20 & 0 & 22 & 0 & 11 & 0 & 36 & 1 \\
\hline $11: 30$ & $11: 45$ & 39 & 1 & 113 & 2 & 20 & 0 & 19 & 1 & 114 & 1 & 21 & 0 & 16 & 1 & 9 & 0 & 8 & 0 & 27 & 0 & 8 & 0 & 30 & 0 \\
\hline $11: 45$ & $12: 00$ & 46 & 1 & 90 & 5 & 25 & 0 & 24 & 0 & 65 & 2 & 31 & 0 & 22 & 1 & 11 & 0 & 11 & 0 & 29 & 0 & 6 & 0 & 40 & 0 \\
\hline $12: 00$ & $12: 15$ & 44 & 0 & 113 & 0 & 28 & 1 & 19 & 1 & 80 & 2 & 39 & 0 & 11 & 0 & 15 & 0 & 19 & 0 & 41 & 0 & 12 & 0 & 45 & 1 \\
\hline $12: 15$ & $12: 30$ & 48 & 3 & 82 & 0 & 27 & 1 & 23 & 0 & 73 & 2 & 40 & 1 & 23 & 1 & 6 & 0 & 12 & 0 & 49 & 1 & 17 & 0 & 42 & 0 \\
\hline $12: 30$ & $12: 45$ & 54 & 2 & 84 & 0 & 23 & 1 & 17 & 1 & 87 & 0 & 33 & 1 & 23 & 1 & 18 & 0 & 30 & 0 & 31 & 1 & 6 & 0 & 46 & 2 \\
\hline $12: 45$ & $13: 00$ & 33 & 1 & 100 & 3 & 29 & 0 & 16 & 0 & 72 & 2 & 30 & 1 & 20 & 1 & 15 & 0 & 21 & 2 & 31 & 1 & 10 & 0 & 52 & 2 \\
\hline PM & eak & & & & & & & & & & & & & & & & & & & & & & & & \\
\hline 3:00 & $3: 15$ & 45 & 0 & 59 & 7 & 23 & 0 & 14 & 0 & 99 & 1 & 31 & 3 & 21 & 1 & 4 & 1 & 16 & 0 & 41 & 1 & 5 & 0 & 33 & 0 \\
\hline $3: 15$ & $3: 30$ & 32 & 0 & 112 & 1 & 15 & 0 & 11 & 0 & 98 & 6 & 39 & 0 & 14 & 0 & 6 & 0 & 17 & 1 & 32 & 0 & 9 & 0 & 34 & 0 \\
\hline $3: 30$ & $3: 45$ & 55 & 2 & 57 & 0 & 15 & 0 & 19 & 0 & 120 & 0 & 24 & 0 & 27 & 0 & 8 & 0 & 12 & 0 & 42 & 0 & 8 & 0 & 40 & 2 \\
\hline $3: 45$ & $4: 00$ & 46 & 1 & 93 & 4 & 22 & 1 & 15 & 0 & 60 & 3 & 24 & 0 & 29 & 0 & 9 & 0 & 15 & 1 & 29 & 2 & 5 & 0 & 52 & 0 \\
\hline 4:00 & $4: 15$ & 33 & 0 & 117 & 1 & 24 & 1 & 15 & 0 & 116 & 3 & 25 & 0 & 24 & 0 & 10 & 0 & 24 & 0 & 28 & 0 & 3 & 0 & 34 & 0 \\
\hline $4: 15$ & $4: 30$ & 42 & 1 & 95 & 1 & 12 & 0 & 17 & 0 & 70 & 1 & 35 & 2 & 14 & 0 & 12 & 0 & 21 & 0 & 38 & 0 & 8 & 0 & 42 & 0 \\
\hline $4: 30$ & $4: 45$ & 46 & 0 & 97 & 3 & 17 & 0 & 9 & 0 & 113 & 2 & 29 & 1 & 24 & 0 & 13 & 0 & 16 & 0 & 33 & 1 & 7 & 0 & 41 & 0 \\
\hline $4: 45$ & $5: 00$ & 49 & 0 & 98 & 4 & 17 & 0 & 8 & 0 & 101 & 1 & 33 & 0 & 16 & 0 & 7 & 0 & 15 & 0 & 37 & 0 & 4 & 0 & 31 & 0 \\
\hline $5: 00$ & $5: 15$ & 44 & 1 & 85 & 0 & 10 & 1 & 15 & 0 & 79 & 1 & 39 & 0 & 11 & 0 & 6 & 0 & 16 & 0 & 28 & 1 & 2 & 0 & 33 & 0 \\
\hline $5: 15$ & $5: 30$ & 44 & 3 & 94 & 0 & 10 & 0 & 13 & 0 & 106 & 2 & 26 & 0 & 21 & 0 & 6 & 0 & 14 & 0 & 42 & 0 & 7 & 0 & 49 & 0 \\
\hline $5: 30$ & $5: 45$ & 43 & 0 & 110 & 2 & 13 & 0 & 17 & 0 & 69 & 0 & 33 & 1 & 15 & 0 & 5 & 0 & 13 & 0 & 29 & 0 & 3 & 0 & 45 & 1 \\
\hline $5: 45$ & $6: 00$ & 36 & 0 & 92 & 1 & 18 & 0 & 10 & 0 & 93 & 2 & 25 & 0 & 16 & 0 & 7 & 0 & 20 & 0 & 37 & 3 & 6 & 0 & 31 & 0 \\
\hline
\end{tabular}




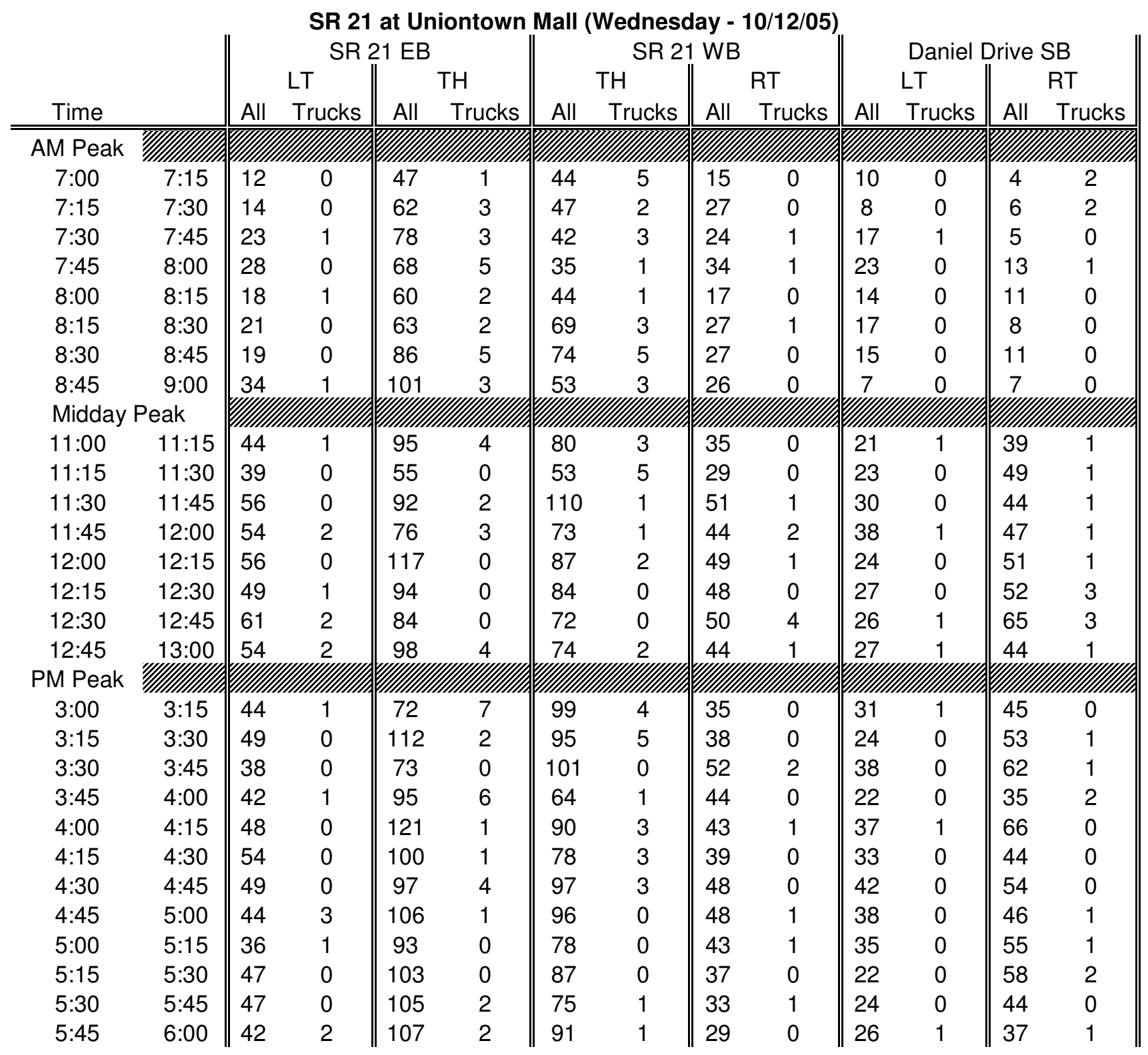


Travel Time Runs

AM Peak (Tuesday 10-18-05)

Eastbound

$\begin{array}{ccc}\text { Run } & \text { Clock } & \text { time } \\ 1 & 7: 29 \text { AM } & 01: 27 \\ 2 & 7: 31 \text { AM } & 02: 10 \\ 3 & 7: 37 \text { AM } & 01: 37 \\ 4 & 7: 41 \text { AM } & 01: 24 \\ 5 & 7: 45 \text { AM } & 02: 05 \\ 6 & 7: 52 \text { AM } & 01: 38 \\ 7 & 7: 59 \text { AM } & 02: 25 \\ 8 & 8: 05 \text { AM } & 02: 20 \\ 9 & \text { 8:10 AM } & 02: 33 \\ 10 & \text { 8:17 AM } & 01: 58 \\ & \text { average } & 01: 58 \\ & \text { stdev } & 00: 25 \\ & \text { count } & \end{array}$

Westbound

Run Clock time

$1 \quad$ 7:27 AM 00:58 second

$2 \quad 7: 31$ AM 01:15 75

$3 \quad 7: 37$ AM $01: 06 \quad 66$

$4 \quad 7: 41$ AM $00: 52 \quad 52$

$5 \quad 7: 45$ AM $02: 38 \quad 158$

$6 \quad 7: 52$ AM $02: 00 \quad 120$

$\begin{array}{llll}7 & 7: 59 \text { AM } & 02: 22 & 142\end{array}$

$8 \quad 8: 05$ AM $\quad 01: 53 \quad 113$

$9 \quad 8: 10$ AM $01: 39 \quad 99$

$10 \quad 8: 17$ AM $02: 09 \quad 129$

average $\quad 01: 41 \quad 101$

stdev $\quad 00: 37 \quad 37$

count

\begin{tabular}{|c|c|c|c|}
\hline \multirow{2}{*}{ Daniel } & \multicolumn{2}{|c|}{ Delays at } & \multirow{3}{*}{ Mall } \\
\hline & Cherry & Work & \\
\hline & 18 & & \\
\hline & 60 & & \\
\hline & 39 & & \\
\hline & & 23 & \\
\hline & 70 & & \\
\hline & 47 & & \\
\hline & 79 & & \\
\hline & 68 & & 5 \\
\hline & 73 & 15 & \\
\hline & 70 & & \\
\hline & 58 & 19 & 5 \\
\hline & 20 & 6 & \\
\hline 0 & 9 & 2 & 1 \\
\hline
\end{tabular}

Delays at

Mall Work Matthew Daniel

13

68

48

$5 \quad 61$

52

34

$18 \quad 23$

$12 \quad 43$

920

$\begin{array}{lll}2 & 7 & 0\end{array}$

Midday Peak (Monday 10-17-05)

Eastbound

$\begin{array}{cccc}\text { Run } & \text { Clock } & \text { time } & \text { seconds } \\ 1 & 11: 58 \text { AM } & 02: 31 & 151 \\ 2 & 12: 05 \text { PM } & 01: 50 & 110 \\ 3 & 12: 10 \text { PM } & 04: 21 & 261 \\ 4 & 12: 18 \text { PM } & 03: 22 & 202 \\ 5 & 12: 25 \text { PM } & 03: 59 & 239 \\ 6 & 12: 36 \text { PM } & 02: 39 & 159 \\ 7 & 12: 41 \text { PM } & 02: 49 & 169 \\ 8 & 12: 47 \text { PM } & 02: 47 & 167 \\ 9 & 12: 54 \text { PM } & 03: 04 & 184 \\ 10 & 1: 01 \text { PM } & 03: 55 & 235 \\ & \text { average } & 03: 08 & 188 \\ & \text { stdev } & 00: 46 & 46 \\ & \text { count } & & \end{array}$

Delays at

$\begin{array}{ccc}\begin{array}{c}\text { Cherry } \\ 28\end{array} & \text { Work } & \text { Mall } \\ 44 & & \\ 170 & & \\ 43 & & 16 \\ 128 & 39 & \\ 98 & & \\ 76 & 33 & \\ 66 & & 12 \\ 115 & & \\ 106 & 55 & \\ 87 & 42 & 17 \\ 44 & 11 & 5 \\ 10 & 3 & 3\end{array}$




\begin{tabular}{cccccccc}
\multicolumn{4}{c}{ Westbound } & \multicolumn{4}{c}{ Delays at } \\
Run & Clock & time & seconds & Mall & Work & Matthew & Daniel \\
1 & $11: 55$ AM & $02: 28$ & 148 & & & 75 & \\
2 & $12: 02$ PM & $01: 06$ & 66 & & & & \\
3 & $12: 08$ PM & $01: 20$ & 80 & & & & \\
4 & $12: 15$ PM & $01: 46$ & 106 & & 28 & & \\
5 & $12: 21$ PM & $03: 33$ & 213 & & 64 & 66 & \\
6 & $12: 30$ PM & $02: 42$ & 162 & & 15 & 73 & \\
7 & $12: 38$ PM & $02: 40$ & 160 & & 13 & 54 & 52 \\
8 & $12: 45$ PM & $02: 15$ & 135 & & & 20 \\
9 & $12: 50$ PM & $02: 33$ & 153 & & 50 & 20 \\
10 & $12: 58$ PM & $03: 25$ & 205 & & 48 & 73 & \\
& average & $02: 23$ & 143 & & 36 & 59 & \\
& stdev & $00: 48$ & 48 & & 21 & 20 &
\end{tabular}

PM Peak (Monday 10-17-05)

\section{Eastbound}

$\begin{array}{lllr}1 & 2: 55 \text { PM } & 03: 17 & 197\end{array}$

2 3:01 PM $02: 38 \quad 158$

$3 \quad 3: 07$ PM $\quad 03: 43 \quad 223$

$4 \quad 3: 17$ PM $03: 07 \quad 187$

$5 \quad 3: 24$ PM $03: 12 \quad 192$

$6 \quad 3: 32$ PM 03:35 215

$7 \quad 3: 40$ PM $\quad 04: 50 \quad 290$

$8 \quad 3: 52$ PM $\quad 05: 14 \quad 314$

$9 \quad 4: 02$ PM $04: 08 \quad 248$

$10 \quad 4: 15$ PM 01:05

average 03:29 209

stdev 01:10 70

count

Westbound

Run
1
2
3
4
5
6
7
8
9
10

97

\section{Clock time} 2.53 PM

3:00 PM

3:05 PM

3:12 PM

3:21 PM

3:29 PM

3:37 PM

3:46 PM

3:58 PM

4:07 PM

average

stdev

count time seconds

01:37

00:55

01:21

04:28

02:04

$02: 12$

$01: 10$

03:38

$01: 38$

02:55

02:12

01:09
55

81

268

124

132

70

218

98

175

132

69

\begin{tabular}{cccc}
\multicolumn{5}{c}{ Delays at } & \\
Daniel & Cherry & Work & Mall \\
& 116 & & \\
& 100 & & \\
& 154 & & \\
& 115 & & \\
& 94 & & \\
& 126 & 10 & \\
85 & 142 & & \\
246 & 13 & & \\
15 & 110 & 27 & 23 \\
& & & \\
115 & 108 & 19 & 23 \\
118 & 40 & 12 & \\
3 & 9 & 2 & 1
\end{tabular}

Delays at

Mall Work Matthew Daniel

17

57

114

46

38

$\begin{array}{lll}25 & 88 & 26\end{array}$

27

$23 \quad 81$

$30 \quad 73 \quad 26$

$16 \quad 31$

$\begin{array}{lll}5 & 5 & 1\end{array}$ 
Cycle Lengths and Splits at Matthew Drive \& S.R. 0021

(Field Measured 3:04 to 4:50, Wednesday 10-26-05)

$\begin{array}{ccccc}\text { Start Times } & & & & \\ \text { WB LTs } & \text { EB TH } & \text { NB LT } & \text { SB TH } & \text { End } \\ \text { 00:00 } & 00: 44 & 01: 29 & 02: 11 & 03: 00 \\ 03: 00 & 03: 41 & 04: 30 & 05: 13 & 05: 47 \\ 05: 47 & 06: 23 & 07: 06 & 07: 50 & 08: 42 \\ 08: 42 & 09: 19 & 10: 17 & 11: 00 & 11: 43 \\ 11: 43 & 12: 10 & 13: 13 & 13: 43 & 14: 34 \\ 14: 34 & 15: 16 & 16: 01 & 17: 22 & 18: 07 \\ 18: 07 & 18: 58 & 20: 03 & 21: 00 & 21: 50 \\ 21: 50 & 22: 31 & 23: 19 & 24: 07 & 24: 58 \\ 24: 58 & 25: 32 & 26: 24 & 26: 54 & 27: 30 \\ 27: 30 & 27: 55 & 29: 14 & 29: 38 & 30: 28 \\ 30: 28 & 31: 09 & 31: 53 & 32: 16 & 33: 07 \\ 33: 07 & 33: 44 & 34: 22 & 35: 15 & 35: 52 \\ 35: 52 & 36: 44 & 37: 38 & 38: 22 & 39: 13 \\ 39: 13 & 39: 46 & 40: 48 & 41: 28 & 42: 01 \\ 42: 01 & 42: 40 & 43: 44 & 44: 22 & 45: 07 \\ 45: 07 & 45: 33 & 46: 14 & 46: 45 & 47: 26 \\ 47: 26 & 47: 58 & 48: 56 & 49: 40 & 50: 31 \\ 50: 31 & 50: 59 & 51: 40 & 52: 27 & 53: 17 \\ 53: 17 & 53: 42 & 54: 15 & 54: 43 & 55: 20 \\ 55: 20 & 55: 42 & 56: 36 & 57: 02 & 57: 51 \\ 57: 51 & 58: 31 & 59: 10 & 59: 41 & 1: 00: 32 \\ 1: 00: 32 & 1: 01: 14 & 1: 01: 48 & 1: 02: 29 & 1: 03: 06 \\ 1: 03: 06 & 1: 03: 28 & 1: 04: 26 & 1: 05: 16 & 1: 05: 51 \\ 1: 05: 51 & 1: 06: 29 & 1: 07: 29 & 1: 08: 24 & 1: 09: 16 \\ 1: 09: 16 & 1: 09: 57 & 1: 10: 46 & 1: 11: 13 & 1: 11: 43 \\ 1: 11: 43 & 1: 12: 18 & 1: 12: 57 & 1: 13: 22 & 1: 14: 13 \\ 1: 14: 13 & 1: 14: 47 & 1: 15: 33 & 1: 16: 15 & 1: 16: 46 \\ 1: 16: 46 & 1: 17: 37 & 1: 18: 35 & 1: 19: 20 & 1: 20: 07 \\ 1: 20: 07 & 1: 20: 51 & 1: 21: 43 & 1: 22: 08 & 1: 22: 52 \\ 1: 22: 52 & 1: 23: 28 & 1: 24: 16 & 1: 24: 58 & 1: 25: 44 \\ 1: 25: 44 & 1: 26: 03 & 1: 26: 48 & 1: 27: 29 & 1: 28: 12 \\ 1: 28: 12 & 1: 28: 58 & 1: 29: 57 & 1: 30: 21 & 1: 31: 12 \\ 1: 31: 12 & 1: 31: 58 & 1: 32: 39 & 1: 33: 27 & 1: 34: 10 \\ 1: 34: 10 & 1: 35: 01 & 1: 36: 03 & 1: 37: 11 & 1: 38: 02 \\ 1: 38: 02 & 1: 38: 41 & 1: 40: 20 & 1: 41: 29 & 1: 42: 20 \\ 1: 42: 20 & 1: 43: 02 & 1: 44: 27 & 1: 45: 25 & 1: 46: 17\end{array}$

\begin{tabular}{|c|c|c|c|c|c|}
\hline \multicolumn{6}{|c|}{ Durations } \\
\hline & WB LTs & EB TH & NB LT & SB TH & Cycle \\
\hline & $00: 44$ & $00: 45$ & $00: 42$ & $00: 49$ & 03:00 \\
\hline & $00: 41$ & $00: 49$ & $00: 43$ & $00: 34$ & $02: 47$ \\
\hline & $00: 36$ & $00: 43$ & 00:44 & 00:52 & $02: 55$ \\
\hline & $00: 37$ & $00: 58$ & $00: 43$ & $00: 43$ & 03:01 \\
\hline & $00: 27$ & $01: 03$ & $00: 30$ & $00: 51$ & $02: 51$ \\
\hline & $00: 42$ & $00: 45$ & $01: 21$ & $00: 45$ & $03: 33$ \\
\hline & $00: 51$ & $01: 05$ & $00: 57$ & $00: 50$ & $03: 43$ \\
\hline & $00: 41$ & $00: 48$ & $00: 48$ & $00: 51$ & 03:08 \\
\hline & $00: 34$ & $00: 52$ & $00: 30$ & $00: 36$ & $02: 32$ \\
\hline & $00: 25$ & $01: 19$ & $00: 24$ & $00: 50$ & $02: 58$ \\
\hline & $00: 41$ & $00: 44$ & $00: 23$ & $00: 51$ & $02: 39$ \\
\hline & $00: 37$ & $00: 38$ & $00: 53$ & $00: 37$ & $02: 45$ \\
\hline & $00: 52$ & $00: 54$ & $00: 44$ & $00: 51$ & $03: 21$ \\
\hline & $00: 33$ & 01:02 & $00: 40$ & $00: 33$ & $02: 48$ \\
\hline & $00: 39$ & $01: 04$ & 00:38 & $00: 45$ & 03:06 \\
\hline & $00: 26$ & $00: 41$ & $00: 31$ & $00: 41$ & $02: 19$ \\
\hline & $00: 32$ & $00: 58$ & $00: 44$ & $00: 51$ & 03:05 \\
\hline & $00: 28$ & $00: 41$ & $00: 47$ & $00: 50$ & $02: 46$ \\
\hline & $00: 25$ & $00: 33$ & $00: 28$ & $00: 37$ & $02: 03$ \\
\hline & $00: 22$ & $00: 54$ & $00: 26$ & $00: 49$ & $02: 31$ \\
\hline & $00: 40$ & $00: 39$ & $00: 31$ & $00: 51$ & $02: 41$ \\
\hline & $00: 42$ & $00: 34$ & $00: 41$ & $00: 37$ & $02: 34$ \\
\hline & $00: 22$ & $00: 58$ & $00: 50$ & $00: 35$ & $02: 45$ \\
\hline & $00: 38$ & 01:00 & $00: 55$ & $00: 52$ & $03: 25$ \\
\hline & $00: 41$ & $00: 49$ & $00: 27$ & $00: 30$ & $02: 27$ \\
\hline & $00: 35$ & 00:39 & 00:25 & $00: 51$ & $02: 30$ \\
\hline & $00: 34$ & $00: 46$ & $00: 42$ & $00: 31$ & $02: 33$ \\
\hline & $00: 51$ & $00: 58$ & $00: 45$ & $00: 47$ & $03: 21$ \\
\hline & $00: 44$ & $00: 52$ & $00: 25$ & $00: 44$ & $02: 45$ \\
\hline & $00: 36$ & $00: 48$ & $00: 42$ & $00: 46$ & $02: 52$ \\
\hline & 00:19 & $00: 45$ & $00: 41$ & $00: 43$ & $02: 28$ \\
\hline & $00: 46$ & $00: 59$ & $00: 24$ & $00: 51$ & 03:00 \\
\hline & $00: 46$ & $00: 41$ & $00: 48$ & $00: 43$ & $02: 58$ \\
\hline & $00: 51$ & 01:02 & 01:08 & $00: 51$ & $03: 52$ \\
\hline & $00: 39$ & 01:39 & 01:09 & $00: 51$ & $04: 18$ \\
\hline & $00: 42$ & $01: 25$ & $00: 58$ & $00: 52$ & $03: 57$ \\
\hline Average & $00: 37$ & $00: 53$ & $00: 42$ & $00: 45$ & $02: 57$ \\
\hline Stdev & 00:09 & $00: 14$ & $00: 14$ & $00: 07$ & $00: 29$ \\
\hline Maximum & $00: 52$ & $01: 39$ & $01: 21$ & $00: 52$ & $04: 18$ \\
\hline Minimum & $00: 19$ & $00: 33$ & $00: 23$ & $00: 30$ & $02: 03$ \\
\hline Splits (\%) & $21 \%$ & $30 \%$ & $24 \%$ & $25 \%$ & $100 \%$ \\
\hline
\end{tabular}




\section{Saturation Flow Rate}

\begin{tabular}{|c|c|c|c|c|c|c|c|}
\hline \multirow{3}{*}{$\begin{array}{l}\text { Intersection } \\
\text { Work }\end{array}$} & \multirow{3}{*}{$\begin{array}{l}\text { Approach } \\
\text { SR } 21 \mathrm{~EB}\end{array}$} & \multirow{3}{*}{$\begin{array}{c}\text { Movement } \\
\text { TH/RT }\end{array}$} & \multirow[b]{2}{*}{ Vehicles } & \multicolumn{3}{|c|}{ Ave } & \\
\hline & & & & Time & Headway & SFR & \\
\hline & & & 10 & 24.17 & 2.4 & 1,490 & \\
\hline & & & 10 & 26.67 & 2.7 & 1,350 & \\
\hline & & & 5 & 11.74 & 2.3 & 1,530 & 1,460 \\
\hline & Work SB & LT/TH & 5 & 16.7 & 3.3 & 1,080 & \\
\hline & & & 2 & 5.4 & 2.7 & 1,330 & 1,210 \\
\hline Matthew & NB SR & LT & 8 & 19.57 & 2.4 & 1,470 & \\
\hline & 119 & & 4 & 9.72 & 2.4 & 1,480 & \\
\hline & & & 13 & 30.44 & 2.3 & 1,540 & \\
\hline & & & 5 & 10.27 & 2.1 & 1,750 & \\
\hline & & & 13 & 32.12 & 2.5 & 1,460 & \\
\hline & & & 8 & 17.27 & 2.2 & 1,670 & 1,560 \\
\hline & & $\mathrm{TH}$ & 13 & 36.62 & 2.8 & 1,280 & \\
\hline & & & 10 & 23.1 & 2.3 & 1,560 & \\
\hline & & & 7 & 17.06 & 2.4 & 1,480 & \\
\hline & & & 7 & 17.38 & 2.5 & 1,450 & \\
\hline & & & 9 & 21.01 & 2.3 & 1,540 & 1,460 \\
\hline & EB SR 21 & $\mathrm{TH}$ & 6 & 11.87 & 2.0 & 1,820 & \\
\hline & & & 5 & 8.96 & 1.8 & 2,010 & \\
\hline & & & 5 & 11.14 & 2.2 & 1,620 & \\
\hline & & & 8 & 23.84 & 3.0 & 1,210 & \\
\hline & & & 4 & 9.1 & 2.3 & 1,580 & \\
\hline & & & 4 & 5.94 & 1.5 & 2,420 & 1,780 \\
\hline & WB SR 21 & LT & 5 & 12.74 & 2.5 & 1,410 & \\
\hline & & & 8 & 14.8 & 1.9 & 1,950 & \\
\hline & & & 13 & 32.34 & 2.5 & 1,450 & \\
\hline & & & 9 & 18.52 & 2.1 & 1,750 & 1,640 \\
\hline & SB & $\mathrm{TH} / \mathrm{RT}$ & 12 & 24.99 & 2.1 & 1,730 & \\
\hline & Matthew & & 6 & 13.98 & 2.3 & 1,550 & 1,640 \\
\hline Cherry & SR $21 \mathrm{~EB}$ & TH/RT & 5 & 11.16 & 2.2 & 1,610 & \\
\hline Tree & & & 12 & 24.93 & 2.1 & 1,730 & \\
\hline & & & 15 & 28.29 & 1.9 & 1,910 & 1,750 \\
\hline
\end{tabular}




\section{Cycle Lengths}

$\begin{array}{ccccccc} & \text { AM 1 } & \text { AM 2 } & \text { MD 1 } & \text { MD 2 } & \text { PM 1 } & \text { PM 2 } \\ \text { Mall } & 01: 00 & 01: 45 & 01: 06 & 00: 47 & 02: 05 & 01: 55 \\ \text { Work } & 02: 35 & --- & 02: 05 & 01: 45 & 00: 47 & 01: 20 \\ \text { Matthew } & 02: 00 & 01: 52 & 03: 15 & 03: 30 & 03: 00 & 02: 45 \\ \text { Daniel } & 05: 18 & --- & 01: 10 & 02: 41 & 01: 45 & ---\end{array}$

'---' = insufficient minor phase demand to create a cycle.

AM Notes: $8: 25$ to $8: 45$

Mall $-L T=10$, Mainline $=40$, Side Road $=10$, Cycle $=60$ seconds

Mall - Mainline $=85$, Side Road $=20$, Cycle $=1: 45$

Work - Mainline $=2: 25$, side road $=10$, Cycle $=2: 35$. No side road demand

Matthew $-21 \mathrm{LTs}=15$, mainline $=55,119 \mathrm{LTs}=40$, side road $=20$, Cycle $=2: 00$

Matthew $-21 \mathrm{LTs}=20$, mainline $=40,119 \mathrm{LTs}=30$, side $\mathrm{road}=22$, Cycle $=1: 52$

Daniel - Side Road $=13$, mainline $=5: 05$, Cycle $=5: 18$. no side road demand

Midday Notes: $1: 45$ to 2:15

Mall - Mainline $=50$, Side Road $=15$, Cycle $=1: 06$ seconds

Mall - Mainline $=39$, Side Road $=8$, Cycle $=47 \mathrm{sec}$

Work - LTs $=20$, Mainline $=70$, side road $=35$, Cycle $=2: 05$

Work - LTs $=20$, Mainline $=45$, side road $=20$, Cycle $=1: 25$

Matthew $-21 \mathrm{LTs}=25$, mainline $=80,119 \mathrm{LTs}=40$, side $\mathrm{road}=50$, Cycle $=3: 15$

Matthew $-21 \mathrm{LTs}=50$, mainline $=65,119 \mathrm{LTs}=45$, side $\mathrm{road}=50$, Cycle $=3: 30$

Daniel - Side Road $=15$, mainline $=55$, Cycle $=1: 10$

Daniel - Side Road $=12$, mainline $=150$, Cycle $=2: 41$

PM Notes: $4: 15$ to $4: 45$

Mall $-\mathrm{LT}=10$, Mainline $=95$, Side Road $=15$, Cycle $=2: 05$

Mall $-\mathrm{LT}=10$, Mainline $=80$, Side Road $=20$, Cycle $=1: 55$

Work - Mainline $=30$, side road $=15$, Cycle $=0: 47$

Work $-\mathrm{LTs}=13$, Mainline $=35$, side road $=25$, Cycle $=1: 20$

Matthew $-21 \mathrm{LTs}=20$, mainline $=50,119 \mathrm{LTs}=60$, side $\mathrm{road}=50$, Cycle $=3: 00$

Matthew $-21 \mathrm{LTs}=25$, mainline $=60,119 \mathrm{LTs}=25$, side $\mathrm{road}=55$, Cycle $=2: 45$

Daniel - Side Road=15, mainline $=80, \mathrm{LTs}=10$, Cycle $=1: 45$. No side road demand.

Queue Length Observations

Midday Peak - Queuing on EB SR 21 at Cherry Tree Lane past Daniel Drive

(20 vehicles before spillback) for one or two cycles. Nothing long elsewhere.

PM Peak - 10 vehicle queue fits between SR 21 and Daniel Drive on Matthew Drive

PM Peak (3:30) - Queue on EB SR 21 Cherry Tree Lane is approximately 35 vehicles

PM Peak (3:50) - Queue on EB SR 21 Cherry Tree Lane is approximately 60 vehicles

PM Peak (4:10) - Queue on EB SR 21 Cherry Tree Lane dissipates to approximately 25 vehicles, queue up Matthew Drive is at least 20 vehicles.

PM Peak (4:15) - Queue on WB SR 21 from Work all the way to the Mall, dissipates within 5 minutes

PM Peak (4:15 to 4:45) - 6 vehicle queue on Mall, 4 fit before stop sign. Queues on Work appx 5, none on Gabes, 13 vehicle on Matthew, no queue on Daniel 


\section{APPENDIX B - SIMULATION STATISTICS}




\section{Travel Time Summary}

\begin{tabular}{lcccccc}
\multicolumn{4}{c}{ Eastbound } & \multicolumn{4}{c}{ Westbound } \\
& Field & Model & $\%$ Diff & Field & Model & $\%$ Diff \\
AM & & & & & & \\
Peak & $01: 58$ & $01: 44$ & $-11 \%$ & $01: 41$ & $01: 37$ & $-4 \%$ \\
Midday & $03: 08$ & $03: 20$ & $7 \%$ & $02: 23$ & $02: 22$ & $0 \%$ \\
PM & & & & & & \\
Peak & $03: 29$ & $03: 42$ & $7 \%$ & $02: 12$ & $02: 17$ & $4 \%$
\end{tabular}

Tests of Statistical Significance between Means

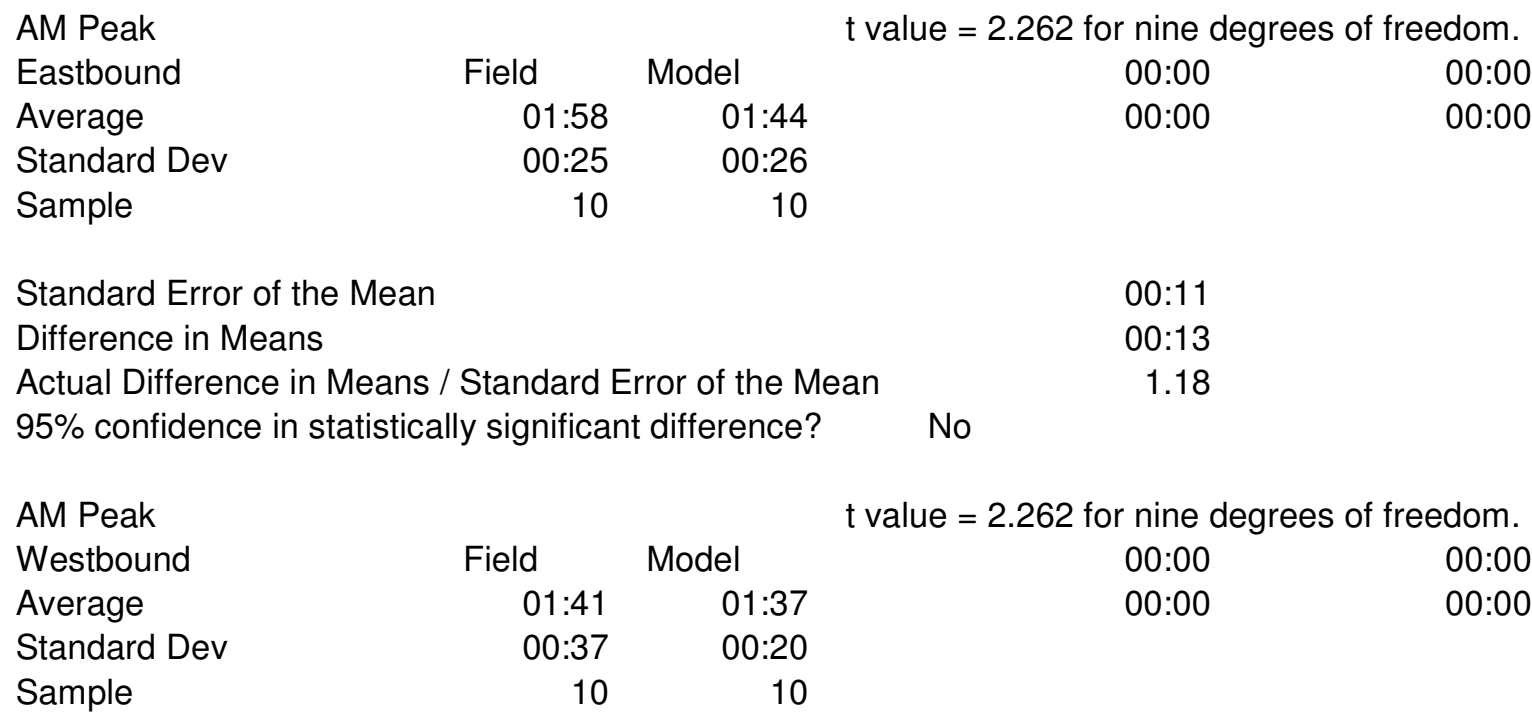

Standard Error of the Mean $\quad 00: 13$

Difference in Means $\quad$ 00:04

Actual Difference in Means / Standard Error of the Mean 0.33

$95 \%$ confidence in statistically significant difference? No 
Midday Peak

Eastbound

Average

Standard Dev

Sample

Field
03:08
00:46

10 t value $=2.262$ for nine degrees of freedom .

00:00

00:00

03:20

00:00

00:00

Standard Error of the Mean

$00: 16$

Difference in Means

$00: 22$

Actual Difference in Means / Standard Error of the

Mean

$00: 13$

$95 \%$ confidence in statistically significant difference?

Midday Peak

Westbound

Average

Field Model

10

Standard Dev

Sample

$\begin{array}{rr}02: 23 & 02: 22 \\ 00: 48 & 00: 44 \\ 10 & 10\end{array}$

$\mathrm{t}$ value $=2.262$ for nine degrees of freedom $\mathrm{s}$

No

0.78

00:00

00:00

00:00

00:00

Standard Error of the Mean

$00: 21$

Difference in Means

00:01

Actual Difference in Means / Standard Error of the

Mean

0.03

$95 \%$ confidence in statistically significant difference?

No

PM Peak

Eastbound

Average

Standard Dev

Sample
Field

$\begin{array}{ll}\text { 03:29 } & \text { Model } \\ 01: 10 & \end{array}$

t value $=2.262$ for nine degrees of freedom.

00:00

00:00

00:00

$03: 42$

$00: 19$

10

Standard Error of the Mean

$00: 23$

Difference in Means

$00: 14$

Actual Difference in Means / Standard Error of the Mean

$95 \%$ confidence in statistically significant difference?

No

0.60

PM Peak

Westbound

Field

Model

$t$ value $=2.262$ for nine degrees of freedom

Average

$02: 12$

01:09

$02: 17$

$00: 00$

00:00

Standard Dev

10

01:03

10

Standard Error of the Mean

$00: 29$

Difference in Means

$00: 06$

Actual Difference in Means / Standard Error of the Mean

0.19

No 


\begin{tabular}{|c|c|c|c|c|c|c|c|c|}
\hline & $\begin{array}{l}\text { Baseline } \\
\text { AM Peak } \\
\text { SR } 21\end{array}$ & & & & Total Netwo & & & \\
\hline & Delay/Veh & TT & $\begin{array}{l}\text { Ave } \\
\text { Speed }\end{array}$ & $\begin{array}{l}\text { Fuel } \\
\text { Used }\end{array}$ & Delay/Veh & TT & $\begin{array}{c}\text { Ave } \\
\text { Speed }\end{array}$ & $\begin{array}{l}\text { Fuel } \\
\text { Used }\end{array}$ \\
\hline 1 & 26.3 & 21.5 & 19 & 58 & 44.7 & 41.2 & 16 & 95 \\
\hline 196707 & 27.0 & 22.1 & 19 & 68 & 43.9 & 41.8 & 16 & 104 \\
\hline 862089 & 25.3 & 20.6 & 19 & 57 & 38.3 & 37.9 & 17 & 92 \\
\hline 556682 & 25.7 & 21.8 & 19 & 65 & 44.5 & 41.6 & 16 & 101 \\
\hline 437068 & 32.1 & 25.2 & 17 & 62 & 48.0 & 44.5 & 16 & 101 \\
\hline 950495 & 29.5 & 23.1 & 18 & 61 & 44.0 & 41.9 & 16 & 93 \\
\hline 689432 & 26.3 & 22.6 & 19 & 70 & 41.4 & 41.6 & 17 & 107 \\
\hline 245122 & 27.2 & 22.2 & 19 & 68 & 42.0 & 40.0 & 17 & 103 \\
\hline 759075 & 30.3 & 22.6 & 18 & 62 & 44.1 & 39.8 & 17 & 97 \\
\hline 518658 & 29.1 & 23.9 & 18 & 67 & 46.0 & 44.0 & 16 & 110 \\
\hline average & 27.9 & 22.6 & 19 & 64 & 43.7 & 41.4 & 16 & 100 \\
\hline stdev & 2.2 & 1.3 & 0.7 & 4.5 & 2.6 & 1.9 & 0.5 & 6.0 \\
\hline cov & $8 \%$ & $6 \%$ & $4 \%$ & $7 \%$ & $6 \%$ & $5 \%$ & $3 \%$ & $6 \%$ \\
\hline & $\begin{array}{l}\text { Baseline } \\
\text { Midday }\end{array}$ & & & & & & & \\
\hline & SR 21 & & & & Total Netwo & & & \\
\hline & Delay/Veh & TT & $\begin{array}{c}\text { Ave } \\
\text { Speed }\end{array}$ & $\begin{array}{l}\text { Fuel } \\
\text { Used }\end{array}$ & Delay/Veh & TT & $\begin{array}{c}\text { Ave } \\
\text { Speed }\end{array}$ & $\begin{array}{l}\text { Fuel } \\
\text { Used }\end{array}$ \\
\hline 1 & 50.1 & 47.2 & 13 & 92 & 76.9 & 91.6 & 12 & 158 \\
\hline 196707 & 59.2 & 52.1 & 11 & 93 & 83.4 & 93.4 & 11 & 155 \\
\hline 862089 & 44.1 & 43.7 & 13 & 94 & 66.6 & 82.0 & 13 & 156 \\
\hline 556682 & 44.7 & 44.4 & 14 & 90 & 66.2 & 83.1 & 13 & 153 \\
\hline 437068 & 43.1 & 42.0 & 14 & 87 & 68.5 & 82.1 & 12 & 146 \\
\hline 950495 & 45.0 & 42.9 & 13 & 82 & 67.5 & 82.0 & 12 & 143 \\
\hline 689432 & 46.0 & 44.8 & 13 & 91 & 67.7 & 84.8 & 12 & 155 \\
\hline 245122 & 48.2 & 45.4 & 13 & 88 & 68.9 & 83.5 & 12 & 149 \\
\hline 759075 & 42.5 & 41.8 & 14 & 86 & 64.2 & 80.5 & 13 & 149 \\
\hline 518658 & 44.4 & 44.2 & 14 & 91 & 65.9 & 83.6 & 13 & 149 \\
\hline average & 46.7 & 44.9 & 13 & 89 & 69.6 & 84.7 & 12 & 151 \\
\hline stdev & 4.9 & 3.0 & 0.9 & 3.8 & 5.9 & 4.3 & 0.7 & 4.7 \\
\hline COV & $11 \%$ & $7 \%$ & $7 \%$ & $4 \%$ & $9 \%$ & $5 \%$ & $5 \%$ & $3 \%$ \\
\hline
\end{tabular}




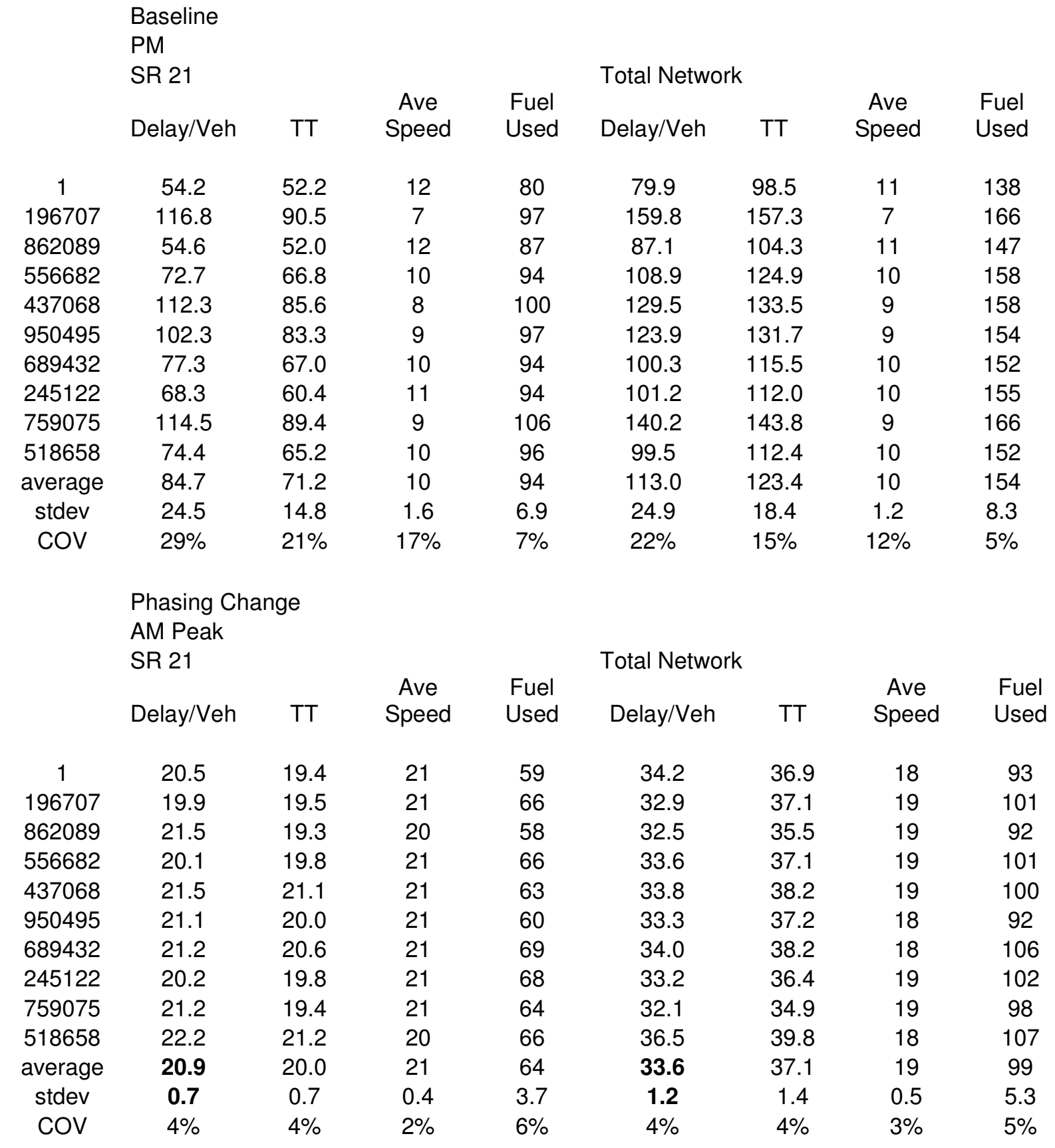


Phasing Change

Midday

SR 21

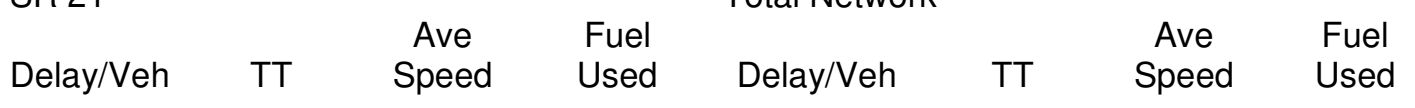

$\begin{array}{ccccccccc}1 & 35.5 & 38.6 & 15 & 89 & 60.7 & 79.9 & 13 & 153 \\ 196707 & 35.6 & 38.8 & 15 & 92 & 58.2 & 76.1 & 14 & 153 \\ 862089 & 33.4 & 37.3 & 16 & 91 & 56.9 & 75.3 & 14 & 153 \\ 556682 & 36.9 & 39.7 & 15 & 89 & 60.7 & 79.3 & 13 & 153 \\ 437068 & 35.1 & 37.4 & 15 & 86 & 60.0 & 76.3 & 13 & 146 \\ 950495 & 33.2 & 36.3 & 16 & 81 & 56.7 & 74.7 & 14 & 142 \\ 689432 & 37.9 & 40.1 & 15 & 89 & 61.1 & 80.0 & 13 & 151 \\ 245122 & 37.7 & 39.6 & 15 & 90 & 62.0 & 79.0 & 13 & 153 \\ 759075 & 36.0 & 38.1 & 15 & 87 & 58.1 & 76.3 & 14 & 149 \\ 518658 & 34.9 & 38.9 & 15 & 89 & 59.7 & 79.2 & 13 & 149 \\ \text { average } & \mathbf{3 5 . 6} & 38.5 & 15 & 88 & \mathbf{5 9 . 4} & 77.6 & 13 & 150 \\ \text { stdev } & \mathbf{1 . 6} & 1.2 & 0.4 & 3.3 & \mathbf{1 . 8} & 2.0 & 0.5 & 3.8 \\ \text { COV } & 4 \% & 3 \% & 3 \% & 4 \% & 3 \% & 3 \% & 4 \% & 3 \%\end{array}$

Phasing Change

PM

SR 21

$\begin{array}{lcccccc} & & \text { Ave } & \text { Fuel } & & \text { Ave } & \text { Fuel } \\ \text { Delay/Veh } & \text { TT } & \text { Speed } & \text { Used Delay/Veh } & \text { TT } & \text { Speed } & \text { Used }\end{array}$

$\begin{array}{ccccccccc}1 & 35.4 & 40.7 & 16 & 75 & 60.1 & 83.6 & 13 & 131 \\ 196707 & 52.2 & 53.4 & 13 & 87 & 75.8 & 97.8 & 12 & 145 \\ 862089 & 42.3 & 45.0 & 14 & 86 & 74.9 & 95.6 & 12 & 144 \\ 556682 & 41.7 & 47.8 & 15 & 88 & 70.3 & 96.0 & 13 & 147 \\ 437068 & 53.9 & 52.0 & 13 & 91 & 74.8 & 94.6 & 12 & 147 \\ 950495 & 47.0 & 50.0 & 14 & 83 & 75.2 & 97.0 & 12 & 140 \\ 689432 & 48.0 & 49.8 & 13 & 86 & 71.0 & 93.8 & 12 & 142 \\ 245122 & 38.6 & 42.2 & 15 & 83 & 63.3 & 84.6 & 13 & 140 \\ 759075 & 46.7 & 49.6 & 14 & 89 & 75.9 & 97.8 & 12 & 146 \\ 518658 & 40.4 & 45.4 & 15 & 86 & 72.0 & 93.8 & 12 & 144 \\ \text { average } & 44.6 & 47.6 & 14 & 85 & \mathbf{7 1 . 3} & 93.5 & 12 & 143 \\ \text { stdev } & 5.9 & 4.2 & 1.0 & 4.5 & \mathbf{5 . 5} & 5.1 & 0.5 & 5.0 \\ \text { COV } & 13 \% & 9 \% & 7 \% & 5 \% & 8 \% & 6 \% & 4 \% & 3 \%\end{array}$


Synchro Coordinated System

\section{AM Peak}

SR 21

Delay/Veh TT Ave Speed Used

Total Network

$\begin{array}{cccc}\text { Delay/Veh } & \text { TT } & \begin{array}{c}\text { Ave } \\ \text { Speed }\end{array} & \begin{array}{c}\text { Fuel } \\ \text { Used }\end{array} \\ & & & \\ 52.3 & 44.5 & 15 & 95 \\ 50.1 & 44.5 & 15 & 106 \\ 45.2 & 40.8 & 16 & 92 \\ 49.2 & 43.5 & 16 & 103 \\ 56.5 & 57.9 & 15 & 105 \\ 46.2 & 42.8 & 16 & 91 \\ 48.8 & 44.7 & 16 & 109 \\ 47.5 & 42.4 & 16 & 106 \\ 60.6 & 46.5 & 14 & 101 \\ 53.0 & 46.9 & 15 & 110 \\ \mathbf{5 0 . 9} & 45.5 & 15 & 102 \\ \mathbf{4 . 8} & 4.7 & 0.7 & 6.8 \\ 9 \% & 10 \% & 5 \% & 7 \%\end{array}$

Synchro Coordinated System

Midday

SR 21

Total Network

$\begin{array}{llllll} & \text { Fuel } & \text { Ave } & \text { Fuel } \\ \text { Delay/Veh TT Ave Speed Used Delay/Veh TT Speed } & \text { Used }\end{array}$

$\begin{array}{ccccccccc}1 & 40.9 & 41.5 & 14 & 86 & 104.1 & 110.0 & 11 & 163 \\ 196707 & 40.3 & 41.1 & 14 & 87 & 71.7 & 85.3 & 12 & 151 \\ 862089 & 37.3 & 39.6 & 15 & 89 & 77.0 & 89.4 & 12 & 157 \\ 556682 & 39.1 & 41.1 & 15 & 87 & 69.8 & 85.6 & 12 & 153 \\ 437068 & 41.0 & 40.8 & 14 & 83 & 72.2 & 84.8 & 12 & 146 \\ 950495 & 36.0 & 37.9 & 15 & 77 & 64.8 & 80.3 & 13 & 142 \\ 689432 & 43.2 & 42.9 & 14 & 87 & 73.7 & 88.9 & 12 & 153 \\ 245122 & 43.6 & 43.1 & 14 & 87 & 71.0 & 85.2 & 12 & 153 \\ 759075 & 36.2 & 38.1 & 15 & 84 & 87.8 & 96.3 & 11 & 155 \\ 518658 & 36.6 & 39.8 & 15 & 84 & 68.3 & 85.4 & 12 & 146 \\ \text { average } & 39.4 & 40.6 & 15 & 85 & 76.0 & 89.1 & 12 & 152 \\ \text { stdev } & 2.8 & 1.8 & 0.5 & 3.4 & 11.6 & 8.4 & 0.6 & 6.0 \\ \text { COV } & 7 \% & 4 \% & 4 \% & 4 \% & 15 \% & 9 \% & 5 \% & 4 \%\end{array}$


Synchro Coordinated System

$$
\text { PM }
$$

SR 21

$\begin{array}{llllll} & \text { Fuel } & \text { Ave } & \text { Fuel } \\ \text { Delay/Veh TT Ave Speed Used Delay/Veh TT Speed Used }\end{array}$

$\begin{array}{ccccccccc}1 & 46.1 & 46.8 & 13 & 75 & 124.8 & 130.0 & 11 & 150 \\ 196707 & 54.9 & 54.0 & 12 & 81 & 144.3 & 147.9 & 9 & 164 \\ 862089 & 40.0 & 43.2 & 15 & 79 & 124.7 & 129.7 & 11 & 154 \\ 556682 & 44.4 & 49.0 & 14 & 82 & 147.9 & 153.3 & 11 & 167 \\ 437068 & 60.0 & 55.7 & 12 & 87 & 123.5 & 130.6 & 10 & 158 \\ 950495 & 79.0 & 69.5 & 10 & 90 & 149.0 & 151.1 & 9 & 163 \\ 689432 & 48.3 & 49.9 & 13 & 83 & 107.6 & 120.5 & 10 & 152 \\ 245122 & 49.0 & 48.3 & 13 & 83 & 114.6 & 120.9 & 11 & 154 \\ 759075 & 89.5 & 73.9 & 10 & 98 & 155.3 & 153.1 & 9 & 169 \\ 518658 & 64.9 & 59.7 & 12 & 90 & 114.0 & 123.8 & 10 & 154 \\ \text { average } & \mathbf{5 7 . 6} & 55.0 & 12 & 85 & \mathbf{1 3 0 . 6} & 136.1 & 10 & 158 \\ \text { stdev } & \mathbf{1 6 . 1} & 10.0 & 1.6 & 6.4 & \mathbf{1 7 . 0} & 13.7 & 0.9 & 6.8 \\ \text { COV } & 28 \% & 18 \% & 13 \% & 8 \% & 13 \% & 10 \% & 9 \% & 4 \%\end{array}$

Custom Coordinated

AM Peak

SR 21

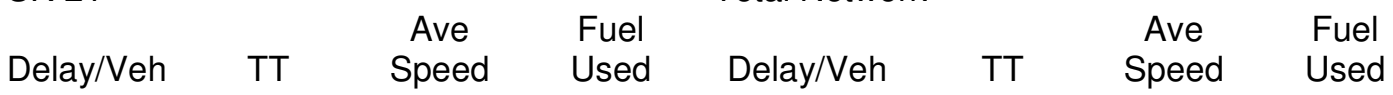

$\begin{array}{ccccccccc}1 & 24.5 & 20.9 & 19 & 53 & 46.2 & 42.1 & 16 & 90 \\ 196707 & 26.6 & 21.9 & 19 & 63 & 46.3 & 42.9 & 16 & 101 \\ 862089 & 25.0 & 20.5 & 19 & 55 & 42.3 & 39.6 & 17 & 91 \\ 556682 & 25.7 & 21.7 & 19 & 61 & 48.4 & 43.3 & 16 & 99 \\ 437068 & 29.6 & 24.2 & 18 & 60 & 51.7 & 46.0 & 15 & 100 \\ 950495 & 28.3 & 22.7 & 18 & 56 & 47.1 & 43.2 & 16 & 90 \\ 689432 & 22.8 & 21.1 & 20 & 63 & 42.7 & 42.1 & 17 & 102 \\ 245122 & 25.8 & 21.7 & 19 & 62 & 44.9 & 41.2 & 16 & 98 \\ 759075 & 27.2 & 21.5 & 19 & 58 & 45.3 & 40.3 & 16 & 94 \\ 518658 & 28.1 & 23.3 & 18 & 58 & 50.5 & 45.8 & 16 & 102 \\ \text { average } & \mathbf{2 6 . 4} & 22.0 & 19 & 59 & 46.5 & 42.7 & 16 & 97 \\ \text { stdev } & \mathbf{2 . 0} & 1.1 & 0.6 & 3.4 & 3.0 & 2.1 & 0.6 & 4.9 \\ \text { COV } & 8 \% & 5 \% & 3 \% & 6 \% & 7 \% & 5 \% & 4 \% & 5 \%\end{array}$


Custom Coordinated

Midday

SR 21

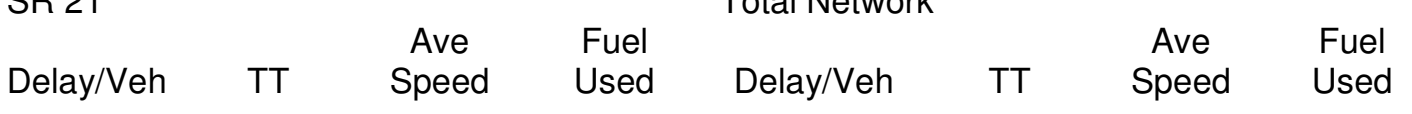

$\begin{array}{ccccccccc}1 & 48.0 & 46.2 & 13 & 91 & 86.1 & 98.3 & 11 & 160 \\ 196707 & 55.1 & 49.9 & 12 & 91 & 85.3 & 94.4 & 11 & 155 \\ 862089 & 42.2 & 42.4 & 14 & 90 & 75.7 & 88.4 & 12 & 157 \\ 556682 & 44.4 & 44.4 & 14 & 87 & 74.6 & 89.1 & 12 & 154 \\ 437068 & 45.3 & 43.5 & 13 & 83 & 76.3 & 88.1 & 12 & 146 \\ 950495 & 45.0 & 42.9 & 13 & 78 & 76.9 & 88.5 & 12 & 143 \\ 689432 & 46.8 & 45.2 & 13 & 88 & 78.2 & 92.2 & 11 & 154 \\ 245122 & 47.4 & 45.4 & 13 & 88 & 77.1 & 89.6 & 12 & 153 \\ 759075 & 44.2 & 43.0 & 14 & 87 & 74.3 & 87.8 & 12 & 153 \\ 518658 & 43.5 & 44.0 & 14 & 89 & 75.2 & 90.5 & 12 & 152 \\ \text { average } & 46.2 & 44.7 & 13 & 87 & 78.0 & 90.7 & 12 & 152 \\ \text { stdev } & 3.6 & 2.2 & 0.7 & 3.9 & 4.2 & 3.4 & 0.5 & 4.9 \\ \text { COV } & 8 \% & 5 \% & 5 \% & 4 \% & 5 \% & 4 \% & 4 \% & 3 \%\end{array}$

Custom Coordinated

PM

SR 21

Total Network

$\begin{array}{ccccccc}\text { Delay/Veh } & \text { AT } & \text { Ave } & \text { Fuel } & & \text { Ave } & \text { Fuel } \\ \text { Speed } & \text { Used Delay/Veh } & \text { TT } & \text { Speed } & \text { Used }\end{array}$

$\begin{array}{ccccccccc}1 & 61.7 & 56.4 & 11 & 80 & 103.9 & 116.7 & 10 & 145 \\ 196707 & 85.4 & 72.5 & 9 & 90 & 157.2 & 157.1 & 8 & 168 \\ 862089 & 59.8 & 55.2 & 12 & 85 & 106.5 & 117.8 & 10 & 148 \\ 556682 & 65.4 & 62.4 & 11 & 89 & 130.6 & 141.8 & 10 & 163 \\ 437068 & 71.7 & 62.9 & 10 & 91 & 102.9 & 116.2 & 10 & 153 \\ 950495 & 78.1 & 68.3 & 10 & 89 & 139.3 & 144.8 & 8 & 161 \\ 689432 & 71.3 & 64.0 & 10 & 90 & 109.0 & 122.6 & 9 & 153 \\ 245122 & 61.1 & 55.4 & 11 & 85 & 103.7 & 113.6 & 10 & 149 \\ 759075 & 113.1 & 87.0 & 9 & 101 & 157.7 & 155.3 & 9 & 168 \\ 518658 & 68.5 & 61.6 & 11 & 88 & 107.1 & 119.0 & 10 & 149 \\ \text { average } & \mathbf{7 3 . 6} & 64.6 & 10 & 89 & \mathbf{1 2 1 . 8} & 130.5 & 9 & 156 \\ \text { stdev } & \mathbf{1 6 . 0} & 9.6 & 1.0 & 5.6 & \mathbf{2 2 . 5} & 17.3 & 0.8 & 8.6 \\ \text { COV } & 22 \% & 15 \% & 9 \% & 6 \% & 18 \% & 13 \% & 9 \% & 5 \%\end{array}$


APPENDIX C - SYNCHRO SIGNAL TIMING OUTPUTS 


\section{Baseline - AM Peak}

Lanes, Volumes, Timings

12: SR 21 \& Daniel Drive

$2 / 14 / 2006$

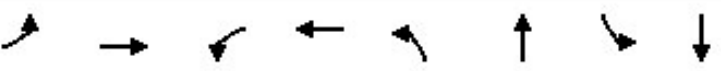

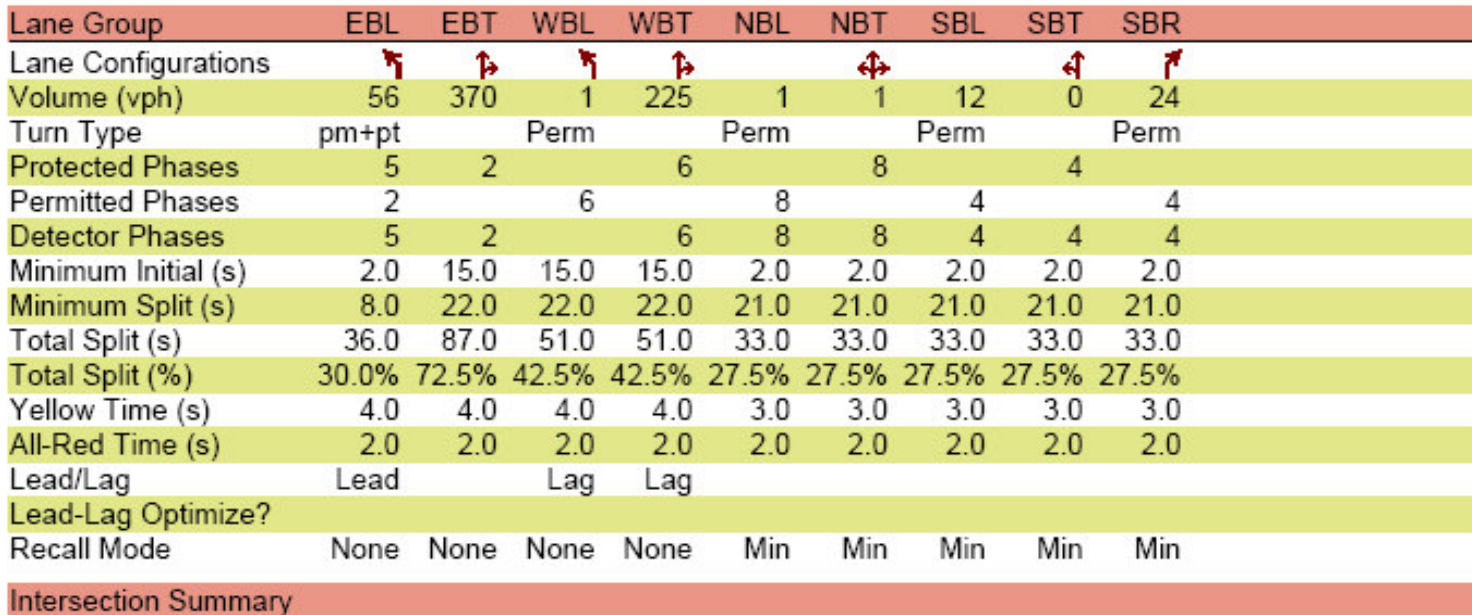

Cycle Length: 120

Actuated Cycle Length: 42

Natural Cycle: 55

Control Type: Actuated-Uncoordinated

Splits and Phases: 12: SR 21 \& Daniel Drive

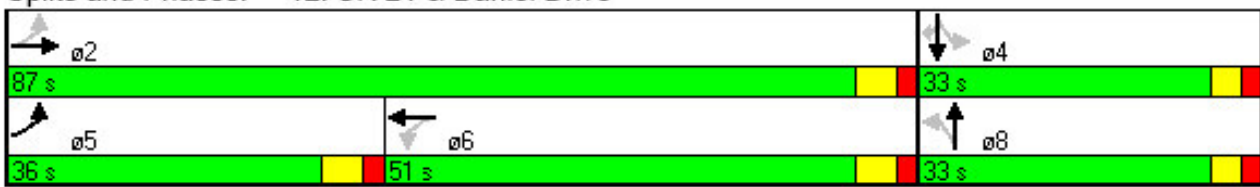


Lanes, Volumes, Timings

15: SR 21 \& Brewer

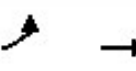

\begin{tabular}{|c|c|c|c|c|c|c|c|c|c|c|c|c|}
\hline Lane Group & EBL & EBT & WBL & WBT & NBL & NBT & NBR & SBL & SBT & $ø 1$ & ø3 & 05 \\
\hline Lane Configurations & K & $\hat{\omega}$ & 1 & $\uparrow$ & & $\uparrow$ & $\bar{r}$ & & $\$$ & & & \\
\hline Volume (vph) & 5 & 335 & 225 & 221 & 20 & 4 & 68 & 2 & 1 & & & \\
\hline Turn Type & Perm & & custom & & Perm & & custom & Perm & & & & \\
\hline Protected Phases & & 2 & 139 & 1239 & & 4 & 13 & & 4 & 1 & 3 & 5 \\
\hline Permitted Phases & 2 & & 3 & & 4 & & 4 & 4 & & & & \\
\hline Detector Phases & 2 & 2 & 139 & 9 & 4 & 4 & 13 & 4 & 4 & & & \\
\hline Minimum Initial (s) & 4.0 & 4.0 & & & 4.0 & 4.0 & & 4.0 & 4.0 & 4.0 & 4.0 & 4.0 \\
\hline Minimum Split (s) & 22.0 & 22.0 & & & 19.0 & 19.0 & & 19.0 & 19.0 & 10.0 & 10.0 & 10.0 \\
\hline Total Split (s) & 44.0 & 44.0 & 57.0 & 101.0 & 19.0 & 19.0 & 49.0 & 19.0 & 19.0 & 14.0 & 35.0 & 24.0 \\
\hline Total Split (\%) & $36.7 \%$ & $36.7 \%$ & $47.5 \%$ & $84.2 \%$ & $15.8 \%$ & $15.8 \%$ & $40.8 \%$ & $15.8 \%$ & $15.8 \%$ & $12 \%$ & $29 \%$ & $20 \%$ \\
\hline Yellow Time & 4.0 & 4.0 & & & 4.0 & 4.0 & & 4.0 & 4.0 & 4.0 & 4.0 & 4.0 \\
\hline All-Red Time (s) & 2.0 & 2.0 & & & 2.0 & 2.0 & & 2.0 & 2.0 & 2.0 & 2.0 & 2.0 \\
\hline Lead/Lag & Lag & Lag & & & Lag & Lag & & Lag & Lag & Lead & Lead & Lead \\
\hline Lead-Lag Opt & & & & & & & & & & & & Yes \\
\hline Recall Mode & None & None & & & Min & Min & & Min & Min & None & None & None \\
\hline
\end{tabular}

Intersection Summary

Cycle Length: 120

Actuated Cycle Length: 118

Natural Cycle: 100

Control Type: Actuated-Uncoordinated

Splits and Phases: 15: SR 21 \& Brewer

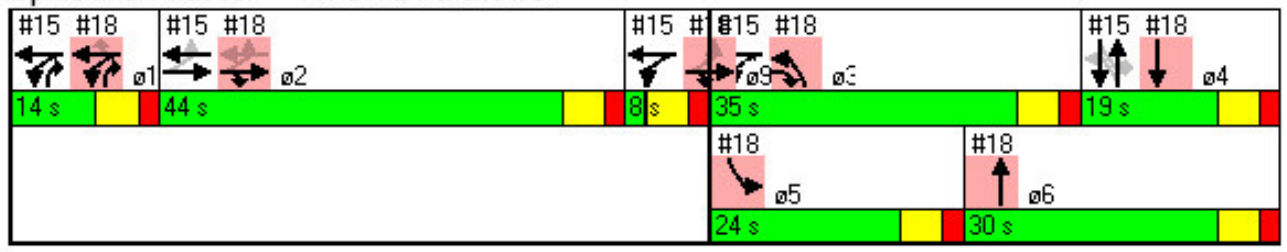


Lanes, Volumes, Timings

18: SR 21 \& Matthew

\section{$\Rightarrow \rightarrow>r \leftarrow<\uparrow \uparrow \uparrow \downarrow \downarrow$}

\begin{tabular}{|c|c|c|c|c|c|c|c|c|c|c|c|c|}
\hline ane Group & EBL & EBT & EBR & WBL & WBT & WBR & NBL & NBT & NBR & SBL & SBT & \\
\hline Lane Configurations & & $\uparrow$ & $\pi$ & 7 & $\uparrow$ & $\pi$ & * & $\uparrow$ & $\pi$ & 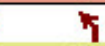 & 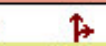 & \\
\hline Volume (vph) & 3 & 186 & 216 & 86 & 126 & 57 & 295 & 155 & 186 & 46 & 102 & \\
\hline Turn Type & Perm & & $\mathrm{pt}+\mathrm{ov}$ & Split & & Perm & Prot & & Over & Prot & & \\
\hline Protected Phases & & 29 & 239 & 1 & 1 & & 3 & 6 & 1 & 5 & 4 & \\
\hline Permitted Phases & 29 & & & & 2 & 1 & & & & & & \\
\hline Detector Phases & 9 & 9 & 9 & 1 & 1 & 1 & 3 & 6 & 1 & 5 & 4 & \\
\hline Minimum Initial (s & & & & 4.0 & 4.0 & 4.0 & 4.0 & 4.0 & 4.0 & 4.0 & 4.0 & \\
\hline Minimum Split (s) & & & & 10.0 & 10.0 & 10.0 & 10.0 & 22.0 & 10.0 & 10.0 & 19.0 & \\
\hline Total Split (s) & 52.0 & 52.0 & 87.0 & 14.0 & 14.0 & 14.0 & 35.0 & 30.0 & 14.0 & 24.0 & 19.0 & \\
\hline Total Split (\%) & $43.3 \%$ & $43.3 \%$ & $72.5 \%$ & $11.7 \%$ & $11.7 \%$ & $11.7 \%$ & $29.2 \%$ & $25.0 \%$ & $11.7 \%$ & $20.0 \%$ & $15.8 \%$ & \\
\hline Yellow Time (s) & & & & 4.0 & 4.0 & 4.0 & 4.0 & 4.0 & 4.0 & 4.0 & 4.0 & \\
\hline All-Red Time (s) & & & & 2.0 & 2.0 & 2.0 & 2.0 & 2.0 & 2.0 & 2.0 & 2.0 & \\
\hline Lead/Lag & & & & Lead & Lead & Lead & Lead & Lag & Lead & Lead & Lag & \\
\hline Lead-Lag Optimize? & & & & & & & & Yes & & Yes & & \\
\hline Recall Mode & & & & N & Nono & Ne & ne & Min & one & None & Min & \\
\hline
\end{tabular}

\section{Intersection Summary}

Cycle Length: 120

Actuated Cycle Length: 118

Natural Cycle: 100

Control Type: Actuated-Uncoordinated

Splits and Phases: 18: SR 21 \& Matthew

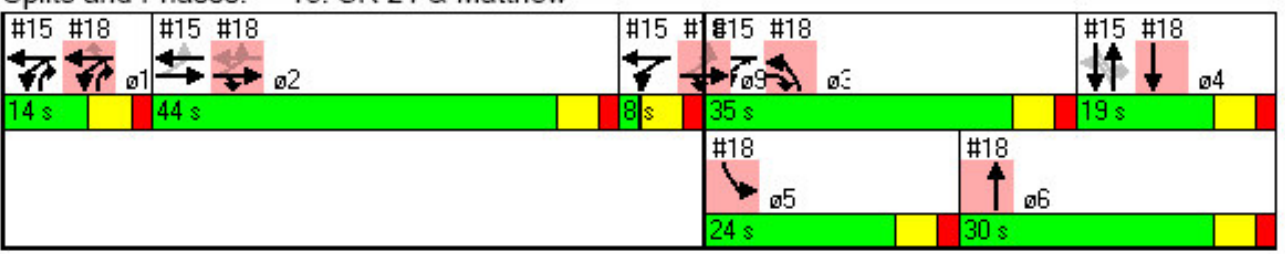




\begin{tabular}{|c|c|c|c|c|c|c|c|c|c|c|}
\hline Lane Group & EBL & EBT & WBL & WBT & NBL & NBT & NBR & SBL & SBT & SBR \\
\hline Lane Configurations & $\boldsymbol{1}$ & $\uparrow$ & 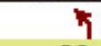 & $\uparrow$ & & $\uparrow$ & $\bar{t}$ & & $\uparrow$ & $\pi$ \\
\hline Volume (vph) & 80 & 319 & 20 & 176 & 16 & 7 & 13 & 70 & 5 & 77 \\
\hline Turn Type & $\mathrm{pm}+\mathrm{pt}$ & & $\mathrm{pm}+\mathrm{pt}$ & & Perm & & Perm & Perm & & Perm \\
\hline Protected Phases & 5 & 2 & 1 & 6 & & 8 & & & 4 & \\
\hline Permitted Phases & 2 & & 6 & & 8 & & 8 & 4 & & 4 \\
\hline Detector Phases & 5 & 2 & 1 & 6 & 8 & 8 & & 4 & 4 & \\
\hline Minimum Initial (s) & 4.0 & 4.0 & 4.0 & 4.0 & 4.0 & 4.0 & 4.0 & 4.0 & 4.0 & 4.0 \\
\hline Minimum Split (s) & 10.0 & 22.0 & 10.0 & 22.0 & 21.0 & 21.0 & 21.0 & 21.0 & 21.0 & 21.0 \\
\hline Total Split (s) & 20.0 & 52.0 & 20.0 & 52.0 & 48.0 & 48.0 & 48.0 & 48.0 & 48.0 & 48.0 \\
\hline Total Split (\%) & $16.7 \%$ & $43.3 \%$ & $16.7 \%$ & $43.3 \%$ & $40.0 \%$ & $40.0 \%$ & $40.0 \%$ & $40.0 \%$ & $40.0 \%$ & $40.0 \%$ \\
\hline Yellow Time (s) & 4.0 & 4.0 & 4.0 & 4.0 & 3.0 & 3.0 & 3.0 & 3.0 & 3.0 & 3.0 \\
\hline All-Red Time (s) & 2.0 & 2.0 & 2.0 & 2.0 & 2.0 & 2.0 & 2.0 & 2.0 & 2.0 & 2.0 \\
\hline Lead/Lag & Lead & Lag & Lead & Lag & & & & & & \\
\hline \multicolumn{11}{|l|}{ Lead-Lag Optimize? } \\
\hline Recall Mode & None & Min & None & Min & None & None & None & None & None & None \\
\hline \multicolumn{11}{|l|}{ Intersection Summary } \\
\hline \multicolumn{11}{|c|}{ Cycle Length: 120} \\
\hline \multicolumn{11}{|c|}{ Actuated Cycle Length: 69.9} \\
\hline \multicolumn{11}{|c|}{ Natural Cycle: 60} \\
\hline Control Type: Actuat & Uncooro & ate & & & & & & & & \\
\hline
\end{tabular}

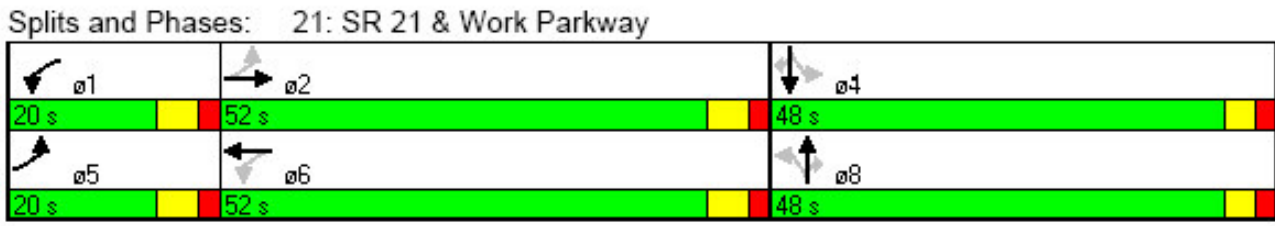


Lanes, Volumes, Timings

24: SR 21 \& Mall

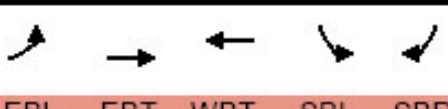

\begin{tabular}{|c|c|c|c|c|c|}
\hline Lane Group & EBL & EBT & WBT & SBL & SBR \\
\hline Lane Configurations & 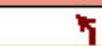 & $\uparrow$ & $\uparrow$ & 7 & $\bar{r}$ \\
\hline Volume (vph) & 92 & 310 & 240 & 53 & 37 \\
\hline Turn Type & $\mathrm{pm}+\mathrm{pt}$ & & & & Perm \\
\hline Protected Phases & 5 & 2 & 6 & 4 & \\
\hline Permitted Phases & 2 & & & & 4 \\
\hline Detector Phases & 5 & 2 & 6 & 4 & \\
\hline Minimum Initial (s) & 4.0 & 4.0 & 4.0 & 4.0 & 4.0 \\
\hline Minimum Split (s) & 9.0 & 22.0 & 22.0 & 21.0 & 21.0 \\
\hline Total Split (s) & 23.0 & 93.0 & 70.0 & 27.0 & 27.0 \\
\hline Total Split (\%) & $19.2 \%$ & $77.5 \%$ & $58.3 \%$ & $22.5 \%$ & $22.5 \%$ \\
\hline Yellow Time (s) & 3.0 & 4.0 & 4.0 & 3.0 & 3.0 \\
\hline All-Red Time (s) & 2.0 & 2.0 & 2.0 & 2.0 & 2.0 \\
\hline Lead/Lag & Lead & & Lag & & \\
\hline Lead-Lag Optimize? & Yes & & Yes & & \\
\hline Recall Mode & None & Min & Min & None & None \\
\hline
\end{tabular}

Intersection Summary

Cycle Length: 120

Actuated Cycle Length: 68.7

Natural Cycle: 60

Control Type: Actuated-Uncoordinated

Splits and Phases: 24: SR 21 \& Mall

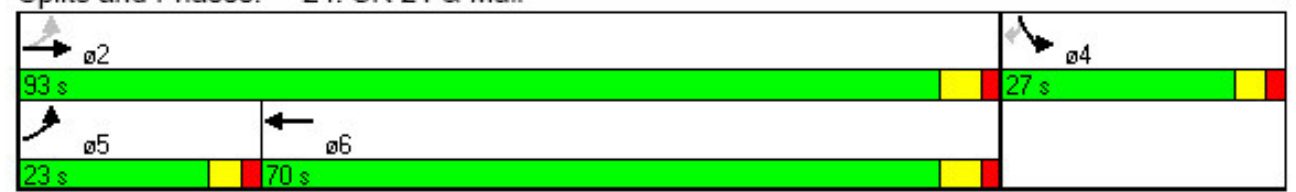




\section{Baseline - Midday Peak}

\begin{tabular}{|c|c|c|c|c|c|c|c|c|c|}
\hline Lane Group & EBL & EBT & WBL & WBT & NBL & NBT & SBL & SBT & SBR \\
\hline Lane Configurations & 4 & $\hat{b}$ & 4 & $\uparrow$ & & $\$$ & & $\uparrow$ & $\pi$ \\
\hline Volume (vph) & 89 & 319 & 1 & 267 & 1 & 1 & 122 & 0 & 39 \\
\hline Turn Type & $\mathrm{pm}+\mathrm{pt}$ & & Perm & & Perm & & Perm & & Perm \\
\hline Protected Phases & 5 & 2 & & 6 & & 8 & & 4 & \\
\hline Permitted Phases & 2 & & 6 & & 8 & & 4 & & 4 \\
\hline Detector Phases & 5 & 2 & & 6 & 8 & 8 & 4 & 4 & 4 \\
\hline Minimum Initial (s) & 2.0 & 15.0 & 15.0 & 15.0 & 2.0 & 2.0 & 2.0 & 2.0 & 2.0 \\
\hline Minimum Split (s) & 8.0 & 22.0 & 22.0 & 22.0 & 21.0 & 21.0 & 21.0 & 21.0 & 21.0 \\
\hline Total Split (s) & 36.0 & 87.0 & 51.0 & 51.0 & 33.0 & 33.0 & 33.0 & 33.0 & 33.0 \\
\hline Total Split (\%) & $30.0 \%$ & $72.5 \%$ & $42.5 \%$ & $42.5 \%$ & $27.5 \%$ & $27.5 \%$ & $27.5 \%$ & $27.5 \%$ & $27.5 \%$ \\
\hline Yellow Time (s) & 4.0 & 4.0 & 4.0 & 4.0 & 3.0 & 3.0 & 3.0 & 3.0 & 3.0 \\
\hline All-Red Time (s) & 2.0 & 2.0 & 2.0 & 2.0 & 2.0 & 2.0 & 2.0 & 2.0 & 2.0 \\
\hline Lead/Lag & Lead & & Lag & Lag & & & & & \\
\hline \multicolumn{10}{|l|}{ Lead-Lag Optimize? } \\
\hline Recall Mode & None & None & None & None & Min & Min & Min & Min & Min \\
\hline \multicolumn{10}{|l|}{ Intersection Summary } \\
\hline \multicolumn{10}{|l|}{ Cycle Length: 120} \\
\hline \multicolumn{10}{|c|}{ Actuated Cycle Length: 59.6} \\
\hline \multicolumn{10}{|c|}{ Natural Cycle: 60} \\
\hline \multicolumn{10}{|c|}{ Control Type: Actuated-Uncoordinated } \\
\hline
\end{tabular}

Splits and Phases: 12: SR 21 \& Daniel Drive

\begin{tabular}{|c|c|c|}
\hline$\rightarrow \curvearrowleft 2$ & & 104 \\
\hline $87 \mathrm{~s}$ & & $33 s$ \\
\hline$>_{05}$ & $\sqrt{66}$ & $1_{08}$ \\
\hline
\end{tabular}


Lanes, Volumes, Timings

15: SR 21 \& Brewer

\section{$\rightarrow \rightarrow \leftarrow+\uparrow+\downarrow$}

\begin{tabular}{|c|c|c|c|c|c|c|c|c|c|c|c|c|}
\hline Lane Group & EBL & EBT & WBL & WBT & NBL & NBT & NBR & SBL & SBT & $ø 1$ & $ø 3$ & $₫ 5$ \\
\hline Lane Configurations & 5 & $\hat{\beta}$ & 7 & $\hat{\theta}$ & & $\uparrow$ & $\bar{t}$ & & $\$$ & & & \\
\hline Volume (vph) & 5 & 326 & 134 & 298 & 36 & 9 & 167 & 7 & 6 & & & \\
\hline Turn Type & Perm & & custom & & Perm & & custom & Perm & & & & \\
\hline Protected Phases & & 2 & 139 & 1239 & & 4 & 13 & & 4 & 1 & 3 & 5 \\
\hline Permitted Phases & 2 & & 3 & & 4 & & 4 & 4 & & & & \\
\hline Detector Phases & 2 & 2 & 139 & 9 & 4 & 4 & 13 & 4 & 4 & & & \\
\hline Minimum Initial (s) & 4.0 & 4.0 & & & 4.0 & 4.0 & & 4.0 & 4.0 & 4.0 & 4.0 & 4.0 \\
\hline Minimum Split (s) & 22.0 & 22.0 & & & 22.0 & 22.0 & & 22.0 & 22.0 & 10.0 & 10.0 & 10.0 \\
\hline Total Split (s) & 66.0 & 66.0 & 94.0 & 160.0 & 50.0 & 50.0 & 86.0 & 50.0 & 50.0 & 41.0 & 45.0 & 29.0 \\
\hline Total Split (\%) & $31.4 \%$ & $31.4 \%$ & $44.8 \%$ & $76.2 \%$ & $23.8 \%$ & $23.8 \%$ & $41.0 \%$ & $23.8 \%$ & $23.8 \%$ & $20 \%$ & $21 \%$ & $14 \%$ \\
\hline Yellow Time (s) & 4.0 & 4.0 & & & 4.0 & 4.0 & & 4.0 & 4.0 & 4.0 & 4.0 & 4.0 \\
\hline All-Red Time (s) & 2.0 & 2.0 & & & 2.0 & 2.0 & & 2.0 & 2.0 & 2.0 & 2.0 & 2.0 \\
\hline Lead/Lag & Lag & Lag & & & Lag & Lag & & Lag & Lag & Lead & Lead & Lead \\
\hline Lead-Lag & & & & & & & & & & & & Yes \\
\hline Recall Mode & None & None & & & Min & Min & & Min & Min & None & None & None \\
\hline
\end{tabular}

Intersection Summary

Cycle Length: 210

Actuated Cycle Length: 207.9

Natural Cycle: 140

Control Type: Actuated-Uncoordinated

Splits and Phases: 15: SR 21 \& Brewer

\begin{tabular}{|c|c|c|c|}
\hline$\# 15 \# 18$ & $\# 15 \# 18$ & $\# 19$ \#BB $\# 18$ & $\begin{array}{l}\# 15 \# 18 \\
11\end{array}$ \\
\hline $41 \mathrm{~s}$ & $66 s$ & \begin{tabular}{l|l|l|l|}
$8 s$ & $45 s$ \\
\end{tabular} & $50 \mathrm{~s}$ \\
\hline
\end{tabular}




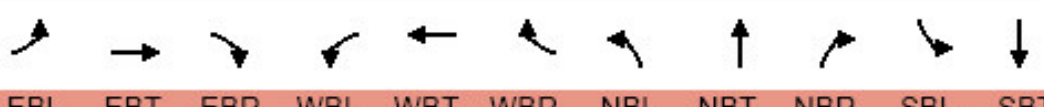

\begin{tabular}{|c|c|c|c|c|c|c|c|c|c|c|c|c|}
\hline Lane Group & EBL & EBT & EBR & WBL & WBT & WBR & NBL & NBT & NBR & SBL & SBT & $\emptyset 2$ \\
\hline Lane Configurations & & $\uparrow$ & $\pi$ & 7 & $\uparrow$ & $\pi$ & 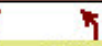 & $\uparrow$ & $\bar{t}$ & 1 & $\$$ & \\
\hline Volume (vph) & 15 & 261 & 224 & $190^{\circ}$ & 213 & 154 & 200 & 253 & 259 & 144 & 243 & \\
\hline Turn Type & Perm & & pt+ov & Split & & Perm & Prot & & Over & Prot & & \\
\hline Protected Phases & & 29 & 239 & 1 & 1 & & 3 & 6 & 1 & 5 & 4 & 2 \\
\hline Permitted Phases & 29 & & & & 2 & 1 & & & & & & \\
\hline Detector Phases & 9 & 9 & 9 & 1 & 1 & 1 & 3 & 6 & 1 & 5 & 4 & \\
\hline Minimum Initial (s) & & & & 4.0 & 4.0 & 4.0 & 4.0 & 4.0 & 4.0 & 4.0 & 4.0 & 4.0 \\
\hline Minimum Split (s) & & & & 10.0 & 10.0 & 10.0 & 10.0 & 22.0 & 10.0 & 10.0 & 22.0 & 22.0 \\
\hline Total Split (s) & 74.0 & 74.0 & 119.0 & 41.0 & 41.0 & 41.0 & 45.0 & 66.0 & 41.0 & 29.0 & 50.0 & 66.0 \\
\hline Total Split (\%) & $35.2 \%$ & $35.2 \%$ & $56.7 \%$ & $19.5 \%$ & $19.5 \%$ & $19.5 \%$ & $21.4 \%$ & $31.4 \%$ & $19.5 \%$ & $13.8 \%$ & $23.8 \%$ & $31 \%$ \\
\hline Yellow Time (s) & & & & 4.0 & 4.0 & 4.0 & 4.0 & 4.0 & 4.0 & 4.0 & 4.0 & 4.0 \\
\hline All-Red Time (s) & & & & 2.0 & 2.0 & 2.0 & 2.0 & 2.0 & 2.0 & 2.0 & 2.0 & 2.0 \\
\hline Lead/Lag & & & & Lead & Lead & Lead & Lead & Lag & Lead & Lead & Lag & Lag \\
\hline Lead-Lag Optimize? & & & & & & & & Yes & & Yes & & \\
\hline Recall Mode & & & & None & None & None & None & Min & None & None & Min & None \\
\hline \multicolumn{13}{|l|}{ Intersection Summary } \\
\hline \multicolumn{13}{|l|}{ Cycle Length: 210} \\
\hline \multicolumn{13}{|c|}{ Actuated Cycle Length: 207.9} \\
\hline Natural Cycle: 140 & & & & & & & & & & & & \\
\hline
\end{tabular}

Splits and Phases: 18: SR 21 \& Matthew

\begin{tabular}{|c|c|c|c|c|}
\hline $\begin{array}{ll}\# 15 & \# 18 \\
7 / 7 & 01\end{array}$ & $\begin{array}{l}\# 15 \text { \#18 } \\
\longrightarrow \div-2\end{array}$ & 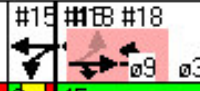 & & $\begin{array}{ll}\# 15 & \# 18 \\
11 & 1\end{array}$ \\
\hline 41 s & $66 s$ & Bs $45 \mathrm{~s}$ & & $50 \mathrm{~s}$ \\
\hline & & & $\begin{array}{r}\# 18 \\
4\end{array}$ & \\
\hline
\end{tabular}




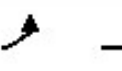

Lane Group
Lane Configurations
Volume (vph)

Turn Type

Protected Phases

Permitted Phases

Detector Phases

Minimum Initial (s)

Minimum Split (s)

Total Split (s)

Total Split (\%)

EBL EBT WBL WBT NBL NBT NBR SBL SBT SBR

Yellow Time (s)

All-Red Time (s)

Lead/Lag

Lead-Lag Optimize?

Recall Mode

192369

t)

\% 305

$\mathrm{pm}+\mathrm{pt}$

305

5

5

$2 \quad 1 \quad 6$

Perm

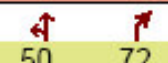

$\begin{array}{rr}2 & \\ 2 & 150 \\ & \text { Perm }\end{array}$

$\begin{array}{rr}\uparrow & \boldsymbol{r} \\ 41 & 173 \\ & \text { Perm }\end{array}$

$\begin{array}{rrrrrrrrrr}5 & 2 & 1 & 6 & 8 & 8 & & 4 & 4 & \\ 4.0 & 4.0 & 4.0 & 4.0 & 4.0 & 4.0 & 4.0 & 4.0 & 4.0 & 4.0\end{array}$

$\begin{array}{llllllllll}10.0 & 22.0 & 10.0 & 22.0 & 21.0 & 21.0 & 21.0 & 21.0 & 21.0 & 21.0\end{array}$

$\begin{array}{llllllllll}20.0 & 52.0 & 20.0 & 52.0 & 48.0 & 48.0 & 48.0 & 48.0 & 48.0 & 48.0\end{array}$

$\begin{array}{rrrrrrrrrr}20.0 & 52.0 & 20.0 & 52.0 & 48.0 & 48.0 & 48.0 & 48.0 & 48.0 & 48.0\end{array}$

Intersection Summary

Cycle Length: 120

Actuated Cycle Length: 95.5

Natural Cycle: 75

Control Type: Actuated-Uncoordinated

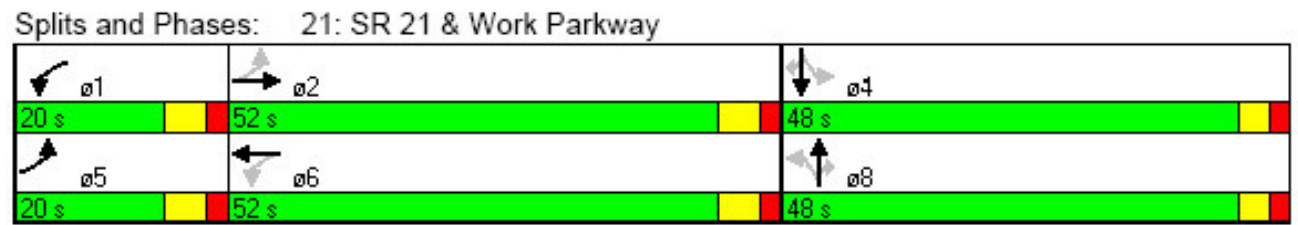




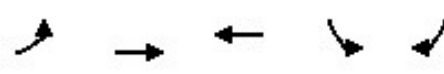

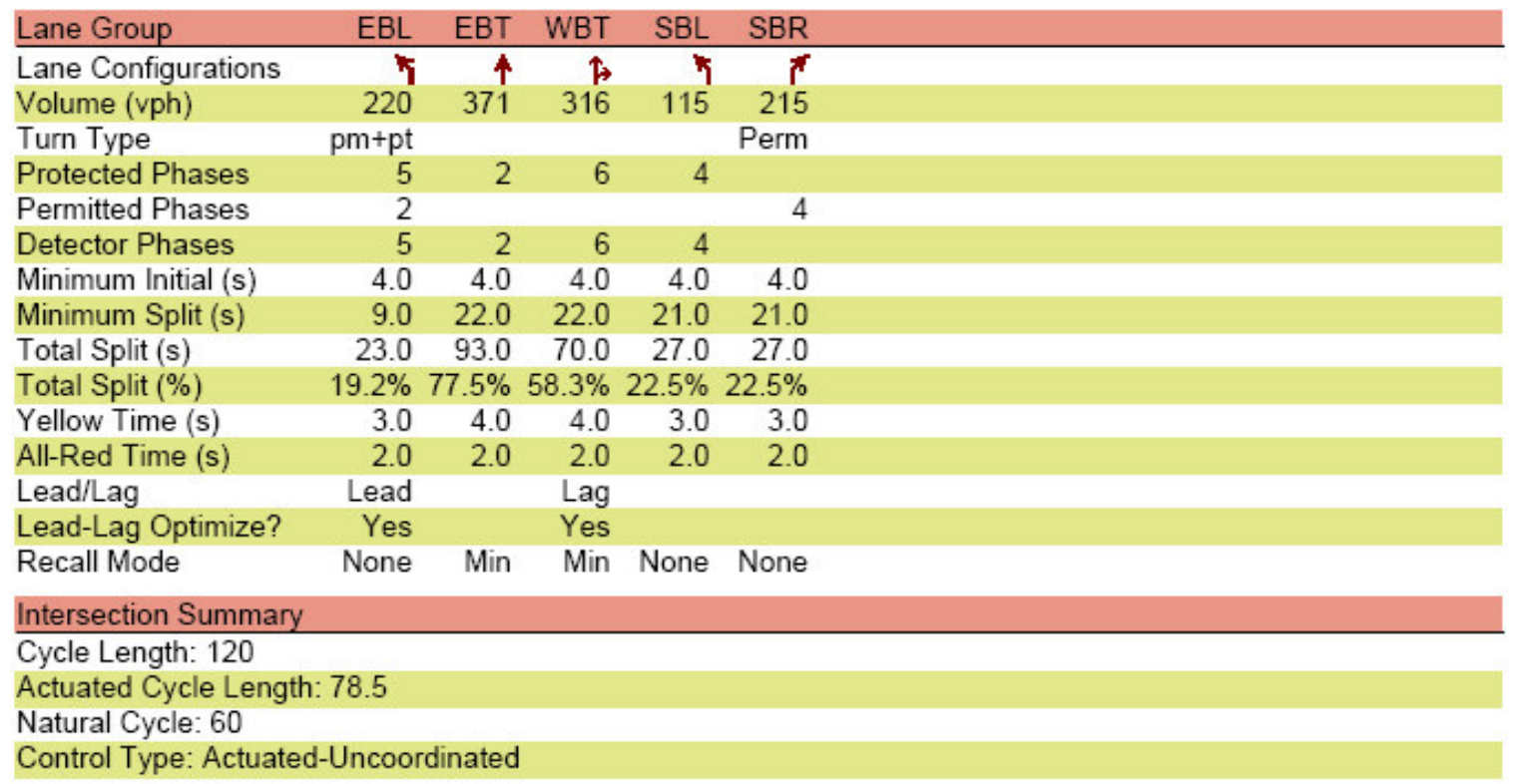

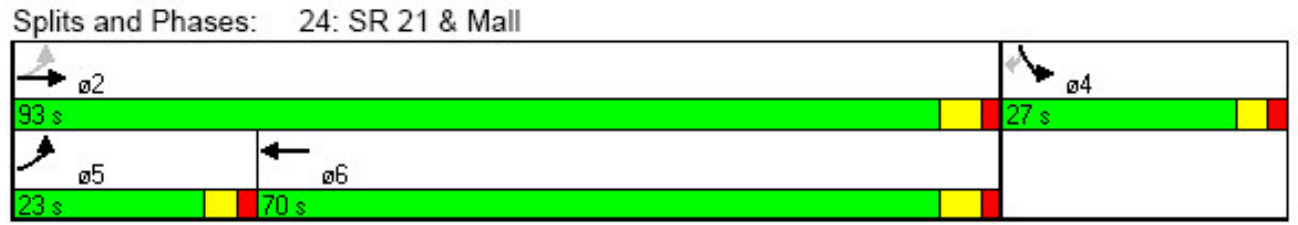


Lanes, Volumes, Timings

Baseline - PM Peak

12: SR 21 \& Daniel Drive

\begin{tabular}{|c|c|c|c|c|c|c|c|c|c|}
\hline Lane Group & EBL & EBT & WBL & WBT & NBL & NBT & SBL & SBT & SBR \\
\hline Lane Configurations & 1 & $\hat{t}$ & 7 & $\uparrow$ & & $\$$ & & $\uparrow$ & $\pi$ \\
\hline Volume (vph) & 111 & 387 & 1 & 457 & 1 & 1 & 31 & 0 & 147 \\
\hline Turn Type & $\mathrm{pm}+\mathrm{pt}$ & & Perm & & Perm & & Perm & & Perm \\
\hline Protected Phases & 5 & 2 & & 6 & & 8 & & 4 & \\
\hline Permitted Phases & 2 & & 6 & & 8 & & 4 & & 4 \\
\hline Detector Phases & 5 & 2 & & 6 & 8 & 8 & 4 & 4 & 4 \\
\hline Minimum Initial (s) & 2.0 & 15.0 & 15.0 & 15.0 & 2.0 & 2.0 & 2.0 & 2.0 & 2.0 \\
\hline Minimum Split (s) & 8.0 & 22.0 & 22.0 & 22.0 & 21.0 & 21.0 & 21.0 & 21.0 & 21.0 \\
\hline Total Split (s) & 36.0 & 87.0 & 51.0 & 51.0 & 33.0 & 33.0 & 33.0 & 33.0 & 33.0 \\
\hline Total Split (\%) & $30.0 \%$ & $72.5 \%$ & $42.5 \%$ & $42.5 \%$ & $27.5 \%$ & $27.5 \%$ & $27.5 \%$ & $27.5 \%$ & $27.5 \%$ \\
\hline Yellow Time (s) & 4.0 & 4.0 & 4.0 & 4.0 & 3.0 & 3.0 & 3.0 & 3.0 & 3.0 \\
\hline All-Red Time (s) & 2.0 & 2.0 & 2.0 & 2.0 & 2.0 & 2.0 & 2.0 & 2.0 & 2.0 \\
\hline Lead/Lag & Lead & & Lag & Lag & & & & & \\
\hline \multicolumn{10}{|l|}{ Lead-Lag Optimize? } \\
\hline Recall Mode & None & None & None & None & Min & Min & Min & Min & Min \\
\hline \multicolumn{10}{|l|}{ Intersection Summary } \\
\hline \multicolumn{10}{|l|}{ Cycle Length: 120} \\
\hline \multicolumn{10}{|c|}{ Actuated Cycle Length: 81.8} \\
\hline \multicolumn{10}{|l|}{ Natural Cycle: 60} \\
\hline \multicolumn{10}{|c|}{ Control Type: Actuated-Uncoordinated } \\
\hline
\end{tabular}

Splits and Phases: 12: SR 21 \& Daniel Drive

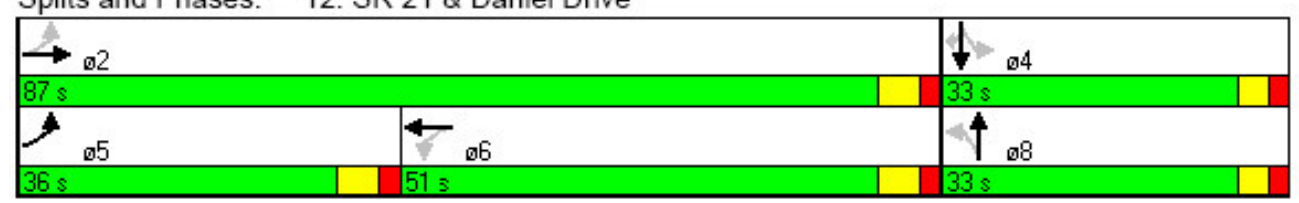




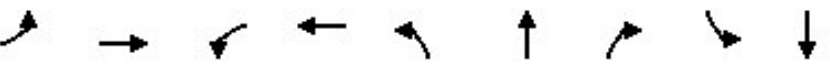

\begin{tabular}{|c|c|c|c|c|c|c|c|c|c|c|c|c|}
\hline Lane Group & EBL & EBT & WBL & WBT & NBL & NBT & NBR & SBL & SBT & $ø 1$ & 03 & 05 \\
\hline Lane Configurations & 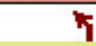 & $\uparrow$ & 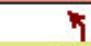 & $\uparrow$ & & $\uparrow$ & $\bar{r}$ & & $\uparrow$ & & & \\
\hline Volume (vph) & 6 & 397 & 92 & 450 & 52 & 3 & 165 & 16 & 2 & & & \\
\hline Turn Type & Perm & & custom & & Perm & & custom & Perm & & & & \\
\hline Protected Phases & & 2 & 139 & 1239 & & 4 & 13 & & 4 & 1 & 3 & 5 \\
\hline Permitted Phases & 2 & & 3 & & 4 & & 4 & 4 & & & & \\
\hline Detector Phases & 2 & 2 & 139 & 9 & 4 & 4 & 13 & 4 & 4 & & & \\
\hline Minimum Initial (s) & 4.0 & 4.0 & & & 4.0 & 4.0 & & 4.0 & 4.0 & 4.0 & 4.0 & 4.0 \\
\hline Minimum Split (s) & 22.0 & 22.0 & & & 22.0 & 22.0 & & 22.0 & 22.0 & 10.0 & 10.0 & 10.0 \\
\hline Total Split (s) & 58.0 & 58.0 & 93.0 & 151.0 & 58.0 & 58.0 & 86.0 & 58.0 & 58.0 & 36.0 & 50.0 & 37.0 \\
\hline Total Split (\%) & $27.8 \%$ & $27.8 \%$ & $44.5 \%$ & $72.2 \%$ & $27.8 \%$ & $27.8 \%$ & $41.1 \%$ & $27.8 \%$ & $27.8 \%$ & $17 \%$ & $24 \%$ & $18 \%$ \\
\hline Yellow Time (s) & 4.0 & 4.0 & & & 4.0 & 4.0 & & 4.0 & 4.0 & 4.0 & 4.0 & 4.0 \\
\hline All-Red Time (s) & 2.0 & 2.0 & & & 2.0 & 2.0 & & 2.0 & 2.0 & 2.0 & 2.0 & 2.0 \\
\hline Lead/Lag & Lag & Lag & & & Lag & Lag & & Lag & Lag & Lead & Lead & Lead \\
\hline Lead-Lag Optimize? & & & & & & & & & & & & Yes \\
\hline Recall Mode & None & None & & & Min & Min & & Min & Min & None & None & None \\
\hline
\end{tabular}

Cycle Length: 209

Actuated Cycle Length: 209

Natural Cycle: 150

Control Type: Actuated-Uncoordinated

Splits and Phases: 15: SR 21 \& Brewer

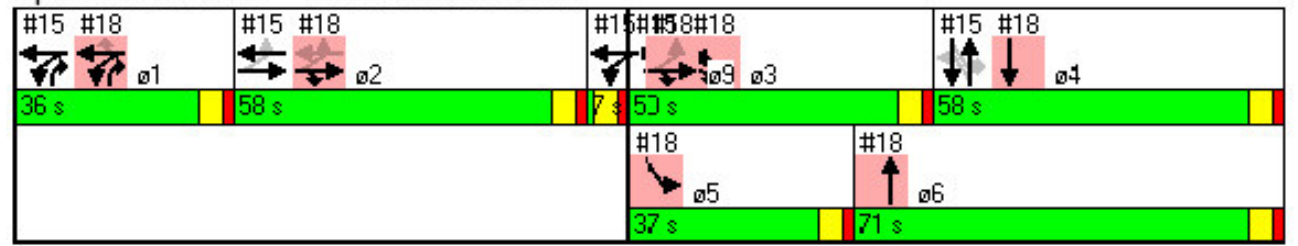


Lanes, Volumes, Timings

18: SR 21 \& Matthew

\section{$\rightarrow \rightarrow+\leftarrow \leftarrow \uparrow+\downarrow$}

\begin{tabular}{|c|c|c|c|c|c|c|c|c|c|c|c|c|}
\hline ane Group & EBL & EBT & EBR & WBL & WBT & WBR & NBL & NBT & NBR & SBL & SBT & \\
\hline Lane Configurations & & $\uparrow$ & $\pi$ & $\hbar$ & $\uparrow$ & $\pi$ & 7 & $\uparrow$ & $\pi$ & ${ }_{1}$ & $\hat{F}$ & \\
\hline Volume (vph) & 6 & 254 & 318 & 247 & 222 & 150 & 305 & 268 & 243 & 147 & 318 & \\
\hline Turn Type & Perm & & $\mathrm{pt+ov}$ & Split & & Perm & Prot & & Over & Prot & & \\
\hline Protected Phases & & 29 & 239 & 1 & 1 & & 3 & 6 & 1 & 5 & 4 & \\
\hline Permitted Phases & 29 & & & & 2 & 1 & & & & & & \\
\hline Detector Phases & 9 & 9 & 9 & 1 & 1 & 1 & 3 & 6 & 1 & 5 & 4 & \\
\hline Minimum Initial (s) & & & & 4.0 & 4.0 & 4.0 & 4.0 & 4.0 & 4.0 & 4.0 & 4.0 & \\
\hline Minimum Split (s) & & & & 10.0 & 10.0 & 10.0 & 10.0 & 22.0 & 10.0 & 10.0 & 22.0 & \\
\hline Tota & 65.0 & 65.0 & 115.0 & 36.0 & 36.0 & 36.0 & 50.0 & 71.0 & 36.0 & 37.0 & 58.0 & \\
\hline Total Split (\%) & $31.1 \%$ & $31.1 \%$ & $55.0 \%$ & $17.2 \%$ & $17.2 \%$ & $17.2 \%$ & $23.9 \%$ & $34.0 \%$ & $17.2 \%$ & $17.7 \%$ & $27.8 \%$ & \\
\hline Yellc & & & & 4.0 & 4.0 & 4.0 & 4.0 & 4.0 & 4.0 & 4.0 & 4.0 & \\
\hline All-Red Time & & & & 2.0 & 2.0 & 2.0 & 2.0 & 2.0 & 2.0 & 2.0 & 2.0 & \\
\hline Lead/Lag & & & & Lead & Lead & Lead & Lead & Lag & Lead & Lead & Lag & \\
\hline Leac & & & & & & & & Yes & & Yes & & \\
\hline Recall Mode & & & & None & one & one & Ione & Min & None & None & Min & \\
\hline
\end{tabular}

Intersection Summary

Cycle Length: 209

Actuated Cycle Length: 209

Natural Cycle: 150

Control Type: Actuated-Uncoordinated

Splits and Phases: 18: SR 21 \& Matthew

\begin{tabular}{|c|c|c|c|}
\hline$\frac{15}{718}$ & 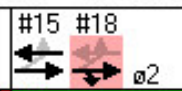 & 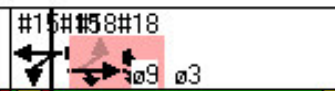 & $\begin{array}{ll}\# 15 & \# 18 \\
11 & 1\end{array}$ \\
\hline $36 s$ & $58 \mathrm{~s}$ & 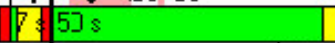 & $58 \mathrm{~s}$ \\
\hline
\end{tabular}




\begin{tabular}{|c|c|c|c|c|c|c|c|c|c|c|}
\hline Lane Group & EBL & EBT & WBL & WBT & NBL & NBT & NBR & SBL & SBT & SBR \\
\hline Lane Configurations & 5 & 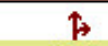 & 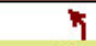 & $\uparrow$ & & $\uparrow$ & $\pi$ & & $\uparrow$ & $\pi$ \\
\hline Volume (vph) & 167 & 402 & 56 & 359 & 91 & 44 & 76 & 128 & 23 & 169 \\
\hline Turn Type & $\mathrm{pm}+\mathrm{pt}$ & & $\mathrm{pm}+\mathrm{pt}$ & & Perm & & Perm & Perm & & Perm \\
\hline Protected Phases & 5 & 2 & 1 & 6 & & 8 & & & 4 & \\
\hline Permitted Phases & 2 & & 6 & & 8 & & 8 & 4 & & 4 \\
\hline Detector Phases & 5 & 2 & 1 & 6 & 8 & 8 & & 4 & 4 & \\
\hline Minimum Initial (s) & 4.0 & 4.0 & 4.0 & 4.0 & 4.0 & 4.0 & 4.0 & 4.0 & 4.0 & 4.0 \\
\hline Minimum Split (s) & 10.0 & 22.0 & 10.0 & 22.0 & 21.0 & 21.0 & 21.0 & 21.0 & 21.0 & 21.0 \\
\hline Total Split (s) & 20.0 & 52.0 & 20.0 & 52.0 & 48.0 & 48.0 & 48.0 & 48.0 & 48.0 & 48.0 \\
\hline Total Split (\%) & $16.7 \%$ & $43.3 \%$ & $16.7 \%$ & $43.3 \%$ & $40.0 \%$ & $40.0 \%$ & $40.0 \%$ & $40.0 \%$ & $40.0 \%$ & $40.0 \%$ \\
\hline Yellow Time (s) & 4.0 & 4.0 & 4.0 & 4.0 & 3.0 & 3.0 & 3.0 & 3.0 & 3.0 & 3.0 \\
\hline All-Red Time (s) & 2.0 & 2.0 & 2.0 & 2.0 & 2.0 & 2.0 & 2.0 & 2.0 & 2.0 & 2.0 \\
\hline Lead/Lag & Lead & Lag & Lead & Lag & & & & & & \\
\hline \multicolumn{11}{|l|}{ Lead-Lag Optimize? } \\
\hline Recall Mode & None & Min & None & Min & None & None & None & None & None & None \\
\hline \multicolumn{11}{|l|}{ Intersection Summary } \\
\hline \multicolumn{11}{|l|}{ Cycle Length: 120} \\
\hline \multicolumn{11}{|c|}{ Actuated Cycle Length: 93.3} \\
\hline \multirow{2}{*}{\multicolumn{11}{|c|}{$\begin{array}{l}\text { Natural Cycle: } 60 \\
\text { Control Type: Actuat }\end{array}$}} \\
\hline & & & & & & & & & & \\
\hline
\end{tabular}

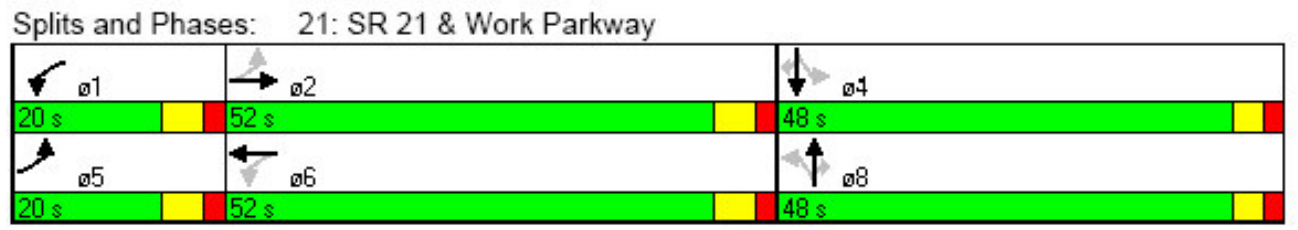




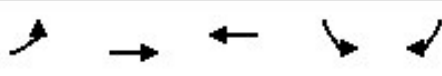

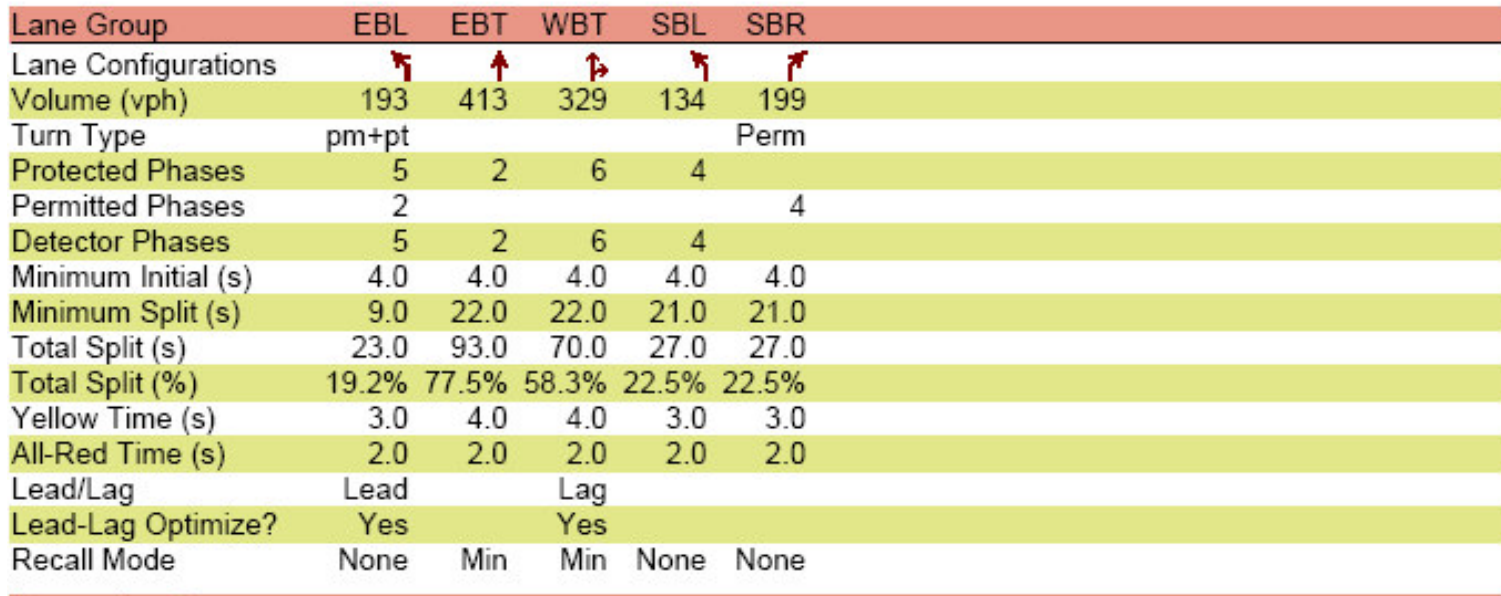

Intersection Summary

Cycle Length: 120

Actuated Cycle Length: 81.8

Natural Cycle: 60

Control Type: Actuated-Uncoordinated

Splits and Phases: 24: SR 21 \& Mall

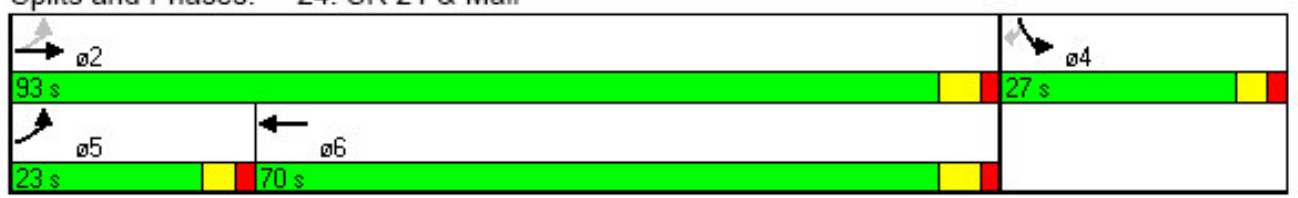


Lanes, Volumes, Timings

Phasing Change - AM Peak

\begin{tabular}{|c|c|c|c|c|c|c|c|c|c|}
\hline Lane Group & EBL & EBT & WBL & WBT & NBL & NBT & SBL & SBT & SBR \\
\hline Lane Configurations & $\mathbf{y}$ & $\hat{F}$ & \% & $\uparrow$ & & $\leftrightarrow$ & & $\uparrow$ & $\pi$ \\
\hline Volume (vph) & 56 & 370 & 1 & 225 & 1 & 1 & 12 & 0 & 24 \\
\hline Turn Type & $\mathrm{pm}+\mathrm{pt}$ & & Perm & & Perm & & Perm & & Perm \\
\hline Protected Phases & 5 & 2 & & 6 & & 8 & & 4 & \\
\hline Permitted Phases & 2 & & 6 & & 8 & & 4 & & 4 \\
\hline Detector Phases & 5 & 2 & & 6 & 8 & 8 & 4 & 4 & 4 \\
\hline Minimum Initial (s) & 2.0 & 15.0 & 15.0 & 15.0 & 2.0 & 2.0 & 2.0 & 2.0 & 2.0 \\
\hline Minimum Split (s) & 8.0 & 22.0 & 22.0 & 22.0 & 21.0 & 21.0 & 21.0 & 21.0 & 21.0 \\
\hline Total Split (s) & 36.0 & 87.0 & 51.0 & 51.0 & 33.0 & 33.0 & 33.0 & 33.0 & 33.0 \\
\hline Total Split (\%) & $30.0 \%$ & $72.5 \%$ & $42.5 \%$ & $42.5 \%$ & $27.5 \%$ & $27.5 \%$ & $27.5 \%$ & $27.5 \%$ & $27.5 \%$ \\
\hline Yellow Time (s) & 4.0 & 4.0 & 4.0 & 4.0 & 3.0 & 3.0 & 3.0 & 3.0 & 3.0 \\
\hline All-Red Time (s) & 2.0 & 2.0 & 2.0 & 2.0 & 2.0 & 2.0 & 2.0 & 2.0 & 2.0 \\
\hline Lead/Lag & Lead & & Lag & Lag & & & & & \\
\hline \multicolumn{10}{|l|}{ Lead-Lag Optimize? } \\
\hline Recall Mode & None & None & None & None & Min & Min & Min & Min & Min \\
\hline \multicolumn{10}{|l|}{ Intersection Summary } \\
\hline \multicolumn{10}{|l|}{ Cycle Length: 120} \\
\hline \multicolumn{10}{|c|}{ Actuated Cycle Length: 42} \\
\hline \multicolumn{10}{|c|}{ Natural Cycle: 55} \\
\hline \multicolumn{10}{|c|}{ Control Type: Actuated-Uncoordinated } \\
\hline
\end{tabular}

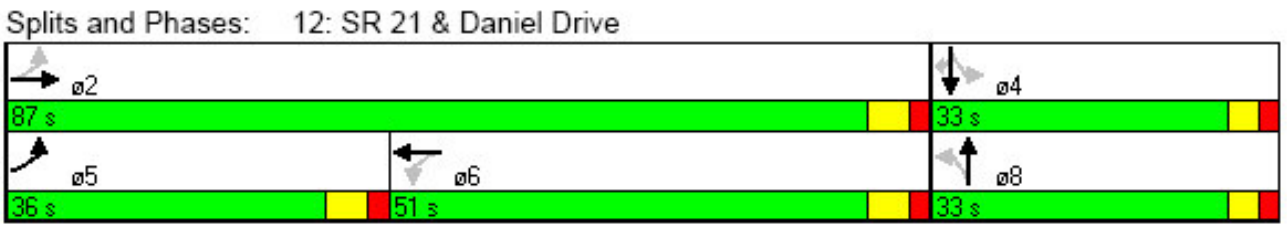


Lanes, Volumes, Timings

15: SR 21 \& Brewer

\section{$\rightarrow \rightarrow r \leftarrow \uparrow \uparrow \vdash \downarrow \downarrow$}

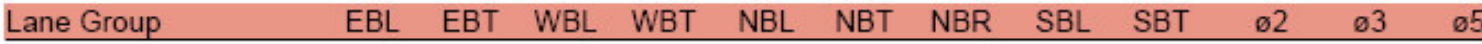

\begin{tabular}{|c|c|c|c|c|c|c|c|c|c|c|c|c|}
\hline ne Configurations & 1 & 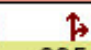 & $\pi$ & to & & 4 & 7 & & $\$$ & & & \\
\hline Volume (vph) & 5 & 335 & 225 & 221 & 20 & 4 & 68 & 2 & 1 & & & \\
\hline Turn Type & Perm & & custom & & Perm & & $\mathrm{pm}+\mathrm{ov}$ & Perm & & & & \\
\hline Protected Phases & & 23 & 1 & 123 & & 4 & 1 & & 4 & 2 & 3 & \\
\hline Permitted Phases & 23 & & 3 & & 4 & & 4 & 4 & & & & \\
\hline Detector Phases & 23 & 23 & 1 & 123 & 4 & 4 & 1 & 4 & 4 & & & \\
\hline Minim & & & 4.0 & & 4.0 & 4.0 & 4.0 & 4.0 & 4.0 & 4.0 & 4.0 & \\
\hline Minimur & & & 10.0 & & 19.0 & 19.0 & 10.0 & 19.0 & 19.0 & 22.0 & 10.0 & 10 \\
\hline Total & 63.0 & 63.0 & 17.0 & 80.0 & 20.0 & 20.0 & 17.0 & 20.0 & 20.0 & 27.0 & 36.0 & 14 \\
\hline Total & $63.0 \%$ & $63.0 \%$ & $17.0 \%$ & $80.0 \%$ & $20.0 \%$ & $20.0 \%$ & $17.0 \%$ & $20.0 \%$ & $20.0 \%$ & $27 \%$ & $36 \%$ & 14 \\
\hline Yellow & & & 4.0 & & 4.0 & 4.0 & 4.0 & 4.0 & 4.0 & 4. & 4.0 & 4 \\
\hline All-Rec & & & 2.0 & & 2.0 & 2.0 & 2.0 & 2.0 & 2.0 & 2.0 & 2.0 & \\
\hline ead/Lag & & & Lead & & Lag & Lag & Lead & Lag & Lag & Lag & Lead & Lea \\
\hline & & & & & & & & & & & & \\
\hline 111 & & & ne & & Min & Min & None & Min & Min & Ione & None & Nor \\
\hline
\end{tabular}

Intersection Summary

Cycle Length: 100

Actuated Cycle Length: 92.8

Natural Cycle: 80

Control Type: Actuated-Uncoordinated

Splits and Phases: 15: SR 21 \& Brewer

\begin{tabular}{|c|c|c|c|}
\hline $\begin{array}{l}\# 15 \# 18 \\
77\end{array}$ & $\begin{array}{l}\# 15 \Rightarrow 18 \\
\longrightarrow \div 2\end{array}$ & $\begin{array}{l}\# 15 \neq 18 \\
+4\end{array}$ & $\begin{array}{l}\# 15 \# 18 \\
1+\left.\right|^{-18}\end{array}$ \\
\hline $17 s$ & $27 s$ & $36 s$ & $20 s$ \\
\hline & & $\#$ & \\
\hline & & $42 \mathrm{~s}$ & \\
\hline
\end{tabular}


Lanes, Volumes, Timings

18: SR 21 \& Matthew

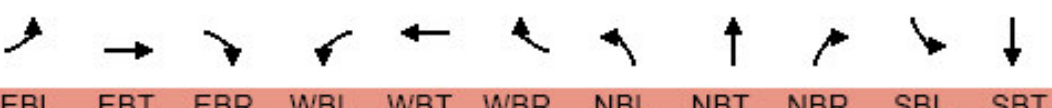

\begin{tabular}{|c|c|c|c|c|c|c|c|c|c|c|c|}
\hline Lane Group & EBL & EBT & EBR & WBL & WBT & WBR & NBL & NBT & NBR & SBL & SBT \\
\hline Lane Configurations & & $\uparrow$ & $\pi$ & 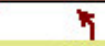 & $\uparrow$ & $\bar{r}$ & 7 & $\uparrow$ & $\pi$ & 4 & $\uparrow$ \\
\hline Volume (vph) & 3 & 186 & 216 & 86 & 126 & 57 & $295^{\circ}$ & $15 \dot{5}$ & 186 & 46 & 102 \\
\hline Turn Type & Perm & & pt+ov & Split & & Perm & Prot & & Over & Prot & \\
\hline Protected Phases & & 2 & 23 & 1 & 1 & & 3 & 6 & 1 & 5 & 4 \\
\hline Permitted Phases & 2 & & & & 2 & 1 & & & & & \\
\hline Detector Phases & 2 & 2 & 23 & 1 & 1 & 1 & 3 & 6 & 1 & 5 & 4 \\
\hline Minimum Initial (s) & 4.0 & 4.0 & & 4.0 & 4.0 & 4.0 & 4.0 & 4.0 & 4.0 & 4.0 & 4.0 \\
\hline Minimum Split (s) & 22.0 & 22.0 & & 10.0 & 10.0 & 10.0 & 10.0 & 22.0 & 10.0 & 10.0 & 19.0 \\
\hline Total Split (s) & 27.0 & 27.0 & 63.0 & 17.0 & 17.0 & 17.0 & 36.0 & 42.0 & 17.0 & 14.0 & 20.0 \\
\hline Total Split (\%) & $27.0 \%$ & $27.0 \%$ & $63.0 \%$ & $17.0 \%$ & $17.0 \%$ & $17.0 \%$ & $36.0 \%$ & $42.0 \%$ & $17.0 \%$ & $14.0 \%$ & $20.0 \%$ \\
\hline Yellow Time (s) & 4.0 & 4.0 & & 4.0 & 4.0 & 4.0 & 4.0 & 4.0 & 4.0 & 4.0 & 4.0 \\
\hline All-Red Time (s) & 2.0 & 2.0 & & 2.0 & 2.0 & 2.0 & 2.0 & 2.0 & 2.0 & 2.0 & 2.0 \\
\hline Lead/Lag & Lag & Lag & & Lead & Lead & Lead & Lead & Lag & Lead & Lead & Lag \\
\hline Lead-Lag Optimize? & & & & & & & & Yes & & Yes & \\
\hline Recall Mode & None & None & & None & None & None & None & Min & None & None & Min \\
\hline
\end{tabular}

Cycle Length: 100

Actuated Cycle Length: 92.8

Natural Cycle: 80

Control Type: Actuated-Uncoordinated

Splits and Phases: 18: SR 21 \& Matthew

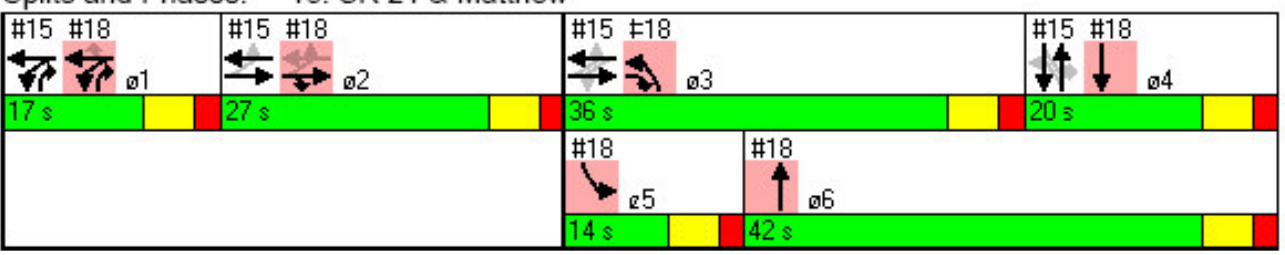




\begin{tabular}{|c|c|c|c|c|c|c|c|c|c|c|}
\hline Lane Group & $\mathrm{EBL}$ & EBT & WBL & WBT & NBL & NBT & NBR & SBL & SBT & SBR \\
\hline Lane Configurations & 5 & $\uparrow$ & 7 & $\hat{b}$ & & $\uparrow$ & $\pi$ & & $\uparrow$ & $\bar{t}$ \\
\hline Volume (vph) & $80^{\circ}$ & 319 & 20 & 176 & 16 & 7 & 13 & 70 & 5 & 77 \\
\hline Turn Type & $\mathrm{pm}+\mathrm{pt}$ & & $\mathrm{pm}+\mathrm{pt}$ & & Perm & & Perm & Perm & & Perm \\
\hline Protected Phases & 5 & 2 & 1 & 6 & & 8 & & & 4 & \\
\hline Permitted Phases & 2 & & 6 & & 8 & & 8 & 4 & & 4 \\
\hline Detector Phases & 5 & 2 & 1 & 6 & 8 & 8 & & 4 & 4 & \\
\hline Minimum Initial (s) & 4.0 & 4.0 & 4.0 & 4.0 & 4.0 & 4.0 & 4.0 & 4.0 & 4.0 & 4.0 \\
\hline Minimum Split (s) & 10.0 & 22.0 & 10.0 & 22.0 & 21.0 & 21.0 & 21.0 & 21.0 & 21.0 & 21.0 \\
\hline Total Split (s) & 20.0 & 52.0 & 20.0 & 52.0 & 48.0 & 48.0 & 48.0 & 48.0 & 48.0 & 48.0 \\
\hline Total Split (\%) & $16.7 \%$ & $43.3 \%$ & $16.7 \%$ & $43.3 \%$ & $40.0 \%$ & $40.0 \%$ & $40.0 \%$ & $40.0 \%$ & $40.0 \%$ & $40.0 \%$ \\
\hline Yellow Time (s) & 4.0 & 4.0 & 4.0 & 4.0 & 3.0 & 3.0 & 3.0 & 3.0 & 3.0 & 3.0 \\
\hline All-Red Time (s) & 2.0 & 2.0 & 2.0 & 2.0 & 2.0 & 2.0 & 2.0 & 2.0 & 2.0 & 2.0 \\
\hline Lead/Lag & Lead & Lag & Lead & Lag & & & & & & \\
\hline \multicolumn{11}{|l|}{ Lead-Lag Optimize? } \\
\hline Recall Mode & None & Min & None & Min & None & None & None & None & None & None \\
\hline \multicolumn{11}{|l|}{ Intersection Summary } \\
\hline \multicolumn{11}{|c|}{ Cycle Length: 120} \\
\hline \multicolumn{11}{|c|}{ Actuated Cycle Length: 69.9} \\
\hline \multicolumn{11}{|l|}{ Natural Cycle: 60} \\
\hline Control Type: Actua & $\mathrm{coc}$ & ated & & & & & & & & \\
\hline
\end{tabular}

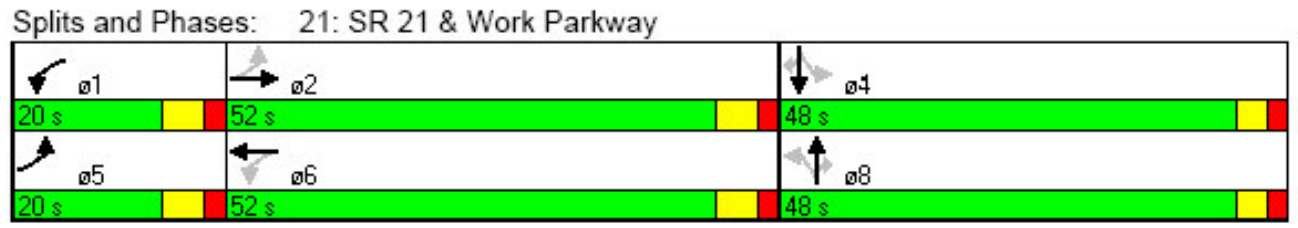


Lanes, Volumes, Timings

24: SR 21 \& Mall

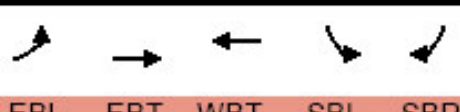

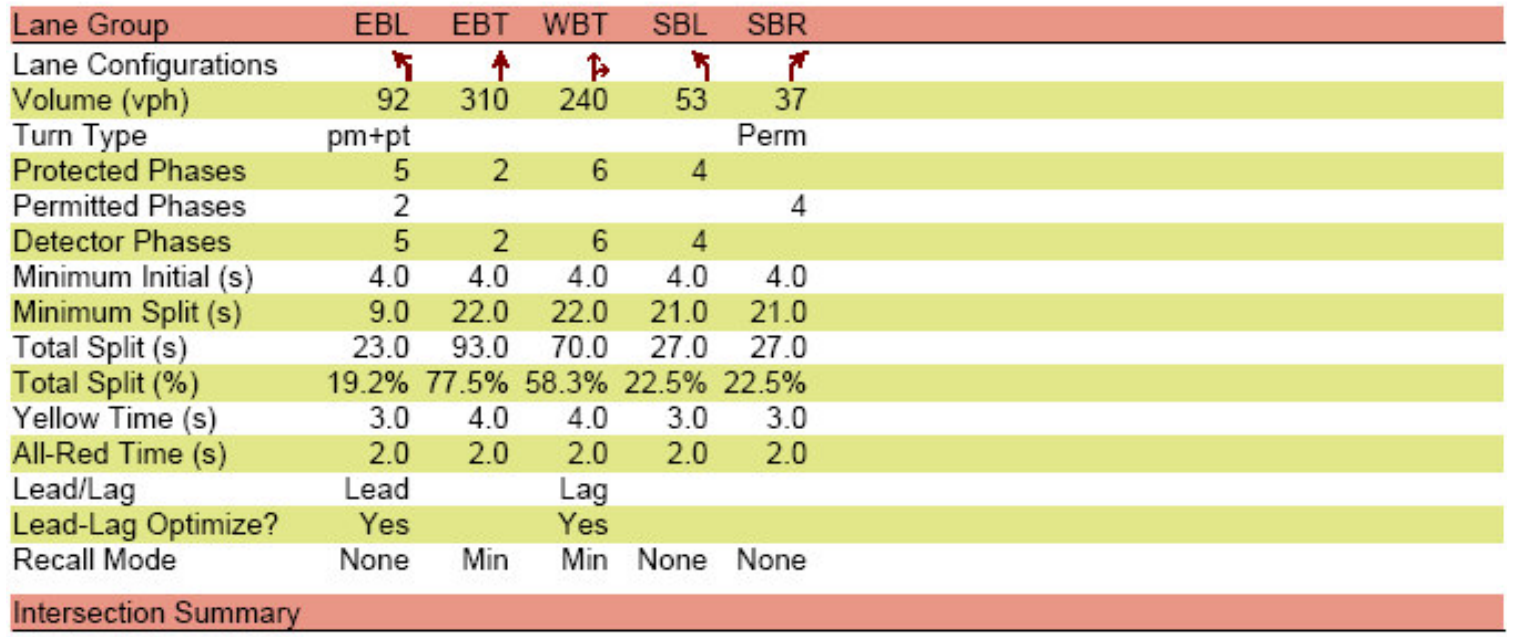

Cycle Length: 120

Actuated Cycle Length: 68.7

Natural Cycle: 60

Control Type: Actuated-Uncoordinated

Splits and Phases: 24: SR 21 \& Mall

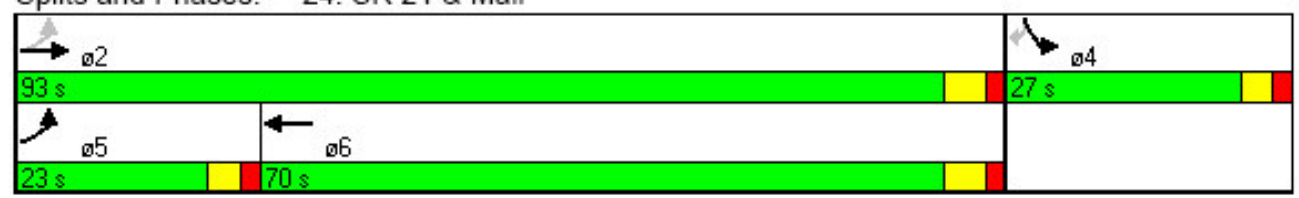




\section{Phasing Change - Midday Peak}

\begin{tabular}{|c|c|c|c|c|c|c|c|c|c|}
\hline Lane Group & EBL & EBT & WBL & WBT & NBL & NBT & SBL & SBT & SBR \\
\hline Lane Configurations & 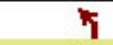 & $\uparrow$ & 7 & $\hat{F}$ & & $\$$ & & $\uparrow$ & 7 \\
\hline Volume (vph) & 89 & 319 & 1 & 267 & 1 & 1 & 122 & 0 & 39 \\
\hline Turn Type & $\mathrm{pm}+\mathrm{pt}$ & & Perm & & Perm & & Perm & & Perm \\
\hline Protected Phases & 5 & 2 & & 6 & & 8 & & 4 & \\
\hline Permitted Phases & 2 & & 6 & & 8 & & 4 & & 4 \\
\hline Detector Phases & 5 & 2 & & 6 & 8 & 8 & 4 & 4 & 4 \\
\hline Minimum Initial (s) & 2.0 & 15.0 & 15.0 & 15.0 & 2.0 & 2.0 & 2.0 & 2.0 & 2.0 \\
\hline Minimum Split (s) & 8.0 & 22.0 & 22.0 & 22.0 & 21.0 & 21.0 & 21.0 & 21.0 & 21.0 \\
\hline Total Split (s) & 36.0 & 87.0 & 51.0 & 51.0 & 33.0 & 33.0 & 33.0 & 33.0 & 33.0 \\
\hline Total Split (\%) & $30.0 \%$ & $72.5 \%$ & $42.5 \%$ & $42.5 \%$ & $27.5 \%$ & $27.5 \%$ & $27.5 \%$ & $27.5 \%$ & $27.5 \%$ \\
\hline Yellow Time (s) & 4.0 & 4.0 & 4.0 & 4.0 & 3.0 & 3.0 & 3.0 & 3.0 & 3.0 \\
\hline All-Red Time (s) & 2.0 & 2.0 & 2.0 & 2.0 & 2.0 & 2.0 & 2.0 & 2.0 & 2.0 \\
\hline Lead/Lag & Lead & & Lag & Lag & & & & & \\
\hline \multicolumn{10}{|l|}{ Lead-Lag Optimize? } \\
\hline Recall Mode & None & None & None & None & Min & Min & Min & Min & Min \\
\hline \multicolumn{10}{|l|}{ Intersection Summary } \\
\hline \multicolumn{10}{|l|}{ Cycle Length: 120} \\
\hline \multicolumn{10}{|c|}{ Actuated Cycle Length: 59.6} \\
\hline \multicolumn{10}{|c|}{ Natural Cycle: 60} \\
\hline \multicolumn{10}{|c|}{ Control Type: Actuated-Uncoordinated } \\
\hline
\end{tabular}

Splits and Phases: 12: SR 21 \& Daniel Drive

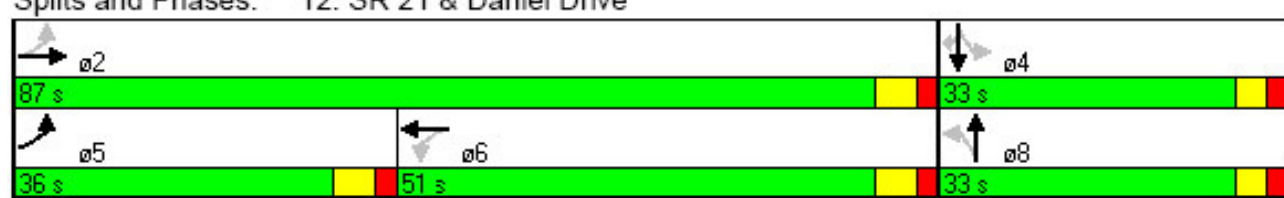


Lanes, Volumes, Timings

15: SR 21 \& Brewer

\section{$\mapsto \rightarrow \vdash \leftarrow \uparrow \uparrow \uparrow \downarrow \downarrow$}

\begin{tabular}{|c|c|c|c|c|c|c|c|c|c|c|c|c|}
\hline Lane Group & EBL & EBT & WBL & WBT & NBL & NBT & NBR & SBL & SBT & $ø 2$ & $ø 3$ & 95 \\
\hline Lane Configurations & 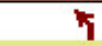 & $\uparrow$ & 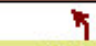 & $\hat{F}$ & & $\uparrow$ & $\bar{t}$ & & $\leftrightarrow$ & & & \\
\hline Volume (vph) & 5 & 326 & 134 & 298 & 36 & 9 & 167 & 7 & 6 & & & \\
\hline Turn Type & Perm & & custom & & Perm & & $p m+o v$ & Perm & & & & \\
\hline Protected Phases & & 23 & 1 & 123 & & 4 & 1 & & 4 & 2 & 3 & 5 \\
\hline Permitted Phases & 23 & & 3 & & 4 & & 4 & 4 & & & & \\
\hline Detector Phases & 23 & 23 & 1 & 123 & 4 & 4 & 1 & 4 & 4 & & & \\
\hline Minimum Initial (s) & & & 4.0 & & 4.0 & 4.0 & 4.0 & 4.0 & 4.0 & 4.0 & 4.0 & 4.0 \\
\hline Minimum Split (s) & & & 10.0 & & 22.0 & 22.0 & 10.0 & 22.0 & 22.0 & 22.0 & 10.0 & 10.0 \\
\hline Total Split (s) & 109.0 & 109.0 & 42.0 & 151.0 & 49.0 & 49.0 & 42.0 & 49.0 & 49.0 & 62.0 & 47.0 & 35.0 \\
\hline Total Split (\%) & $54.5 \%$ & $54.5 \%$ & $21.0 \%$ & $75.5 \%$ & $24.5 \%$ & $24.5 \%$ & $21.0 \%$ & $24.5 \%$ & $24.5 \%$ & $31 \%$ & $24 \%$ & $18 \%$ \\
\hline Yellow Time (s) & & & 4.0 & & 4.0 & 4.0 & 4.0 & 4.0 & 4.0 & 4.0 & 4.0 & 4.0 \\
\hline All-Red Time (s) & & & 2.0 & & 2.0 & 2.0 & 2.0 & 2.0 & 2.0 & 2.0 & 2.0 & 2.0 \\
\hline Lead/Lag & & & Lead & & Lag & Lag & Lead & Lag & Lag & Lag & Lead & Lead \\
\hline Lead-Lag Optimize? & & & & & & & & & & & & Yes \\
\hline Recall Mode & & & None & & Min & Min & None & Min & Min & None & None & None \\
\hline
\end{tabular}

Cycle Length: 200

Actuated Cycle Length: 186.4

Natural Cycle: 90

Control Type: Actuated-Uncoordinated

Splits and Phases: 15: SR 21 \& Brewer

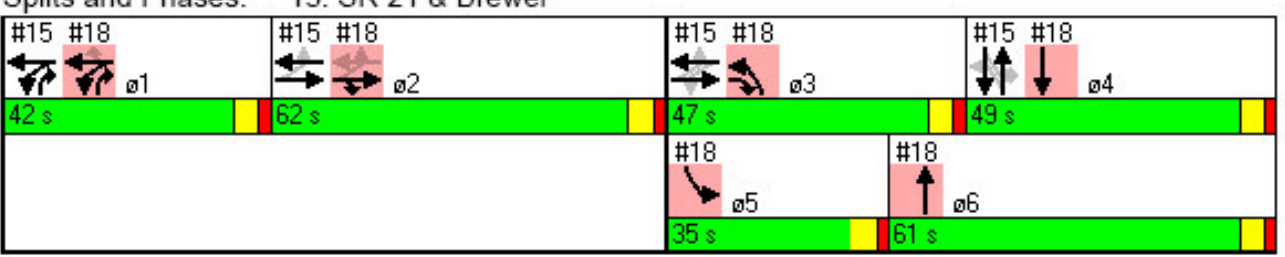


Lanes, Volumes, Timings

18: SR 21 \& Matthew

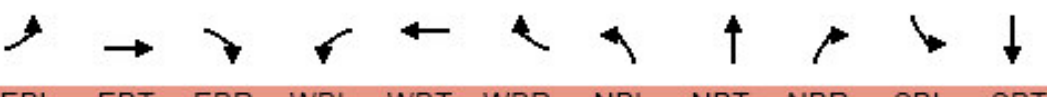

\begin{tabular}{|c|c|c|c|c|c|c|c|c|c|c|c|}
\hline Lane Group & EBL & EBT & EBR & WBL & WBT & WBR & NBL & NBT & NBR & SBL & SBT \\
\hline Lane Configurations & & $\uparrow$ & $\pi$ & 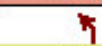 & $\uparrow$ & 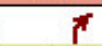 & 7 & $\uparrow$ & $\pi$ & 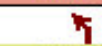 & 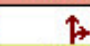 \\
\hline Volume (vph) & 15 & 261 & 224 & 190 & 213 & 154 & 200 & 253 & 259 & 144 & 243 \\
\hline Turn Type & Perm & & pt+ov & Split & & Perm & Prot & & Over & Prot & \\
\hline Protected Phases & & 2 & 23 & 1 & 1 & & 3 & 6 & 1 & 5 & 4 \\
\hline Permitted Phases & 2 & & & & 2 & 1 & & & & & \\
\hline Detector Phases & 2 & 2 & 23 & 1 & 1 & 1 & 3 & 6 & 1 & 5 & 4 \\
\hline Minimum Initial (s) & 4.0 & 4.0 & & 4.0 & 4.0 & 4.0 & 4.0 & 4.0 & 4.0 & 4.0 & 4.0 \\
\hline Minimum Split (s) & 22.0 & 22.0 & & 10.0 & 10.0 & 10.0 & 10.0 & 22.0 & 10.0 & 10.0 & 22.0 \\
\hline Total Split (s) & 62.0 & 62.0 & 109.0 & 42.0 & 42.0 & 42.0 & 47.0 & 61.0 & 42.0 & 35.0 & 49.0 \\
\hline Total Split (\%) & $31.0 \%$ & $31.0 \%$ & $54.5 \%$ & $21.0 \%$ & $21.0 \%$ & $21.0 \%$ & $23.5 \%$ & $30.5 \%$ & $21.0 \%$ & $17.5 \%$ & $24.5 \%$ \\
\hline Yellow Time (s) & 4.0 & 4.0 & & 4.0 & 4.0 & 4.0 & 4.0 & 4.0 & 4.0 & 4.0 & 4.0 \\
\hline All-Red Time (s) & 2.0 & 2.0 & & 2.0 & 2.0 & 2.0 & 2.0 & 2.0 & 2.0 & 2.0 & 2.0 \\
\hline Lead/Lag & Lag & Lag & & Lead & Lead & Lead & Lead & Lag & Lead & Lead & Lag \\
\hline Lead-Lag Optimize? & & & & & & & & Yes & & Yes & \\
\hline Recall Mode & None & None & & None & None & None & None & Min & None & None & Min \\
\hline
\end{tabular}

Cycle Length: 200

Actuated Cycle Length: 186.4

Natural Cycle: 90

Control Type: Actuated-Uncoordinated

Splits and Phases: 18: SR 21 \& Matthew

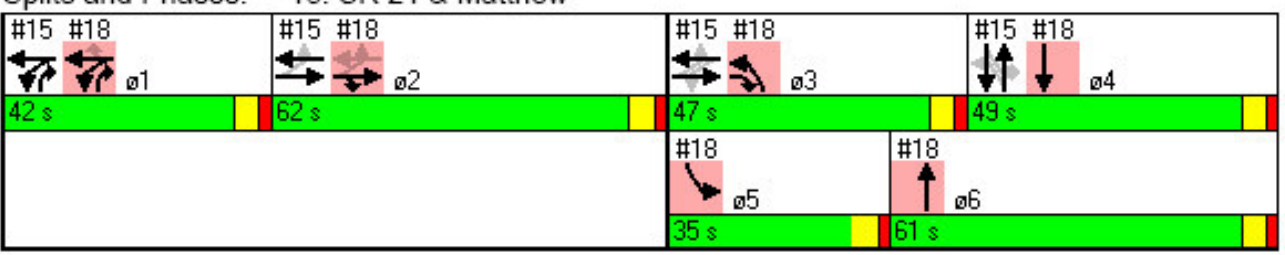


Lanes, Volumes, Timings

21: SR 21 \& Work Parkway

\begin{tabular}{|c|c|c|c|c|c|c|c|c|c|c|}
\hline Lane Group & EBL & EBT & WBL & WBT & NBL & NBT & NBR & SBL & SBT & SBR \\
\hline Lane Configurations & k & $\uparrow$ & 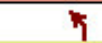 & 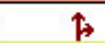 & & $\uparrow$ & $\pi$ & & $\uparrow$ & $\pi$ \\
\hline Volume (vph) & $192^{\prime}$ & 369 & 83 & 305 & 79 & 50 & 72 & 150 & 41 & 173 \\
\hline Turn Type & $\mathrm{pm}+\mathrm{pt}$ & & $\mathrm{pm}+\mathrm{pt}$ & & Perm & & Perm & Perm & & Perm \\
\hline Protected Phases & 5 & 2 & 1 & 6 & & 8 & & & 4 & \\
\hline Permitted Phases & 2 & & 6 & & 8 & & 8 & 4 & & 4 \\
\hline Detector Phases & 5 & 2 & 1 & 6 & 8 & 8 & & 4 & 4 & \\
\hline Minimum Initial (s) & 4.0 & 4.0 & 4.0 & 4.0 & 4.0 & 4.0 & 4.0 & 4.0 & 4.0 & 4.0 \\
\hline Minimum Split (s) & 10.0 & 22.0 & 10.0 & 22.0 & 21.0 & 21.0 & 21.0 & 21.0 & 21.0 & 21.0 \\
\hline Total Split (s) & 20.0 & 52.0 & 20.0 & 52.0 & 48.0 & 48.0 & 48.0 & 48.0 & 48.0 & 48.0 \\
\hline Total Split (\%) & $16.7 \%$ & $43.3 \%$ & $16.7 \%$ & $43.3 \%$ & $40.0 \%$ & $40.0 \%$ & $40.0 \%$ & $40.0 \%$ & $40.0 \%$ & $40.0 \%$ \\
\hline Yellow Time (s) & 4.0 & 4.0 & 4.0 & 4.0 & 3.0 & 3.0 & 3.0 & 3.0 & 3.0 & 3.0 \\
\hline All-Red Time (s) & 2.0 & 2.0 & 2.0 & 2.0 & 2.0 & 2.0 & 2.0 & 2.0 & 2.0 & 2.0 \\
\hline Lead/Lag & Lead & Lag & Lead & Lag & & & & & & \\
\hline \multicolumn{11}{|l|}{ Lead-Lag Optimize? } \\
\hline Recall Mode & None & Min & None & Min & None & None & None & None & None & None \\
\hline \multicolumn{11}{|l|}{ Intersection Summary } \\
\hline \multicolumn{11}{|l|}{ Cycle Length: 120} \\
\hline \multicolumn{11}{|c|}{ Actuated Cycle Length: 95.5} \\
\hline \multicolumn{11}{|l|}{ Natural Cycle: 75} \\
\hline Control Type: Actuate & Incoc & dinated & & & & & & & & \\
\hline
\end{tabular}

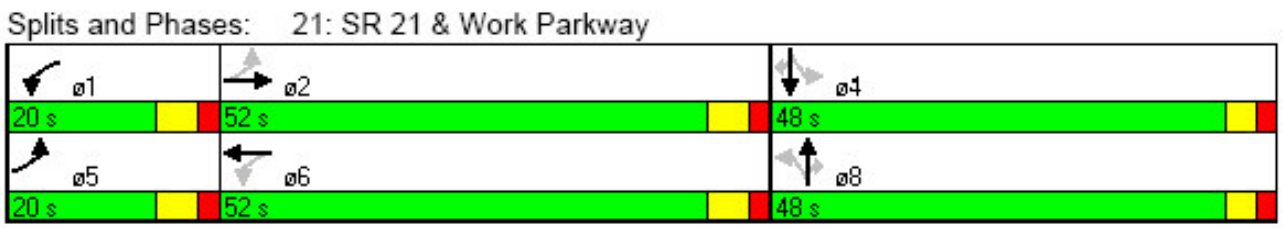




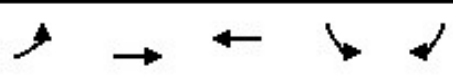

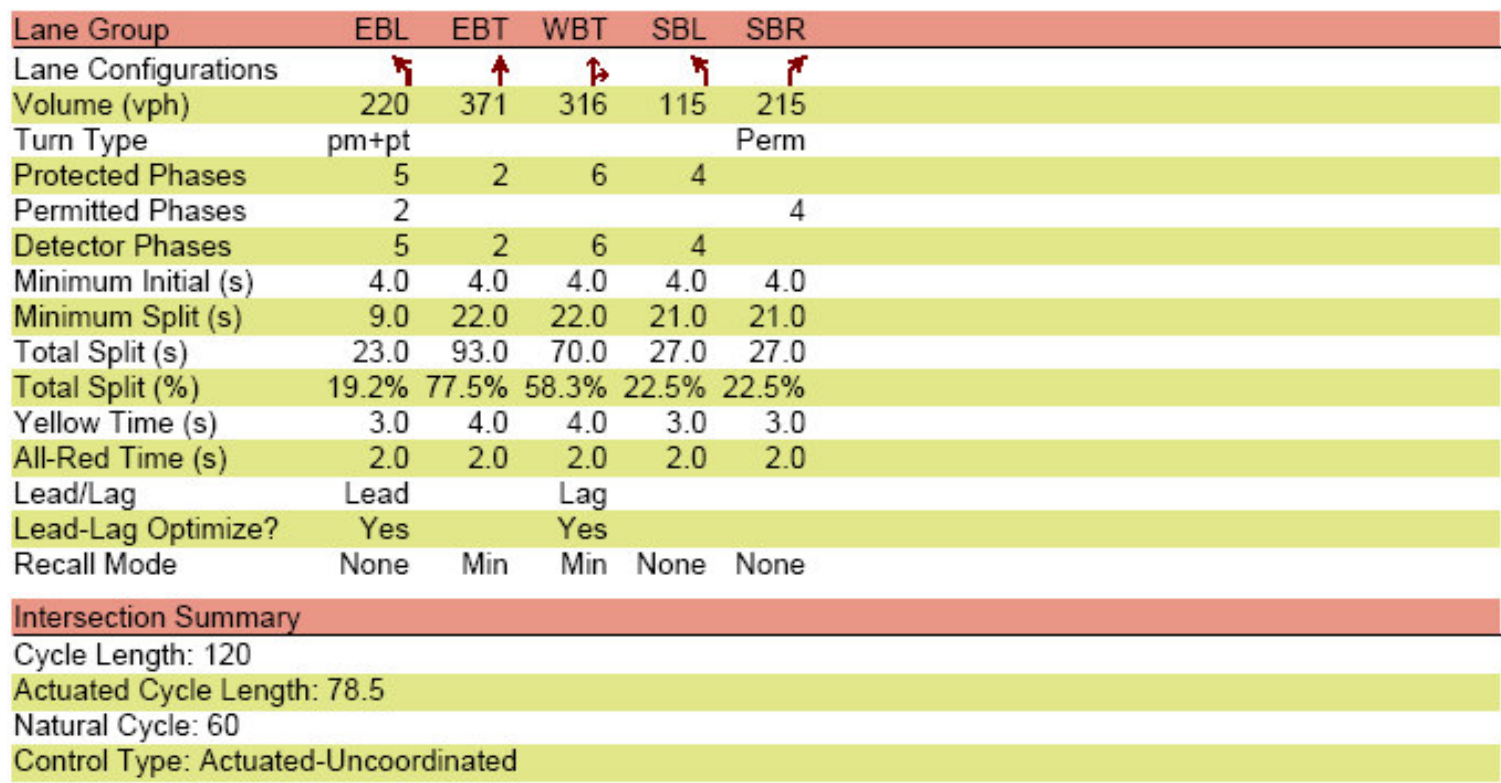

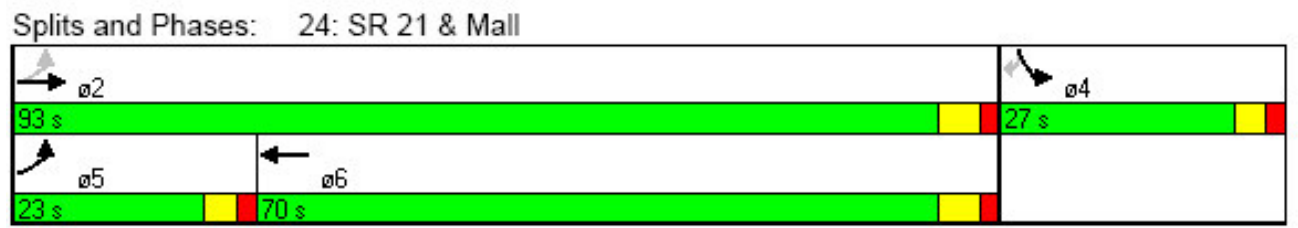


Lanes, Volumes, Timings

Phasing Change - PM Peak

12: SR 21 \& Daniel Drive

\begin{tabular}{|c|c|c|c|c|c|c|c|c|c|}
\hline Lane Group & EBL & EBT & WBL & WBT & NBL & NBT & SBL & SBT & SBR \\
\hline Lane Configurations & \% & $\uparrow$ & 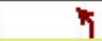 & $\uparrow$ & & $\$$ & & $\uparrow$ & $\pi$ \\
\hline Volume (vph) & 111 & 387 & 1 & 457 & 1 & 1 & 31 & 0 & 147 \\
\hline Turn Type & $\mathrm{pm}+\mathrm{pt}$ & & Perm & & Perm & & Perm & & Perm \\
\hline Protected Phases & 5 & 2 & & 6 & & 8 & & 4 & \\
\hline Permitted Phases & 2 & & 6 & & 8 & & 4 & & 4 \\
\hline Detector Phases & 5 & 2 & & 6 & 8 & 8 & 4 & 4 & 4 \\
\hline Minimum Initial (s) & 2.0 & 15.0 & 15.0 & 15.0 & 2.0 & 2.0 & 2.0 & 2.0 & 2.0 \\
\hline Minimum Split (s) & 8.0 & 22.0 & 22.0 & 22.0 & 21.0 & 21.0 & 21.0 & 21.0 & 21.0 \\
\hline Total Split (s) & 36.0 & 87.0 & 51.0 & 51.0 & 33.0 & 33.0 & 33.0 & 33.0 & 33.0 \\
\hline Total Split (\%) & $30.0 \%$ & $72.5 \%$ & $42.5 \%$ & $42.5 \%$ & $27.5 \%$ & $27.5 \%$ & $27.5 \%$ & $27.5 \%$ & $27.5 \%$ \\
\hline Yellow Time (s) & 4.0 & 4.0 & 4.0 & 4.0 & 3.0 & 3.0 & 3.0 & 3.0 & 3.0 \\
\hline All-Red Time (s) & 2.0 & 2.0 & 2.0 & 2.0 & 2.0 & 2.0 & 2.0 & 2.0 & 2.0 \\
\hline Lead/Lag & Lead & & Lag & Lag & & & & & \\
\hline \multicolumn{10}{|l|}{ Lead-Lag Optimize? } \\
\hline Recall Mode & None & None & None & None & Min & Min & Min & Min & Min \\
\hline \multicolumn{10}{|l|}{ Intersection Summary } \\
\hline \multicolumn{10}{|l|}{ Cycle Length: 120} \\
\hline \multicolumn{10}{|c|}{ Actuated Cycle Length: 81.8} \\
\hline \multicolumn{10}{|c|}{ Natural Cycle: 60} \\
\hline \multicolumn{10}{|c|}{ Control Type: Actuated-Uncoordinated } \\
\hline
\end{tabular}

Splits and Phases: 12: SR 21 \& Daniel Drive

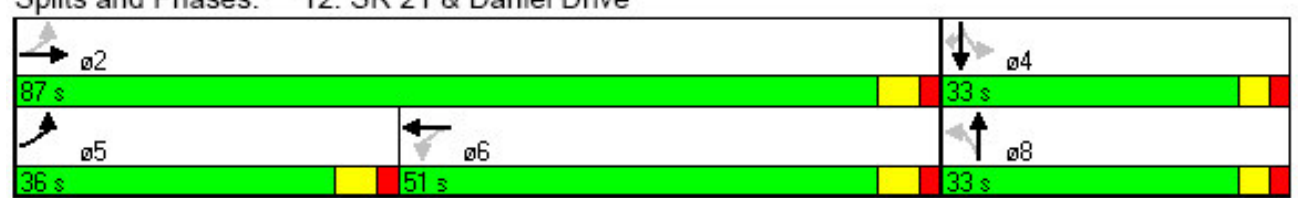




\section{$\rightarrow \rightarrow \leftarrow+\uparrow+1$}

\begin{tabular}{|c|c|c|c|c|c|c|c|c|c|c|c|c|}
\hline Lane Group & EBL & EBT & WBL & WBT & NBL & NBT & NBR & SBL & SBT & $ø 2$ & $ø 3$ & 95 \\
\hline Lane Configurations & 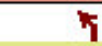 & $\uparrow$ & 7 & t & & $\uparrow$ & $\bar{r}$ & & $\leftrightarrow$ & & & \\
\hline Volume (vph) & 6 & 397 & 92 & 450 & 52 & 3 & 165 & 16 & 2 & & & \\
\hline Turn Type & Perm & & D.P $+P$ & & Perm & & $\mathrm{pm+ov}$ & Perm & & & & \\
\hline Protected Phases & & 23 & 1 & 123 & & 4 & 1 & & 4 & 2 & 3 & 5 \\
\hline Permitted Phases & 23 & & 23 & & 4 & & 4 & 4 & & & & \\
\hline Detector Pha & 23 & 23 & 1 & 123 & 4 & 4 & 1 & 4 & 4 & & & \\
\hline Minimum Initial (s) & & & 4.0 & & 4.0 & 4.0 & 4.0 & 4.0 & 4.0 & 4.0 & 4.0 & 4.0 \\
\hline Minimum Split (s) & & & 10.0 & & 22.0 & 22.0 & 10.0 & 22.0 & 22.0 & 22.0 & 10.0 & 10.0 \\
\hline Total Split (s) & 108.0 & 108.0 & 36.0 & 144.0 & 58.0 & 58.0 & 36.0 & 58.0 & 58.0 & 56.0 & 52.0 & 44.0 \\
\hline Total Split (\%) & $53.5 \%$ & $53.5 \%$ & $17.8 \%$ & $71.3 \%$ & $28.7 \%$ & $28.7 \%$ & $17.8 \%$ & $28.7 \%$ & $28.7 \%$ & $28 \%$ & $26 \%$ & $22 \%$ \\
\hline Yellow Time (s) & & & 4.0 & & 4.0 & 4.0 & 4.0 & 4.0 & 4.0 & 4 & 4 & 4.0 \\
\hline All-Red Time (s) & & & 2.0 & & 2.0 & 2.0 & 2.0 & 2.0 & 2.0 & 2.0 & 2.0 & 2.0 \\
\hline Lead/Lag & & & Lead & & Lag & Lag & Lead & Lag & Lag & Lag & Lead & Lead \\
\hline ead-Lag C & & & & & & & & & & & & Yes \\
\hline Recall Mode & & & None & & Min & Min & lone & Min & Min & lone & None & Vone \\
\hline
\end{tabular}

\section{Intersection Summary}

Cycle Length: 202

Actuated Cycle Length: 200.3

Natural Cycle: 110

Control Type: Actuated-Uncoordinated

Splits and Phases: 15: SR 21 \& Brewer

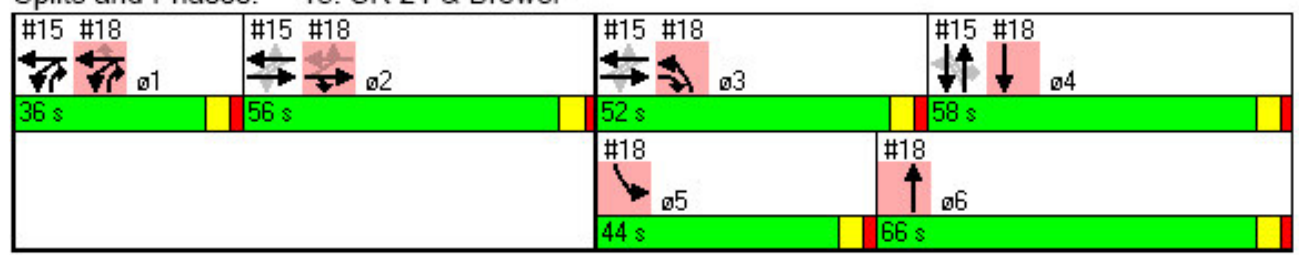


Lanes, Volumes, Timings

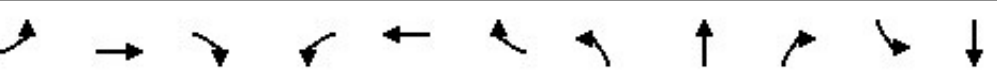

\begin{tabular}{|c|c|c|c|c|c|c|c|c|c|c|c|}
\hline Lane Group & EBL & EBT & EBR & WBL & WBT & WBR & NBL & NBT & NBR & SBL & SBT \\
\hline Lane Configurations & & $\uparrow$ & $\pi$ & 7 & $\uparrow$ & 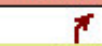 & 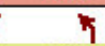 & $\uparrow$ & $\pi$ & 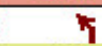 & t) \\
\hline Volume (vph) & 6 & 254 & 318 & 247 & 222 & 150 & $305^{\circ}$ & 268 & 243 & $147^{\circ}$ & 318 \\
\hline Turn Type & Perm & & $\mathrm{pt}+\mathrm{ov}$ & Split & & Perm & Prot & & Over & Prot & \\
\hline Protected Phases & & 2 & 23 & 1 & 1 & & 3 & 6 & 1 & 5 & 4 \\
\hline Permitted Phases & 2 & & & & 2 & 1 & & & & & \\
\hline Detector Phases & 2 & 2 & 23 & 1 & 1 & 1 & 3 & 6 & 1 & 5 & 4 \\
\hline Minimum Initial (s) & 4.0 & 4.0 & & 4.0 & 4.0 & 4.0 & 4.0 & 4.0 & 4.0 & 4.0 & 4.0 \\
\hline Minimum Split (s) & 22.0 & 22.0 & & 10.0 & 10.0 & 10.0 & 10.0 & 22.0 & 10.0 & 10.0 & 22.0 \\
\hline Total Split (s) & 56.0 & 56.0 & 108.0 & 36.0 & 36.0 & 36.0 & 52.0 & 66.0 & 36.0 & 44.0 & 58.0 \\
\hline Total Split (\%) & $27.7 \%$ & $27.7 \%$ & $53.5 \%$ & $17.8 \%$ & $17.8 \%$ & $17.8 \%$ & $25.7 \%$ & $32.7 \%$ & $17.8 \%$ & $21.8 \%$ & $28.7 \%$ \\
\hline Yellow Time (s) & 4.0 & 4.0 & & 4.0 & 4.0 & 4.0 & 4.0 & 4.0 & 4.0 & 4.0 & 4.0 \\
\hline All-Red Time (s) & 2.0 & 2.0 & & 2.0 & 2.0 & 2.0 & 2.0 & 2.0 & 2.0 & 2.0 & 2.0 \\
\hline Lead/Lag & Lag & Lag & & Lead & Lead & Lead & Lead & Lag & Lead & Lead & Lag \\
\hline Lead-Lag Optimize? & & & & & & & & Yes & & Yes & \\
\hline Recall Mode & None & None & & None & None & None & None & Min & None & None & Min \\
\hline
\end{tabular}

Intersection Summary

Cycle Length: 202

Actuated Cycle Length: 200.3

Natural Cycle: 110

Control Type: Actuated-Uncoordinated

Splits and Phases: 18: SR 21 \& Matthew

\begin{tabular}{|c|c|c|c|c|}
\hline $\begin{array}{l}\# 15 \# 18 \\
47\end{array}$ & $\begin{array}{l}\# 15 \text { \#18 } \\
\longrightarrow \rightarrow 02\end{array}$ & $\begin{array}{l}\# 15 \quad \# 18 \\
-41\end{array}$ & & $\begin{array}{l}\# 15 \text { \#18 } \\
11\end{array}$ \\
\hline $36 s$ & $56 s$ & $52 s$ & & $8 \mathrm{~s}$ \\
\hline & & & & 96 \\
\hline & & $44 s$ & $66 s$ & \\
\hline
\end{tabular}




\begin{tabular}{|c|c|c|c|c|c|c|c|c|c|c|}
\hline Lane Group & EBL & EBT & WBL & WBT & NBL & NBT & NBR & SBL & SBT & SBR \\
\hline Lane Configurations & 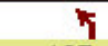 & $\uparrow$ & 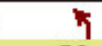 & $\uparrow$ & & $\uparrow$ & $\bar{r}$ & & $\uparrow$ & $\bar{t}$ \\
\hline Volume (vph) & 167 & 402 & 56 & 359 & 91 & 44 & 76 & 128 & 23 & 169 \\
\hline Turn Type & $\mathrm{pm}+\mathrm{pt}$ & & $\mathrm{pm}+\mathrm{pt}$ & & Perm & & Perm & Perm & & Perm \\
\hline Protected Phases & 5 & 2 & 1 & 6 & & 8 & & & 4 & \\
\hline Permitted Phases & 2 & & 6 & & 8 & & 8 & 4 & & 4 \\
\hline Detector Phases & 5 & 2 & 1 & 6 & 8 & 8 & & 4 & 4 & \\
\hline Minimum Initial (s) & 4.0 & 4.0 & 4.0 & 4.0 & 4.0 & 4.0 & 4.0 & 4.0 & 4.0 & 4.0 \\
\hline Minimum Split (s) & 10.0 & 22.0 & 10.0 & 22.0 & 21.0 & 21.0 & 21.0 & 21.0 & 21.0 & 21.0 \\
\hline Total Split (s) & 20.0 & 52.0 & 20.0 & 52.0 & 48.0 & 48.0 & 48.0 & 48.0 & 48.0 & 48.0 \\
\hline Total Split (\%) & $16.7 \%$ & $43.3 \%$ & $16.7 \%$ & $43.3 \%$ & $40.0 \%$ & $40.0 \%$ & $40.0 \%$ & $40.0 \%$ & $40.0 \%$ & $40.0 \%$ \\
\hline Yellow Time (s) & 4.0 & 4.0 & 4.0 & 4.0 & 3.0 & 3.0 & 3.0 & 3.0 & 3.0 & 3.0 \\
\hline All-Red Time (s) & 2.0 & 2.0 & 2.0 & 2.0 & 2.0 & 2.0 & 2.0 & 2.0 & 2.0 & 2.0 \\
\hline Lead/Lag & Lead & Lag & Lead & Lag & & & & & & \\
\hline \multicolumn{11}{|l|}{ Lead-Lag Optimize? } \\
\hline Recall Mode & None & Min & None & Min & None & None & None & None & None & None \\
\hline \multicolumn{11}{|l|}{ Intersection Summary } \\
\hline \multicolumn{11}{|l|}{ Cycle Length: 120} \\
\hline \multicolumn{11}{|c|}{ Actuated Cycle Length: 93.3} \\
\hline \multicolumn{11}{|l|}{ Natural Cycle: 60} \\
\hline Control Type: Actua & nc & ate & & & & & & & & \\
\hline
\end{tabular}

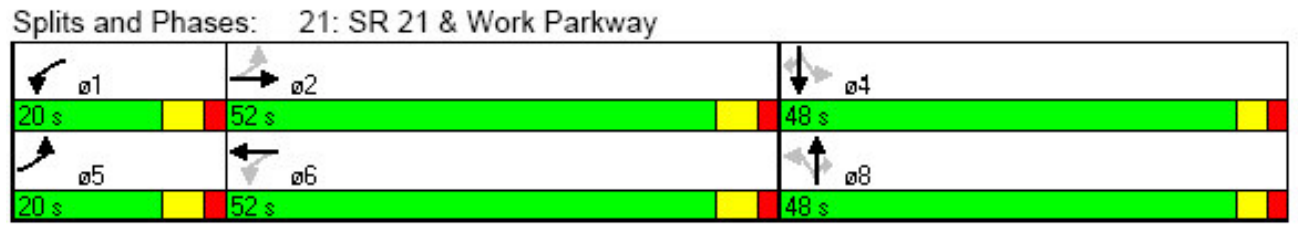




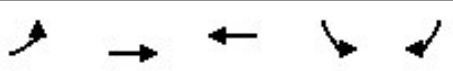

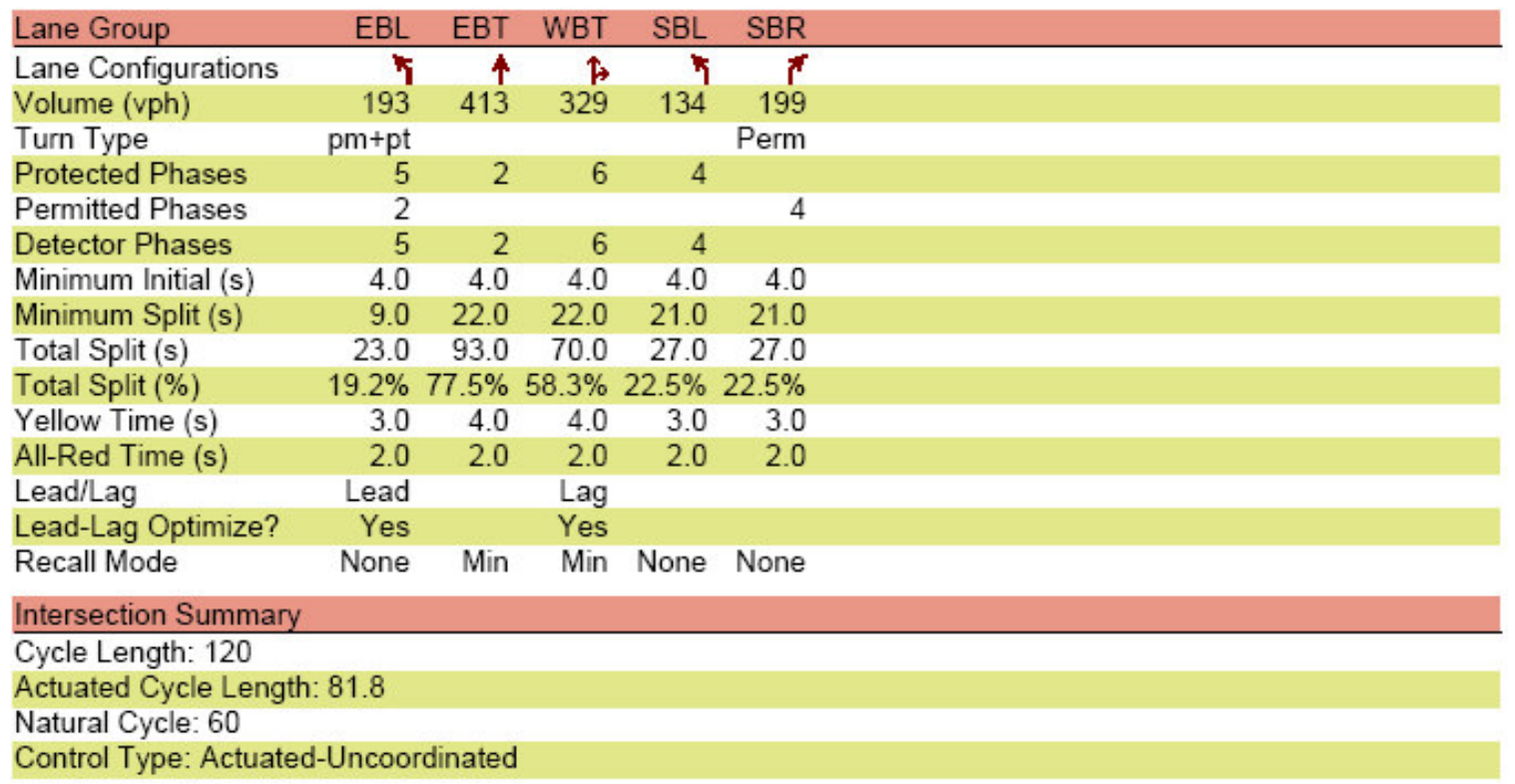

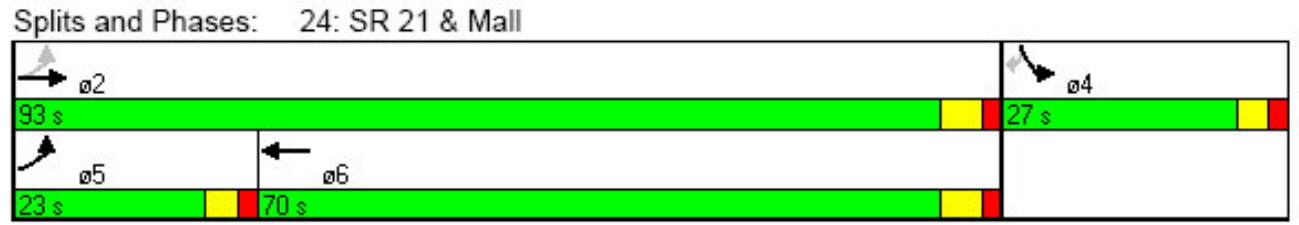




\section{Synchro Optimized - AM Peak}

Lanes, Volumes, Timings

\begin{tabular}{|c|c|c|c|c|c|c|c|c|c|}
\hline Lane Group & EBL & EBT & WBL & WBT & NBL & NBT & SBL & SBT & SBR \\
\hline Lane Configurations & 4 & 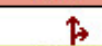 & 4 & $\uparrow$ & & $\$$ & & $\uparrow$ & t' \\
\hline Volume (vph) & 56 & 370 & 1 & 225 & 1 & 1 & 12 & 0 & 24 \\
\hline Turn Type & $\mathrm{pm}+\mathrm{pt}$ & & Perm & & Perm & & Perm & & Perm \\
\hline Protected Phases & 5 & 2 & & 6 & & 8 & & 4 & \\
\hline Permitted Phases & 2 & & 6 & & 8 & & 4 & & 4 \\
\hline Detector Phases & 5 & 2 & & 6 & 8 & 8 & 4 & 4 & 4 \\
\hline Minimum Initial (s) & 6.0 & 15.0 & 15.0 & 15.0 & 6.0 & 6.0 & 6.0 & 6.0 & 6.0 \\
\hline Minimum Split (s) & 12.0 & 22.0 & 22.0 & 22.0 & 21.0 & 21.0 & 21.0 & 21.0 & 21.0 \\
\hline Total Split (s) & 18.0 & 41.0 & 23.0 & 23.0 & 22.0 & 22.0 & 22.0 & 22.0 & 22.0 \\
\hline Total Split (\%) & $28.6 \%$ & $65.1 \%$ & $36.5 \%$ & $36.5 \%$ & $34.9 \%$ & $34.9 \%$ & $34.9 \%$ & $34.9 \%$ & $34.9 \%$ \\
\hline Yellow Time (s) & 4.0 & 4.0 & 4.0 & 4.0 & 3.0 & 3.0 & 3.0 & 3.0 & 3.0 \\
\hline All-Red Time (s) & 2.0 & 2.0 & 2.0 & 2.0 & 2.0 & 2.0 & 2.0 & 2.0 & 2.0 \\
\hline Lead/Lag & Lead & & Lag & Lag & & & & & \\
\hline \multicolumn{10}{|l|}{ Lead-Lag Optimize? } \\
\hline Recall Mode & None & C-Max & C-Max & C-Max & Min & Min & Min & Min & Min \\
\hline \multicolumn{10}{|l|}{ Intersection Summary } \\
\hline \multicolumn{10}{|l|}{ Cycle Length: 63} \\
\hline \multicolumn{10}{|c|}{ Actuated Cycle Length: 63} \\
\hline \\
\hline & & & & & & & & \multicolumn{2}{|c|}{ Natural Cycle: 55} \\
\hline \multicolumn{10}{|c|}{ Control Type: Actuated-Coordinated } \\
\hline \multicolumn{10}{|l|}{ Splits and Phases: } \\
\hline \multicolumn{6}{|l|}{$\rightarrow$ - } & & 94 & & \\
\hline \multicolumn{10}{|l|}{$41 \mathrm{~s}$} \\
\hline$>_{\text {๑5 }}$ & & ब6 & & & & 4 & 68 & & \\
\hline $18 \mathrm{~s}$ & 23 & & & & & $22 \mathrm{~s}$ & & & \\
\hline
\end{tabular}




\section{$\downarrow \rightarrow \leftarrow \leftarrow \uparrow+\downarrow$}

\begin{tabular}{|c|c|c|c|c|c|c|c|c|c|c|c|c|}
\hline Lane Group & EBL & EBT & WBL & WBT & NBL & NBT & NBR & SBL & SBT & $ø 1$ & $ø 3$ & 95 \\
\hline Lane Configurations & 5 & $\hat{F}$ & 7 & t & & $\uparrow$ & ${ }^{\pi}$ & & $\$$ & & & \\
\hline Volume (vph) & 5 & 335 & 225 & 221 & 20 & 4 & 68 & 2 & 1 & & & \\
\hline Turn Type & Perm & & custom & & Perm & & custom & Perm & & & & \\
\hline Protected Phases & & 2 & 139 & 1239 & & 4 & 13 & & 4 & 1 & 3 & 5 \\
\hline Permitted Phases & 2 & & 3 & & 4 & & 4 & 4 & & & & \\
\hline Detector Phases & 2 & 2 & 139 & 9 & 4 & 4 & 13 & 4 & 4 & & & \\
\hline Minimum Initial (s) & 4.0 & 4.0 & & & 4.0 & 4.0 & & 4.0 & 4.0 & 4.0 & 4.0 & 4.0 \\
\hline Minimum Split (s) & 22.0 & 22.0 & & & 19.0 & 19.0 & & 19.0 & 19.0 & 10.0 & 10.0 & 10.0 \\
\hline Total Split (s) & 40.0 & 40.0 & 65.0 & 105.0 & 20.0 & 20.0 & 58.0 & 20.0 & 20.0 & 18.0 & 40.0 & 19.0 \\
\hline Total Sp & $32.0 \%$ & $32.0 \%$ & $52.0 \%$ & $84.0 \%$ & $16.0 \%$ & $16.0 \%$ & $46.4 \%$ & $16.0 \%$ & $16.0 \%$ & $14 \%$ & $32 \%$ & $15 \%$ \\
\hline Yellow Time (s) & 4.0 & 4.0 & & & 4.0 & 4.0 & & 4.0 & 4.0 & 4.0 & 4.0 & 4.0 \\
\hline All-Red Time (s) & 2.0 & 2.0 & & & 2.0 & 2.0 & & 2.0 & 2.0 & 2.0 & 2.0 & 2.0 \\
\hline Lead/Lag & Lag & Lag & & & Lag & Lag & & Lag & Lag & Lead & Lead & Lead \\
\hline Lead-Lag Optimize? & & & & & & & & & & & & Yes \\
\hline Recall Mode & C-Ma & a & & & Min & Min & & Min & Min & None & None & None \\
\hline
\end{tabular}

\section{Intersection Summary}

Cycle Length: 125

Actuated Cycle Length: 125

Offset: $0(0 \%)$, Referenced to phase 2:EBWB, Start of Yellow, Master Intersection

Natural Cycle: 100

Control Type: Actuated-Coordinated

Splits and Phases: 15: SR 21 \& Brewer

\begin{tabular}{|c|c|c|c|c|c|}
\hline $\begin{array}{ll}\# 15 \quad \# 18 \\
47\end{array}$ & $\begin{array}{l}\# 15 \text { \#18 } \\
\longrightarrow \rightarrow \infty 2\end{array}$ & 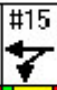 & 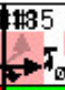 & & 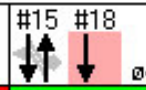 \\
\hline $18 \mathrm{~s}$ & $40 \mathrm{~s}$ & $7 \mathrm{~s}$ & $40 \mathrm{~s}$ & & $20 \mathrm{~s}$ \\
\hline & & & & $\#$ & \\
\hline & & & $19 \mathrm{~s}$ & $41 \mathrm{~s}$ & \\
\hline
\end{tabular}


Lanes, Volumes, I ımıngs

18: SR 21 \& Matthew

\begin{tabular}{|c|c|c|c|c|c|c|c|c|c|c|c|c|}
\hline Lane Group & EBL & EBT & EBR & WBL & WBT & WBR & NBL & NBT & NBR & SBL & SBT & $\oslash 2$ \\
\hline Lane Configurations & & $\uparrow$ & $\pi$ & 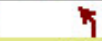 & $\uparrow$ & $\bar{r}$ & 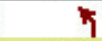 & $\uparrow$ & $\bar{r}$ & $\mathbf{T}$ & 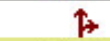 & \\
\hline Volume (vph) & 3 & 186 & 216 & 86 & 126 & 57 & $295^{\circ}$ & 155 & 186 & 46 & 102 & \\
\hline Turn Type & Perm & & $\mathrm{pt}+\mathrm{ov}$ & Split & & Perm & Prot & & Over & Prot & & \\
\hline Protected Phases & & 29 & 239 & 1 & 1 & & 3 & 6 & 1 & 5 & 4 & 2 \\
\hline Permitted Phases & 29 & & & & 2 & 1 & & & & & & \\
\hline Detector Phases & 9 & 9 & 9 & 1 & 1 & 1 & 3 & 6 & 1 & 5 & 4 & \\
\hline Minimum Initial (s) & & & & 4.0 & 4.0 & 4.0 & 4.0 & 4.0 & 4.0 & 4.0 & 4.0 & 4.0 \\
\hline Minimum Split (s) & & & & 10.0 & 10.0 & 10.0 & 10.0 & 22.0 & 10.0 & 10.0 & 19.0 & 22.0 \\
\hline Total Split (s) & 47.0 & 47.0 & 87.0 & 18.0 & 18.0 & 18.0 & 40.0 & 41.0 & 18.0 & 19.0 & 20.0 & 40.0 \\
\hline Total Split (\%) & $37.6 \%$ & $37.6 \%$ & $69.6 \%$ & $14.4 \%$ & $14.4 \%$ & $14.4 \%$ & $32.0 \%$ & $32.8 \%$ & $14.4 \%$ & $15.2 \%$ & $16.0 \%$ & $32 \%$ \\
\hline Yellow Time (s) & & & & 4.0 & 4.0 & 4.0 & 4.0 & 4.0 & 4.0 & 4.0 & 4.0 & 4.0 \\
\hline All-Red Time (s) & & & & 2.0 & 2.0 & 2.0 & 2.0 & 2.0 & 2.0 & 2.0 & 2.0 & 2.0 \\
\hline Lead/Lag & & & & Lead & Lead & Lead & Lead & Lag & Lead & Lead & Lag & Lag \\
\hline Lead-Lag Optimize? & & & & & & & & Yes & & Yes & & \\
\hline Recall Mode & & & & None & None & None & None & Min & None & None & Min & -Max \\
\hline
\end{tabular}

Cycle Length: 125

Actuated Cycle Length: 125

Offset: $0(0 \%)$, Referenced to phase 2:EBWB, Start of Yellow, Master Intersection

Natural Cycle: 100

Control Type: Actuated-Coordinated

Splits and Phases: 18 : SR 21 \& Matthew

\begin{tabular}{|c|c|c|c|c|}
\hline 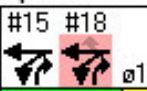 & 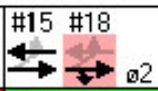 & $\begin{array}{l}\# 15 \\
7\end{array}$ & & $\begin{array}{l}\# 15 \text { \#18 } \\
1 \mid \neq\end{array}$ \\
\hline $18 \mathrm{~s}$ & $40 \mathrm{~s}$ & $40 \mathrm{~s}$ & & $20 \mathrm{~s}$ \\
\hline & & & $\begin{array}{r}\# 18 \\
\uparrow\end{array}$ & \\
\hline & & $19 \mathrm{~s}$ & $41 s$ & \\
\hline
\end{tabular}




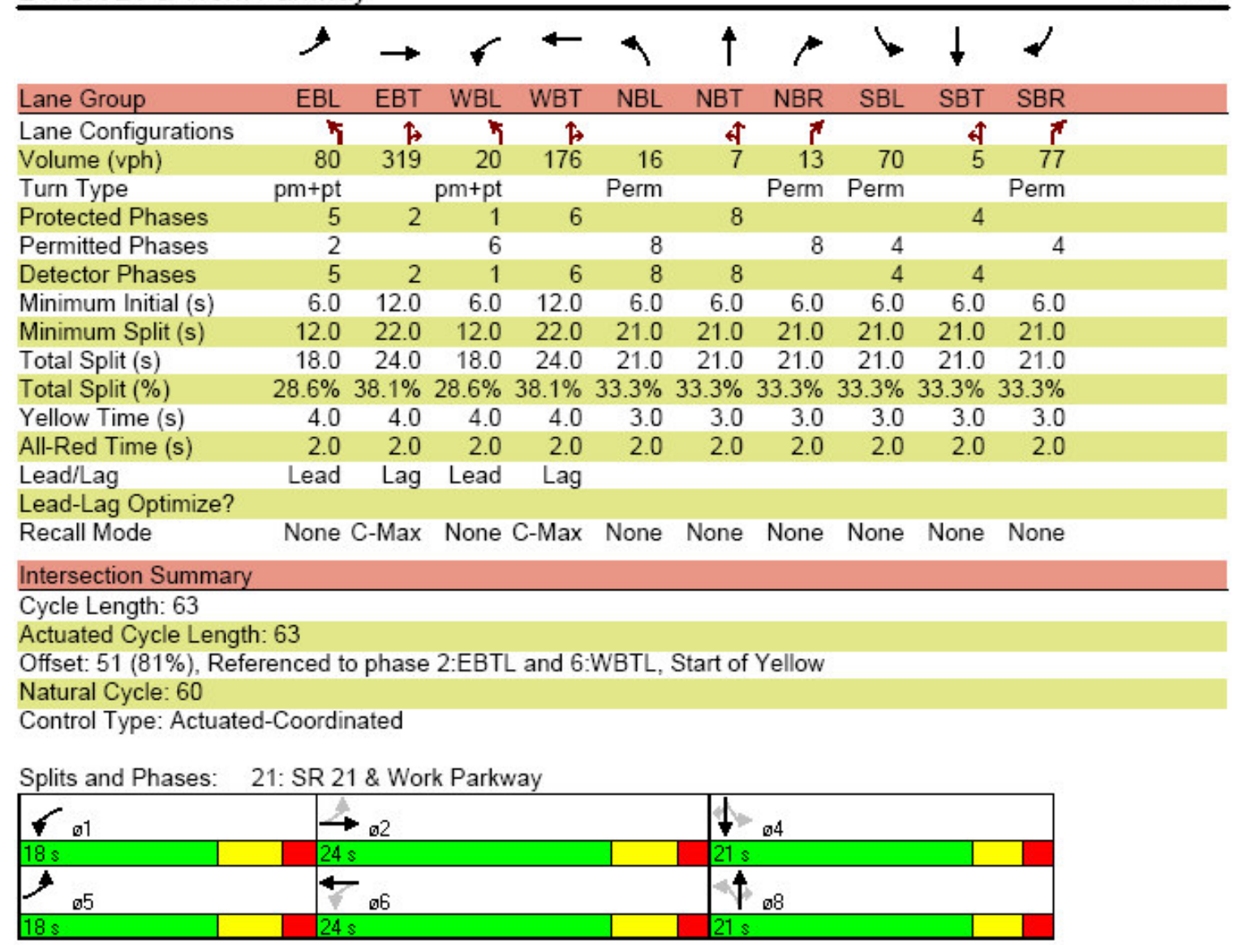




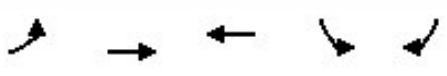

\begin{tabular}{|c|c|c|c|c|c|}
\hline Lane Group & EBL & EBT & WBT & SBL & SBR \\
\hline Lane Configurations & T & $\uparrow$ & 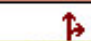 & 4 & 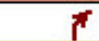 \\
\hline Volume (vph) & 92 & 310 & 240 & 53 & 37 \\
\hline Turn Type & $\mathrm{pm}+\mathrm{pt}$ & & & & Perm \\
\hline Protected Phases & 5 & 2 & 6 & 4 & \multirow[b]{2}{*}{4} \\
\hline Permitted Phases & 2 & & & & \\
\hline Detector Phases & 5 & 2 & 6 & 4 & \\
\hline Minimum Initial (s) & 6.0 & 12.0 & 10.0 & 6.0 & 6.0 \\
\hline Minimum Split (s) & 11.0 & 22.0 & 16.0 & 11.0 & 11.0 \\
\hline Total Split (s) & 19.0 & 43.0 & 24.0 & 20.0 & 20.0 \\
\hline Total Split (\%) & $30.2 \%$ & $68.3 \%$ & $38.1 \%$ & $31.7 \%$ & $31.7 \%$ \\
\hline Yellow Time (s) & 3.0 & 4.0 & 4.0 & 3.0 & 3.0 \\
\hline All-Red Time (s) & 2.0 & 2.0 & 2.0 & 2.0 & 2.0 \\
\hline Lead/Lag & Lead & & Lag & & \\
\hline Lead-Lag Optimize? & Yes & & Yes & & \\
\hline Recall Mode & None & $\mathrm{C}-\mathrm{M}_{2}$ & C-Max & None & ne \\
\hline
\end{tabular}

\section{Intersection Summary}

Cycle Length: 63

Actuated Cycle Length: 63

Offset: 36 (57\%), Referenced to phase 2:EBTL and 6:WBT, Start of Green

Natural Cycle: 45

Control Type: Actuated-Coordinated

Splits and Phases: 24: SR 21 \& Mall

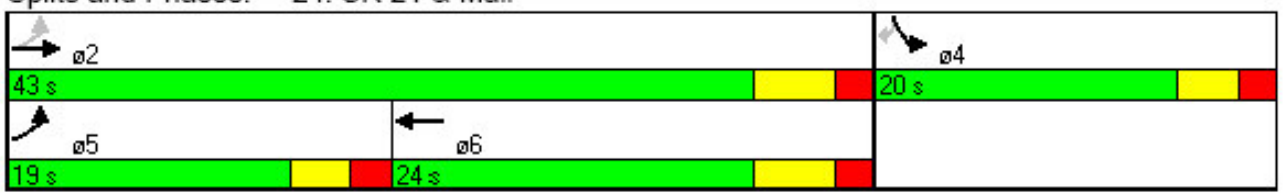


Lanes, Volumes, Timings

\section{Synchro Optimized - Midday Peak}

12: SR 21 \& Daniel Drive

\begin{tabular}{|c|c|c|c|c|c|c|c|c|c|}
\hline Lane Group & EBL & EBT & WBL & WBT & NBL & NBT & SBL & SBT & SBR \\
\hline Lane Configurations & 1 & $\uparrow$ & 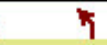 & $\uparrow$ & & $\leftrightarrow$ & & $\uparrow$ & $\pi$ \\
\hline Volume (vph) & 89 & 319 & 1 & 267 & 1 & 1 & 122 & 0 & 39 \\
\hline Turn Type & $\mathrm{pm}+\mathrm{pt}$ & & Perm & & Perm & & Perm & & Perm \\
\hline Protected Phases & 5 & 2 & & 6 & & 8 & & 4 & \\
\hline Permitted Phases & 2 & & 6 & & 8 & & 4 & & 4 \\
\hline Detector Phases & 5 & 2 & & 6 & 8 & 8 & 4 & 4 & 4 \\
\hline Minimum Initial (s) & 6.0 & 15.0 & 15.0 & 15.0 & 6.0 & 6.0 & 6.0 & 6.0 & 6.0 \\
\hline Minimum Split (s) & 12.0 & 22.0 & 22.0 & 22.0 & 21.0 & 21.0 & 21.0 & 21.0 & 21.0 \\
\hline Total Split (s) & 20.0 & 60.0 & 40.0 & 40.0 & 30.0 & 30.0 & 30.0 & 30.0 & 30.0 \\
\hline Total Split (\%) & $22.2 \%$ & $66.7 \%$ & $44.4 \%$ & $44.4 \%$ & $33.3 \%$ & $33.3 \%$ & $33.3 \%$ & $33.3 \%$ & $33.3 \%$ \\
\hline Yellow Time (s) & 4.0 & 4.0 & 4.0 & 4.0 & 3.0 & 3.0 & 3.0 & 3.0 & 3.0 \\
\hline All-Red Time (s) & 2.0 & 2.0 & 2.0 & 2.0 & 2.0 & 2.0 & 2.0 & 2.0 & 2.0 \\
\hline Lead/Lag & Lead & & Lag & Lag & & & & & \\
\hline \multicolumn{10}{|l|}{ Lead-Lag Optimize? } \\
\hline Recall Mode & None & C-Max & C-Max & C-Max & Min & Min & Min & Min & Min \\
\hline
\end{tabular}

Cycle Length: 90

Actuated Cycle Length: 90

Offset: 38 (42\%), Referenced to phase 2:EBTL and 6:WBTL, Start of Yellow

Natural Cycle: 60

Control Type: Actuated-Coordinated

Splits and Phases: $12:$ SR 21 \& Daniel Drive

\begin{tabular}{|c|c|c|}
\hline \multirow{2}{*}{\multicolumn{2}{|c|}{$60 \mathrm{~s}$}} & 104 \\
\hline & & $30 \mathrm{~s}$ \\
\hline$>_{65}$ & $\sqrt{-66}$ & $\varphi_{\text {(1) }}$ \\
\hline $20 \mathrm{~s}$ & $40 s$ & $30 \mathrm{~s}$ \\
\hline
\end{tabular}




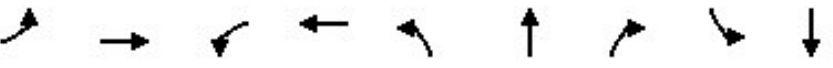

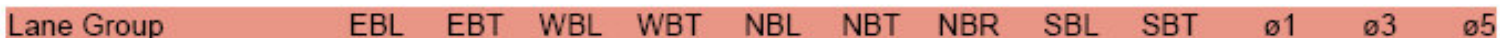

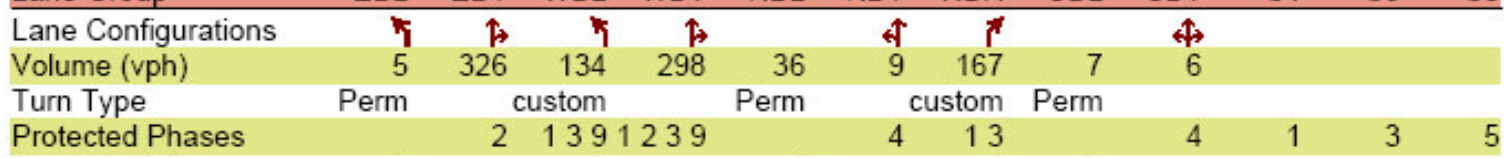

Permitted Phases

Detector Phases

Minimum Initial (s)

2

21391239

$4 \quad 13$

Minimum Split (s)

Total Split (s)

Total Split (\%)

Yellow Time (s)

$\begin{array}{lrrrrr}2 & 2 & 139 & 9 & 4\end{array}$

13

4

$\begin{array}{lllllll}4.0 & 4.0 & 4.0 & 4.0 & 4.0 & 4.0 & 4.0\end{array}$

$\begin{array}{rrrrrrrrr}22.0 & 22.0 & 22.0 & 22.0 & 22.0 & 22.0 & 10.0 & 10.0 & 10.0\end{array}$

$\begin{array}{llllllllllll}61.0 & 61.0 & 80.0 & 141.0 & 39.0 & 39.0 & 70.0 & 39.0 & 39.0 & 33.0 & 37.0 & 26.0\end{array}$

All-Red Time (s)

Lead/Lag

Lead-Lag Optimize?

Recall Mode

$\begin{array}{llllllll}33.9 \% & 33.9 \% & 44.4 \% & 78.3 \% & 21.7 \% & 21.7 \%\end{array}$

$\begin{array}{lr}.9 \% & 33.9 \% \\ 4.0 & 4.0\end{array}$

$7 \% 21.7 \%$

$.7 \% 21.7 \%$

$18 \%$

0

$\begin{array}{rr}4.0 & 4.0 \\ 2.0 & 2.0 \\ \text { Lag } & \text { Lag }\end{array}$

$\begin{array}{lllll}4.0 & 4.0 & 4.0 & 4.0 & 4.0\end{array}$

Lag Lag

$\begin{array}{lllll}2.0 & 2.0 & 2.0 & 2.0 & 2.0\end{array}$

C-I

Intersection Summary

Cycle Length: 180

Actuated Cycle Length: 180

Offset: 160 (89\%), Referenced to phase 2:EBWB, Start of Yellow

Natural Cycle: 140

Control Type: Actuated-Coordinated

Splits and Phases: 15 : SR 21 \& Brewer

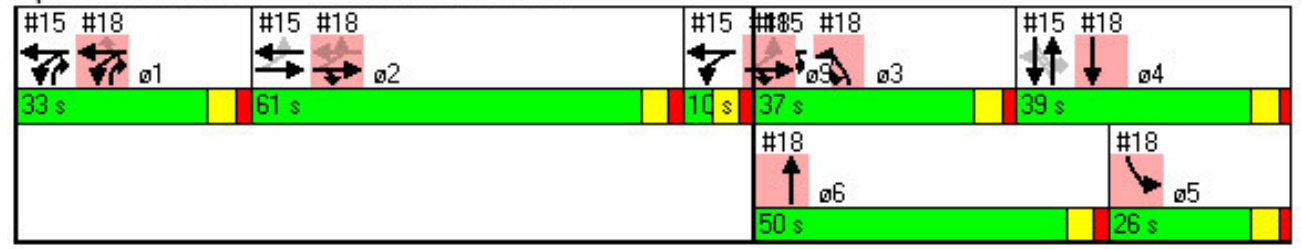




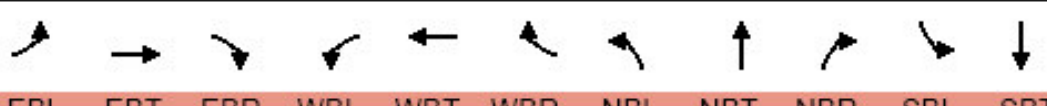

\begin{tabular}{|c|c|c|c|c|c|c|c|c|c|c|c|c|}
\hline Lane Group & EBL & EBT & EBR & WBL & WBT & WBR & NBL & NBT & NBR & SBL & SBT & $\oslash 2$ \\
\hline Lane Configurations & & $\uparrow$ & $\pi$ & 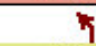 & $\uparrow$ & $\pi$ & 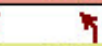 & $\uparrow$ & $\pi$ & 5 & 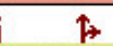 & \\
\hline Volume (vph) & 15 & 261 & 224 & 190 & 213 & 154 & 200 & 253 & 259 & 144 & 243 & \\
\hline Turn Type & Perm & & $\mathrm{pt}+\mathrm{ov}$ & Split & & Perm & Prot & & Over & Prot & & \\
\hline Protected Phases & & 29 & 239 & 1 & 1 & & 3 & 6 & 1 & 5 & 4 & 2 \\
\hline Permitted Phases & 29 & & & & 2 & 1 & & & & & & \\
\hline Detector Phases & 9 & 9 & 9 & 1 & 1 & 1 & 3 & 6 & 1 & 5 & 4 & \\
\hline Minimum Initial (s) & & & & 4.0 & 4.0 & 4.0 & 4.0 & 4.0 & 4.0 & 4.0 & 4.0 & 4.0 \\
\hline Minimum Split (s) & & & & 10.0 & 10.0 & 10.0 & 10.0 & 22.0 & 10.0 & 10.0 & 22.0 & 22.0 \\
\hline Total Split (s) & 71.0 & 71.0 & 108.0 & 33.0 & 33.0 & 33.0 & 37.0 & 50.0 & 33.0 & 26.0 & 39.0 & 61.0 \\
\hline Total Split (\%) & $39.4 \%$ & $39.4 \%$ & $60.0 \%$ & $18.3 \%$ & $18.3 \%$ & $18.3 \%$ & $20.6 \%$ & $27.8 \%$ & $18.3 \%$ & $14.4 \%$ & $21.7 \%$ & $34 \%$ \\
\hline Yellow Time (s) & & & & 4.0 & 4.0 & 4.0 & 4.0 & 4.0 & 4.0 & 4.0 & 4.0 & 4.0 \\
\hline All-Red Time (s) & & & & 2.0 & 2.0 & 2.0 & 2.0 & 2.0 & 2.0 & 2.0 & 2.0 & 2.0 \\
\hline Lead/Lag & & & & Lead & Lead & Lead & Lead & Lead & Lead & Lag & Lag & Lag \\
\hline Lead-Lag Optimize? & & & & & & & & Yes & & Yes & & \\
\hline Recall Mode & & & & None & None & None & None & Min & None & None & Min & C-Max \\
\hline
\end{tabular}

Cycle Length: 180

Actuated Cycle Length: 180

Offset: 160 (89\%), Referenced to phase 2:EBWB, Start of Yellow

Natural Cycle: 140

Control Type: Actuated-Coordinated

Splits and Phases: 18: SR 21 \& Matthew

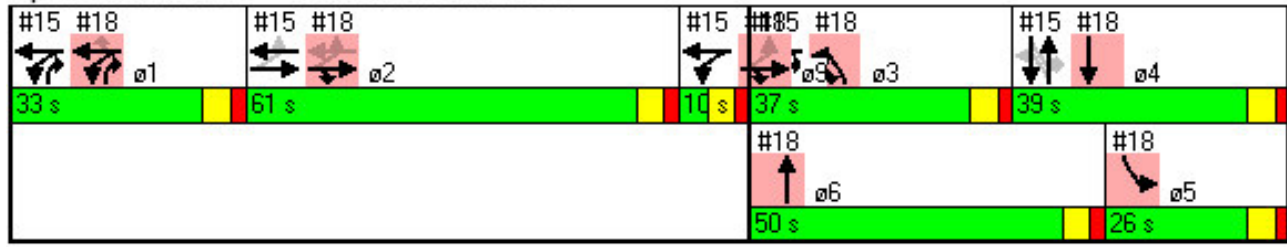




\begin{tabular}{|c|c|c|c|c|c|c|c|c|c|c|}
\hline Lane Group & EBL & EBT & WBL & WBT & NBL & NBT & NBR & SBL & SBT & SBR \\
\hline Lane Configurations & 广 & $\uparrow$ & 1 & $\uparrow$ & & $\uparrow$ & $\bar{r}$ & & $\uparrow$ & $\pi$ \\
\hline Volume (vph) & 192 & 369 & 83 & 305 & 79 & 50 & 72 & 150 & 41 & 173 \\
\hline Turn Type & $\mathrm{pm}+\mathrm{pt}$ & & $\mathrm{pm}+\mathrm{pt}$ & & Perm & & Perm & Perm & & Perm \\
\hline Protected Phases & 5 & 2 & 1 & 6 & & 8 & & & 4 & \\
\hline Permitted Phases & 2 & & 6 & & 8 & & 8 & 4 & & 4 \\
\hline Detector Phases & 5 & 2 & 1 & 6 & 8 & 8 & & 4 & 4 & \\
\hline Minimum Initial (s) & 6.0 & 12.0 & 6.0 & 12.0 & 6.0 & 6.0 & 6.0 & 6.0 & 6.0 & 6.0 \\
\hline Minimum Split (s) & 12.0 & 22.0 & 12.0 & 22.0 & 21.0 & 21.0 & 21.0 & 21.0 & 21.0 & 21.0 \\
\hline Total Split (s) & 28.0 & 83.0 & 26.0 & 81.0 & 71.0 & 71.0 & 71.0 & 71.0 & 71.0 & 71.0 \\
\hline Total Split (\%) & $15.6 \%$ & $46.1 \%$ & $14.4 \%$ & $45.0 \%$ & $39.4 \%$ & $39.4 \%$ & $39.4 \%$ & $39.4 \%$ & $39.4 \%$ & $39.4 \%$ \\
\hline Yellow Time (s) & 4.0 & 4.0 & 4.0 & 4.0 & 3.0 & 3.0 & 3.0 & 3.0 & 3.0 & 3.0 \\
\hline All-Red Time (s) & 2.0 & 2.0 & 2.0 & 2.0 & 2.0 & 2.0 & 2.0 & 2.0 & 2.0 & 2.0 \\
\hline Lead/Lag & Lead & Lag & Lead & Lag & & & & & & \\
\hline \multicolumn{11}{|l|}{ Lead-Lag Optimize? } \\
\hline Recall Mode & None & C-Max & None & C-Max & None & None & None & None & None & None \\
\hline \multicolumn{11}{|l|}{ Intersection Summary } \\
\hline \multicolumn{11}{|l|}{ Cycle Length: 180} \\
\hline \multicolumn{11}{|c|}{ Actuated Cycle Length: 180} \\
\hline \multicolumn{11}{|c|}{ Offset: $172(96 \%)$, Referenced to phase 2:EBTL and 6:WBTL, Start of Yellow } \\
\hline \multicolumn{11}{|c|}{ Natural Cycle: 75} \\
\hline
\end{tabular}

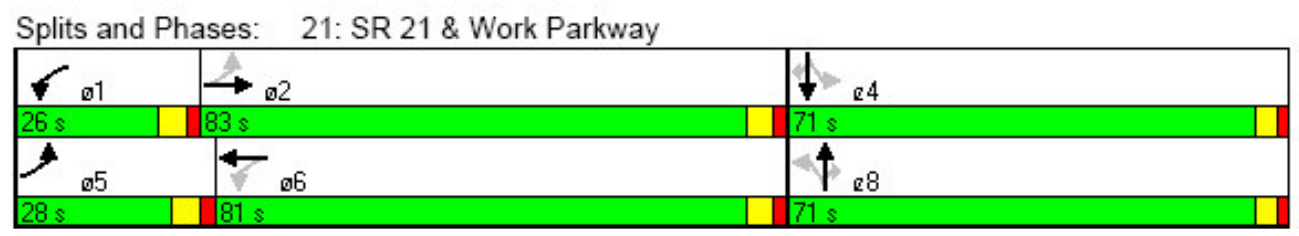




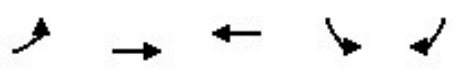

\begin{tabular}{|c|c|c|c|c|c|}
\hline Lane Group & EBL & EBT & WBT & SBL & SBR \\
\hline Lane Configurations & 4 & $\uparrow$ & $\uparrow$ & 4 & $\pi$ \\
\hline Volume (vph) & 220 & 371 & 316 & 115 & 215 \\
\hline Turn Type & $\mathrm{pm}+\mathrm{pt}$ & & & & Perm \\
\hline Protected Phases & 5 & 2 & 6 & 4 & \\
\hline Permitted Phases & 2 & & & & 4 \\
\hline Detector Phases & 5 & 2 & 6 & 4 & \\
\hline Minimum Initial (s) & 6.0 & 12.0 & 12.0 & 6.0 & 6.0 \\
\hline Minimum Split (s) & 20.0 & 22.0 & 22.0 & 21.0 & 21.0 \\
\hline Total Split (s) & 26.0 & 65.0 & 39.0 & 25.0 & 25.0 \\
\hline Total Split (\%) & $28.9 \%$ & $72.2 \%$ & $43.3 \%$ & $27.8 \%$ & $27.8 \%$ \\
\hline Yellow Time (s) & 3.0 & 4.0 & 4.0 & 3.0 & 3.0 \\
\hline All-Red Time (s) & 2.0 & 2.0 & 2.0 & 2.0 & 2.0 \\
\hline Lead/Lag & Lead & & Lag & & \\
\hline Lead-Lag Optimize? & Yes & & Yes & & \\
\hline ecall Mode & lor & & Max & None & \\
\hline
\end{tabular}

\section{Intersection Summary}

Cycle Length: 90

Actuated Cycle Length: 90

Offset: 26 (29\%), Referenced to phase 2:EBTL and 6:WBT, Start of Green

Natural Cycle: 75

Control Type: Actuated-Coordinated

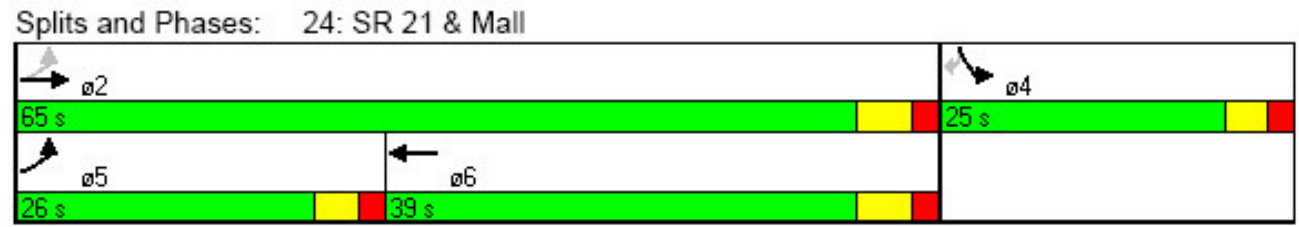




\section{Synchro Optimized - PM Peak}

Lanes, Volumes, Timings

12: SR 21 \& Daniel Drive

\begin{tabular}{|c|c|c|c|c|c|c|c|c|c|}
\hline Lane Group & EBL & EBT & WBL & WBT & NBL & NBT & SBL & SBT & SBR \\
\hline Lane Configurations & $\boldsymbol{1}$ & $\uparrow$ & 7 & $\uparrow$ & & $\$$ & & $\uparrow$ & $\bar{t}$ \\
\hline Volume (vph) & 111 & 387 & 1 & 457 & 1 & 1 & 31 & 0 & 147 \\
\hline Turn Type & $\mathrm{pm}+\mathrm{pt}$ & & Perm & & Perm & & Perm & & Perm \\
\hline Protected Phases & 5 & 2 & & 6 & & 8 & & 4 & \\
\hline Permitted Phases & 2 & & 6 & & 8 & & 4 & & 4 \\
\hline Detector Phases & 5 & 2 & & 6 & 8 & 8 & 4 & 4 & 4 \\
\hline Minimum Initial (s) & 6.0 & 12.0 & 12.0 & 12.0 & 6.0 & 6.0 & 6.0 & 6.0 & 6.0 \\
\hline Minimum Split (s) & 12.0 & 18.0 & 18.0 & 18.0 & 11.0 & 11.0 & 11.0 & 11.0 & 11.0 \\
\hline Total Split (s) & 32.0 & 142.0 & 110.0 & 110.0 & 38.0 & 38.0 & 38.0 & 38.0 & 38.0 \\
\hline Total Split (\%) & $17.8 \%$ & $78.9 \%$ & $61.1 \%$ & $61.1 \%$ & $21.1 \%$ & $21.1 \%$ & $21.1 \%$ & $21.1 \%$ & $21.1 \%$ \\
\hline Yellow Time (s) & 4.0 & 4.0 & 4.0 & 4.0 & 3.0 & 3.0 & 3.0 & 3.0 & 3.0 \\
\hline All-Red Time (s) & 2.0 & 2.0 & 2.0 & 2.0 & 2.0 & 2.0 & 2.0 & 2.0 & 2.0 \\
\hline Lead/Lag & Lead & & Lag & Lag & & & & & \\
\hline \multicolumn{10}{|l|}{ Lead-Lag Optimize? } \\
\hline Recall Mode & None & C-Max & C-Max & C-Max & Min & Min & Min & Min & Min \\
\hline \multicolumn{10}{|l|}{ Intersection Summary } \\
\hline \multirow{2}{*}{\multicolumn{10}{|c|}{$\begin{array}{l}\text { Cycle Length: } 180 \\
\text { Actuated Cycle Length: } 180\end{array}$}} \\
\hline & & & & & & & & & \\
\hline \multicolumn{10}{|c|}{ Offset: $13(7 \%)$, Referenced to phase 2:EBTL and $6:$ WBTL, Start of Yellow } \\
\hline \multirow{2}{*}{\multicolumn{10}{|c|}{$\begin{array}{l}\text { Natural Cycle: } 60 \\
\text { Control Type: Actuated-Coordinated }\end{array}$}} \\
\hline & & & & & & & & & \\
\hline Splits and Phases: & \multicolumn{9}{|c|}{ 12: SR 21 \& Daniel Drive } \\
\hline \multirow{2}{*}{\multicolumn{8}{|c|}{$\rightarrow$ a2 }} & \multicolumn{2}{|l|}{ ๑4 } \\
\hline & & & & & & & & $38 s$ & \\
\hline$>_{32}$ & 96 & & & & & & & $\varphi_{08}$ & \\
\hline
\end{tabular}




\section{$\rightarrow \rightarrow \leftarrow \leftarrow \uparrow+\downarrow$}

\begin{tabular}{|c|c|c|c|c|c|c|c|c|c|c|c|c|}
\hline Lane Group & EBL & EBT & WBL & WBT & NBL & NBT & NBR & SBL & SBT & $ø 1$ & $ø 3$ & 05 \\
\hline Lane Configurations & 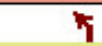 & $\uparrow$ & 7 & $\uparrow$ & & $\uparrow$ & $\pi$ & & $\$$ & & & \\
\hline Volume (vph) & 6 & 397 & 92 & 450 & 52 & 3 & 165 & 16 & 2 & & & \\
\hline Turn Type & Perm & \multicolumn{2}{|c|}{ custom } & & Perm & \multicolumn{2}{|r|}{ custom } & Perm & & & & \\
\hline Protected Phases & & 2 & 139 & 1239 & & 4 & 13 & & 4 & 1 & 3 & 5 \\
\hline Permitted Phases & 2 & & 3 & & 4 & & 4 & 4 & & & & \\
\hline Detec & 2 & 2 & 139 & 9 & 4 & 4 & 13 & 4 & 4 & & & \\
\hline Minimum Ir & 6.0 & 6.0 & & & 12.0 & 12.0 & & 12.0 & 12.0 & 12.0 & 12.0 & 6.0 \\
\hline Minimum Split (s) & 12.0 & 12.0 & & & 18.0 & 18.0 & & 18.0 & 18.0 & 18.0 & 18.0 & 12.0 \\
\hline Total Split (s) & 53.0 & 53.0 & 85.0 & 138.0 & 42.0 & 42.0 & 78.0 & 42.0 & 42.0 & 36.0 & 42.0 & 32.0 \\
\hline Total Split & $9.4 \%$ & $29.4 \%$ & $47.2 \%$ & $76.7 \%$ & $23.3 \%$ & $23.3 \%$ & $43.3 \%$ & $23.3 \%$ & $23.3 \%$ & $20 \%$ & $23 \%$ & $18 \%$ \\
\hline Yellow Tin & 4.0 & 4.0 & & & 4.0 & 4.0 & & 4.0 & 4.0 & 4.0 & 4.0 & 4.0 \\
\hline All-Red Ti & 2.0 & 2.0 & & & 2.0 & 2.0 & & 2.0 & 2.0 & 2.0 & 2.0 & 2.0 \\
\hline Lead/Lag & Lag & Lag & & & Lag & Lag & & Lag & Lag & Lead & Lead & Lead \\
\hline \multicolumn{13}{|l|}{ Lead-Lag Opti } \\
\hline Recall Mode & C-Max & U-lvax & & & None & ne & & e & e & one & one & None \\
\hline
\end{tabular}

Intersection Summary

Cycle Length: 180

Actuated Cycle Length: 180

Offset: $0(0 \%)$, Referenced to phase 2:EBWB, Start of Yellow, Master Intersection

Natural Cycle: 150

Control Type: Actuated-Coordinated

Splits and Phases: 15: SR 21 \& Brewer

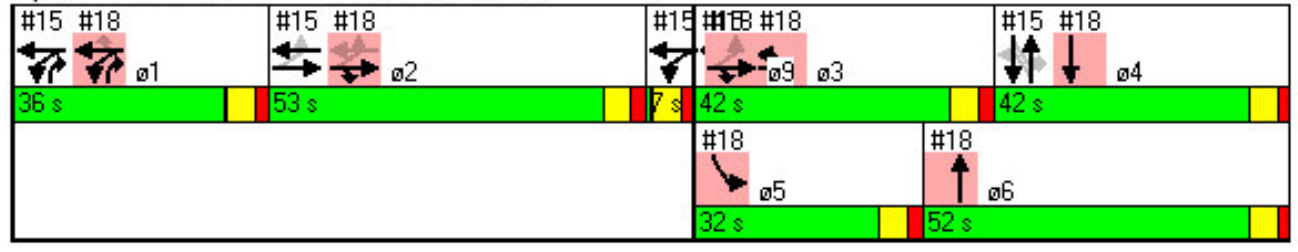




\section{$\rightarrow+\infty+4+1$}

\begin{tabular}{|c|c|c|c|c|c|c|c|c|c|c|c|c|}
\hline Lane Group & EBL & EBT & EBR & WBL & WBT & WBR & NBL & NBT & NBR & SBL & SBT & $\oslash 2$ \\
\hline Lane Configurations & & $\uparrow$ & $\pi$ & 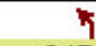 & $\uparrow$ & $\bar{r}$ & 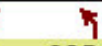 & $\uparrow$ & $\bar{t}$ & 1 & $\uparrow$ & \\
\hline Volume (vph) & 6 & 254 & 318 & 247 & 222 & 150 & 305 & 268 & 243 & 147 & 318 & \\
\hline Turn Type & Perm & & $\mathrm{pt}+\mathrm{ov}$ & Split & & Perm & Prot & & Over & Prot & & \\
\hline Protected Phases & & 29 & 239 & 1 & 1 & & 3 & 6 & 1 & 5 & 4 & 2 \\
\hline Permitted Phases & 29 & & & & 2 & 1 & & & & & & \\
\hline Detector Phases & 9 & 9 & 9 & 1 & 1 & 1 & 3 & 6 & 1 & 5 & 4 & \\
\hline Minimum Initial (s) & & & & 12.0 & 12.0 & 12.0 & 12.0 & 12.0 & 12.0 & 6.0 & 12.0 & 6.0 \\
\hline Minimum Split (s) & & & & 18.0 & 18.0 & 18.0 & 18.0 & 18.0 & 18.0 & 12.0 & 18.0 & 12.0 \\
\hline Total Split (s) & 60.0 & 60.0 & 102.0 & 36.0 & 36.0 & 36.0 & 42.0 & 52.0 & 36.0 & 32.0 & 42.0 & 53.0 \\
\hline Total Split (\%) & $33.3 \%$ & $33.3 \%$ & $56.7 \%$ & $20.0 \%$ & $20.0 \%$ & $20.0 \%$ & $23.3 \%$ & $28.9 \%$ & $20.0 \%$ & $17.8 \%$ & $23.3 \%$ & $29 \%$ \\
\hline Yellow Time (s) & & & & 4.0 & 4.0 & 4.0 & 4.0 & 4.0 & 4.0 & 4.0 & 4.0 & 4.0 \\
\hline All-Red Time (s) & & & & 2.0 & 2.0 & 2.0 & 2.0 & 2.0 & 2.0 & 2.0 & 2.0 & 2.0 \\
\hline Lead/Lag & & & & Lead & Lead & Lead & Lead & Lag & Lead & Lead & Lag & Lag \\
\hline \multicolumn{13}{|l|}{ Lead-Lag Optimize? } \\
\hline Recall Mode & & & & None & None & None & None & None & None & None & None & C-Max \\
\hline
\end{tabular}

Cycle Length: 180

Actuated Cycle Length: 180

Offset: $0(0 \%)$, Referenced to phase 2:EBWB, Start of Yellow, Master Intersection

Natural Cycle: 150

Control Type: Actuated-Coordinated

Splits and Phases: 18: SR 21 \& Matthew

\begin{tabular}{|c|c|c|c|c|}
\hline $\begin{array}{lll}\# 15 & \# 18 \\
7 & 7\end{array}$ & $\underset{t 15}{\# 18}$ & 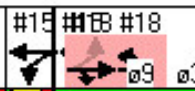 & & $\begin{array}{l}\# 15 \text { \#18 } \\
11\end{array}$ \\
\hline $36 \mathrm{~s}$ & $53 s$ & 7s 42 s & & $42 s$ \\
\hline & & & $\begin{array}{r}\# 18 \\
1\end{array}$ & $₫ 6$ \\
\hline & & $32 s$ & $52 s$ & \\
\hline
\end{tabular}




\begin{tabular}{|c|c|c|c|c|c|c|c|c|c|c|}
\hline Lane Group & EBL & EBT & WBL & WBT & NBL & NBT & NBR & SBL & SBT & SBR \\
\hline Lane Configurations & 1 & $\uparrow$ & 4 & $\uparrow$ & & $\uparrow$ & $\vec{r}$ & & $\uparrow$ & 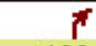 \\
\hline Volume (vph) & 167 & 402 & 56 & 359 & 91 & 44 & 76 & 128 & 23 & 169 \\
\hline Turn Type & $\mathrm{pm}+\mathrm{pt}$ & & $\mathrm{pm}+\mathrm{pt}$ & & Perm & & Perm & Perm & & Perm \\
\hline Protected Phases & 5 & 2 & 1 & 6 & & 8 & & & 4 & \\
\hline Permitted Phases & 2 & & 6 & & 8 & & 8 & 4 & & 4 \\
\hline Detector Phases & 5 & 2 & 1 & 6 & 8 & 8 & & 4 & 4 & \\
\hline Minimum Initial (s) & 6.0 & 12.0 & 6.0 & 12.0 & 6.0 & 6.0 & 6.0 & 6.0 & 6.0 & 6.0 \\
\hline Minimum Split (s) & 12.0 & 18.0 & 12.0 & 18.0 & 11.0 & 11.0 & 11.0 & 11.0 & 11.0 & 11.0 \\
\hline Total Split (s) & 26.0 & 93.0 & 26.0 & 93.0 & 61.0 & 61.0 & 61.0 & 61.0 & 61.0 & 61.0 \\
\hline Total Split (\%) & $14.4 \%$ & $51.7 \%$ & $14.4 \%$ & $51.7 \%$ & $33.9 \%$ & $33.9 \%$ & $33.9 \%$ & $33.9 \%$ & $33.9 \%$ & $33.9 \%$ \\
\hline Yellow Time (s) & 4.0 & 4.0 & 4.0 & 4.0 & 3.0 & 3.0 & 3.0 & 3.0 & 3.0 & 3.0 \\
\hline All-Red Time (s) & 2.0 & 2.0 & 2.0 & 2.0 & 2.0 & 2.0 & 2.0 & 2.0 & 2.0 & 2.0 \\
\hline Lead/Lag & Lead & Lag & Lead & Lag & & & & & & \\
\hline \multicolumn{11}{|l|}{ Lead-Lag Optimize? } \\
\hline Recall Mode & None & C-Max & None & C-Max & None & None & None & None & None & None \\
\hline \multicolumn{11}{|l|}{ Intersection Summary } \\
\hline \multirow{2}{*}{\multicolumn{11}{|c|}{$\begin{array}{l}\text { Cycle Length: } 180 \\
\text { Actuated Cycle Length: } 180\end{array}$}} \\
\hline & $: 180$ & & & & & & & & & \\
\hline \multicolumn{11}{|c|}{ Offset: $67(37 \%)$, Referenced to phase 2:EBTL and 6:WBTL, Start of Yellow } \\
\hline \multirow{2}{*}{\multicolumn{11}{|c|}{ Natural Cycle: 70}} \\
\hline Control Type: Actuated-Coordinated & & & & & & & & & & \\
\hline \multicolumn{11}{|c|}{ Splits and Phases: 21: SR 21 \& Work Parkway } \\
\hline$\lceil$-1 & & & & & & 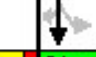 & -44 & & & \\
\hline $26 s$ & & & & & & $61 s$ & & & & \\
\hline$\sqrt{76}$ & & & & & & 1 & ๑8 & & & \\
\hline 口193s & & & & & & $61 s$ & & & & \\
\hline
\end{tabular}




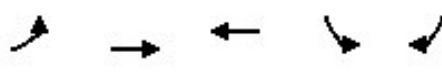

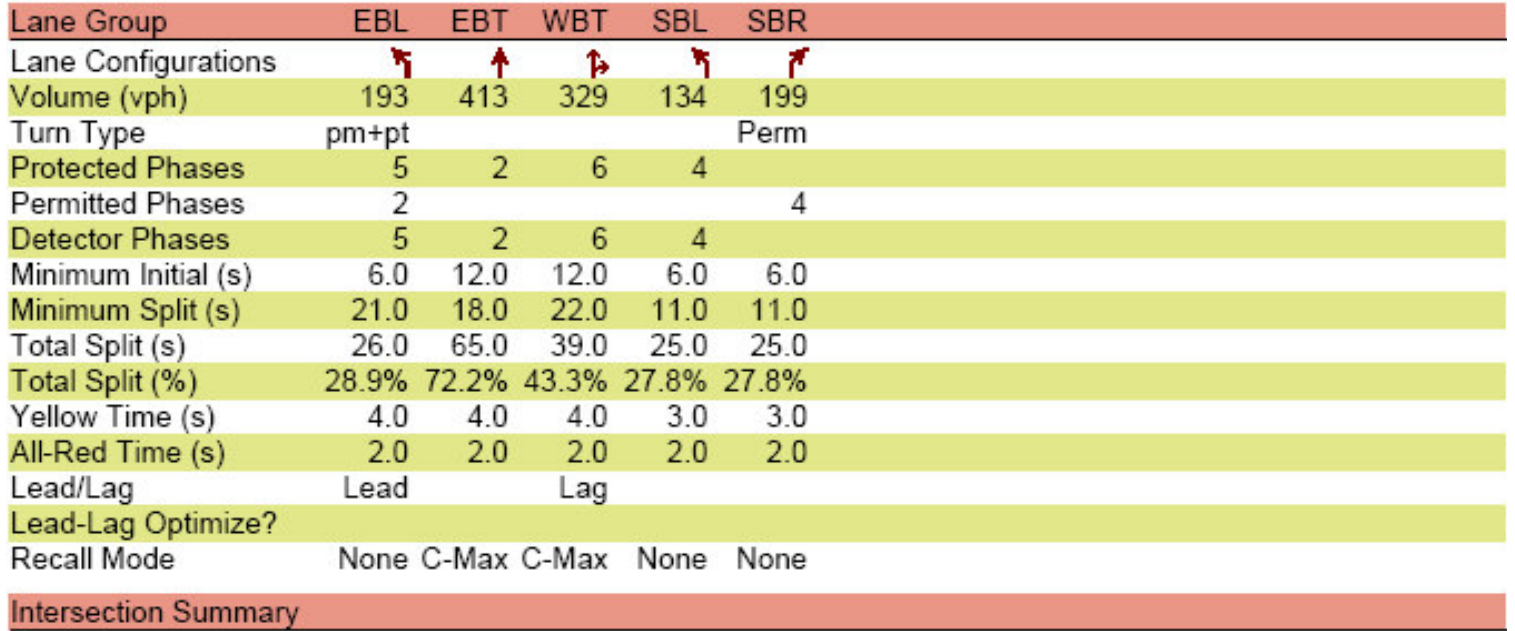

Cycle Length: 90

Actuated Cycle Length: 90

Offset: $11(12 \%)$, Referenced to phase 2:EBTL and 6:WBT, Start of Green

Natural Cycle: 70

Control Type: Actuated-Coordinated

Splits and Phases: 24: SR 21 \& Mall

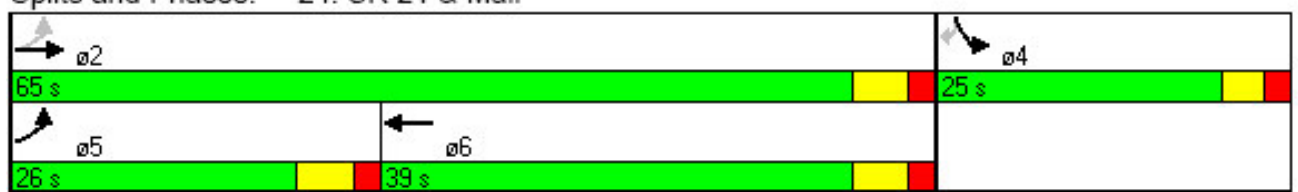




\section{Custom Coordinated - AM Peak}

Lanes, Volumes, Timings

\begin{tabular}{|c|c|c|c|c|c|c|c|c|c|}
\hline Lane Group & EBL & EBT & WBL & WBT & NBL & NBT & SBL & SBT & SBR \\
\hline Lane Configurations & 4 & $\uparrow$ & 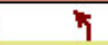 & 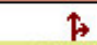 & & $\Leftrightarrow$ & & $\uparrow$ & $\pi$ \\
\hline Volume (vph) & 56 & 370 & 1 & 225 & 1 & 1 & 12 & 0 & 24 \\
\hline Turn Type & $\mathrm{pm}+\mathrm{pt}$ & & Perm & & Perm & & Perm & & Perm \\
\hline Protected Phases & 5 & 2 & & 6 & & 8 & & 4 & \\
\hline Permitted Phases & 2 & & 6 & & 8 & & 4 & & 4 \\
\hline Detector Phases & 5 & 2 & & 6 & 8 & 8 & 4 & 4 & 4 \\
\hline Minimum Initial (s) & 2.0 & 15.0 & 15.0 & 15.0 & 2.0 & 2.0 & 2.0 & 2.0 & 2.0 \\
\hline Minimum Split (s) & 8.0 & 22.0 & 22.0 & 22.0 & 21.0 & 21.0 & 21.0 & 21.0 & 21.0 \\
\hline Total Split (s) & 36.0 & 87.0 & 51.0 & 51.0 & 33.0 & 33.0 & 33.0 & 33.0 & 33.0 \\
\hline Total Split (\%) & $30.0 \%$ & $72.5 \%$ & $42.5 \%$ & $42.5 \%$ & $27.5 \%$ & $27.5 \%$ & $27.5 \%$ & $27.5 \%$ & $27.5 \%$ \\
\hline Yellow Time (s) & 4.0 & 4.0 & 4.0 & 4.0 & 3.0 & 3.0 & 3.0 & 3.0 & 3.0 \\
\hline All-Red Time (s) & 2.0 & 2.0 & 2.0 & 2.0 & 2.0 & 2.0 & 2.0 & 2.0 & 2.0 \\
\hline Lead/Lag & Lead & & Lag & Lag & & & & & \\
\hline \multicolumn{10}{|l|}{ Lead-Lag Optimize? } \\
\hline Recall Mode & None & C-Max & C-Max & C-Max & Min & Min & Min & Min & Min \\
\hline \multicolumn{10}{|l|}{ Intersection Summary } \\
\hline \multirow{2}{*}{\multicolumn{10}{|c|}{$\begin{array}{l}\text { Cycle Length: } 120 \\
\text { Actuated Cycle Length: } 120\end{array}$}} \\
\hline & & & & & & & & & \\
\hline \multirow{2}{*}{\multicolumn{10}{|c|}{ Offset: $75(63 \%)$, Referenced to phase 2:EBTL and 6:WBTL, Start of Yellow }} \\
\hline & & & & & & & & & \\
\hline \multicolumn{10}{|c|}{$\begin{array}{l}\text { Natural Cycle: } 55 \\
\text { Control Type: Actuated- }\end{array}$} \\
\hline \multicolumn{10}{|l|}{ Splits and Phases: } \\
\hline \multicolumn{7}{|l|}{$\rightarrow \curvearrowleft 2$} & & 24 & \\
\hline \multirow{2}{*}{\multicolumn{10}{|c|}{87 s }} \\
\hline & & & & & & & & & \\
\hline $36 s$ & 15 & 15 & & & & & $33 s$ & & \\
\hline
\end{tabular}




\section{$\rightarrow \rightarrow+4+1$}

\begin{tabular}{|c|c|c|c|c|c|c|c|c|c|c|c|c|}
\hline Lane Group & EBL & EBT & WBL & WBT & NBL & NBT & NBR & SBL & SBT & $ø 1$ & $ø 3$ & 95 \\
\hline Lane Configurations & $\sqrt{1}$ & $\uparrow$ & 7 & 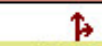 & & $\uparrow$ & $\bar{r}$ & & $\$$ & & & \\
\hline Volume (vph) & 5 & 335 & $225^{\circ}$ & 221 & 20 & 4 & 68 & 2 & 1 & & & \\
\hline Turn Type & Perm & & custom & & Perm & & custom & Perm & & & & \\
\hline Protected Phases & & 2 & 139 & 1239 & & 4 & 13 & & 4 & 1 & 3 & 5 \\
\hline Permitted Phases & 2 & & 3 & & 4 & & 4 & 4 & & & & \\
\hline Detector Phases & 2 & 2 & 139 & 9 & 4 & 4 & 13 & 4 & 4 & & & \\
\hline Minimum Initial (s) & 4.0 & 4.0 & & & 4.0 & 4.0 & & 4.0 & 4.0 & 4.0 & 4.0 & 4.0 \\
\hline Minimum Split (s) & 22.0 & 22.0 & & & 19.0 & 19.0 & & 19.0 & 19.0 & 10.0 & 10.0 & 10.0 \\
\hline Total Split (s) & 44.0 & 44.0 & 57.0 & 101.0 & 19.0 & 19.0 & 49.0 & 19.0 & 19.0 & 14.0 & 35.0 & 24.0 \\
\hline Total Split (\%) & $36.7 \%$ & $36.7 \%$ & $47.5 \%$ & $84.2 \%$ & $15.8 \%$ & $15.8 \%$ & $40.8 \%$ & $15.8 \%$ & $15.8 \%$ & $12 \%$ & $29 \%$ & $20 \%$ \\
\hline Yellow Time (s) & 4.0 & 4.0 & & & 4.0 & 4.0 & & 4.0 & 4.0 & 4.0 & 4.0 & 4.0 \\
\hline All-Red Time (s) & 2.0 & 2.0 & & & 2.0 & 2.0 & & 2.0 & 2.0 & 2.0 & 2.0 & 2.0 \\
\hline Lead/Lag & Lag & Lag & & & Lag & Lag & & Lag & Lag & Lead & Lead & Lead \\
\hline Lead-Lag Optimize? & & & & & & & & & & & & Yes \\
\hline Recall Mode & C-Max & C-Max & & & Min & Min & & Min & Min & None & None & None \\
\hline
\end{tabular}

Cycle Length: 120

Actuated Cycle Length: 120

Offset: $0(0 \%)$, Referenced to phase 2:EBWB, Start of Yellow, Master Intersection

Natural Cycle: 100

Control Type: Actuated-Coordinated

Splits and Phases: 15: SR 21 \& Brewer

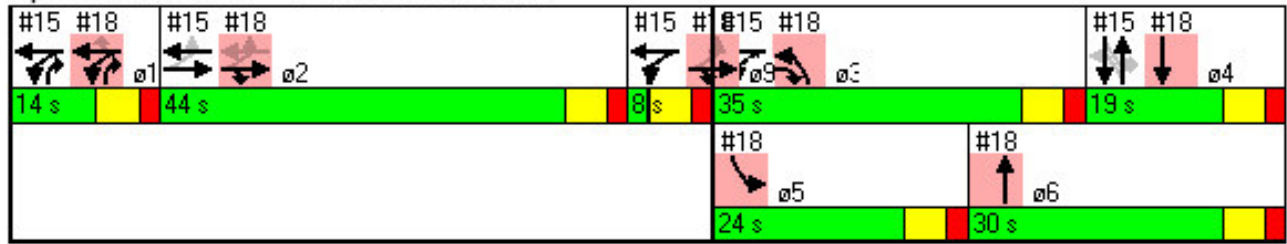




\section{$\rightarrow \rightarrow \vee \leftarrow<\uparrow \uparrow<〉 \downarrow$}

\begin{tabular}{|c|c|c|c|c|c|c|c|c|c|c|c|c|}
\hline Lane Group & EBL & EBT & EBR & WBL & WBT & WBR & NBL & NBT & NBR & SBL & SBT & 02 \\
\hline Lane Configurations & & $\uparrow$ & $\pi$ & 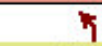 & $\uparrow$ & $\pi$ & 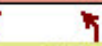 & $\uparrow$ & $\pi$ & 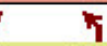 & $\uparrow$ & \\
\hline Volume (vph) & 3 & 186 & 216 & 86 & 126 & 57 & 295 & 155 & 186 & 46 & 102 & \\
\hline Turn Type & Perm & & $\mathrm{pt}+\mathrm{ov}$ & Split & & Perm & Prot & & Over & Prot & & \\
\hline Protected Phases & & 29 & 239 & 1 & 1 & & 3 & 6 & 1 & 5 & 4 & 2 \\
\hline Permitted Phases & 29 & & & & 2 & 1 & & & & & & \\
\hline Detector Phases & 9 & 9 & 9 & 1 & 1 & 1 & 3 & 6 & 1 & 5 & 4 & \\
\hline Minimum Initial (s) & & & & 4.0 & 4.0 & 4.0 & 4.0 & 4.0 & 4.0 & 4.0 & 4.0 & 4.0 \\
\hline Minimum Split (s) & & & & 10.0 & 10.0 & 10.0 & 10.0 & 22.0 & 10.0 & 10.0 & 19.0 & 22.0 \\
\hline Total Split (s) & 52.0 & 52.0 & 87.0 & 14.0 & 14.0 & 14.0 & 35.0 & 30.0 & 14.0 & 24.0 & 19.0 & 44.0 \\
\hline Total Split (\%) & $43.3 \%$ & $43.3 \%$ & $72.5 \%$ & $11.7 \%$ & $11.7 \%$ & $11.7 \%$ & $29.2 \%$ & $25.0 \%$ & $11.7 \%$ & $20.0 \%$ & $15.8 \%$ & $37 \%$ \\
\hline Yellow Time (s) & & & & 4.0 & 4.0 & 4.0 & 4.0 & 4.0 & 4.0 & 4.0 & 4.0 & 4.0 \\
\hline All-Red Time (s) & & & & 2.0 & 2.0 & 2.0 & 2.0 & 2.0 & 2.0 & 2.0 & 2.0 & 2.0 \\
\hline Lead/Lag & & & & Lead & Lead & Lead & Lead & Lag & Lead & Lead & Lag & Lag \\
\hline Lead-Lag Optimize? & & & & & & & & Yes & & Yes & & \\
\hline Recall Mode & & & & None & None & None & None & Min & None & None & Min & C-Max \\
\hline
\end{tabular}

Cycle Length: 120

Actuated Cycle Length: 120

Offset: $0(0 \%)$, Referenced to phase 2:EBWB, Start of Yellow, Master Intersection

Natural Cycle: 100

Control Type: Actuated-Coordinated

Splits and Phases: 18: SR 21 \& Matthew

\begin{tabular}{|l|l|l|l|l|l|l|l|l|l|l|}
\hline$\# 15$ & $\# 18$ & & $\# 15$
\end{tabular}




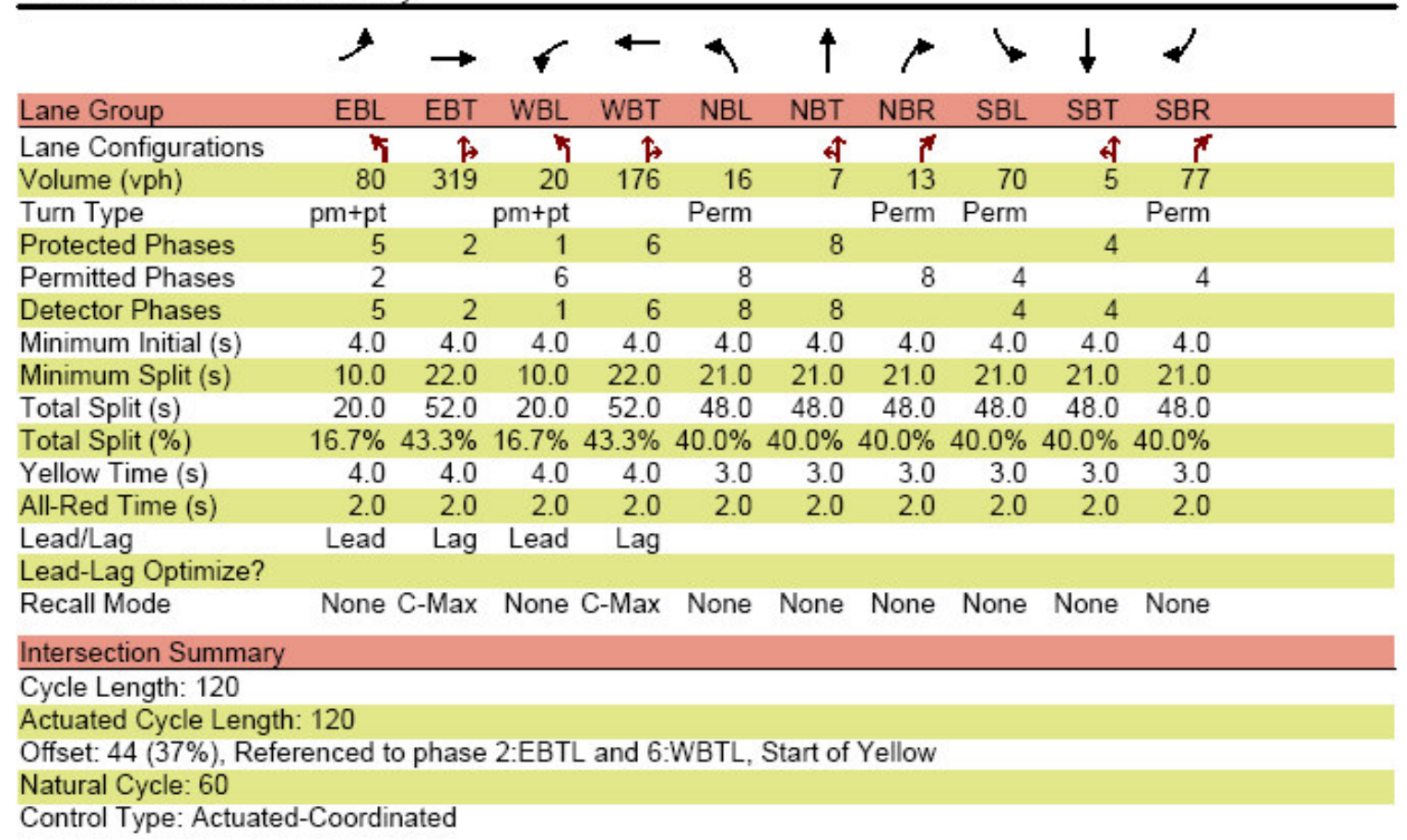

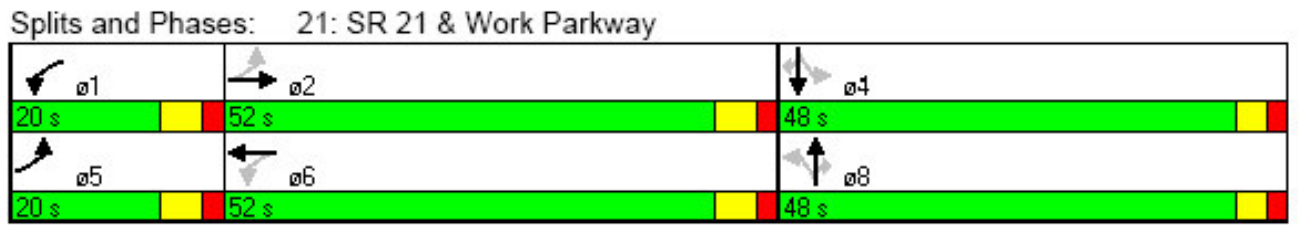




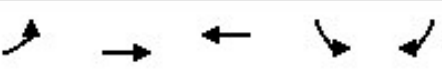

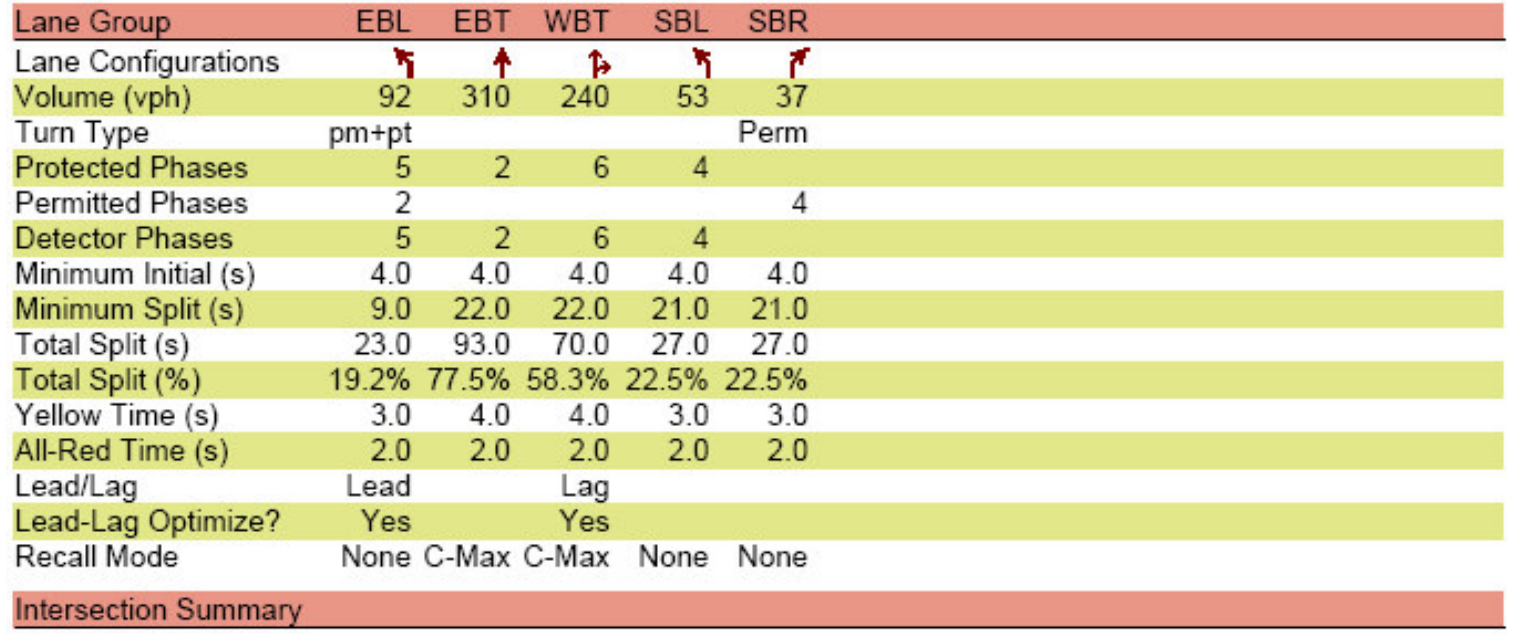

Cycle Length: 120

Actuated Cycle Length: 120

Offset: $84(70 \%)$, Referenced to phase 2:EBTL and 6:WBT, Start of Yellow

Natural Cycle: 60

Control Type: Actuated-Coordinated

Splits and Phases: 24: SR 21 \& Mall

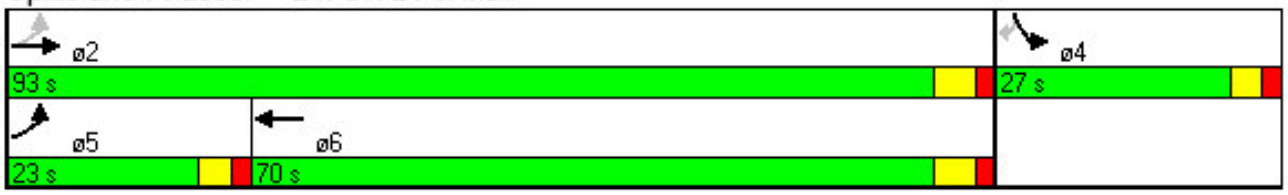




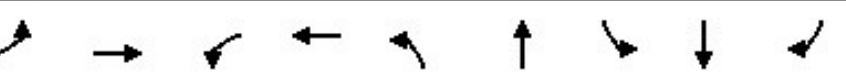

\begin{tabular}{|c|c|c|c|c|c|c|c|c|c|}
\hline Lane Group & EBL & EBT & WBL & WBT & NBL & NBT & SBL & SBT & SBR \\
\hline Lane Configurations & 5 & 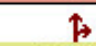 & 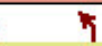 & $\hat{F}$ & & $\$$ & & $\uparrow$ & $\bar{r}$ \\
\hline Volume (vph) & 89 & 319 & 1 & 267 & 1 & 1 & 122 & 0 & 39 \\
\hline Turn Type & $\mathrm{pm}+\mathrm{pt}$ & & Perm & & Perm & & Perm & & Perm \\
\hline Protected Phases & 5 & 2 & & 6 & & 8 & & 4 & \\
\hline Permitted Phases & 2 & & 6 & & 8 & & 4 & & 4 \\
\hline Detector Phases & 5 & 2 & & 6 & 8 & 8 & 4 & 4 & 4 \\
\hline Minimum Initial (s) & 2.0 & 15.0 & 15.0 & 15.0 & 2.0 & 2.0 & 2.0 & 2.0 & 2.0 \\
\hline Minimum Split (s) & 8.0 & 22.0 & 22.0 & 22.0 & 21.0 & 21.0 & 21.0 & 21.0 & 21.0 \\
\hline Total Split (s) & 37.0 & 139.0 & 102.0 & 102.0 & 71.0 & 71.0 & 71.0 & 71.0 & 71.0 \\
\hline Total Split (\%) & $17.6 \%$ & $66.2 \%$ & $48.6 \%$ & $48.6 \%$ & $33.8 \%$ & $33.8 \%$ & $33.8 \%$ & $33.8 \%$ & $33.8 \%$ \\
\hline Yellow Time (s) & 4.0 & 4.0 & 4.0 & 4.0 & 3.0 & 3.0 & 3.0 & 3.0 & 3.0 \\
\hline All-Red Time (s) & 2.0 & 2.0 & 2.0 & 2.0 & 2.0 & 2.0 & 2.0 & 2.0 & 2.0 \\
\hline Lead/Lag & Lead & & Lag & Lag & & & & & \\
\hline \multicolumn{10}{|l|}{ Lead-Lag Optimize? } \\
\hline Recall Mode & None & C-Max & C-Max & C-Max & Min & Min & Min & Min & Min \\
\hline \multicolumn{10}{|l|}{ Intersection Summary } \\
\hline \multicolumn{10}{|l|}{ Cycle Length: 210} \\
\hline \multicolumn{10}{|c|}{ Actuated Cycle Length: 210} \\
\hline \multicolumn{10}{|c|}{ Offset: $205(98 \%)$, Referenced to phase 2:EBTL and 6:WBTL, Start of Yellow } \\
\hline \multicolumn{10}{|c|}{ Natural Cycle: 60} \\
\hline
\end{tabular}

Splits and Phases: 12: SR 21 \& Daniel Drive

\begin{tabular}{|c|c|c|}
\hline \multirow{2}{*}{\multicolumn{2}{|c|}{$139 \mathrm{~s}$}} & 104 \\
\hline & & $71 \mathrm{~s}$ \\
\hline ๑5 & 406 & \\
\hline $37 \mathrm{~s}$ & $102 s$ & $71 \mathrm{~s}$ \\
\hline
\end{tabular}




\section{$\rightarrow \rightarrow+4+1$}

\begin{tabular}{|c|c|c|c|c|c|c|c|c|c|c|c|c|}
\hline Lane Group & EBL & EBT & WBL & WBT & NBL & NBT & NBR & SBL & SBT & $ø 1$ & 03 & 95 \\
\hline Lane Configurations & T & $\uparrow$ & F & $\uparrow$ & & $\uparrow$ & $\pi$ & & $\leftrightarrow$ & & & \\
\hline Volume (vph) & 5 & 326 & 134 & 298 & 36 & 9 & 167 & 7 & 6 & & & \\
\hline Turn Type & Perm & & custom & & Perm & & custom & Perm & & & & \\
\hline Protected Phases & & 2 & 139 & 1239 & & 4 & 13 & & 4 & 1 & 3 & 5 \\
\hline Permitted Phases & 2 & & 3 & & 4 & & 4 & 4 & & & & \\
\hline Detector Phases & 2 & 2 & 139 & 9 & 4 & 4 & 13 & 4 & 4 & & & \\
\hline Minimum Initial (s) & 4.0 & 4.0 & & & 4.0 & 4.0 & & 4.0 & 4.0 & 4.0 & 4.0 & 4.0 \\
\hline Minimum Split (s) & 22.0 & 22.0 & & & 22.0 & 22.0 & & 22.0 & 22.0 & 10.0 & 10.0 & 10.0 \\
\hline Total Split (s) & 66.0 & 66.0 & 94.0 & 160.0 & 50.0 & 50.0 & 86.0 & 50.0 & 50.0 & 41.0 & 45.0 & 29.0 \\
\hline Total Split (\%) & $31.4 \%$ & $31.4 \%$ & $44.8 \%$ & $76.2 \%$ & $23.8 \%$ & $23.8 \%$ & $41.0 \%$ & $23.8 \%$ & $23.8 \%$ & $20 \%$ & $21 \%$ & $14 \%$ \\
\hline Yellow Time (s) & 4.0 & 4.0 & & & 4.0 & 4.0 & & 4.0 & 4.0 & 4.0 & 4.0 & 4.0 \\
\hline All-Red Time (s) & 2.0 & 2.0 & & & 2.0 & 2.0 & & 2.0 & 2.0 & 2.0 & 2.0 & 2.0 \\
\hline Lead/Lag & Lag & Lag & & & Lag & Lag & & Lag & Lag & Lead & Lead & Lead \\
\hline Lead-Lag Optimize? & & & & & & & & & & & & Yes \\
\hline Recall Mode & C-Max & C-Max & & & Min & Min & & Min & Min & None & None & None \\
\hline
\end{tabular}

Cycle Length: 210

Actuated Cycle Length: 210

Offset: $0(0 \%)$, Referenced to phase 2:EBWB, Start of Yellow, Master Intersection

Natural Cycle: 140

Control Type: Actuated-Coordinated

Splits and Phases: 15: SR 21 \& Brewer

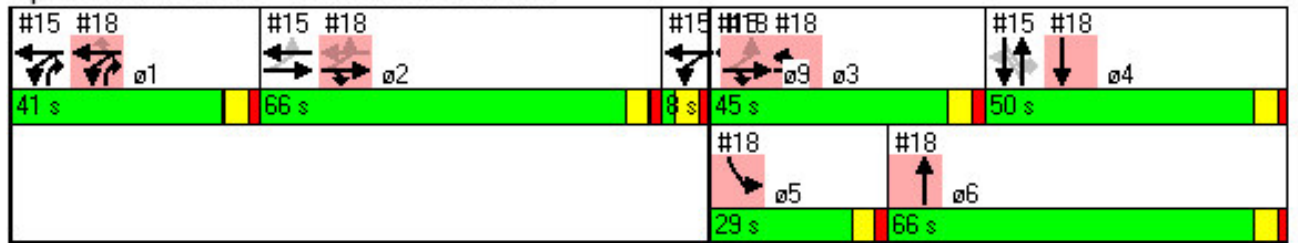




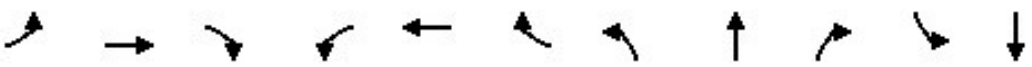

\begin{tabular}{|c|c|c|c|c|c|c|c|c|c|c|c|c|}
\hline Lane Group & EBL & EBT & EBR & WBL & WBT & WBR & NBL & NBT & NBR & SBL & SBT & 02 \\
\hline Lane Configurations & & $\uparrow$ & 7 & 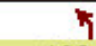 & $\uparrow$ & $\vec{r}$ & 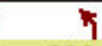 & $\uparrow$ & $\vec{r}$ & $\mathbf{1}$ & 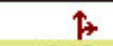 & \\
\hline Volume (vph) & 15 & 261 & 224 & 190 & 213 & 154 & 200 & 253 & 259 & 144 & 243 & \\
\hline Turn Type & Perm & & pt+ov & Split & & Perm & Prot & & Over & Prot & & \\
\hline Protected Phases & & 29 & 239 & 1 & 1 & & 3 & 6 & 1 & 5 & 4 & 7 \\
\hline Permitted Ph & 29 & & & & 2 & 1 & & & & & & \\
\hline or Pha & 9 & 9 & 9 & 1 & 1 & 1 & 3 & 6 & 1 & 5 & 4 & \\
\hline linir & & & & 4.0 & 4.0 & 4.0 & 4.0 & 4.0 & 4.0 & 4.0 & 4.0 & 4.0 \\
\hline m Split (s) & & & & 10.0 & 10.0 & 10.0 & 10.0 & 22.0 & 10.0 & 10.0 & 22.0 & 22.0 \\
\hline Tota & 74.0 & 74.0 & 119.0 & 41.0 & 41.0 & 41.0 & 45.0 & 66.0 & 41.0 & 29.0 & 50.0 & 66.0 \\
\hline Total Split (\%) & $35.2 \%$ & $35.2 \%$ & $56.7 \%$ & $19.5 \%$ & $19.5 \%$ & $19.5 \%$ & $21.4 \%$ & $31.4 \%$ & $19.5 \%$ & $13.8 \%$ & $23.8 \%$ & $31 \%$ \\
\hline Yellow Tim & & & & 4.0 & 4.0 & 4.0 & 4.0 & 4.0 & 4.0 & 4.0 & 4.0 & 4.0 \\
\hline Time (s) & & & & 2.0 & 2.0 & 2.0 & 2.0 & 2.0 & 2.0 & 2.0 & 2.0 & 2.0 \\
\hline ead/Lag & & & & Lead & Lead & Lead & Lead & Lag & Lead & Lead & Lag & Lag \\
\hline ead-Lag Op & & & & & & & & Yes & & Yes & & \\
\hline ecall Mode & & & & on & on & None & lon & Min & None & Vone & Min & $-\operatorname{Max}$ \\
\hline
\end{tabular}

\section{Intersection Summary}

Cycle Length: 210

Actuated Cycle Length: 210

Offset: $0(0 \%)$, Referenced to phase 2:EBWB, Start of Yellow, Master Intersection

Natural Cycle: 140

Control Type: Actuated-Coordinated

Splits and Phases: 18: SR 21 \& Matthew

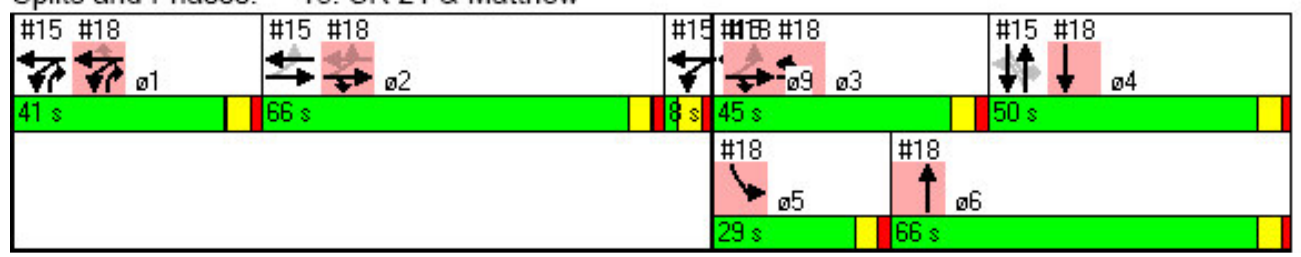




\begin{tabular}{|c|c|c|c|c|c|c|c|c|c|c|}
\hline Lane Group & $\mathrm{EBL}$ & EBT & WBL & WBT & NBL & NBT & NBR & SBL & SBT & SBR \\
\hline Lane Configurations & 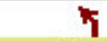 & $\uparrow$ & 7 & $\uparrow$ & & $\uparrow$ & $\vec{r}$ & & $\uparrow$ & $\vec{r}$ \\
\hline Volume (vph) & 192 & 369 & 83 & 305 & 79 & 50 & 72 & 150 & 41 & 173 \\
\hline Turn Type & $\mathrm{pm}+\mathrm{pt}$ & & $\mathrm{pm}+\mathrm{pt}$ & & Perm & & Perm & Perm & & Perm \\
\hline Protected Phases & 5 & 2 & 1 & 6 & & 8 & & & 4 & \\
\hline Permitted Phases & 2 & & 6 & & 8 & & 8 & 4 & & 4 \\
\hline Detector Phases & 5 & 2 & 1 & 6 & 8 & 8 & & 4 & 4 & \\
\hline Minimum Initial (s) & 4.0 & 4.0 & 4.0 & 4.0 & 4.0 & 4.0 & 4.0 & 4.0 & 4.0 & 4.0 \\
\hline Minimum Split (s) & 10.0 & 22.0 & 10.0 & 22.0 & 21.0 & 21.0 & 21.0 & 21.0 & 21.0 & 21.0 \\
\hline Total Split (s) & 18.0 & 47.0 & 18.0 & 47.0 & 40.0 & 40.0 & 40.0 & 40.0 & 40.0 & 40.0 \\
\hline Total Split (\%) & $17.1 \%$ & $44.8 \%$ & $17.1 \%$ & $44.8 \%$ & $38.1 \%$ & $38.1 \%$ & $38.1 \%$ & $38.1 \%$ & $38.1 \%$ & $38.1 \%$ \\
\hline Yellow Time (s) & 4.0 & 4.0 & 4.0 & 4.0 & 3.0 & 3.0 & 3.0 & 3.0 & 3.0 & 3.0 \\
\hline All-Red Time (s) & 2.0 & 2.0 & 2.0 & 2.0 & 2.0 & 2.0 & 2.0 & 2.0 & 2.0 & 2.0 \\
\hline Lead/Lag & Lead & Lag & Lead & Lag & & & & & & \\
\hline \multicolumn{11}{|l|}{ Lead-Lag Optimize? } \\
\hline Recall Mode & None & C-Max & None & C-Max & None & None & None & None & None & None \\
\hline \multicolumn{11}{|l|}{ Intersection Summary } \\
\hline \multicolumn{11}{|l|}{ Cycle Length: 105} \\
\hline \multicolumn{11}{|c|}{ Actuated Cycle Length: 105} \\
\hline \multicolumn{11}{|c|}{ Offset: 95 (90\%), Referenced to phase 2:EBTL and 6:WBTL, Start of Yellow } \\
\hline \multicolumn{11}{|c|}{ Natural Cycle: 75} \\
\hline
\end{tabular}

\begin{tabular}{|c|c|c|}
\hline$\digamma_{01}$ & $\rightarrow$ - & 104 \\
\hline $18 \mathrm{~s}$ & $47 s$ & $40 \mathrm{~s}$ \\
\hline$>_{05}$ & 4 & 1 \\
\hline $18 \mathrm{~s}$ & $47 \mathrm{~s}$ & $140 \mathrm{~s}$ \\
\hline
\end{tabular}




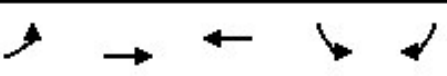

\begin{tabular}{|c|c|c|c|c|c|}
\hline Lane Group & EBL & EBT & WBT & SBL & SBR \\
\hline Lane Configurations & 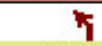 & $\uparrow$ & 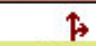 & 4 & $\bar{t}$ \\
\hline Volume (vph) & $220^{\circ}$ & 371 & 316 & $115^{\circ}$ & 215 \\
\hline Turn Type & $\mathrm{pm}+\mathrm{pt}$ & & & & Perm \\
\hline Protected Phases & 5 & 2 & 6 & 4 & \\
\hline Permitted Phases & 2 & & & & 4 \\
\hline Detector Phases & 5 & 2 & 6 & 4 & \\
\hline Minimum Initial (s) & 4.0 & 4.0 & 4.0 & 4.0 & 4.0 \\
\hline Minimum Split (s) & 9.0 & 22.0 & 22.0 & 21.0 & 21.0 \\
\hline Total Split (s) & 26.0 & 79.0 & 53.0 & 26.0 & 26.0 \\
\hline Total Split (\%) & $24.8 \%$ & $75.2 \%$ & $50.5 \%$ & $24.8 \%$ & $24.8 \%$ \\
\hline Yellow Time (s) & 3.0 & 4.0 & 4.0 & 3.0 & 3.0 \\
\hline All-Red Time (s) & 2.0 & 2.0 & 2.0 & 2.0 & 2.0 \\
\hline Lead/Lag & Lead & & Lag & & \\
\hline Lead-Lag Optimize? & Yes & & Yes & & \\
\hline Recall Mode & None & 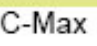 & -Max & None & None \\
\hline
\end{tabular}

Intersection Summary

Cycle Length: 105

Actuated Cycle Length: 105

Offset: $9(9 \%)$, Referenced to phase 2:EBTL and 6:WBT, Start of Green

Natural Cycle: 60

Control Type: Actuated-Coordinated

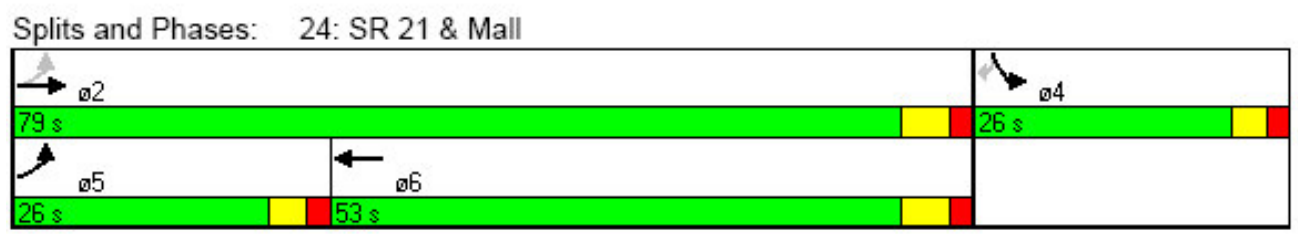


Lanes, Volumes, Timings

\section{Custom Coordinated - PM Peak}

12: SR 21 \& Daniel Drive

\begin{tabular}{|c|c|c|c|c|c|c|c|c|}
\hline Lane Group & EBL & WBL & WBT & NBL & NBT & SBL & SBT & SBR \\
\hline Lane Configurations & $\uparrow$ & 4 & 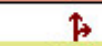 & & $\$$ & & $\uparrow$ & $\bar{r}$ \\
\hline Volume (vph) & 111 & 1 & 457 & 1 & 1 & 31 & 0 & 147 \\
\hline Turn Type & $\mathrm{pm}+\mathrm{pt}$ & Perm & & Perm & & Perm & & Perm \\
\hline Protected Phases & 5 & & 6 & & 8 & & 4 & \\
\hline Permitted Phases & 2 & 6 & & 8 & & 4 & & 4 \\
\hline Detector Phases & 5 & & 6 & 8 & 8 & 4 & 4 & 4 \\
\hline Minimum Initial (s) & 15.0 & 15.0 & 15.0 & 2.0 & 2.0 & 2.0 & 2.0 & 2.0 \\
\hline Minimum Split (s) & 22.0 & 22.0 & 22.0 & 21.0 & 21.0 & 21.0 & 21.0 & 21.0 \\
\hline Total Split (s) & 38.0165 .0 & 127.0 & 127.0 & 45.0 & 45.0 & 45.0 & 45.0 & 45.0 \\
\hline Total Split (\%) & $18.1 \% 78.6 \%$ & $60.5 \%$ & $60.5 \%$ & $21.4 \%$ & $21.4 \%$ & $21.4 \%$ & $21.4 \%$ & $21.4 \%$ \\
\hline Yellow Time (s) & $\begin{array}{ll}4.0 & 4.0\end{array}$ & 4.0 & 4.0 & 3.0 & 3.0 & 3.0 & 3.0 & 3.0 \\
\hline All-Red Time (s) & 2.0 & 2.0 & 2.0 & 2.0 & 2.0 & 2.0 & 2.0 & 2.0 \\
\hline Lead/Lag & Lead & Lag & Lag & & & & & \\
\hline \multicolumn{9}{|l|}{ Lead-Lag Optimize? } \\
\hline Recall Mode & None C-Max & C-Max & C-Max & Min & Min & Min & Min & Min \\
\hline \multicolumn{9}{|l|}{ Intersection Summary } \\
\hline \multicolumn{9}{|l|}{ Cycle Length: 210} \\
\hline \multicolumn{9}{|c|}{ Actuated Cycle Length: 210} \\
\hline \multirow{2}{*}{\multicolumn{9}{|c|}{ Offset: $81(39 \%)$, Referenced to phase 2:EBTL and 6:WBTL, Start of Yellow }} \\
\hline \multirow{2}{*}{\multicolumn{9}{|c|}{ Natural Cycle: 60}} \\
\hline & & & & & & & & \\
\hline \multicolumn{9}{|l|}{ Splits and Phases: } \\
\hline \multicolumn{7}{|l|}{$\rightarrow$ 2 } & & \\
\hline \multicolumn{7}{|c|}{$165 s$} & $45 s$ & \\
\hline \multirow{2}{*}{\multicolumn{7}{|c|}{ 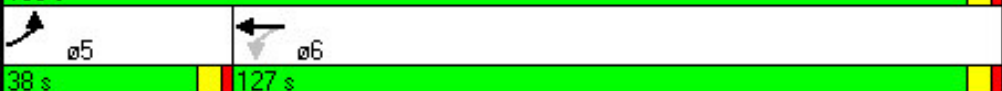 }} & 4 & \\
\hline & & & & & & & $45 s$ & \\
\hline
\end{tabular}




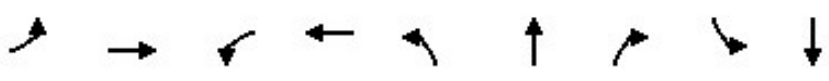

\begin{tabular}{|c|c|c|c|c|c|c|c|c|c|c|c|c|}
\hline Lane Group & EBL & EBT & WBL & WBT & NBL & NBT & NBR & SBL & SBT & ø1 & ๑3 & $ø 5$ \\
\hline Lane Configurations & i & 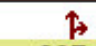 & 1 & $\uparrow$ & & $\uparrow$ & $\bar{r}$ & & 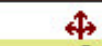 & & & \\
\hline Volume (vph) & 6 & 397 & 92 & 450 & 52 & 3 & 165 & 16 & 2 & & & \\
\hline Turn Type & Perm & \multicolumn{2}{|c|}{ custom } & & Perm & \multicolumn{2}{|c|}{ custom } & Perm & & & & \\
\hline Protected Phases & & 2 & 139 & 1239 & & 4 & 13 & & 4 & 1 & 3 & 5 \\
\hline Permitted Phases & 2 & & 3 & & 4 & & 4 & 4 & & & & \\
\hline Detector Phases & 2 & 2 & 139 & 9 & 4 & 4 & 13 & 4 & 4 & & & \\
\hline Minimum Initial (s) & 4.0 & 4.0 & & & 4.0 & 4.0 & & 4.0 & 4.0 & 4.0 & 4.0 & 4.0 \\
\hline Minimum Split (s) & 22.0 & 22.0 & & & 22.0 & 22.0 & & 22.0 & 22.0 & 10.0 & 10.0 & 10.0 \\
\hline Total Split (s) & 58.0 & 58.0 & 95.0 & 153.0 & 57.0 & 57.0 & 87.0 & 57.0 & 57.0 & 39.0 & 48.0 & 39.0 \\
\hline Total Split (\%) & $27.6 \%$ & $27.6 \%$ & $45.2 \%$ & $72.9 \%$ & $27.1 \%$ & $27.1 \%$ & $41.4 \%$ & $27.1 \%$ & $27.1 \%$ & $19 \%$ & $23 \%$ & $19 \%$ \\
\hline Yellow Tim & 4.0 & 4.0 & & & 4.0 & 4.0 & & 4.0 & 4.0 & 4.0 & 4.0 & 4.0 \\
\hline All-Red Time (s) & 2.0 & 2.0 & & & 2.0 & 2.0 & & 2.0 & 2.0 & 2.0 & 2.0 & 2.0 \\
\hline Lead/Lag & Lag & Lag & & & Lag & Lag & & Lag & Lag & Lead & Lead & Lead \\
\hline Lead-Lag Opt & & & & & & & & & & & & Yes \\
\hline Recall Mode & C-Max & C-Max & & & Min & Min & & Min & Min & None & None & None \\
\hline
\end{tabular}

Intersection Summary

Cycle Length: 210

Actuated Cycle Length: 210

Offset: $0(0 \%)$, Referenced to phase 2:EBWB, Start of Yellow, Master Intersection

Natural Cycle: 150

Control Type: Actuated-Coordinated

Splits and Phases: 15: SR 21 \& Brewer

\begin{tabular}{|l|l|l|l|l|l|l|l|}
\hline$\# 15 \# 18$ & & & & \\
\hline
\end{tabular}




\section{$\rightarrow \rightarrow \vdash \leftarrow+\uparrow \uparrow \downarrow$}

\begin{tabular}{|c|c|c|c|c|c|c|c|c|c|c|c|c|}
\hline Lane Group & EBL & EBT & EBR & WBL & WBT & WBR & NBL & NBT & NBR & SBL & SBT & $\oslash 2$ \\
\hline Lane Configurations & & $\uparrow$ & $\pi$ & \% & $\uparrow$ & $\pi$ & 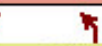 & $\uparrow$ & $\pi$ & T & $\uparrow$ & \\
\hline Volume (vph) & 6 & 254 & 318 & 247 & 222 & 150 & 305 & 268 & 243 & 147 & 318 & \\
\hline Turn Type & Perm & & $\mathrm{pt}+\mathrm{ov}$ & Split & & Perm & Prot & & Over & Prot & & \\
\hline Protected Phases & & 29 & 239 & 1 & 1 & & 3 & 6 & 1 & 5 & 4 & 2 \\
\hline Permitted Phases & 29 & & & & 2 & 1 & & & & & & \\
\hline Detector Phases & 9 & 9 & 9 & 1 & 1 & 1 & 3 & 6 & 1 & 5 & 4 & \\
\hline Minimum Initial (s) & & & & 4.0 & 4.0 & 4.0 & 4.0 & 4.0 & 4.0 & 4.0 & 4.0 & 4.0 \\
\hline Minimum Split (s) & & & & 10.0 & 10.0 & 10.0 & 10.0 & 22.0 & 10.0 & 10.0 & 22.0 & 22.0 \\
\hline Total Split (s) & 66.0 & 66.0 & 114.0 & 39.0 & 39.0 & 39.0 & 48.0 & 66.0 & 39.0 & 39.0 & 57.0 & 58.0 \\
\hline Total Split (\%) & $31.4 \%$ & $31.4 \%$ & $54.3 \%$ & $18.6 \%$ & $18.6 \%$ & $18.6 \%$ & $22.9 \%$ & $31.4 \%$ & $18.6 \%$ & $18.6 \%$ & $27.1 \%$ & $28 \%$ \\
\hline Yellow Time (s) & & & & 4.0 & 4.0 & 4.0 & 4.0 & 4.0 & 4.0 & 4.0 & 4.0 & 4.0 \\
\hline All-Red Time (s) & & & & 2.0 & 2.0 & 2.0 & 2.0 & 2.0 & 2.0 & 2.0 & 2.0 & 2.0 \\
\hline Lead/Lag & & & & Lead & Lead & Lead & Lead & Lag & Lead & Lead & Lag & Lag \\
\hline Lead-Lag Optimize? & & & & & & & & Yes & & Yes & & \\
\hline Recall Mode & & & & None & None & None & None & Min & None & None & Min & $-M a$ \\
\hline
\end{tabular}

Cycle Length: 210

Actuated Cycle Length: 210

Offset: $0(0 \%)$, Referenced to phase 2:EBWB, Start of Yellow, Master Intersection

Natural Cycle: 150

Control Type: Actuated-Coordinated

Splits and Phases: 18: SR 21 \& Matthew

\begin{tabular}{|c|c|c|c|c|}
\hline$\# 15 \# 18$ & 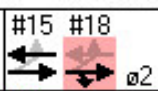 & $\begin{array}{l}\# 19 \text { \#BB } \# 18 \\
7->=69\end{array}$ & & $\begin{array}{l}\# 15 \text { \#18 } \\
11 !\end{array}$ \\
\hline $39 s$ & $58 \mathrm{~s}$ & $\begin{array}{l}8 \mathrm{~s} \\
8 \mathrm{~s}\end{array}$ & 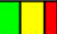 & $57 s$ \\
\hline & & $\# 18$ & †18 & 6 \\
\hline & & $39 s$ & $66 s$ & \\
\hline
\end{tabular}




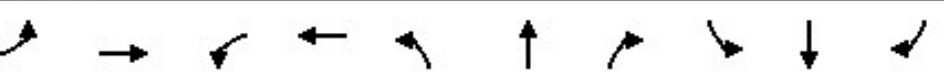

\begin{tabular}{|c|c|c|c|c|c|c|c|c|c|c|}
\hline Lane Group & EBL & EBT & WBL & WBT & NBL & NBT & NBR & SBL & SBT & SBR \\
\hline Lane Configurations & 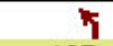 & $\hat{F}$ & 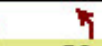 & $\uparrow$ & & $\uparrow$ & $\bar{r}$ & & $\uparrow$ & $\bar{r}$ \\
\hline Volume (vph) & 167 & 402 & 56 & 359 & 91 & 44 & 76 & 128 & 23 & 169 \\
\hline Turn Type & $\mathrm{pm}+\mathrm{pt}$ & & $\mathrm{pm}+\mathrm{pt}$ & & Perm & & Perm & Perm & & Perm \\
\hline Protected Phases & 5 & 2 & 1 & 6 & & 8 & & & 4 & \\
\hline Permitted Phases & 2 & & 6 & & 8 & & 8 & 4 & & 4 \\
\hline Detector Phases & 5 & 2 & 1 & 6 & 8 & 8 & & 4 & 4 & \\
\hline Minimum Initial (s) & 4.0 & 4.0 & 4.0 & 4.0 & 4.0 & 4.0 & 4.0 & 4.0 & 4.0 & 4.0 \\
\hline Minimum Split (s) & 10.0 & 22.0 & 10.0 & 22.0 & 21.0 & 21.0 & 21.0 & 21.0 & 21.0 & 21.0 \\
\hline Total Split (s) & 18.0 & 52.0 & 18.0 & 52.0 & 35.0 & 35.0 & 35.0 & 35.0 & 35.0 & 35.0 \\
\hline Total Split (\%) & $17.1 \%$ & $49.5 \%$ & $17.1 \%$ & $49.5 \%$ & $33.3 \%$ & $33.3 \%$ & $33.3 \%$ & $33.3 \%$ & $33.3 \%$ & $33.3 \%$ \\
\hline Yellow Time (s) & 4.0 & 4.0 & 4.0 & 4.0 & 3.0 & 3.0 & 3.0 & 3.0 & 3.0 & 3.0 \\
\hline All-Red Time (s) & 2.0 & 2.0 & 2.0 & 2.0 & 2.0 & 2.0 & 2.0 & 2.0 & 2.0 & 2.0 \\
\hline Lead/Lag & Lead & Lag & Lead & Lag & & & & & & \\
\hline \multicolumn{11}{|l|}{ Lead-Lag Optimize? } \\
\hline Recall Mode & None & C-Max & None & C-Max & None & None & None & None & None & None \\
\hline \multicolumn{11}{|l|}{ Intersection Summary } \\
\hline \multicolumn{11}{|l|}{ Cycle Length: 105} \\
\hline \multicolumn{11}{|c|}{ Actuated Cycle Length: 105} \\
\hline \multicolumn{11}{|c|}{ Offset: $101(96 \%)$, Referenced to phase 2:EBTL and 6:WBTL, Start of Yellow } \\
\hline \multicolumn{11}{|c|}{ Natural Cycle: 60} \\
\hline
\end{tabular}

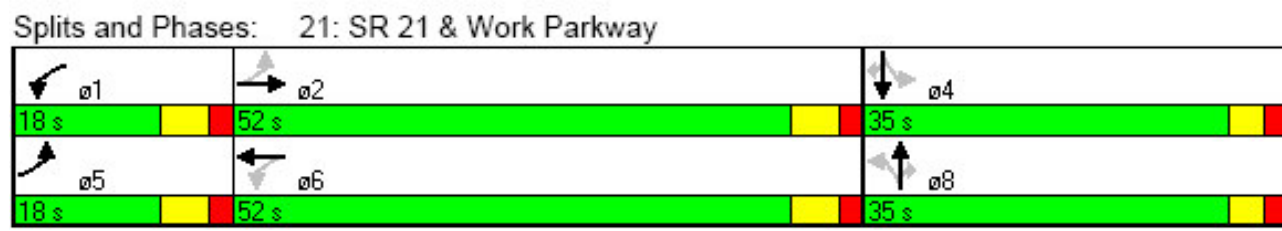




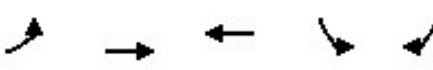

\begin{tabular}{lrrrrr}
\hline Lane Group & EBL & EBT & WBT & SBL & SBR \\
\hline Lane Configurations & 1 & $\uparrow$ & $\$$ & $\uparrow$ & $r$ \\
Volume (vph) & 193 & 413 & 329 & 134 & 199 \\
Turn Type & pm+pt & & & & Perm \\
Protected Phases & 5 & 2 & 6 & 4 & \\
Permitted Phases & 2 & & & & 4 \\
Detector Phases & 5 & 2 & 6 & 4 & \\
Minimum Initial (s) & 4.0 & 4.0 & 4.0 & 4.0 & 4.0 \\
Minimum Split (s) & 9.0 & 22.0 & 22.0 & 21.0 & 21.0 \\
Total Split (s) & 26.0 & 75.0 & 49.0 & 30.0 & 30.0 \\
Total Split (\%) & $24.8 \%$ & $71.4 \%$ & $46.7 \%$ & $28.6 \%$ & $28.6 \%$ \\
Yellow Time (s) & 3.0 & 4.0 & 4.0 & 3.0 & 3.0 \\
All-Red Time (s) & 2.0 & 2.0 & 2.0 & 2.0 & 2.0 \\
Lead/Lag & Lead & \multicolumn{5}{c}{ Lag } \\
Lead-Lag Optimize? & Yes & Yes & & \\
Recall Mode & None C-Max C-Max & None & None
\end{tabular}

Intersection Summary

Cycle Length: 105

Actuated Cycle Length: 105

Offset: 34 (32\%), Referenced to phase 2:EBTL and 6:WBT, Start of Green

Natural Cycle: 60

Control Type: Actuated-Coordinated

Splits and Phases: 24: SR 21 \& Mall

\begin{tabular}{|c|c|c|}
\hline \multirow{2}{*}{\multicolumn{2}{|c|}{$75 s$}} & \\
\hline & & $30 \mathrm{~s}$ \\
\hline$>_{05}$ & 466 & \\
\hline
\end{tabular}




\section{Phasing Change + Synchro Coordinated - AM Peak}

Lanes, Volumes, Timings

12: SR 21 \& Daniel Drive

\begin{tabular}{|c|c|c|c|c|c|c|c|c|c|}
\hline Lane Group & $\mathrm{EBL}$ & EBT & WBL & WBT & NBL & NBT & SBL & SBT & SBR \\
\hline Lane Configurations & $\boldsymbol{1}$ & $\uparrow$ & 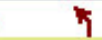 & 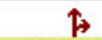 & & $\$$ & & $\uparrow$ & $\vec{r}$ \\
\hline Volume (vph) & 56 & 370 & 1 & 225 & 1 & 1 & 12 & 0 & 24 \\
\hline Turn Type & $\mathrm{pm}+\mathrm{pt}$ & & Perm & & Perm & & Perm & & Perm \\
\hline Protected Phases & 5 & 2 & & 6 & & 8 & & 4 & \\
\hline Permitted Phases & 2 & & 6 & & 8 & & 4 & & 4 \\
\hline Detector Phases & 5 & 2 & & 6 & 8 & 8 & 4 & 4 & 4 \\
\hline Minimum Initial (s) & 2.0 & 15.0 & 15.0 & 15.0 & 2.0 & 2.0 & 2.0 & 2.0 & 2.0 \\
\hline Minimum Split (s) & 8.0 & 22.0 & 22.0 & 22.0 & 21.0 & 21.0 & 21.0 & 21.0 & 21.0 \\
\hline Total Split (s) & 22.0 & 68.0 & 46.0 & 46.0 & 32.0 & 32.0 & 32.0 & 32.0 & 32.0 \\
\hline Total Split (\%) & $22.0 \%$ & $68.0 \%$ & $46.0 \%$ & $46.0 \%$ & $32.0 \%$ & $32.0 \%$ & $32.0 \%$ & $32.0 \%$ & $32.0 \%$ \\
\hline Yellow Time (s) & 4.0 & 4.0 & 4.0 & 4.0 & 3.0 & 3.0 & 3.0 & 3.0 & 3.0 \\
\hline All-Red Time (s) & 2.0 & 2.0 & 2.0 & 2.0 & 2.0 & 2.0 & 2.0 & 2.0 & 2.0 \\
\hline Lead/Lag & Lead & & Lag & Lag & & & & & \\
\hline \multicolumn{10}{|l|}{ Lead-Lag Optimize? } \\
\hline Recall Mode & None & C-Max & C-Max & C-Max & Min & Min & Min & Min & Min \\
\hline \multicolumn{10}{|l|}{ Intersection Summary } \\
\hline \multicolumn{10}{|l|}{ Cycle Length: 100} \\
\hline \multicolumn{10}{|c|}{ Actuated Cycle Length: 100} \\
\hline \multicolumn{10}{|c|}{ Offset: $92(92 \%)$, Referenced to phase 2:EBTL and 6:WBTL, Start of Yellow } \\
\hline \multicolumn{10}{|c|}{ Natural Cycle: 55} \\
\hline
\end{tabular}

Splits and Phases: 12: SR 21 \& Daniel Drive

\begin{tabular}{|c|c|c|}
\hline$\rightarrow 02$ & & $\downarrow$ - 4 \\
\hline $68 \mathrm{~s}$ & & $32 s$ \\
\hline$>_{05}$ & 4 ๑6 & $\varphi_{08}$ \\
\hline
\end{tabular}




\begin{tabular}{|c|c|c|c|c|c|c|c|c|c|c|c|c|}
\hline Lane Group & EBL & EBT & WBL & WBT & NBL & NBT & NBR & SBL & SBT & $ø 2$ & $ø 3$ & 05 \\
\hline Lane Configurations & 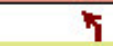 & $\hbar$ & 7 & 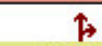 & & $\uparrow$ & $\pi$ & & $\$$ & & & \\
\hline Volume (vph) & 5 & 335 & $225^{\circ}$ & 221 & 20 & 4 & 68 & 2 & 1 & & & \\
\hline Turn Type & Perm & & custom & & Perm & & $\mathrm{pm+ov}$ & Perm & & & & \\
\hline Protected Phases & & 23 & 1 & 123 & & 4 & 1 & & 4 & 2 & 3 & 5 \\
\hline Permitted Phases & 23 & & 3 & & 4 & & 4 & 4 & & & & \\
\hline Detector Phases & 23 & 23 & 1 & 123 & 4 & 4 & 1 & 4 & 4 & & & \\
\hline Minimum Initial (s) & & & 4.0 & & 4.0 & 4.0 & 4.0 & 4.0 & 4.0 & 4.0 & 4.0 & 4.0 \\
\hline Minimum Split (s) & & & 10.0 & & 19.0 & 19.0 & 10.0 & 19.0 & 19.0 & 22.0 & 10.0 & 10.0 \\
\hline Total Split (s) & 63.0 & 63.0 & 17.0 & 80.0 & 20.0 & 20.0 & 17.0 & 20.0 & 20.0 & 27.0 & 36.0 & 14.0 \\
\hline Total Split (\%) & $63.0 \%$ & $63.0 \%$ & $17.0 \%$ & $80.0 \%$ & $20.0 \%$ & $20.0 \%$ & $17.0 \%$ & $20.0 \%$ & $20.0 \%$ & $27 \%$ & $36 \%$ & $14 \%$ \\
\hline Yellow Time (s) & & & 4.0 & & 4.0 & 4.0 & 4.0 & 4.0 & 4.0 & 4.0 & 4.0 & 4.0 \\
\hline All-Red Time (s) & & & 2.0 & & 2.0 & 2.0 & 2.0 & 2.0 & 2.0 & 2.0 & 2.0 & 2.0 \\
\hline Lead/Lag & & & Lead & & Lag & Lag & Lead & Lag & Lag & Lag & Lead & Lead \\
\hline Lead-Lag Optimize? & & & & & Yes & Yes & & Yes & Yes & & Yes & Yes \\
\hline Recall Mode & & & None & & Min & Min & None & Min & Min & C-Max & None & None \\
\hline \multicolumn{13}{|l|}{ Intersection Summary } \\
\hline \multicolumn{13}{|l|}{ Cycle Length: 100} \\
\hline \multicolumn{13}{|c|}{ Actuated Cycle Length: 100} \\
\hline \multirow{2}{*}{\multicolumn{13}{|c|}{$\begin{array}{l}\text { Offset: } 0(0 \%) \text {, Referenced to phase 2:EBWB, Start of Yellow, Master Intersection } \\
\text { Natural Cycle: } 80\end{array}$}} \\
\hline & & & & & & & & \multicolumn{5}{|c|}{ Natural Cycle: 80} \\
\hline Control Type: Actua & & & & & & & & & & & & \\
\hline
\end{tabular}

Splits and Phases: 15: SR 21 \& Brewer

\begin{tabular}{|c|c|c|c|c|}
\hline $\begin{array}{l}\# 15 \quad \# 18 \\
77\end{array}$ & $\begin{array}{l}\# 15 \# 18 \\
\longrightarrow \div 2\end{array}$ & $\begin{array}{l}\# 15 \\
4 \\
4\end{array}$ & & $\begin{array}{l}\# 15 \# 18 \\
1+\downarrow\end{array}$ \\
\hline $17 \mathrm{~s}$ & $27 s$ & $36 s$ & & $20 s$ \\
\hline & & & $\begin{array}{r}\# 18 \\
1\end{array}$ & \\
\hline & & $14 \mathrm{~s}$ & $42 \mathrm{~s}$ & \\
\hline
\end{tabular}




\begin{tabular}{|c|c|c|c|c|c|c|c|c|c|c|c|}
\hline Lane Group & EBL & EBT & EBR & WBL & WBT & WBR & NBL & NBT & NBR & SBL & SBT \\
\hline Lane Configurations & & $\uparrow$ & $\bar{r}$ & 7 & $\uparrow$ & 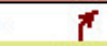 & 7 & $\uparrow$ & $\bar{r}$ & 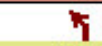 & $\uparrow$ \\
\hline Volume (vph) & 3 & 186 & 216 & 86 & 126 & 57 & 295 & $15 \dot{5}$ & 186 & 46 & 102 \\
\hline Turn Type & Perm & & $\mathrm{pt}+\mathrm{ov}$ & Split & & Perm & Prot & & Over & Prot & \\
\hline Protected Phases & & 2 & 23 & 1 & 1 & & 3 & 6 & 1 & 5 & 4 \\
\hline Permitted Phases & 2 & & & & 2 & 1 & & & & & \\
\hline Detector Phases & 2 & 2 & 23 & 1 & 1 & 1 & 3 & 6 & 1 & 5 & 4 \\
\hline Minimum Initial (s) & 4.0 & 4.0 & & 4.0 & 4.0 & 4.0 & 4.0 & 4.0 & 4.0 & 4.0 & 4.0 \\
\hline Minimum Split (s) & 22.0 & 22.0 & & 10.0 & 10.0 & 10.0 & 10.0 & 22.0 & 10.0 & 10.0 & 19.0 \\
\hline Total Split (s) & 27.0 & 27.0 & 63.0 & 17.0 & 17.0 & 17.0 & 36.0 & 42.0 & 17.0 & 14.0 & 20.0 \\
\hline Total Split (\%) & $27.0 \%$ & $27.0 \%$ & $63.0 \%$ & $17.0 \%$ & $17.0 \%$ & $17.0 \%$ & $36.0 \%$ & $42.0 \%$ & $17.0 \%$ & $14.0 \%$ & $20.0 \%$ \\
\hline Yellow Time (s) & 4.0 & 4.0 & & 4.0 & 4.0 & 4.0 & 4.0 & 4.0 & 4.0 & 4.0 & 4.0 \\
\hline All-Red Time (s) & 2.0 & 2.0 & & 2.0 & 2.0 & 2.0 & 2.0 & 2.0 & 2.0 & 2.0 & 2.0 \\
\hline Lead/Lag & Lag & Lag & & Lead & Lead & Lead & Lead & Lag & Lead & Lead & Lag \\
\hline Lead-Lag Optimize? & & & & & & & Yes & Yes & & Yes & Yes \\
\hline Recall Mode & C-Max & C-Max & & None & None & None & None & Min & None & None & Min \\
\hline \multicolumn{12}{|l|}{ Intersection Summary } \\
\hline \multicolumn{12}{|l|}{ Cycle Length: 100} \\
\hline \multicolumn{12}{|c|}{ Actuated Cycle Length: 100} \\
\hline \multicolumn{12}{|c|}{ Offset: $0(0 \%)$, Referenced to phase 2:EBWB, Start of Yellow, Master Intersection } \\
\hline Natural Cycle: 80 & & & & & & & & & & & \\
\hline
\end{tabular}

Splits and Phases: 18: SR 21 \& Matthew

\begin{tabular}{|c|c|c|c|c|}
\hline $\begin{array}{ll}\# 15 & \# 18 \\
77\end{array}$ & $\begin{array}{l}\# 15 \# 18 \\
\longrightarrow \div 2\end{array}$ & $\begin{array}{l}\# 15 \\
4 \\
\end{array}$ & & $\begin{array}{l}\# 15 \text { \#18 } \\
1 \uparrow \downarrow\end{array}$ \\
\hline $17 \mathrm{~s}$ & $27 \mathrm{~s}$ & $36 s$ & & 203 \\
\hline & & & $\begin{array}{r}\# 18 \\
4\end{array}$ & \\
\hline & & $14 s$ & $42 s$ & \\
\hline
\end{tabular}




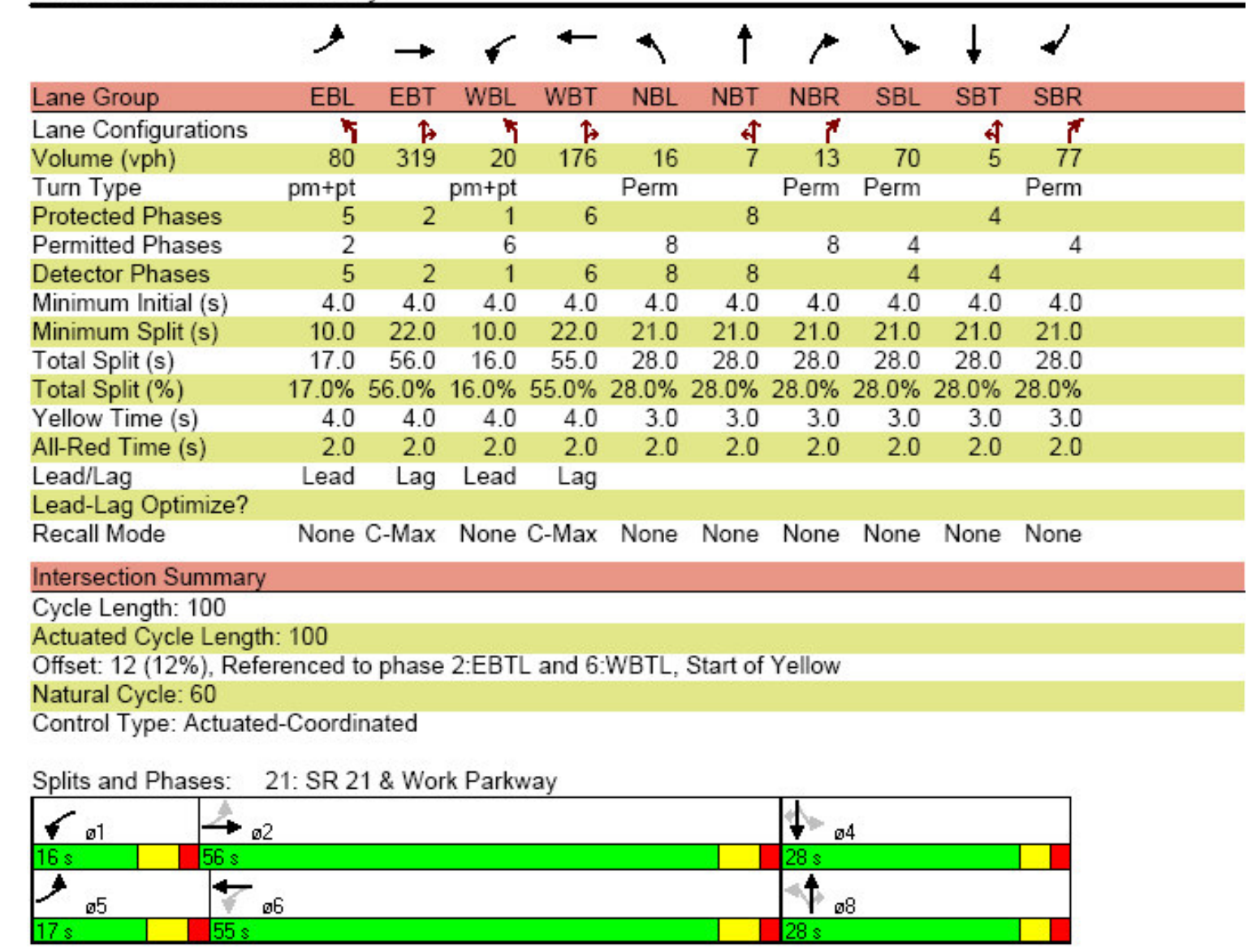




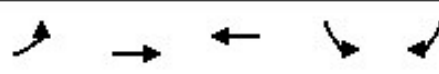

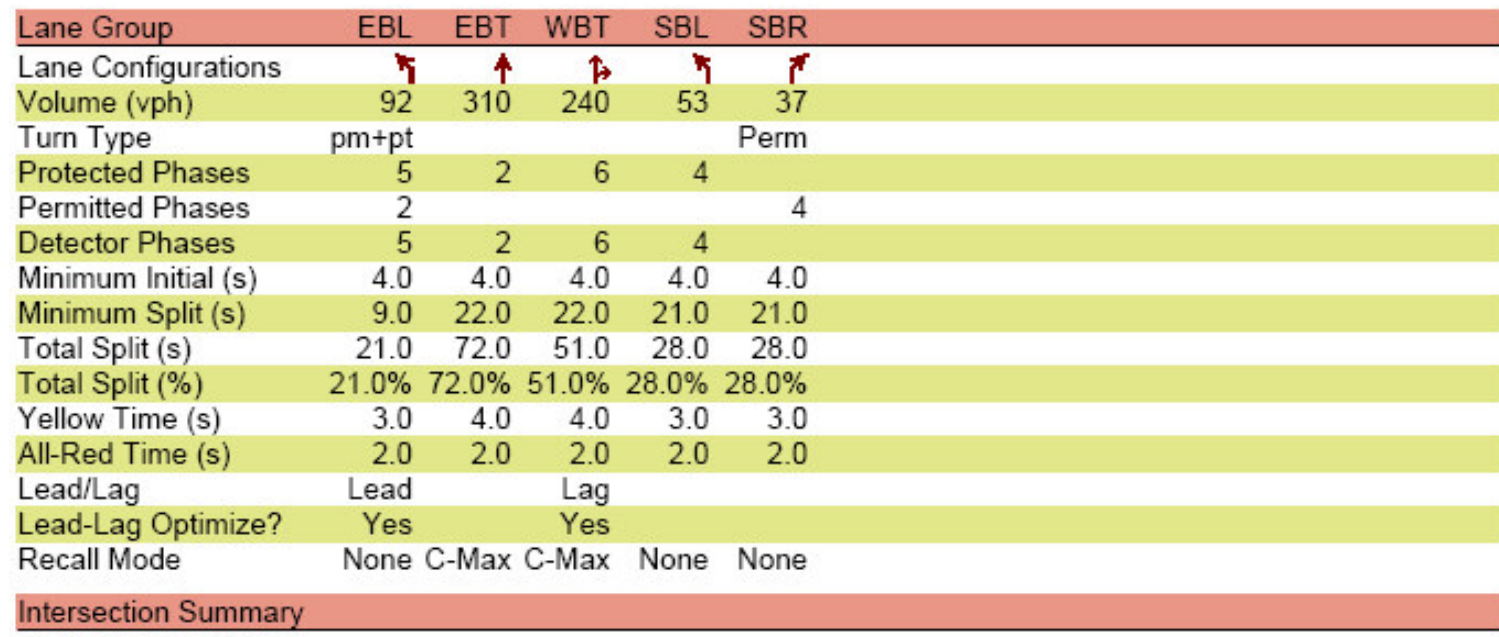

Cycle Length: 100

Actuated Cycle Length: 100

Offset: $91(91 \%)$, Referenced to phase 2:EBTL and 6:WBT, Start of Yellow

Natural Cycle: 60

Control Type: Actuated-Coordinated

Splits and Phases: 24: SR 21 \& Mall

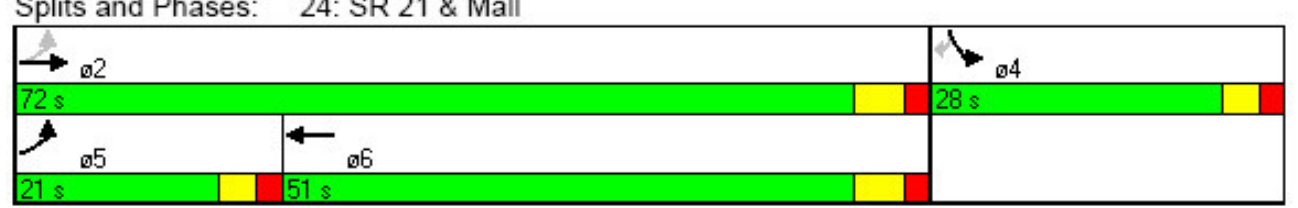




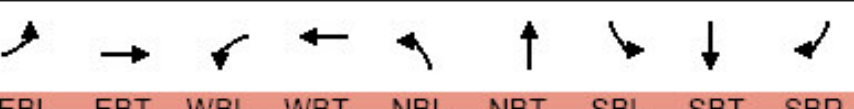

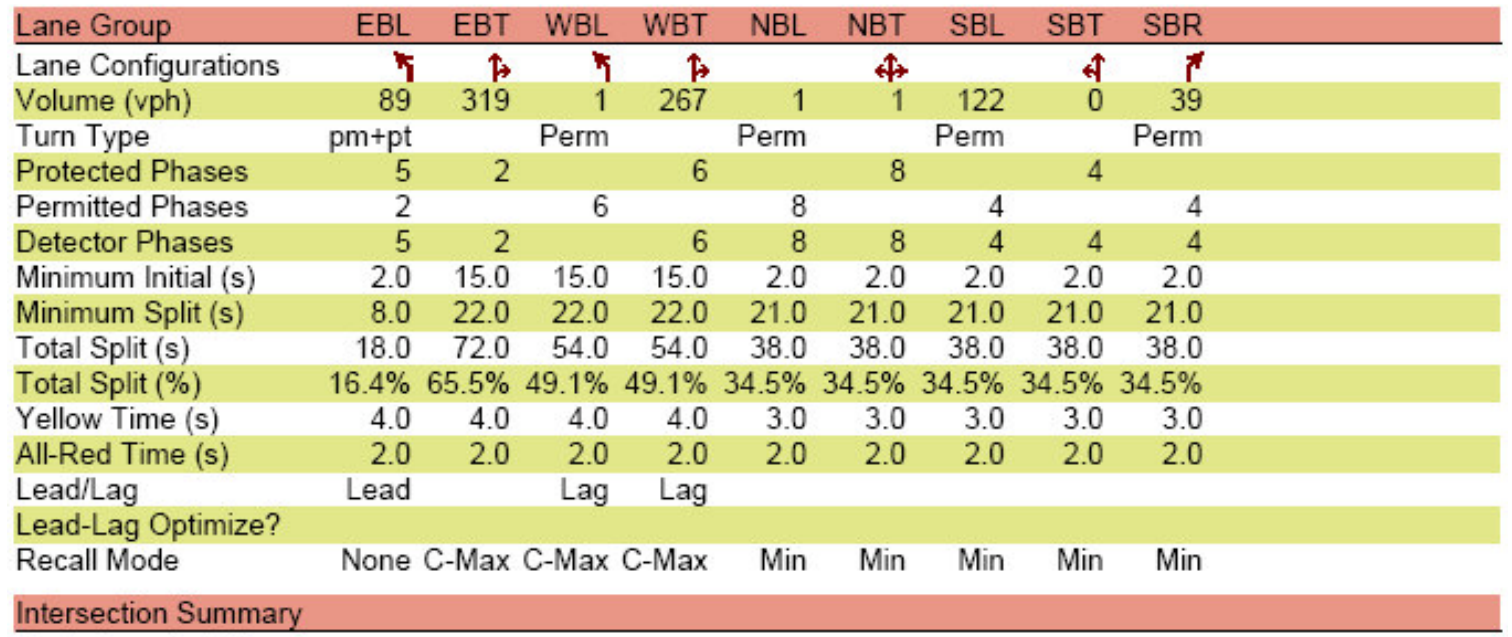

Cycle Length: 110

Actuated Cycle Length: 110

Offset: 48 (44\%), Referenced to phase 2:EBTL and 6:WBTL, Start of Yellow

Natural Cycle: 60

Control Type: Actuated-Coordinated

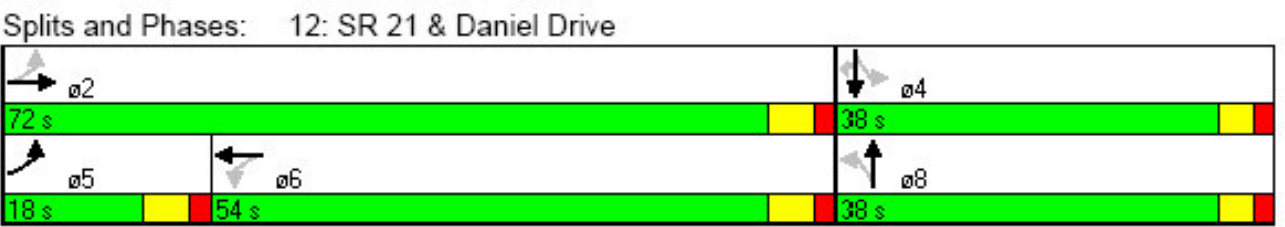




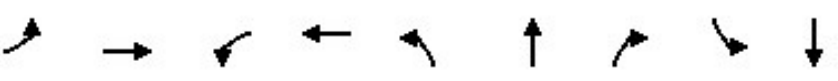

\begin{tabular}{|c|c|c|c|c|c|c|c|c|c|c|c|c|}
\hline Lane Group & EBL & EBT & WBL & WBT & NBL & NBT & NBR & SBL & SBT & $ø 2$ & $ø 3$ & $ø 5$ \\
\hline Lane Configurations & 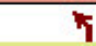 & $\uparrow$ & 7 & $\uparrow$ & & $\uparrow$ & $\bar{t}$ & & $\$$ & & & \\
\hline Volume (vph) & 5 & 326 & 134 & 298 & 36 & 9 & 167 & 7 & 6 & & & \\
\hline Turn Type & Perm & \multicolumn{2}{|c|}{ custom } & & Perm & \multicolumn{2}{|r|}{$\mathrm{pm}+\mathrm{ov}$} & Perm & & & & \\
\hline Protected Phases & & 23 & 1 & 123 & & 4 & 1 & & 4 & 2 & 3 & 5 \\
\hline Permitted Phases & 23 & & 3 & & 4 & & 4 & 4 & & & & \\
\hline Detector Phases & 23 & 23 & 1 & 123 & 4 & 4 & 1 & 4 & 4 & & & \\
\hline Minimum Initial (s) & & & 4.0 & & 4.0 & 4.0 & 4.0 & 4.0 & 4.0 & 4.0 & 4.0 & 4.0 \\
\hline Minimum Split (s) & & & 10.0 & & 22.0 & 22.0 & 10.0 & 22.0 & 22.0 & 22.0 & 10.0 & 10.0 \\
\hline Total Split (s) & 58.0 & 58.0 & 22.0 & 80.0 & 30.0 & 30.0 & 22.0 & 30.0 & 30.0 & 34.0 & 24.0 & 21.0 \\
\hline Total Split (\%) & $52.7 \%$ & $52.7 \%$ & $20.0 \%$ & $72.7 \%$ & $27.3 \%$ & $27.3 \%$ & $20.0 \%$ & $27.3 \%$ & $27.3 \%$ & $31 \%$ & $22 \%$ & $19 \%$ \\
\hline Yellow Time (s) & & & 4.0 & & 4.0 & 4.0 & 4.0 & 4.0 & 4.0 & 4.0 & 4.0 & 4.0 \\
\hline All-Red Time (s) & & & 2.0 & & 2.0 & 2.0 & 2.0 & 2.0 & 2.0 & 2.0 & 2.0 & 2.0 \\
\hline Lead/Lag & & & Lead & & Lag & Lag & Lead & Lag & Lag & Lag & Lead & Lead \\
\hline Lead-Lag Optimize? & & & & & & & & & & & & Yes \\
\hline Recall Mode & & & None & & Min & Min & None & Min & Min & -Max & None & None \\
\hline
\end{tabular}

Cycle Length: 110

Actuated Cycle Length: 110

Offset: $0(0 \%)$, Referenced to phase 2:EBWB, Start of Yellow, Master Intersection

Natural Cycle: 90

Control Type: Actuated-Coordinated

Splits and Phases: 15: SR 21 \& Brewer

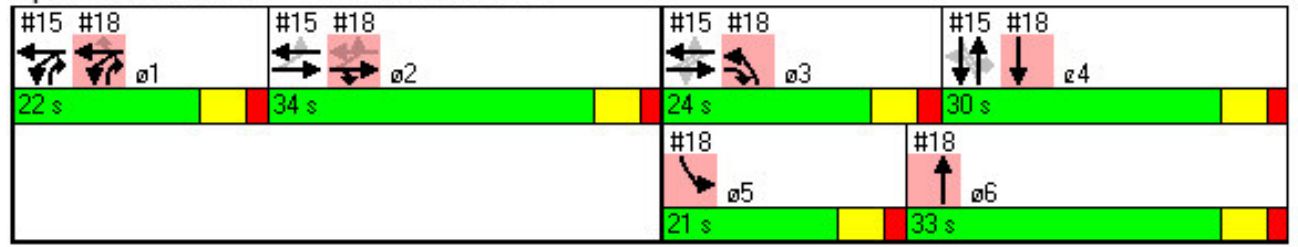




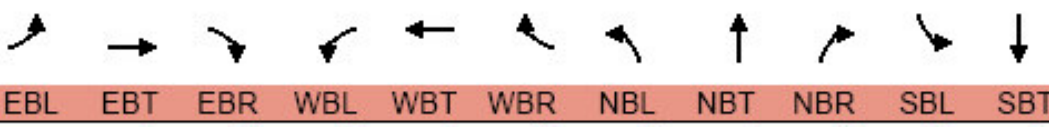

\begin{tabular}{|c|c|c|c|c|c|c|c|c|c|c|c|}
\hline Lane Group & EBL & EBT & EBR & WBL & WBT & WBR & NBL & NBT & NBR & SBL & SBT \\
\hline Lane Configurations & & $\uparrow$ & $\pi$ & T & $\uparrow$ & $\bar{r}$ & 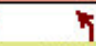 & $\uparrow$ & $\bar{r}$ & 5 & $\uparrow$ \\
\hline Volume (vph) & 15 & 261 & 224 & $190^{\circ}$ & 213 & 154 & 200 & 253 & 259 & 144 & 243 \\
\hline Turn Type & Perm & & $\mathrm{pt}+\mathrm{ov}$ & Split & & Perm & Prot & & Over & Prot & \\
\hline Protected Phases & & 2 & 23 & 1 & 1 & & 3 & 6 & 1 & 5 & 4 \\
\hline Permitted Phases & 2 & & & & 2 & 1 & & & & & \\
\hline Detector Phases & 2 & 2 & 23 & 1 & 1 & 1 & 3 & 6 & 1 & 5 & 4 \\
\hline Minimum Initial (s) & 4.0 & 4.0 & & 4.0 & 4.0 & 4.0 & 4.0 & 4.0 & 4.0 & 4.0 & 4.0 \\
\hline Minimum Split (s) & 22.0 & 22.0 & & 10.0 & 10.0 & 10.0 & 10.0 & 22.0 & 10.0 & 10.0 & 22.0 \\
\hline Total Split (s) & 34.0 & 34.0 & 58.0 & 22.0 & 22.0 & 22.0 & 24.0 & 33.0 & 22.0 & 21.0 & 30.0 \\
\hline Total Split (\%) & $30.9 \%$ & $30.9 \%$ & $52.7 \%$ & $20.0 \%$ & $20.0 \%$ & $20.0 \%$ & $21.8 \%$ & $30.0 \%$ & $20.0 \%$ & $19.1 \%$ & $27.3 \%$ \\
\hline Yellow Time (s) & 4.0 & 4.0 & & 4.0 & 4.0 & 4.0 & 4.0 & 4.0 & 4.0 & 4.0 & 4.0 \\
\hline All-Red Time (s) & 2.0 & 2.0 & & 2.0 & 2.0 & 2.0 & 2.0 & 2.0 & 2.0 & 2.0 & 2.0 \\
\hline Lead/Lag & Lag & Lag & & Lead & Lead & Lead & Lead & Lag & Lead & Lead & Lag \\
\hline Lead-Lag Optimize? & & & & & & & & Yes & & Yes & \\
\hline Recall Mode & C-Max & C-Max & & None & None & None & None & Min & None & None & Min \\
\hline
\end{tabular}

Intersection Summary

Cycle Length: 110

Actuated Cycle Length: 110

Offset: $0(0 \%)$, Referenced to phase 2:EBWB, Start of Yellow, Master Intersection

Natural Cycle: 90

Control Type: Actuated-Coordinated

Splits and Phases: $18:$ SR 21 \& Matthew

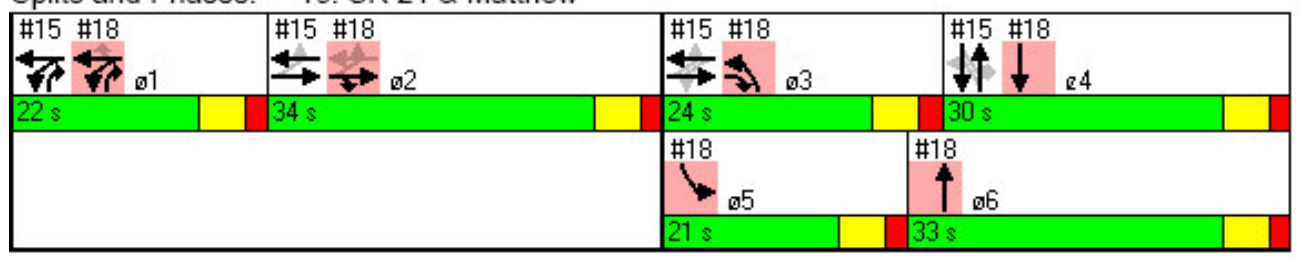




\begin{tabular}{|c|c|c|c|c|c|c|c|c|c|c|}
\hline Lane Group & EBL & EBT & WBL & WBT & NBL & NBT & NBR & SBL & SBT & SBR \\
\hline Lane Configurations & 7 & $\uparrow$ & 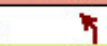 & $\uparrow$ & & $\uparrow$ & $\pi$ & & $\uparrow$ & $\pi$ \\
\hline Volume (vph) & $192^{\circ}$ & 369 & 83 & 305 & 79 & 50 & 72 & 150 & 41 & 173 \\
\hline Turn Type & $\mathrm{pm}+\mathrm{pt}$ & & $\mathrm{pm}+\mathrm{pt}$ & & Perm & & Perm & Perm & & Perm \\
\hline Protected Phases & 5 & 2 & 1 & 6 & & 8 & & & 4 & \\
\hline Permitted Phases & 2 & & 6 & & 8 & & 8 & 4 & & 4 \\
\hline Detector Phases & 5 & 2 & 1 & 6 & 8 & 8 & & 4 & 4 & \\
\hline Minimum Initial (s) & 4.0 & 4.0 & 4.0 & 4.0 & 4.0 & 4.0 & 4.0 & 4.0 & 4.0 & 4.0 \\
\hline Minimum Split (s) & 10.0 & 22.0 & 10.0 & 22.0 & 21.0 & 21.0 & 21.0 & 21.0 & 21.0 & 21.0 \\
\hline Total Split (s) & 18.0 & 56.0 & 12.0 & 50.0 & 42.0 & 42.0 & 42.0 & 42.0 & 42.0 & 42.0 \\
\hline Total Split (\%) & $16.4 \%$ & $50.9 \%$ & $10.9 \%$ & $45.5 \%$ & $38.2 \%$ & $38.2 \%$ & $38.2 \%$ & $38.2 \%$ & $38.2 \%$ & $38.2 \%$ \\
\hline Yellow Time (s) & 4.0 & 4.0 & 4.0 & 4.0 & 3.0 & 3.0 & 3.0 & 3.0 & 3.0 & 3.0 \\
\hline All-Red Time (s) & 2.0 & 2.0 & 2.0 & 2.0 & 2.0 & 2.0 & 2.0 & 2.0 & 2.0 & 2.0 \\
\hline Lead/Lag & Lead & Lag & Lead & Lag & & & & & & \\
\hline \multicolumn{11}{|l|}{ Lead-Lag Optimize? } \\
\hline Recall Mode & None & C-Max & None & C-Max & None & None & None & None & None & None \\
\hline \multicolumn{11}{|l|}{ Intersection Summary } \\
\hline \multicolumn{11}{|l|}{ Cycle Length: 110} \\
\hline \multicolumn{11}{|c|}{ Actuated Cycle Length: 110} \\
\hline \multicolumn{11}{|c|}{ Offset: 38 (35\%), Referenced to phase 2:EBTL and 6:WBTL, Start of Yellow } \\
\hline \multicolumn{11}{|c|}{ Natural Cycle: 75} \\
\hline
\end{tabular}

Splits and Phases: 21: SR 21 \& Work Parkway

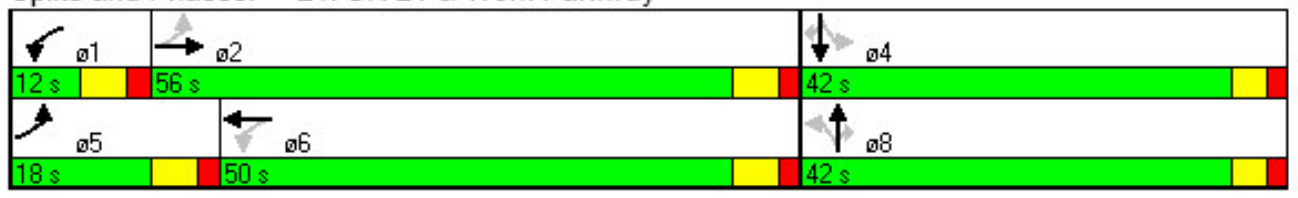




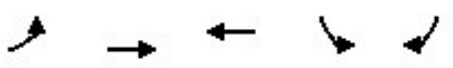

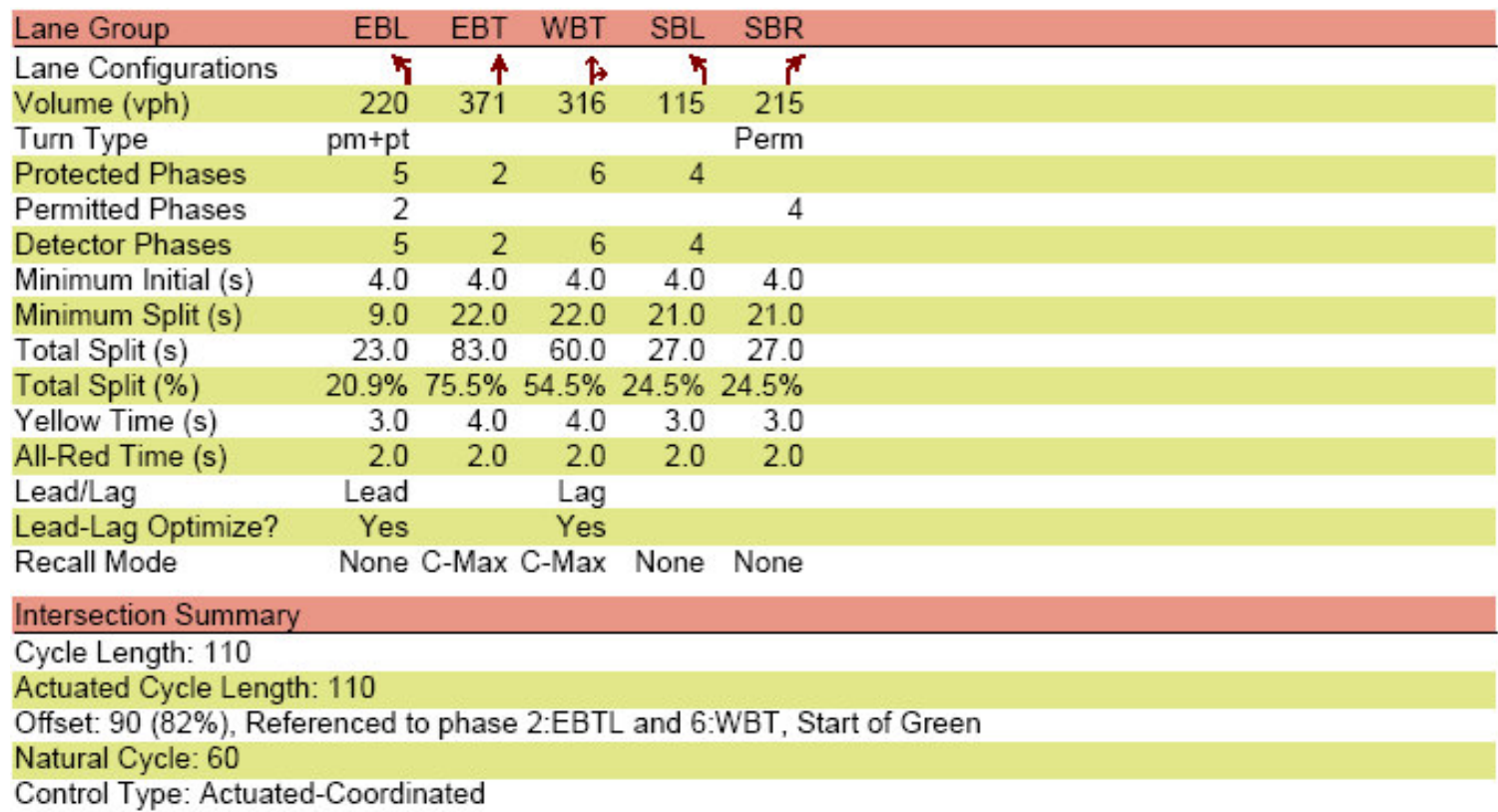

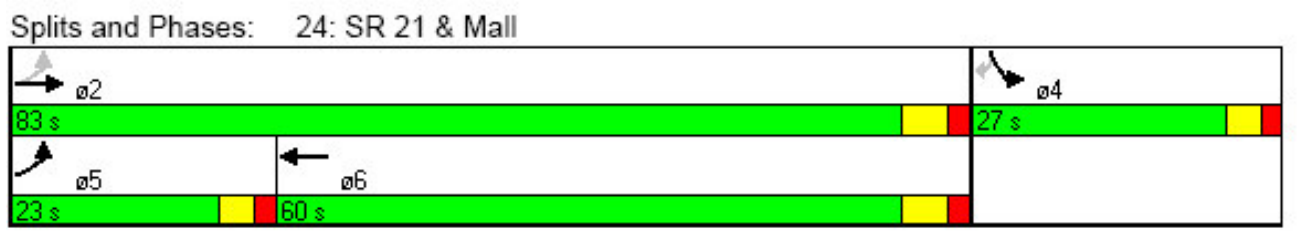




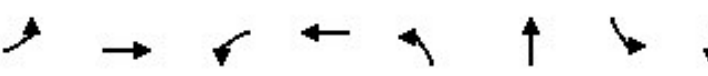

\begin{tabular}{|c|c|c|c|c|c|c|c|c|c|}
\hline Lane Group & EBL & EBT & WBL & WBT & NBL & NBT & SBL & SBT & SBR \\
\hline Lane Configurations & 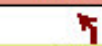 & $\uparrow$ & 4 & $\uparrow$ & & $\leftrightarrow$ & & $\uparrow$ & $\pi$ \\
\hline Volume (vph) & 111 & 387 & 1 & 457 & 1 & 1 & 31 & 0 & 147 \\
\hline Turn Type & $\mathrm{pm}+\mathrm{pt}$ & & Perm & & Perm & & Perm & & Perm \\
\hline Protected Phases & 5 & 2 & & 6 & & 8 & & 4 & \\
\hline Permitted Phases & 2 & & 6 & & 8 & & 4 & & 4 \\
\hline Detector Phases & 5 & 2 & & 6 & 8 & 8 & 4 & 4 & 4 \\
\hline Minimum Initial (s) & 2.0 & 15.0 & 15.0 & 15.0 & 2.0 & 2.0 & 2.0 & 2.0 & 2.0 \\
\hline Minimum Split (s) & 8.0 & 22.0 & 22.0 & 22.0 & 21.0 & 21.0 & 21.0 & 21.0 & 21.0 \\
\hline Total Split (s) & 25.0 & 110.0 & 85.0 & 85.0 & 30.0 & 30.0 & 30.0 & 30.0 & 30.0 \\
\hline Total Split (\%) & $17.9 \%$ & $78.6 \%$ & $60.7 \%$ & $60.7 \%$ & $21.4 \%$ & $21.4 \%$ & $21.4 \%$ & $21.4 \%$ & $21.4 \%$ \\
\hline Yellow Time (s) & 4.0 & 4.0 & 4.0 & 4.0 & 3.0 & 3.0 & 3.0 & 3.0 & 3.0 \\
\hline All-Red Time (s) & 2.0 & 2.0 & 2.0 & 2.0 & 2.0 & 2.0 & 2.0 & 2.0 & 2.0 \\
\hline Lead/Lag & Lead & & Lag & Lag & & & & & \\
\hline \multicolumn{10}{|l|}{ Lead-Lag Optimize? } \\
\hline Recall Mode & None & C-Max & C-Max & C-Max & Min & Min & Min & Min & Min \\
\hline
\end{tabular}

Cycle Length: 140

Actuated Cycle Length: 140

Offset: $127(91 \%)$, Referenced to phase 2:EBTL and 6:WBTL, Start of Yellow

Natural Cycle: 60

Control Type: Actuated-Coordinated

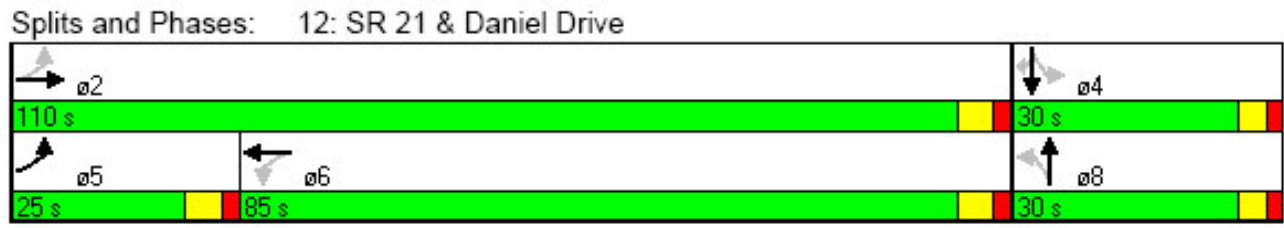




\section{$\rightarrow \rightarrow+4+1$}

\begin{tabular}{|c|c|c|c|c|c|c|c|c|c|c|c|c|}
\hline Lane Group & EBL & EBT & WBL & WBT & $\mathrm{NBL}$ & NBT & NBR & SBL & SBT & $ø 2$ & $ø 3$ & 95 \\
\hline Lane Configurations & 4 & 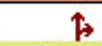 & 7 & $\uparrow$ & & $\uparrow$ & $\bar{r}$ & & $\uparrow$ & & & \\
\hline Volume (vph) & 6 & 397 & 92 & 450 & 52 & 3 & 165 & 16 & 2 & & & \\
\hline Turn Type & Perm & \multicolumn{2}{|c|}{ D. $P+P$} & & Perm & \multicolumn{2}{|r|}{$\mathrm{pm}+\mathrm{ov}$} & Perm & & & & \\
\hline Protected Phases & & 23 & 1 & 123 & & 4 & 1 & & 4 & 2 & 3 & 5 \\
\hline Permitted Phases & 23 & & 23 & & 4 & & 4 & 4 & & & & \\
\hline Detector Phases & 23 & 23 & 1 & 123 & 4 & 4 & 1 & 4 & 4 & & & \\
\hline Minimum Initial (s) & & & 4.0 & & 4.0 & 4.0 & 4.0 & 4.0 & 4.0 & 4.0 & 4.0 & 4.0 \\
\hline Minimum Split (s) & & & 10.0 & & 22.0 & 22.0 & 10.0 & 22.0 & 22.0 & 22.0 & 10.0 & 10.0 \\
\hline Total Split (s) & 67.0 & 67.0 & 32.0 & 99.0 & 41.0 & 41.0 & 32.0 & 41.0 & 41.0 & 31.0 & 36.0 & 31.0 \\
\hline Total Split (\%) & $47.9 \%$ & $47.9 \%$ & $22.9 \%$ & $70.7 \%$ & $29.3 \%$ & $29.3 \%$ & $22.9 \%$ & $29.3 \%$ & $29.3 \%$ & $22 \%$ & $26 \%$ & $22 \%$ \\
\hline Yellow Time (s) & & & 4.0 & & 4.0 & 4.0 & 4.0 & 4.0 & 4.0 & 4.0 & 4.0 & 4.0 \\
\hline All-Red Time (s) & & & 2.0 & & 2.0 & 2.0 & 2.0 & 2.0 & 2.0 & 2.0 & 2.0 & 2.0 \\
\hline Lead/Lag & & & Lead & & Lag & Lag & Lead & Lag & Lag & Lag & Lead & Lead \\
\hline \multicolumn{13}{|l|}{ Lead-Lag Optimize? } \\
\hline Recall Mode & & & None & & Min & Min & None & Min & Min & C-Max & None & None \\
\hline
\end{tabular}

Cycle Length: 140

Actuated Cycle Length: 140

Offset: $0(0 \%)$, Referenced to phase 2:EBWB, Start of Yellow, Master Intersection

Natural Cycle: 120

Control Type: Actuated-Coordinated

Splits and Phases: 15 : SR 21 \& Brewer

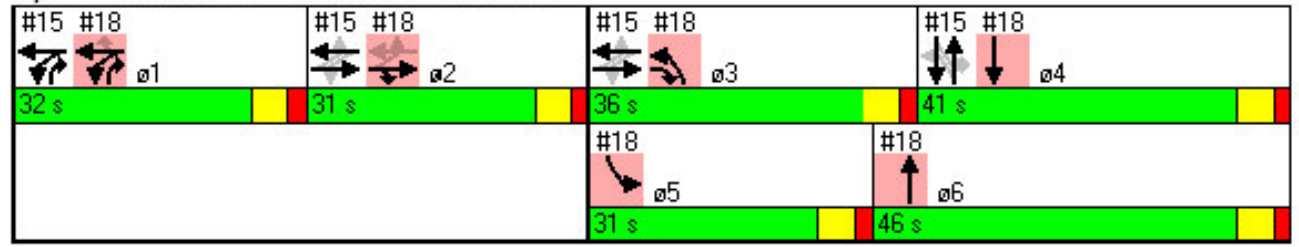




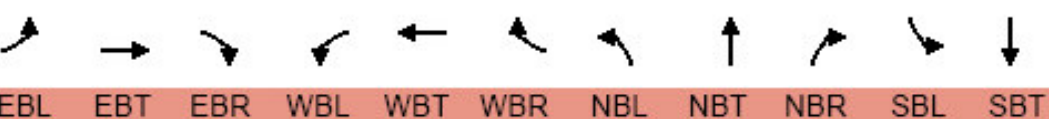

\begin{tabular}{|c|c|c|c|c|c|c|c|c|c|c|c|}
\hline Lane Group & EBL & EBT & EBR & WBL & WBT & WBR & NBL & NBT & NBR & SBL & SBT \\
\hline Lane Configurations & & $\uparrow$ & $\pi$ & $\pi$ & $\uparrow$ & $\pi$ & 7 & $\uparrow$ & $\pi$ & 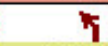 & $\uparrow$ \\
\hline Volume (vph) & 6 & 254 & 318 & 247 & 222 & 150 & 305 & 268 & 243 & 147 & 318 \\
\hline Turn Type & Perm & & $\mathrm{pt}+\mathrm{ov}$ & Split & & Perm & Prot & & Over & Prot & \\
\hline Protected Phases & & 2 & 23 & 1 & 1 & & 3 & 6 & 1 & 5 & 4 \\
\hline Permitted Phases & 2 & & & & 2 & 1 & & & & & \\
\hline Detector Phases & 2 & 2 & 23 & 1 & 1 & 1 & 3 & 6 & 1 & 5 & 4 \\
\hline Minimum Initial (s) & 4.0 & 4.0 & & 4.0 & 4.0 & 4.0 & 4.0 & 4.0 & 4.0 & 4.0 & 4.0 \\
\hline Minimum Split (s) & 22.0 & 22.0 & & 10.0 & 10.0 & 10.0 & 10.0 & 22.0 & 10.0 & 10.0 & 22.0 \\
\hline Total Split (s) & 31.0 & 31.0 & 67.0 & 32.0 & 32.0 & 32.0 & 36.0 & 46.0 & 32.0 & 31.0 & 41.0 \\
\hline Total Split (\%) & $22.1 \%$ & $22.1 \%$ & $47.9 \%$ & $22.9 \%$ & $22.9 \%$ & $22.9 \%$ & $25.7 \%$ & $32.9 \%$ & $22.9 \%$ & $22.1 \%$ & $29.3 \%$ \\
\hline Yellow Time (s) & 4.0 & 4.0 & & 4.0 & 4.0 & 4.0 & 4.0 & 4.0 & 4.0 & 4.0 & 4.0 \\
\hline All-Red Time (s) & 2.0 & 2.0 & & 2.0 & 2.0 & 2.0 & 2.0 & 2.0 & 2.0 & 2.0 & 2.0 \\
\hline Lead/Lag & Lag & Lag & & Lead & Lead & Lead & Lead & Lag & Lead & Lead & Lag \\
\hline \multicolumn{12}{|l|}{ Lead-Lag Optimize? } \\
\hline Recall Mode & C-Max & C-Max & & None & None & None & None & Min & None & None & Min \\
\hline \multicolumn{12}{|l|}{ Intersection Summary } \\
\hline \multicolumn{12}{|l|}{ Cycle Length: 140} \\
\hline \multicolumn{12}{|c|}{ Actuated Cycle Length: 140} \\
\hline \multicolumn{12}{|c|}{ Offset: $0(0 \%)$, Referenced to phase 2:EBWB, Start of Yellow, Master Intersection } \\
\hline Natural Cycle: 120 & & & & & & & & & & & \\
\hline
\end{tabular}

Splits and Phases: 18: SR 21 \& Matthew

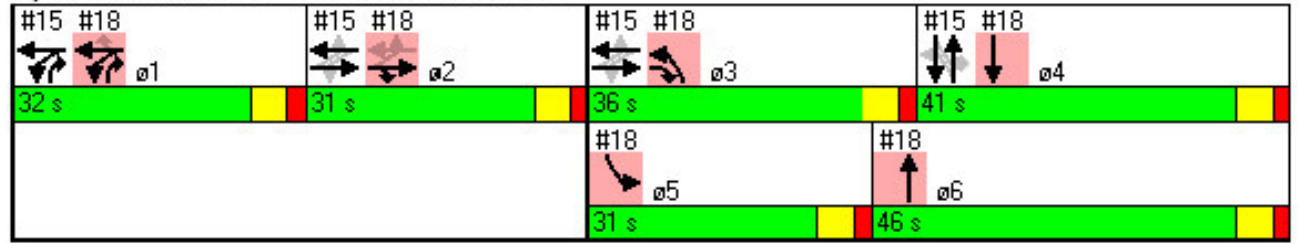




\begin{tabular}{|c|c|c|c|c|c|c|c|c|}
\hline Lane Group & EBL & WBT & NBL & NBT & NBR & SBL & SBT & SBR \\
\hline Lane Configurations & $\uparrow$ & 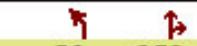 & & $\uparrow$ & $\pi$ & & $\uparrow$ & $\vec{r}$ \\
\hline Volume (vph) & 167 & 359 & 91 & 44 & 76 & 128 & 23 & 169 \\
\hline Turn Type & $\mathrm{pm}+\mathrm{pt}$ & $\mathrm{pm}+\mathrm{pt}$ & Perm & & Perm & Perm & & Perm \\
\hline Protected Phases & 5 & 6 & & 8 & & & 4 & \\
\hline Permitted Phases & 2 & 6 & 8 & & 8 & 4 & & 4 \\
\hline Detector Phases & 5 & 1 & 8 & 8 & & 4 & 4 & \\
\hline Minimum Initial (s) & 4.0 & 4.0 & 4.0 & 4.0 & 4.0 & 4.0 & 4.0 & 4.0 \\
\hline Minimum Split (s) & 10.0 & 22.0 & 21.0 & 21.0 & 21.0 & 21.0 & 21.0 & 21.0 \\
\hline Total Split (s) & 12.0 & 35.0 & 23.0 & 23.0 & 23.0 & 23.0 & 23.0 & 23.0 \\
\hline Total Split (\%) & $17.1 \% 50.0 \%$ & $17.1 \% 50.0 \%$ & $32.9 \%$ & $32.9 \%$ & $32.9 \%$ & $32.9 \%$ & $32.9 \%$ & $32.9 \%$ \\
\hline Yellow Time (s) & 4.0 & 4.0 & 3.0 & 3.0 & 3.0 & 3.0 & 3.0 & 3.0 \\
\hline All-Red Time (s) & 2.0 & 2.0 & 2.0 & 2.0 & 2.0 & 2.0 & 2.0 & 2.0 \\
\hline Lead/Lag & Lead & Lead & & & & & & \\
\hline \multicolumn{9}{|l|}{ Lead-Lag Optimize? } \\
\hline Recall Mode & None C-Max & None C-Max & None & None & None & None & None & None \\
\hline \multicolumn{9}{|l|}{ Intersection Summary } \\
\hline \multicolumn{9}{|l|}{ Cycle Length: 70} \\
\hline \multicolumn{9}{|c|}{ Actuated Cycle Length: 70} \\
\hline \multirow{2}{*}{\multicolumn{9}{|c|}{ Offset: $12(17 \%)$, Referenced to phase 2:EBTL and 6:WBTL, Start of Yellow }} \\
\hline \multicolumn{6}{|c|}{ Natural Cycle: 60} & & & \\
\hline \multicolumn{9}{|c|}{ Control Type: Actuated-Coordinated } \\
\hline \multicolumn{9}{|l|}{ Splits and Phases: } \\
\hline$\leftarrow 01$ & 2 & & & & 04 & & & \\
\hline $12 s$ & & & & $23 s$ & & & & \\
\hline$>_{05}$ & 96 & & & & ๑8 & & & \\
\hline $12 s$ & & & & $23 \mathrm{~s}$ & & & & \\
\hline
\end{tabular}




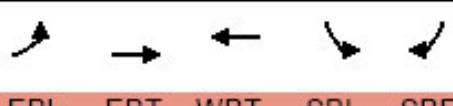

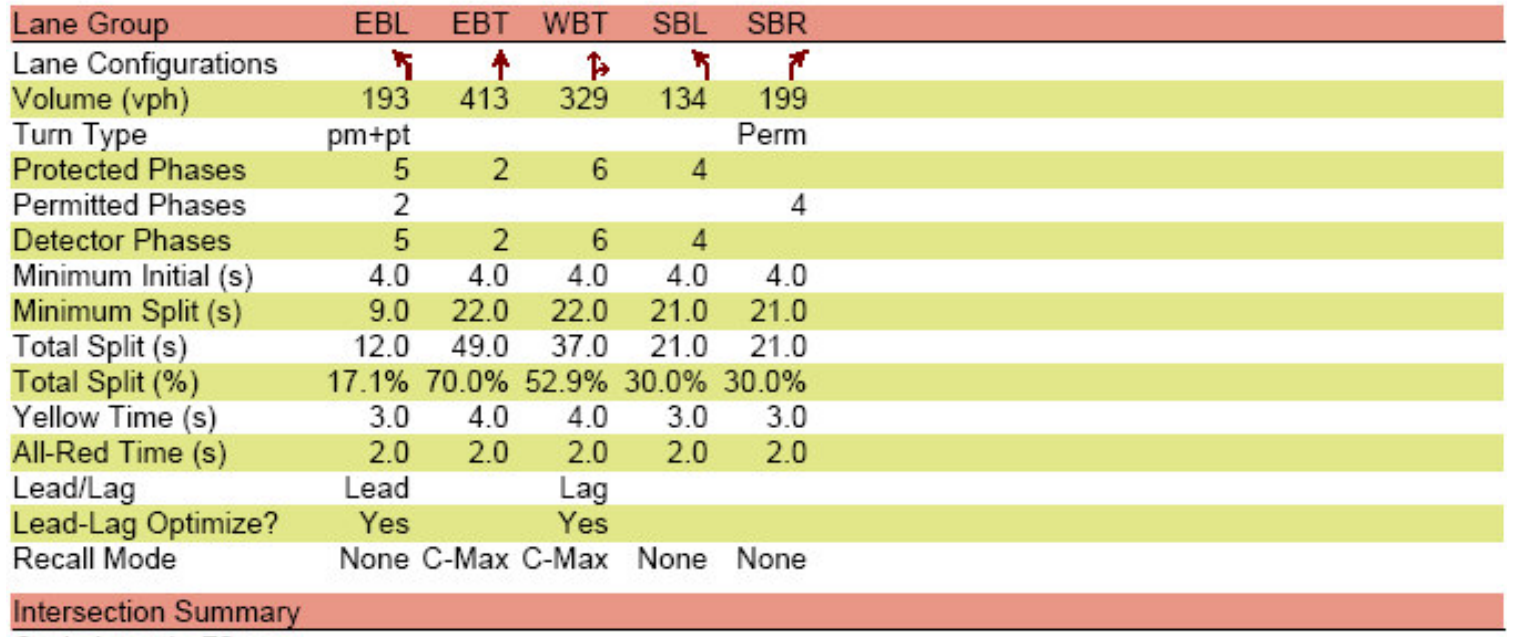

\section{Cycle Length: 70}

Actuated Cycle Length: 70

Offset: 27 (39\%), Referenced to phase 2:EBTL and 6:WBT, Start of Green

Natural Cycle: 60

Control Type: Actuated-Coordinated

Splits and Phases: 24: SR 21 \& Mall

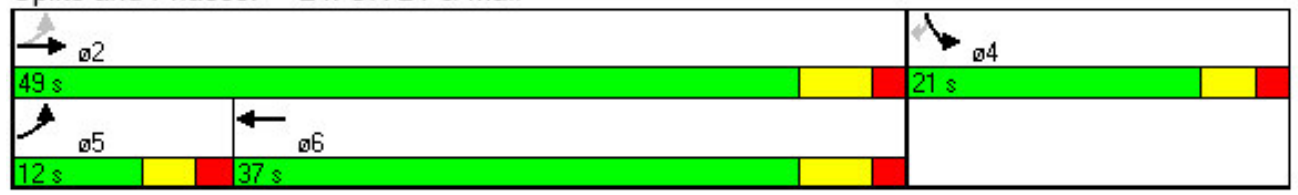




\section{VITA}

Darian Glitz was born in Uniontown, Pennsylvania on January 6, 1974. He was raised there and in1988 moved to Morgantown, West Virginia. Darian received his Bachelor of Science in Civil Engineering in 1997 from West Virginia University. In that same year, he began a career at PENNDOT District 12-0 in Uniontown, Pennsylvania which continues to this day. Currently he is a candidate for a Master of Science in Civil Engineering at West Virginia University specializing in transportation engineering. 